\title{
Wabash River Integrated Methanol and Power Production from Clean Coal Technologies (IMPPCCT)
}

\author{
Phase II
}

\section{Final Report}

Report Date: January 15, 2008

\author{
Prepared for \\ U.S. Department of Energy \\ Cooperative Agreement No. DE-FC26-99FT40659 \\ by \\ ConocoPhillips Company \\ 600 N. Dairy Ashford \\ Houston, Texas 77079-1175
}




\section{DISCLAIMER}

This report was prepared by ConocoPhillips Company as an account of work pursuant to a cooperative agreement partially sponsored by an agency of the United Sates Department of Energy. Neither the ConocoPhillips Company, nor any of its subcontractors, nor the United States Department of Energy, nor any person or agency acting on behalf of either:

(A) Makes any warranty, express or implied, or assumes any legal liability or responsibility for the accuracy. Completeness or usefulness of any information, apparatus, product or process disclosed, or represents that its use would not infringe privately owned rights.

(B) Assumes any liabilities with respect to the use of, or for damages resulting from the use of any information, apparatus, method or process disclosed in this report.

Reference herein to any specific commercial product, process, or service by trade name, trademark, manufacturer, or otherwise does not necessarily constitute or imply its endorsement, recommendation, or favoring by the United States Department of Energy nor any agency thereof. The views and opinions of authors expressed therein do not necessarily state or reflect those of the United States Department of Energy or any agency thereof. 


\section{ABSTRACT}

The Wabash River Integrated Methanol and Power Production from Clean Coal Technologies (IMPPCCT) project was established to evaluate integrated electrical power generation and methanol production through clean coal technologies. The project was under the leadership of ConocoPhillips Company (COP), after it acquired Gasification Engineering Corporation (GEC) and the E-Gas gasification technology from Global Energy Inc. in July 2003. The project has completed both Phase I and Phase II of development.

The two project phases include the following:

I. Feasibility study and conceptual design for an integrated demonstration facility at SG Solutions LLC (SGS), previously the Wabash River Energy Limited, Gasification Facility located in West Terre Haute, Indiana, and for a fence-line commercial embodiment plant (CEP) operated at the Dow Chemical Company or Dow Corning Corporation chemical plant locations

II. Research, development, and testing (RD\&T) to define any technology gaps or critical design and integration issues.

Phase I of this project was supported by a multi-industry team consisting of Air Products and Chemicals, Inc., The Dow Chemical Company, Dow Corning Corporation, Methanex Corporation, and Siemens Westinghouse Power Corporation, while Phase II was supported by Gas Technology Institute, TDA Research Inc., and Nucon International, Inc.

The SGS integrated gasification combined cycle (IGCC) facility was designed, constructed, and operated under a project selected and co-funded under the Round IV of the United States Department of Energy's (DOE’s) Clean Coal Technology Program. In this project, coal and/or other carbonaceous fuel feedstocks are gasified in an oxygen-blown, entrained-flow gasifier with continuous slag removal and a dry particulate removal system. The resulting product synthesis gas (syngas) is used to fuel a combustion turbine generator whose exhaust is integrated with a heat recovery steam generator to drive a refurbished steam turbine generator. The gasifier uses technology initially developed by The Dow Chemical Company (the Destec Gasification Process), and now acquired and offered commercially by COP as the E-Gas technology.

In a joint effort with the DOE, a Cooperative Agreement was awarded under the Early Entrance Coproduction Plant (EECP) solicitation. GEC, and later COP and the industrial partners investigated the use of syngas produced by the E-Gas technology in a coproduction environment to enhance the efficiency and productivity of solid fuel gasification combined cycle power plants.

The objectives of this effort were to determine the feasibility of an EECP located at a specific site which produces some combination of electric power (or heat), fuels, and/or chemicals from syngas derived from coal, or, coal in combination with some other carbonaceous feedstock. The intended result of the project was to provide the necessary technical, economic, and environmental information that would be needed to move the EECP forward to detailed design, construction, and operation by industry. 
The EECP study conducted in Phase I of the IMPPCCT Project confirmed that the concept for the integration of gasification-based (E-Gas) electricity generation from coal and/or petroleum coke and methanol production (Liquid Phase Methanol or LPMEOH ${ }^{\mathrm{TM}}$ ) processes was feasible for the coproduction of power and chemicals. The results indicated that while there were minimal integration issues that impact the deployment of an IMPPCCT CEP, the major concern was the removal of sulfur and other trace contaminants, which are known methanol catalyst poisons, from the syngas. However, economic concerns in the domestic methanol market which is driven by periodic low natural gas prices and cheap offshore supplies limit the commercial viability of this more capital intensive concept.

The objective of Phase II was to conduct RD\&T as outlined in the Phase I RD\&T Plan to enhance the development and commercial acceptance of coproduction technology. Studies were designed to address the technical concerns that would make the IMPPCCT concept competitive with natural gas-based systems in the commercial marketplace. Efforts in Phase II investigated the cleanup of the syngas by removing contaminants, particularly sulfur species, to a level acceptable for the methanol synthesis catalyst, and reducing the cost of the current sulfur removal system such as via warm gas cleanup methods. Laboratory testing followed by on-site field testing at SGS with bench-scale slipstream units was conducted. Actual syngas produced by the facility was evaluated at system pressure and temperature.

The following three processes, which potentially would be low in capital and operating costs, were originally chosen to be investigated for syngas application:

1. A direct sulfur oxidation recovery process developed by TDA to remove sulfur species from natural gas at warm temperatures;

2. A regenerable activated carbon system developed by Nucon for removing sulfur species in a syngas stream to parts-per-billion (ppb) levels; and

3. A regenerable sorbent developed by COP to remove sulfur contaminants from gasoline at high temperatures.

After laboratory and slipstream testing at the SGS Wabash Gasification Facility, the warm gas regenerable sorbent developed by COP was found to be very promising in removing sulfur contaminants. Preliminary economics also favors the continued development of the technology. 


\section{TABLE OF CONTENTS}

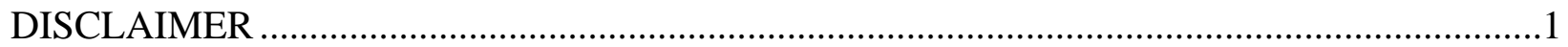

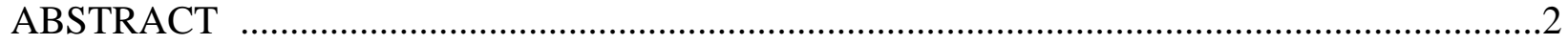

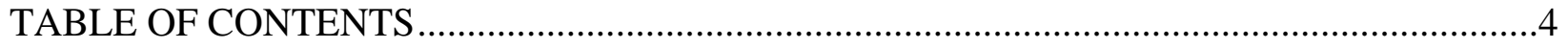

FIGURES

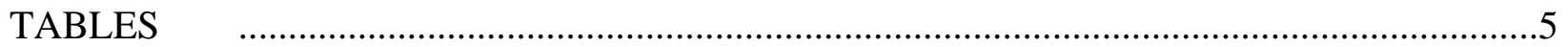

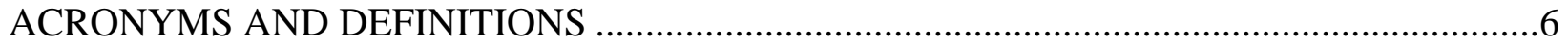

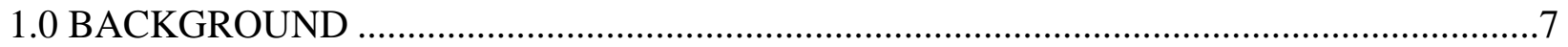

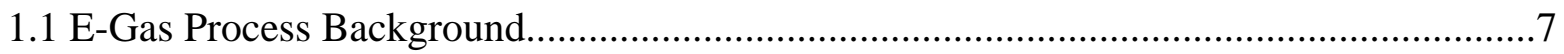

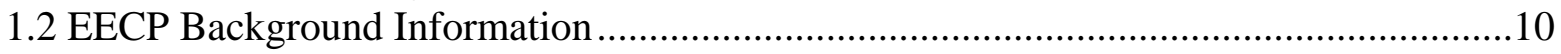

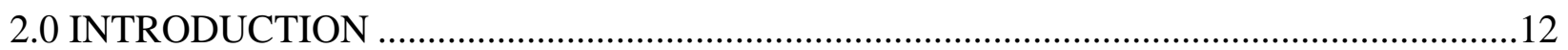

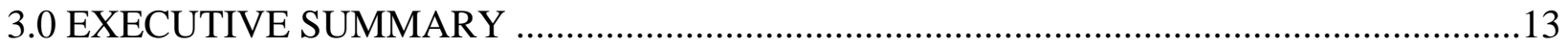

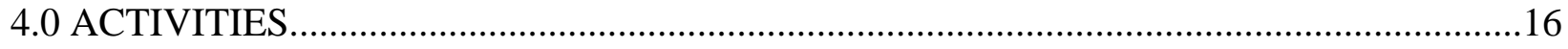

4.1 Direct Sulfur Oxidation Recovery Process (GTI/TDA) ...............................................16

4.2 Regenerable Carbon for Sulfur Polishing (Nucon) ...................................................17

4.3 ConocoPhillips’ S Zorb Warm Gas Desulfurization Process ........................................19

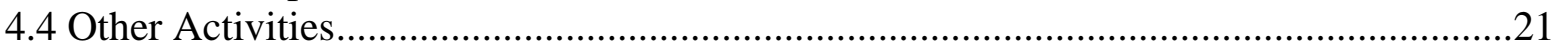

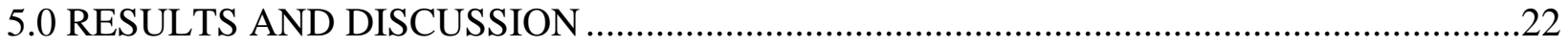

5.1 Direct Sulfur Oxidation Recovery Process (GTI/TDA) ............................................22

5.2 Regenerable Carbon for Sulfur Polishing (Nucon) ..................................................22

5.3 ConocoPhillips’ S Zorb Warm Gas Desulfurization Process .......................................23

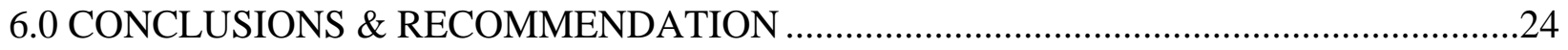

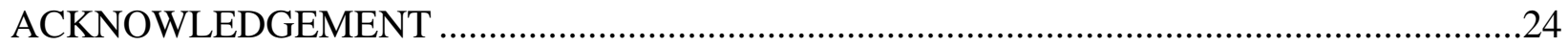

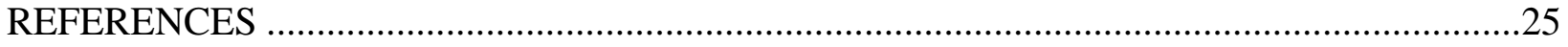

APPENDICES

I. Wabash Syngas Desulfurization Test Summary Report (TDA Report)

II. Slipstream Testing of Regenerable Activated Carbon for Removing Trace Levels of Sulfur Contaminants from Syngas (Nucon Report)

III. Testing of ConocoPhillips' Sorbent for Removal of Sulfur from Syngas at High Temperature - Topical Report (ConocoPhillips Report)

IV. "Slipstream Testing of Novel Sulfur Removal Processes for Gasification Application" presentated in the $22^{\text {nd }}$ Pittsburgh Coal Conference in 2005

V. "Sulfur Removal from E-Gas ${ }^{\mathrm{TM}}$ Technology Gas Streams using SZorb ${ }^{\mathrm{TM}}$ Sorbent” presented in the $23^{\text {rd }}$ Pittsburgh Coal Conference in 2006 


\section{FIGURES}

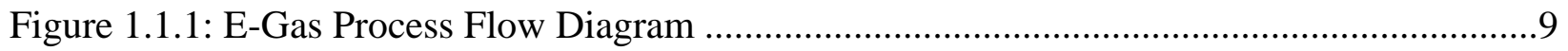

Figure 4.2.1: Nucon Bench-Scale Slipstream Unit, Front View ...........................................19

Figure 4.2.2: Nucon Bench-Scale Slipstream Unit, Right Side View ......................................19

Figure 4.3.1: Conventional Amine-Based Syngas Cleanup Scheme ..........................................20

Figure 4.3.2: S Zorb Warm Gas Cleanup Scheme.............................................................20

TABLES

Table 1.1.1: SGS Gasification Production Statistics during the Demonstration Period of the Clean Coal Technology Program ...................................................................9

Table 1.1.2: Overall Thermal Performance of Gasification at SGS .........................................10 


\section{ACRONYMS AND DEFINITIONS}

$\begin{array}{ll}\text { Acronym } & \text { Description } \\ \text { ASU } & \text { Air Separation Unit } \\ \text { CEP } & \text { Commercial Embodiment Plant } \\ \text { COP } & \text { ConocoPhillips Company } \\ \text { COS } & \text { Carbonyl Sulfide } \\ \text { DOE } & \text { Department of Energy } \\ \text { EECP } & \text { Early Entrance Coproduction Plant } \\ \text { E-Gas } & \text { Title ConocoPhillips' gasification process } \\ \text { GEC } & \text { Gasification Engineering Corporation } \\ \text { H2S } & \text { Hydrogen Sulfide } \\ \text { HCl } & \text { Hydrogen Chloride } \\ \text { HHV } & \text { Higher Heating Value in Btu/Standard Cubic Feet } \\ \text { HRSG } & \text { Heat Recovery Steam Generator } \\ \text { HTHRU } & \text { High Temperature Heat Recovery Unit } \\ \text { IGCC } & \text { Integrated Gasification Combined Cycle } \\ \text { IMPPCCT } & \text { Integrated Methanol and Power Production from Clean Coal Technologies } \\ \text { LGTI } & \text { Louisiana Gasification Technology Incorporated } \\ \text { LPMEOH } & \text { Liquid Phase Methanol (process) } \\ \text { MMBtu } & \text { Million British Thermal Units } \\ \text { Mt } & \text { Metric Ton } \\ \text { MW } & \text { Mega Watt } \\ \text { NETL } & \text { National Energy Technology Laboratory } \\ \text { NOx } & \text { Oxides of Nitrogen (symbol) } \\ \text { RD\&T } & \text { Research, Development \& Testing (plan) } \\ \text { SGS } & \text { SG Solutions LLC } \\ \text { Syngas } & \text { Synthesis Gas } \\ \text { TPD } & \text { Tons Per Day } \\ \text { WREL } & \text { Wabash River Energy Limited } \\ & \end{array}$




\subsection{BACKGROUND}

\subsection{E-Gas Process Background}

The E-Gas gasification technology, acquired by ConocoPhillips Company (COP) in July 2003, is utilized at the SG Solutions (SGS), previously the Wabash River Energy Limited (WREL) Facility located at Duke Energy's Wabash River Generating Station in West Terre Haute, Indiana. SGS is jointly owned by Wabash Valley Power Association and Global Energy, Inc., the previous owner of the E-Gas technology. COP, headquartered in Houston Texas, continues to develop and market the technology.

The E-Gas process features an oxygen-blown, continuous-slagging, two-stage, entrained-flow gasifier, which uses natural gas for start-up. Coal or petroleum coke is milled with water in a rod-mill to form slurry. The slurry is combined with oxygen in mixer nozzles and injected into the first stage of the gasifier, which operates at approximately $2600^{\circ} \mathrm{F}$ and $400 \mathrm{psi}$. A turnkey, Air Liquide, 2,060-ton/day low-pressure cryogenic distillation facility that SGS owns and operates, supplies oxygen of 95\% purity.

In the first stage, slurry fuel undergoes a partial oxidation reaction at temperatures high enough to bring the coal's ash above its melting point. The fluid ash falls through a taphole at the bottom of the first stage into a water quench, forming an inert vitreous slag. The synthesis gas (syngas) produced by this reaction then flows to the second stage, where additional coal slurry is injected. This coal is pyrolyzed in an endothermic reaction with the hot syngas to enhance the heating value of the syngas and to improve the overall efficiency of the process.

The syngas then flows to the high-temperature heat-recovery unit (HTHRU), essentially a fire tube steam generator, to produce high-pressure saturated steam. After cooling in the HTHRU, particulates in the syngas called char are removed in a hot/dry filter and recycled to the gasifier where the carbon content in the char is converted into syngas. The syngas is further cooled in a series of heat exchangers, is water scrubbed to remove the chloride, and is passed through a catalyst, which hydrolyzes carbonyl sulfide into hydrogen sulfide. Hydrogen sulfide is removed from the syngas using a methyl-di-ethanol-based amine solvent in an absorber/stripper column process. The "sweet" syngas is then moisturized, preheated, and piped over to the power block.

The key elements of the power block are the General Electric MS 7001 FA (GE 7 FA) hightemperature combustion turbine/generator, the heat recovery steam generator (HRSG), and the repowered steam turbine. The GE 7 FA is a dual-fuel turbine (syngas for operations and No. 2 fuel oil for startup) that is capable of generating a nominal $192 \mathrm{MW}$ when firing syngas, which is about a seven percent (7\%) higher power output than the same turbine fired on natural gas. The enhanced power production is attributed to the increased mass flows associated with syngas. Steam injection is used for control of nitrogen oxides called NOx within the combustion turbine. The required steam flow is minimal compared to that of conventional systems as the syngas is moisturized at the gasification facility, by recovery of low-level heat in the process. The water consumed in this process is continuously made up at the power block by water treatment systems, which clarify and further treat river water. 
The HRSG for this project is a single-drum design capable of superheating 754,000 lb/hr of high-pressure steam at $1010^{\circ} \mathrm{F}$, and $600,820 \mathrm{lb} / \mathrm{hr}$ of reheat steam at $1010^{\circ} \mathrm{F}$ when operating on design-basis syngas. The HRSG configuration was specifically optimized to utilize both the gasturbine exhaust energy and the heat energy made available in the gasification process. The nature of the gasification process in combination with the need for strict temperature and pressure control of the steam turbine led to a great deal of creative integration between the HRSG and the gasification facility. The repowered steam turbine produces $104 \mathrm{MW}$, which when combined with the 192 MW output of the combustion turbine generator and the approximately 34 MW output of the system auxiliary load yields 262 MW (net) to the Duke Energy grid.

The Air Separation Unit (ASU) provides oxygen and nitrogen for use in the gasification process but is not an integral part of the plant thermal balance. The ASU uses services such as cooling water and steam from the gasification facilities and is operated from the gasification plant control room.

The gasification facility produces two commercial by-products during operation. Sulfur, which is ultimately removed as 99.99 percent pure elemental sulfur, is marketed to sulfur users. Slag is targeted as an aggregate in asphalt roads and as structural fill in various types of construction applications. In fact, the roads at the SGS Facility have been top-coated with asphalt incorporating slag as the aggregate. Furthermore, at least two surrounding area sites have been audited, approved, and have used SGS-generated slag as structural fill under the Solid Waste Management Rules of Indiana. Another beneficial use of the slag by-product is as a fluxing agent during petroleum coke operation as this feed is typically deficient in mineral content required for proper slag fusion and flow. For this use, SGS has retained a reserve supply of slag generated from coal gasification.

The E-Gas process flow diagram presented in Figure 1.1.1 illustrates the features and components described in the above text. In Table 1.1.1, the SGS production statistics during the demonstration period of the Clean Coal Technology Program are presented in both English and Metric units. In Table 1.1.2, the SGS thermal performance variables are compared to the process design basis for both coal and petroleum coke feedstocks. At the end of 2007, the SGS Facility has processed 1.7 million tons of locally mined bituminous coal and over two million tons of petroleum coke, at the same time reclaiming over 300 million pounds of sulfur byproduct since its start up in September 1995.

Please refer to the Reference section of this report for additional information on the SGS Facility and the E-Gas technology. 
Figure 1.1.1: E-Gas Process Flow Diagram

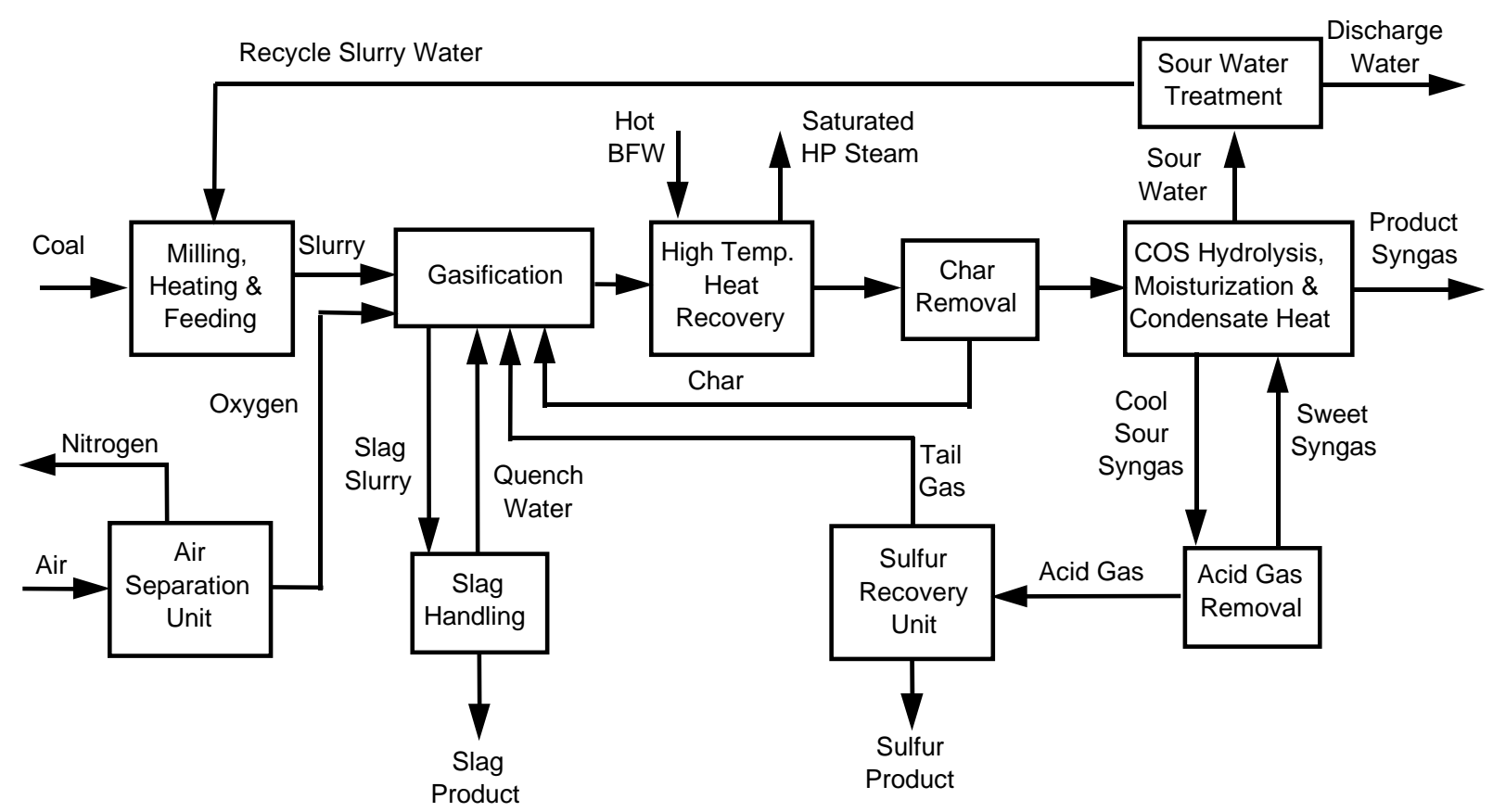

Table 1.1.1 - SGS Gasification Production Statistics during the Demonstration Period of the Clean Coal Technology Program

\begin{tabular}{|l|l|l|l|l|l|}
\hline \multirow{2}{*}{ Production Variable } & \multicolumn{4}{l|}{ Production Year } \\
\cline { 2 - 6 } & 1996 & 1997 & 1998 & 1999 & 2000 \\
\hline Gasifier Operation, Hrs & 1,902 & 3,885 & 5,279 & $3,496 *$ & $3,406^{* *}$ \\
\hline $\begin{array}{l}\text { Dry Synthesis Gas } \\
\text { Produced, GJ (MMBtu) }\end{array}$ & $2,922,015$ & $6,555,626$ & $9,316,716$ & $6,132,874$ & $5,497,588$ \\
\hline $\begin{array}{l}\text { Coal Processed, Mt } \\
\text { (Tons) }\end{array}$ & $167,769,683)$ & $(6,213,864)$ & $(8,831,011)$ & $(5,813,151)$ & $(5,210,984)$ \\
\hline
\end{tabular}

* Three months of production were lost to the GE 7FA compressor failure and repair.

** Three months of production were lost during commercial negotiations required when the SGS Facility transitioned to market-based operation. 
Table 1.1.2: Overall Thermal Performance of Gasification at SGS

\begin{tabular}{|l|l|l|l|}
\hline \multirow{2}{*}{ Performance Feature } & \multirow{2}{*}{ Design } & \multicolumn{2}{|l|}{ Actual Performance } \\
\cline { 3 - 4 } & & Coal & Coke \\
\hline Nominal Throughput, TPD & 2550 & 2450 & 2000 \\
\hline Synthesis Gas Capacity, MMBtu/hr & 1780 & $1690^{\dagger}$ & $1690^{\dagger}$ \\
\hline Combustion Turbine, MW & 192 & 192 & 192 \\
\hline Steam Turbine, MW & 105 & 96 & 96 \\
\hline Aux. Power, MW & 35 & 36 & 36 \\
\hline Net Generation, MW & 262 & 261 & 261 \\
\hline Plant Efficiency, \% (HHV) & 37.8 & 39.7 & 40.2 \\
\hline Sulfur Removal Efficiency, \% & $>98$ & $>99$ & $>99$ \\
\hline
\end{tabular}

${ }^{\dagger}$ Synthesis gas capacity referenced for coal and petroleum coke are the actual quantities fed to the combustion turbine when 192 MW (100\%) of power generation occurs.

\subsection{EECP Background Information}

The request for Cooperative Agreement Proposals under the "Early Entrance Coproduction Plant (EECP)," Solicitation Number DE-SC26-99FT40040 was issued on February 17, 1999, by the United States Department of Energy.

The objective of this effort was to determine the feasibility of an EECP located at a specific site which produces some combination of electric power (or heat), fuels, and/or chemicals from synthesis gas derived from coal, or, coal in combination with some other carbonaceous feedstock. The scope of this effort includes the following activities:

1. Market analysis to define site-specific product requirements (i.e. products needed by market, market size, and price), process financials, feedstock availability, and feedstock cost;

2. System analysis to define feedstocks, feedstock preparation, conversion to syngas, syngas cleanup, and conversion of syngas to market-identified products;

3. Preliminary engineering design of the EECP facility;

4. Preparation of a research, development, and testing (RD\&T) Plan that addresses the technical uncertainties associated with eventual design, construction, and operation of the EECP;

5. Implementation of RD\&T Plan;

6. Update of the preliminary engineering design; and

7. Update of the preliminary economic analysis. 
Efforts under Solicitation No. DE-SC26-99FT40040 must support an EECP that at a minimum meets the following criteria:

1. Is a single-train facility of sufficient size to permit scaling to commercial size with minimal technical risk;

2. Provides the capability of processing multiple feedstocks (must be capable of processing coal) and producing more than one product;

3. Is undertaken by an industrial consortium;

4. Reduces risk such that future coproduction plants may be deployed with no government assistance; and

5. Meets or exceeds environmental requirements and discusses the issue of carbon dioxide reduction by one or more routes, which include mitigation, utilization, and sequestration.

Using a focused RD\&T Plan, the EECP Project would enhance the development and commercial acceptance of coproduction technology that produces high-value products, particularly those that were critical to our domestic chemical, fuel, and power requirements. The project would resolve critical knowledge and technology gaps on the integration of gasification and downstream processing to coproduce some combination of power, fuels and/or chemicals from coal or coal in combination with other carbonaceous feedstocks. The project's intended result was to provide the necessary technical, financial, and environmental information that would be needed to move the EECP forward to detailed design, construction, and operation by industry. 


\subsection{INTRODUCTION}

The Wabash River Integrated Methanol and Power Production from Clean Coal Technologies (IMPPCCT) Project was a \$2,168,943 cooperative agreement awarded by the United States Department of Energy (DOE) to the former Gasification Engineering Corporation (GEC). The project was later under the leadership of ConocoPhillips Company (COP) after it acquired GEC and the E-Gas gasification technology from Global Energy Inc. in July 2003. The project evaluated the integration of gasification-based electrical generation and methanol production processes to determine the economic and technical feasibility of power and chemicals coproduction. A multi-industry team led by the previous E-Gas Gasification Technology owner, GEC, and consisting of Air Products and Chemicals, Inc., Dow Chemical Company, Dow Corning Corporation, Methanex Corporation, and Siemens Westinghouse Power Corporation performed and completed the Phase I IMPPCCT study. Phase II, which has just been completed, was led by COP and was supported by Gas Technology Institute, TDA Research, Inc., and Nucon International, Inc.

The IMPPCCT Project team analyzed and developed a concept of methanol and power coproduction based on the E-Gas gasification technology, now owned and licensed by COP, utilizing coal and other feedstocks. In the two-phase project, the team reviewed and analyzed the domestic methanol market, examined the criteria needed and developed a financial model to study the economics of full-scale implementation of this gasification to power and methanol coproduction concept. Potential Dow Chemical and Dow Corning sites for the Commercial Embodiment Plant (CEP) were examined. Feasibility studies, testing and engineering, and economics of IMPPCCT based on addition of methanol production facilities at the SG Solutions (SGS), previously the Wabash River Energy Limited (WREL), Gasification Facility in West Terre Haute, Indiana were developed to enable the commercialization of the gasification to power and methanol coproduction concept.

The vision of this project was to demonstrate the commercial viability of coproducing electric power, process energy (steam), and chemicals (methanol) from coal and other hydrocarbon feedstocks to satisfy the demands of at least two types and corresponding sizes of host chemical complexes. An efficient, low capital, integrated facility would convert the feedstock initially to synthesis gas (syngas) and ultimately to electric power, process energy, and methanol with a series of reliable, commercially-proven, and environmentally-sound unit operations. The chemical products, required process energy, and at least a portion of the electric power would be delivered to the host chemical complex for further conversion to higher value products. Any products in excess of the requirements of the host chemical complex would be sold through readily accessible distribution networks. The CEP would be technically verified from the implementation of the Research, Development, and Testing (RD\&T) Plan and commercially verified by an economic model. 


\subsection{EXECUTIVE SUMMARY}

The Wabash River Integrated Methanol and Power Production from Clean Coal Technologies (IMPPCCT) Project was established to evaluate integrated electrical power generation and methanol coproduction through clean coal technologies. The project was conducted by a multiindustry team lead initially by Gasification Engineering Corporation (GEC). The project was later under the leadership of ConocoPhillips Company (COP) after it acquired GEC and the EGas gasification technology from Global Energy Inc. in July 2003. Phase I of this project was supported by Air Products and Chemicals, Inc., Dow Chemical Company, Dow Corning Corporation, Methanex Corporation, and Siemens Westinghouse Power Corporation, while Phase II was supported by Gas Technology Institute (GTI), TDA Research Inc., and Nucon International, Inc. The project has completed both Phase I and Phase II of development. The two project phases include the following:

I. Feasibility study and conceptual design for an integrated demonstration facility at SG Solutions (SGS), previously the Wabash River Energy Limited (WERL), Facility in West Terre Haute, Indiana, and for a fence-line commercial embodiment plants (CEP) operated at Dow Chemical or Dow Corning chemical plant locations

II. Research, development, and testing (RD\&T) to define any technology gaps or critical design and integration issues.

The Wabash River Repowering Project, a joint effort between Destec Energy, the previous owner of the E-Gas technology, and PSI Energy, now Duke Energy, was selected and co-funded under Round IV of the United States Department of Energy's (DOE's) Clean Coal Technology Program. In this project, coal and/or other carbonaceous feedstocks are gasified in an oxygenblown, entrained-flow gasifier with continuous slag removal and a dry particulate removal system. The resulting product synthesis gas (syngas) is used to fuel a combustion turbine generator whose exhaust is integrated with a heat recovery steam generator to drive a refurbished steam turbine generator. The gasifier uses technology initially developed by The Dow Chemical Company (the Destec Gasification Process), and now offered commercially by COP as the E-Gas technology.

The demonstration project was completed in December 1999, having achieved all of its objectives. The facility built for this project is located at Duke Energy's Wabash River Generating Station near West Terre Haute, Indiana.

The Wabash River Repowering Project successfully demonstrated commercial application of the E-Gas coal gasification technology in conjunction with power generation. The combustion turbine generates $192 \mathrm{MW}$ while the repowered steam turbine generates $104 \mathrm{MW}$. With the parasitic load of the system approximately $34 \mathrm{MW}$, the net power production is $262 \mathrm{MW}$, which meets the target goal. By the end of the demonstration period of the Clean Coal Technology Program, operating time had exceeded 18,000 hours, with over 5 million MW of power produced. The SGS Facility operates successfully on baseload dispatch in the Duke Energy power grid, and continues to operate as a privately owned facility after the demonstration period to supply syngas to Duke Energy. 
Gasification is an environmentally superior means of utilizing domestic coal resources for power production. It also offers the opportunity to use lower quality, less expensive feedstocks such as petroleum coke. Petroleum coke operation was successfully tested at the SGS Facility as early as November 1997. Since August 2000, the facility has been operating on 100\% petroleum coke feed. Over two million tons of fuel-grade petroleum coke has been processed, demonstrating the commercial viability of petroleum coke as the principle fuel for gasification.

Sulfur removal from the solid feed to the gasifier is recovered and sold, as is the slag byproduct. Sulfur removal exceeds $97 \%$ resulting in sulfur oxides emissions from the turbine exhaust of 0.1 $\mathrm{lb} /$ million Btu, which is far below regulatory requirements of $1.2 \mathrm{lb} / \mathrm{million}$ Btu. Particulate emissions are less than the detectible limit and nitrogen oxides emissions are $0.15 \mathrm{lb} / \mathrm{million}$ Btu, which meets the current target for coal-fired power generation plants. The SGS Facility is one of the cleanest solid fuel-based power plants in the world.

In a joint effort with DOE, a Cooperative Agreement for the IMPPCCT Project was awarded under the Early Entrance Coproduction Plant (EECP) solicitation. GEC, now COP, and the industrial partners investigated the use of syngas produced by the E-Gas technology in a coproduction environment to enhance the efficiency and productivity of solid fuel gasification combined cycle plants.

The objective of this effort was to determine the feasibility of an EECP located at a specific site which produces some combination of electric power (or heat), fuels, and/or chemicals from syngas derived from coal, or, coal in combination with some other carbonaceous feedstock. The intended result of the project was to provide the necessary technical, financial, and environmental information that would be needed to move the EECP forward to detailed design, construction, and operation by industry.

The EECP study conducted in Phase I of the IMPPCCT Project confirmed that the concept for the integration of gasification-based (E-Gas) electricity generation from coal and/or petroleum coke and methanol production (Liquid Phase Methanol or LPMEOH ${ }^{\mathrm{TM}}$ ) processes was feasible for the coproduction of power and chemicals. The results indicated that while there are minimal integration issues that impact the deployment of an IMPPCCT CEP, the major concern was the removal of sulfur and other trace contaminants, which are known methanol catalyst poisons, from the syngas. However, economic concerns in the domestic methanol market which is driven by periodic low natural gas prices and cheap offshore supplies limit the commercial viability of this more capital intensive concept.

The objective of Phase II was to conduct RD\&T as outlined in the Phase I RD\&T Plan to enhance the development and commercial acceptance of coproduction technology. Studies were designed to address the technical concerns that would make the IMPPCCT concept competitive with natural gas-based systems in the commercial marketplace. Efforts in Phase II investigated the cleanup of the syngas by removing contaminants, particularly sulfur species, to a level acceptable to maintain high activity of the methanol synthesis catalyst, and reducing the cost of the current sulfur removal system such as via warm gas cleanup methods. Laboratory testing followed by on-site testing at SGS with bench-scale slipstream units was conducted. Actual syngas produced by the facility was evaluated at system pressure and temperature. 
The following three processes, which potentially would be low in capital and operating costs, were chosen to be investigated for syngas application:

1. A direct sulfur oxidation recovery process developed by TDA to remove sulfur species from natural gas at warm temperatures;

2. A regenerable activated carbon system developed by Nucon for removing sulfur species in a syngas stream to parts-per-billion (ppb) levels; and

3. A regenerable sorbent developed by COP to remove sulfur contaminants from gasoline at high temperatures.

The TDA Direct Oxidation Sulfur Recovery slipstream work was terminated in 2005 after laboratory testing showed that the catalyst selected for the slipstream testing was too reactive and was oxidizing the hydrogen instead of the hydrogen sulfide $\left(\mathrm{H}_{2} \mathrm{~S}\right)$ at the temperature required to operate the catalyst. Relatively high temperature was required due to the high concentration of $\mathrm{H}_{2} \mathrm{~S}$ in the syngas produced at the SGS Facility. TDA was not able to develop another catalyst more suitable for the high $\mathrm{H}_{2} \mathrm{~S}$ environment. As a result, bench-scale slipstream testing at the SGS Facility was not conducted.

Laboratory investigation of the Nucon sorbent was completed in 2004 with very favorable results. A bench-scale slipstream unit was designed, constructed, and installed at the SGS Facility in late 2005. Preliminary results were very encouraging, showing that both $\mathrm{H}_{2} \mathrm{~S}$ and carbonyl sulfide (COS) can be removed to less than ppm levels, and that the carbon sorbent can be regenerated. Subsequent tests, however, showed that COS removal capability deteriorated rapidly. Various measures were tried but to no avail. Nucon will continue to investigate the anomaly between the favorable laboratory test results compared to the slipstream test results outside of the IMPPCCT Project.

Laboratory studies to investigate COP's S Zorb warm gas temperature sulfur removal sorbent were completed in June 2005, and a bench-scale slipstream unit was constructed, delivered, and installed at the SGS Facility in September 2005. Start up of the unit commenced in midNovember 2005. Following favorable initial results a six-cycle successive absorptionregeneration was then conducted. Results showed that $\mathrm{H}_{2} \mathrm{~S}$, COS, as well as hydrogen chloride $(\mathrm{HCl})$, were effectively removed in each of the cycles. The capacity of the sorbent was adequately restored in the regeneration cycles. Samples of the sorbent showed no chemical or physical deterioration after the six-cycle testing. In view of the encouraging results, a process and economic evaluation of the E-Gas gasification process with the $S$ Zorb warm gas desulfurization was conducted with favorable results. 


\subsection{ACTIVITIES}

The main focus of RD\&T being pursued under the IMPPCCT Project was in syngas contaminant removal. Potential technologies to be evaluated included TDA's direct sulfur oxidation recovery process, Nucon's regenerable activated carbon, and COP's warm gas temperature sorbent to remove $\mathrm{H}_{2} \mathrm{~S}$ and other sulfur species. Laboratory testing on these technologies was completed in 2004 and early 2005; and bench-scale slipstream testing at the SGS Facility to evaluate these technologies was completed in 2005 and 2006.

\subsection{Direct Oxidation Sulfur Recovery (GTI/TDA)}

Under this study, GTI provided technical and operating support for an experimental investigation of TDA's proprietary Direct Oxidation Sulfur Recovery Process to desulfurize syngas produced by coal gasification at the SGS Facility. TDA developed a direct oxidation process that converts $\mathrm{H}_{2} \mathrm{~S}$ into elemental sulfur at temperatures between $300^{\circ} \mathrm{F}$ and $500^{\circ} \mathrm{F}$. The process was projected to be economical in the range of 20-200 tons per day of sulfur.

To determine if TDA's process was practicable for desulfurizing syngas from the SGS Facility, a bench-scale slipstream field test using TDA's automated catalyst test apparatus was to be conducted. Under subcontract from GTI, TDA planned to perform the following activities:

1) Modify TDA's existing bench-scale direct sulfur oxidation unit for high pressure and high flow rate operation;

2) Perform bench-scale tests of the apparatus at TDA with simulated syngas that has a composition that closely matches that of the SGS Facility; and

3) Transport the bench-scale unit to the SGS Facility and, with the help of GTI, jointly perform desulfurization tests with a slipstream of the actual syngas.

To expedite the implementation of the work, it was decided to proceed co-currently on Activities 1 and 2 above. Activity 1 progressed smoothly and the construction and assembly of the benchscale slipstream unit was essentially completed during the spring of 2004.

Testing in the laboratory was conducted in a smaller unit at TDA while the slipstream unit was under construction. The direct oxidation catalyst that TDA planned to use for the slipstream testing was developed for natural gas applications. The catalyst is active at low temperatures near $180^{\circ} \mathrm{C}\left(356^{\circ} \mathrm{F}\right)$. Because of the high concentration of $\mathrm{H}_{2} \mathrm{~S}(1.5 \mathrm{vol} \%)$ present in the feed gas from the SGS Facility, the reaction had to be conducted at a higher temperature of $280^{\circ} \mathrm{C}$ $\left(536^{\circ} \mathrm{F}\right)$ to prevent the sulfur produced from condensing inside of the catalyst pores. At this temperature, the laboratory tests conducted by TDA showed that hydrogen $\left(\mathrm{H}_{2}\right)$ was preferentially being oxidized. All of the oxygen added was consumed and no $\mathrm{H}_{2} \mathrm{~S}$ was converted.

From the results of these laboratory tests it was concluded that the catalyst was too active. An alternate or modified catalyst that would be more appropriate for the high concentration of $\mathrm{H}_{2} \mathrm{~S}$ conditions present at the SGS Facility would be required. Further testing was put on hold in 
April 2004, pending on the development of a more suitable catalyst. Over the next year, TDA pursued to develop a catalyst more suitable for the syngas from the SGS Facility. The catalyst development, which was conducted under a separate DOE Phase I Small Business Innovative Research grant, did not produce any encouraging results. Therefore investigation of TDA's Direct Sulfur Oxidation Recovery process was terminated in June 2005 with the concurrence of GTI and DOE.

A summary report prepared by TDA on the work conducted is included as Appendix I.

\subsection{Regenerable Carbon for Sulfur Polishing (Nucon)}

The objective of this study was to determine the feasibility of removing sulfur-containing compounds in syngas using an impregnated regenerable activated carbon developed by Nucon. Even though most of the sulfur contaminants are removed by the acid gas removal system in the gasification process, the remaining level is still too high for the methanol synthesis processes in the IMPPCCT Project. The removal of the remaining sulfur containing compounds $-\mathrm{H}_{2} \mathrm{~S}$, and COS - is critical in preventing the poisoning of the catalyst used to convert syngas to methanol.

Laboratory tests to determine the optimum sorbent and operating conditions were completed in early 2004 with favorable results. A bench-scale slipstream unit was then designed and constructed for on-site testing at the SGS Facility. The slipstream unit was shipped and installed with the re-commissioning and re-starting of the SGS Facility in the second half of 2005 . The slipstream unit was started up on December 1, 2005.

Figures 4.2.1 and 4.2.2 are photographs of the Nucon bench-scale slipstream unit as it was installed at the SGS Facility.

Initial testing showed that the sorbent can remove $\mathrm{H}_{2} \mathrm{~S}$ and COS to less than ppm levels in the presence of carbon monoxide (CO). The spent sorbent can also be regenerated. Subsequent tests, however, showed COS removal capability deteriorated rapidly even though the $\mathrm{H}_{2} \mathrm{~S}$ removal capability did not seem to be affected. Various measures to improve the regeneration condition, to avoid moisture condensation, and to improve the reliability and accuracy of the analyses by installing a dedicated analyzer, were implemented. A final testing was conducted in August 2006. Results were consistent with the earlier observations.

Based on the results from the slipstream testing, Nucon concluded that the sorbent lost its capability for removing COS readily and the regeneration method employed was not effective in restoring the COS removal capability. Nucon will continue to investigate, outside of the IMPPCCT Project, the anomaly on the sorbent performing well in the laboratory with blended syngas but not in the field with actual syngas.

A summary report on the work prepared by Nucon is included as Appendix II. 
Figure 4.2.1: Nucon Bench-Scale Slipstream Unit, Front View

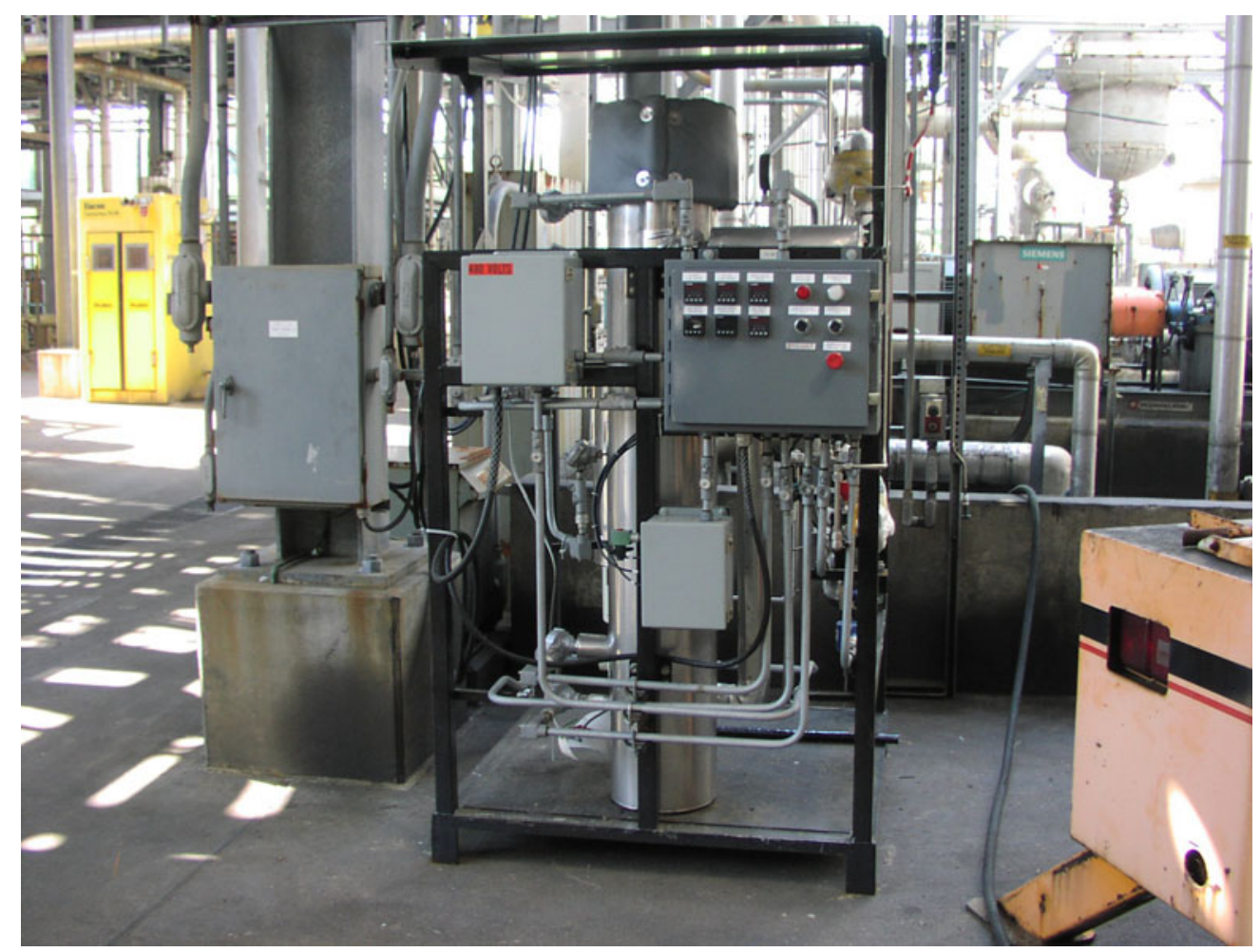

Figure 4.2.2: Nucon Bench-Scale Slipstream Unit, Right Side View

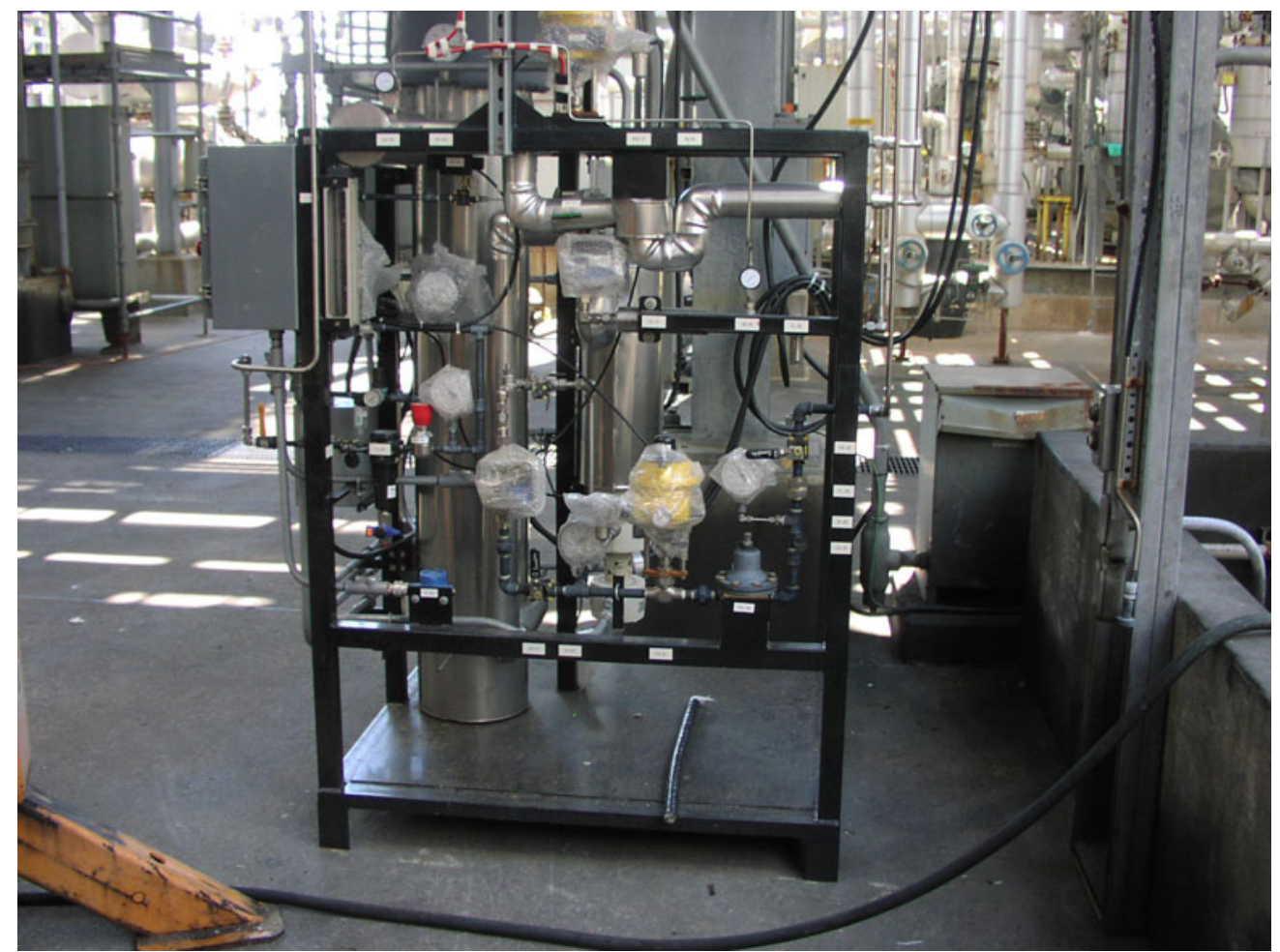




\subsection{ConocoPhillips’ S Zorb Warm Gas Desulfurization Process}

The objective of this study was to test the ability of COP's new generation of regenerable SZorb $^{\mathrm{TM}}$ sorbents to remove sulfur from the hot raw syngas produced by the E-Gas gasifier located at the SGS Facility. The sorbent is a commercial product for removing sulfur from

gasoline. Sorbent activity and capacity were first measured in a laboratory test unit at pressure and temperature using a feed gas that simulates the syngas stream from the E-Gas gasifier. Sorbent tolerance for contaminants was determined by a slipstream test conducted at the SGS Facility.

COP's S Zorb SRT process to remove sulfur from gasoline is unique in that it uses a fluidizedbed sorbent to remove the sulfur. The sorbent also removes COS and is resistant to chlorides. There are currently four commercial-scale S Zorb ${ }^{\mathrm{TM}}$ SRT units operating in COP refineries and several units licensed to other domestic and international refining companies. Two of these licensed units are already operating with several more under construction. In these gasoline desulfurization units, the gasoline is completely vaporized and mixed with hydrogen. The gas flow rate to the adsorber in the COP's Borger, Texas, refinery, the first demonstration unit of the technology, ranges from 10-20 million cubic feet per day. The unit has been operating since April 2001. The latest unit in COP's Wood River, Missouri refinery has been operating since February 2007 and has gas flow rates through the adsorber of approximately 100 million cubic feet per day. The S Zorb ${ }^{\mathrm{TM}}$ SRT absorber is operated at process conditions similar in temperature, pressure and flow rates to the hot raw unscrubbed syngas produced in the E-Gas gasification process.

The S Zorb SRT technology, if successful, would greatly simplify the gasification processes for a new IMPPCCT CEP and thus reduce the capital, operating and maintenance costs as well as improving the efficiency of the process. The high cost of the gas cleanup system of the IMPPCCT CEP is one of the obstacles for commercialization identified in the Phase I study.

Laboratory studies to investigate COP's warm gas temperature sulfur removal sorbent were completed in June 2005, and a bench-scale slipstream unit was constructed and delivered to the SGS Facility in September 2005. Start up of the unit commenced in mid-November 2005 when the SGS Facility was re-started. An initial test with the S Zorb sorbent was conducted on December 1, 2005, and a series of six complete adsorption/regeneration test cycles was completed by mid-December 2005. The sorbent, as tested in a fixed-bed reactor, removed the sulfur contaminants, reaching near theoretical sulfur loading capacity of the sorbent, with very low sulfur levels $(<5 \mathrm{ppm})$ measured at the reactor outlet through all of the absorption cycles. The sorbent is easily regenerated with no degradation of the sorbent observed from the multicycle test.

During 2006, a process and economic evaluation of the E-Gas Process with the S Zorb warm gas desulfurization scheme was undertaken by the COP Gasification Process Engineering Group. A conventional amine-based syngas cleanup scheme shown in Figure 4.3.1 was compared to the $\mathrm{S}$ Zorb $^{\mathrm{TM}}$ SRT warm gas cleanup scheme, shown in Figure 4.3.2. The evaluation showed that compared to the conventional gas cleanup process using amines, the $\mathrm{S}$ Zorb ${ }^{\mathrm{TM}}$ retrofit would result in a reduction in capital cost by as much as $40 \%$ in the gas cleanup section of the E-Gas 
process. The savings would be even greater if a Selexol or Rectisol system is used to deliver a lower sulfur-content syngas such as that obtainable from the S Zorb ${ }^{\mathrm{TM}}$ system.

Figure 4.3.1 - Convention Amine-Based Syngas Cleanup Scheme

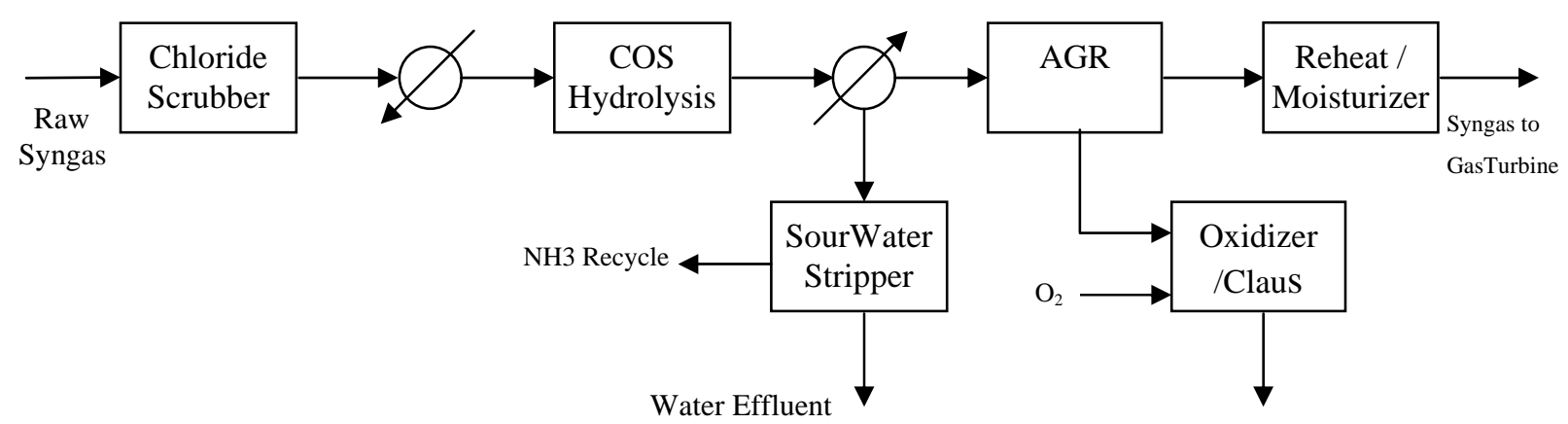

Figure 4.3.2 - S Zorb ${ }^{T M}$ SRT Warm Gas Cleanup Scheme

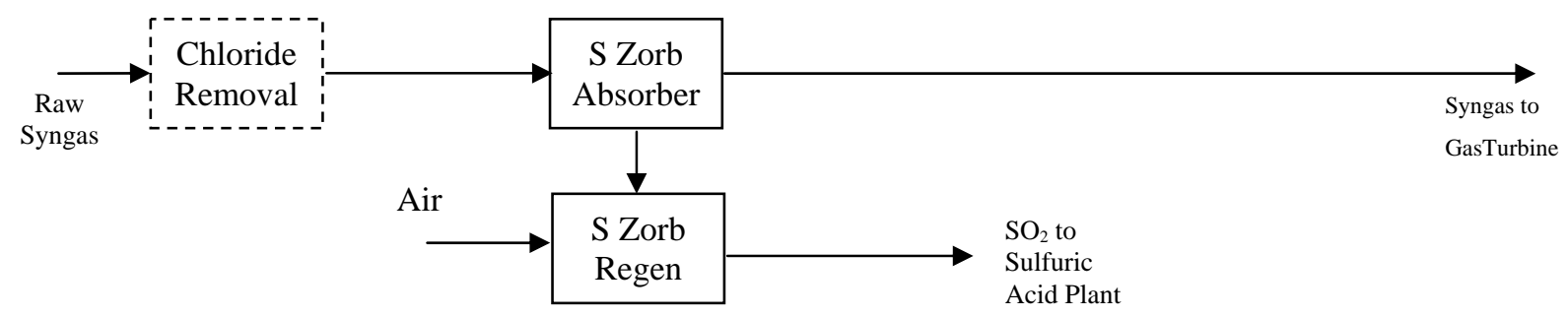

The evaluation and cost estimates compared favorably with the information presented by Eastman Chemical Company and Research Triangle Institute (RTI) at the 2006 Gasification Technology Conference ${ }^{1}$. The RTI/Eastman work is very similar to the E-Gas/S Zorb ${ }^{\mathrm{TM}}$ warm gas cleanup process that was evaluated under the IMPPCCT Project.

The work scope planned for evaluating the S Zorb sorbent under the IMPPCCT Project was completed and a Topical Report to document the laboratory and slipstream testing was published in July 2007. A copy of the Topical Report is included as Appendix III.

1 “Field Testing of a Warm-Gas Desulfurization Process in a Pilot-Scale Transport Reactor System”, Gasification Technology Conference, Washington D.C., October 2006 


\subsection{Other Activities}

Two conference papers were presented as part of the Phase II activity under the IMPPCCT Project. A paper titled "Slipstream Testing of Novel Sulfur Removal Processes for Gasification Application", which briefly described the work being conducted in Phase II of the IMPPCCT Project at the time, was presented by Albert Tsang of COP at the $22^{\text {nd }}$ International Pittsburgh Coal Conference on September 14, 2005. Also a paper titled "Sulfur Removal from E-Gas"TM Technology Gas Streams using S Zorb ${ }^{\mathrm{TM}}$ Sorbent” was presented in the $23^{\text {rd }}$ International Pittsburgh Coal Conference on September 27, 2006 by Dr. Roland Schmidt of COP who conducted the laboratory and slipstream testing. A copy of the presentations and the papers are included as Appendix IV and V, respectively. 


\subsection{RESULTS AND DISCUSSION}

The main focus of RD\&T being pursued under the IMPPCCT Project was in syngas contaminant removal. Potential technologies identified for evaluation included TDA's Direct Sulfur Oxidation Recovery process, Nucon's regenerable activated carbon, and COP's warm gas temperature sorbent, to remove $\mathrm{H}_{2} \mathrm{~S}$ and other sulfur species. Laboratory testing on the technologies was completed in 2004 and early 2005, and bench-scale slipstream testing at the SGS Facility to evaluate these technologies was completed in 2005 and 2006.

\subsection{Direct Oxidation Sulfur Recovery (GTI/TDA)}

The direct oxidation catalyst that TDA planned to use for the slipstream testing was developed for natural gas applications. The catalyst is active at low temperatures near $180^{\circ} \mathrm{C}\left(356^{\circ} \mathrm{F}\right)$. For syngas produced at the SGS Facility which contains a high concentration of $\mathrm{H}_{2} \mathrm{~S}(1.5 \mathrm{vol} \%)$ in the feed gas, the reaction had to be conducted at a higher temperature of $280^{\circ} \mathrm{C}\left(536^{\circ} \mathrm{F}\right)$ to prevent the sulfur produced from condensing inside of the catalyst pores. At this temperature, however, the laboratory tests conducted by TDA showed that hydrogen was preferentially being oxidized. All of the oxygen added was consumed and no $\mathrm{H}_{2} \mathrm{~S}$ was converted.

It was concluded from the results of these laboratory tests that the catalyst was too active. An alternate or modified catalyst that would be more appropriate for the conditions present at the SGS Facility, i.e. high $\mathrm{H}_{2} \mathrm{~S}$ concentration in the syngas, would be required. Further testing was put on hold in April 2004, pending on the development of a more suitable catalyst. The catalyst development, which was conducted under a separate DOE Phase I SBIR grant, did not produce any encouraging results. Therefore investigation of TDA's Direct Sulfur Oxidation Recovery process was terminated.

For more detail on the work, please refer to the summary report prepared by TDA included as Appendix I.

\subsection{Regenerable Carbon for Sulfur Polishing (Nucon)}

Nucon's activated carbon performed well in simulated syngas in the laboratory - with $\mathrm{H}_{2} \mathrm{~S}$ and COS individually in the syngas, both $\mathrm{H}_{2} \mathrm{~S}$ and $\mathrm{COS}$ together in the syngas, in atmospheric and pressurized conditions - and the sorbent was completely regenerable in all the conditions tested. However, results from the slipstream testing were less favorable. It showed that the sorbent worked well in removing $\mathrm{H}_{2} \mathrm{~S}$ but readily loses its capability for removing $\mathrm{COS}$, and the regeneration method employed was not effective in restoring the COS removal capability even though the $\mathrm{H}_{2} \mathrm{~S}$ removal capability did not seem to be affected. Various measures to improve the regeneration condition, to prevent moisture condensation, and to improve the reliability and accuracy of the analyses by installing a dedicated analyzer, were implemented by Nucon, but the regeneration continued to be a problem. Nucon will continue to investigate, outside of the IMPPCCT Project, the anomaly on the sorbent performing well in the laboratory but not in the field.

For more detail on the work, please refer to the summary report prepared by Nucon that is included as Appendix II. 


\subsection{ConocoPhillips' S Zorb Warm Gas Desulfurization Process}

The evaluation of COP's warm gas temperature sulfur removal sorbent went smoothly and expeditiously. The laboratory-scale system to investigate the S Zorb process was constructed and testing was satisfactorily completed in June 2005. A bench-scale slipstream unit was then constructed and installed in a mobile trailer, which was delivered to the SGS Facility on September 1, 2005. Installation and hook up of the equipment to the process was completed by the end of September 2005. Start-up activities commenced in late November 2005 when the SGS Facility resumed stable operation. An initial test with S Zorb sorbent was conducted on December 1, 2005, and a series of six complete absorption/regeneration cycles test was completed by mid-December 2005. Both the laboratory and slipstream investigation were completed in a period of less than one year.

Both laboratory and slipstream testing results showed that the sorbent was removing $\mathrm{H}_{2} \mathrm{~S}$ and COS effectively, and that the sorbent could be easily regenerated. The spent sorbent, after six cycles in the slipstream test, showed no attrition loss or other physical deterioration and no chemical degradation caused by the contaminants in the syngas.

A process and economic evaluation of the E-Gas Process with the S Zorb warm gas desulfurization scheme showed that compared to a conventional gas cleanup process using amines, the S Zorb process would result in a reduction in capital cost by as much as $40 \%$ in the gas cleanup section of the E-Gas Process. The savings would be even more if a Selexol or Rectisol system were used to deliver a lower sulfur-content syngas such as that obtainable from the S Zorb system. The cost estimates compared favorably with the information presented by Eastman Chemical Company and Research Triangle Institute (RTI) at the Gasification Technology Conference titled "Field Testing of a Warm-Gas Desulfurization Process in a PilotScale Transport Reactor System"1. The RTI/Eastman work is very similar to the E-Gas/S Zorb Warm Gas Cleanup Process that is being evaluated under the current IMPPCCT Project.

A Topical Report describing the S Zorb investigation was published and is included as Appendix III. 


\subsection{CONCLUSIONS \& RECOMMENDATION}

The objective of Phase II of the IMPPCCT Project was to conduct RD\&T to enhance the development and commercial acceptance of coproduction technologies. Studies were designed to address the technical concerns that will make the IMPPCCT concept competitive with natural gas-based systems in the commercial marketplace. Efforts in Phase II were to investigate the cleanup of the syngas by removing contaminants, particularly sulfur species, to a level acceptable for the methanol synthesis catalyst, and by reducing the cost of the current sulfur removal system such as via warm gas cleanup methods. Potential technologies identified for evaluation include TDA's Direct Oxidation Sulfur Recovery process, Nucon's regenerable activated carbon, and COP's $\mathrm{S}$ Zorb warm gas sorbent, to remove $\mathrm{H}_{2} \mathrm{~S}$ and other sulfur species. Laboratory testing followed by on-site testing at the SGS Facility with bench-scale slipstream units operating with an actual syngas feed produced by the SGS Facility at system pressure and temperature were the approaches used in the evaluation.

All the testing planned for the IMPPCCT Project has been completed. Results showed that the TDA catalyst and the Nucon sorbent did not perform as well as anticipated. The TDA catalyst was too reactive at the required operating temperature and was oxidizing the hydrogen instead of the $\mathrm{H}_{2} \mathrm{~S}$. The Nucon sorbent worked well in removing $\mathrm{H}_{2} \mathrm{~S}$, but loses its capability for removing COS. The regeneration method employed was not effective in restoring the COS removal capability. Both TDA and Nucon will continue, outside of the IMPPCCT Project, to develop and improve their catalyst/sorbent to meet the requirement of gasification applications.

Results from the laboratory and slipstream studies on the COP warm gas sulfur removal sorbent have demonstrated the technical feasibility of using the $S$ Zorb ${ }^{\mathrm{TM}}$ sulfur removal technology for the E-Gas process. The sorbent, as tested in a fixed-bed reactor, successfully removed the sulfur contaminants, reaching near theoretical sulfur loading capacity of the sorbent, with very low sulfur levels $(<5 \mathrm{ppm})$ measured at the absorber outlet through all of the absorption cycles. The sorbent is easily regenerated with no degradation of the sorbent observed from the multi-cycle test. Economic analysis showed significant capital savings employing the S Zorb ${ }^{\mathrm{TM}}$ SRT warm gas desulfurization process. Further investigation of the process such as in pilot scale testing with actual syngas is recommended.

\section{ACKNOWLEDGEMENTS}

Financial support for this work from DOE/NETL under Cooperative Agreement No. DE-FC2699FT40659 is gratefully acknowledged. A special recognition goes to the DOE Project Manager, Bob Kornosky; his guidance and assistance was critical for the execution and successful completion of the project. Cooperation from personnel from GTI, Nucon, TDA, ConocoPhillips, SG Solutions, and contract personnel on site the SGS Facility is greatly appreciated. 


\title{
REFERENCES
}

\section{Selected References on SGS and E-Gas Available via the Internet}

1. The Gasification Technology Council maintains a website (www.gasification.org) that includes a library of the presentations made at recent GTC conferences and workshops (click “Library” or “Conference Papers”). Recent ConocoPhillips gasification papers are named below. All presentations presented since 2002 can be downloaded from the website:

\author{
“ConocoPhillips E-Gas Technology 2006” 2006 Annual Conference \\ "Low Rank Coal Gasification” March 2007 Workshop \\ "Substitute Natural Gas (SNG) Production from Coal” 2006 Annual Conference \\ “Development Experience with the Mesaba Energy Project” 2006 Annual Conference \\ “ConocoPhillips and Gasification's New World - An Overview” 2005 Annual Conference \\ "E-Gas Applications for Sub-Bituminous Coal” 2005 Annual Conference \\ "Comparative IGCC Costs and Performance for Domestic Coals" 2005 Annual Conference \\ “ConocoPhillips Technology Solutions - Gasification 2004” 2004 Annual Conference \\ “Refueling: Retrofitting Coal Gasification to NGCC” 2004 Annual Conference \\ “ConocoPhillips’ Entry into the Gasification Industry”, 2003 Annual Conference
}

2. “Wabash River Coal Gasification Repowering Project, A DOE Assessment”, January 2002. This is the DOE's official post-project assessment of the Wabash River project.

http://www.netl.doe.gov/technologies/coalpower/cctc/resources/pdfs/wabsh/netl1164.pdf

3. “Wabash River Coal Gasification Repowering Project Final Technical Report”, August 2000, 358 pages. This is a very detailed look at the Wabash River facility and its operation 1995-1999.

http://www.netl.doe.gov/technologies/coalpower/cctc/resources/pdfs/wabsh/Final\%20_Report.pdf

4. “Gasification Plant Performance and Cost Optimization”, May 2002, (23 MB). The final report of Task 1 of this comprehensive (\$2.4 million) study performed by Global Energy, Nexant and Bechtel under subcontract to the DOE to identify cost savings in the next generation of integrated gasification and coproduction facilities utilizing the E-Gas Technology. Detailed cost estimating by Bechtel.

http://www.netl.doe.gov/technologies/coalpower/gasification/projects/systems/docs/rev-40342R01.pdf

5. "Major Environmental Aspects of Gasification-Based Power Generation Technologies", Department of Energy, December 2002, featuring the Wabash station on its front cover.

http://www.netl.doe.gov/technologies/coalpower/cctc/resources/pdfsmisc/igcc/SAIC_Env_Rpt.pdf

\section{More Information on the E-Gas Technology and Announced Projects:}

ConocoPhillips Technology Solutions website: www.coptechnologysolutions.com

Excelsior Energy’s Mesaba Energy Project www.excelsiorenergy.com

Rentech Energy Midwest Corporation East Dubuque Project http://www.rentechenergymidwest.com/index.htm

\section{More General Gasification Information:}

U.S. DOE National Energy Technology Center www.netl.doe.gov

Peabody Energy www.coalcandothat.com

Clean-Energy U.S. http://www.clean-energy.us/index.php 


\title{
APPENDIX I
}

\author{
Final Report from
}

Gas Technology Institute

and

TDA Research

On

“WABASH SYNGAS DESULFURIZATION TEST SUMMARY REPORT” 


\title{
Wabash Syngas Desulfurization Field Test, Summary Status Report
}

Through 6/14/2004

\author{
For \\ Dennis Leppin \\ Raj Palla \\ Gas Technology Institute
}

by:

Girish Srinivas, Ph.D. (P.I.)

Ryan Larsen, B.S., Ch.E.

Steven Gebhard, Ph.D., P.E.

TDA Research Inc.

12345 W. $52^{\text {nd }}$ Avenue

Wheat Ridge, Colorado 80033 


\section{Initial Syngas Desulfurization Data}

In November of 2002, experiments were conducted to determine if TDA's direct $\mathrm{H}_{2} \mathrm{~S}$ oxidation catalyst could be used to remove $\mathrm{H}_{2} \mathrm{~S}$ from syngas produced by petroleum coke gasification (or coal). TDA's catalyst was developed to perform the selective oxidation of $\mathrm{H}_{2} \mathrm{~S}$ to sulfur and water in natural gas applications, according to $\mathrm{H}_{2} \mathrm{~S}+0.5 \mathrm{O}_{2} \rightarrow \mathrm{H}_{2} \mathrm{O}+\mathrm{S}$. The catalyst works extremely well with natural gas, oxidizing $90 \%$ or more of the $\mathrm{H}_{2} \mathrm{~S}$ to sulfur with very little or no oxidation of the hydrocarbons in natural gas and with little or no $\mathrm{SO}_{2}$ production (depending on the exact reaction conditions).

Because of the success of TDA's direct oxidation catalytic technology in removing $\mathrm{H}_{2} \mathrm{~S}$ from natural gas (including a 1200 hour pilot plant demonstration processing 300,000 SCFD for 8000 ppm $\mathrm{H}_{2} \mathrm{~S}$ ), a laboratory experiment was conducted with synthetic syngas containing $300 \mathrm{ppm}$ of $\mathrm{H}_{2} \mathrm{~S}$ to determine if syngas could be selectively desulfurized without oxidizing hydrogen or carbon monoxide. The initial experiment used a simulated gas mixture that had the composition given in Table 1. The temperature of $180^{\circ} \mathrm{C}$ and the pressure was 200 psig.

Table $1 . \quad$ Simulated
Syngas Composition
\begin{tabular}{|l|l|}
\hline $\mathrm{GaS}$ & Vol. \% \\
\hline $\mathrm{H}_{2} \mathrm{~S}$ & $300 p p m$ \\
$\mathrm{O}_{2}$ & $150 p p m$ \\
$\mathrm{CO}$ & 20.0 \\
$\mathrm{H}_{2}$ & 10.0 \\
$\mathrm{H}_{2} \mathrm{O}$ & 6.0 \\
$\mathrm{~N}_{2}$ & Balance \\
\hline
\end{tabular}

The results of this first experiment were very encouraging. Approximately $90 \%$ conversion of the $300 \mathrm{ppm}$ of $\mathrm{H}_{2} \mathrm{~S}$ to sulfur was observed for over 20 hours with no $\mathrm{SO}_{2}$ production and no oxidation of either $\mathrm{H}_{2}$ or $\mathrm{CO}$. A plot of the results is given in Figure 1. A key point to note about this experiment is that the catalyst temperature was $180^{\circ} \mathrm{C}$. This temperature was chosen based on the dewpoint of sulfur vapor at 200 psig. If the reactor or any of the tubing upstream of the condenser is below the sulfur dewpoint temperature then, the sulfur will condense either in the catalyst pores or in the flow system, causing a

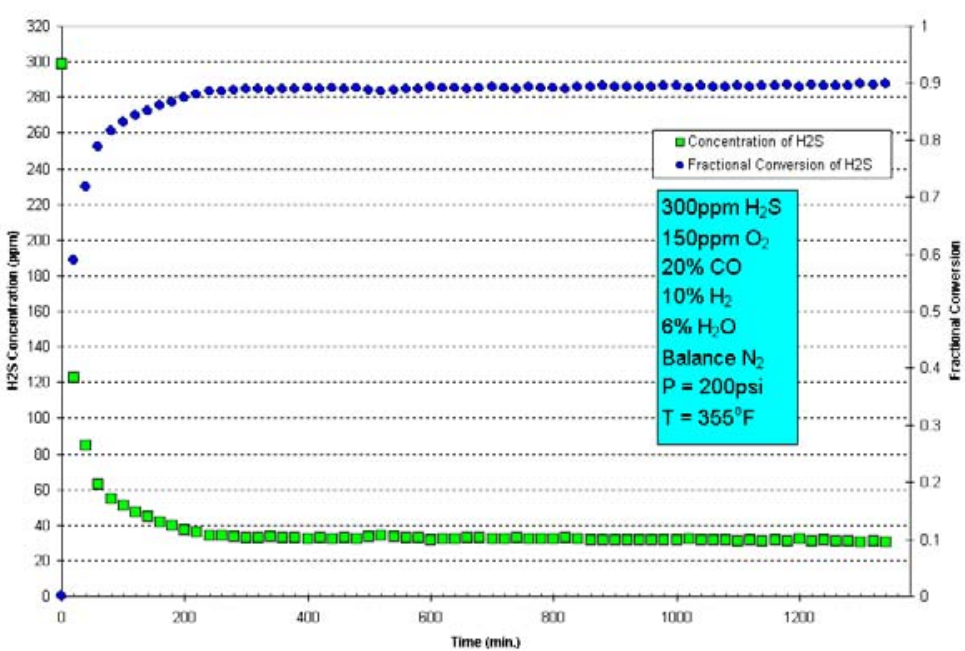

Figure 1. Data for Syngas Desulfurization, November 2002 significant loss of conversion and/or system plugging. 


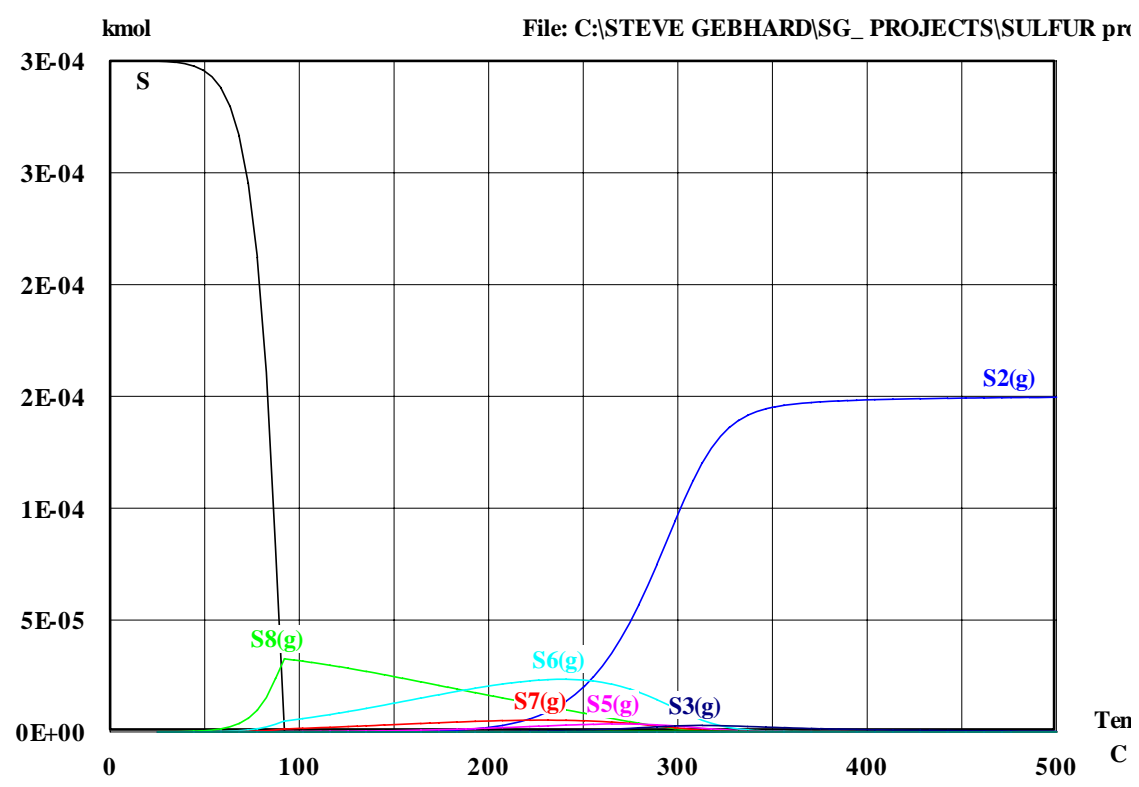

Figure 2. Equilibrium of sulfur species at $200 \mathrm{psig}$ for $300 \mathrm{ppm}$ of sulfur vapor.

HSC Chemistry is a thermodynamics program that we used to calculate the equilibrium composition of sulfur containing gases. At pressures up to a few hundred psi, real gas corrections only increase the sulfur dew point by about $20^{\circ} \mathrm{F}$. For very high pressures ( $>$ 1000 psi) real gas corrections must be done and we use Pitzer's method for calculating the fugacity coefficients for the sulfur species.

A plot of equilibrium concentrations of vapor phase sulfur species, $S_{X}(1 \leq X \leq 8)$ in syngas at 200 psig starting with $300 \mathrm{ppm}$ of $\mathrm{H}_{2} \mathrm{~S}$ is shown in Figure 2. The dew point is below the solidification temperature of sulfur and therefore any temperature above the melting point of sulfur that gives acceptable kinetics can be used as the operating temperature. The optimum temperature for low $\mathrm{H}_{2} \mathrm{~S}$ concentrations is about $180^{\circ} \mathrm{C}$ (ca. $350^{\circ} \mathrm{F}$ ). As shown in Figure 1 neither $\mathrm{H}_{2}$ nor $\mathrm{CO}$ are oxidized at these temperatures. The results of this experiments were very encouraging and suggested that under the right conditions syngas could be effectively desulfurized by selectivity oxidation of $\mathrm{H}_{2} \mathrm{~S}$ without any combustion of the hydrogen or $\mathrm{CO}$ in the syngas stream. 


\section{Laboratory Scale Testing with Simulated Wabash Syngas}

In May 2004, we began laboratory tests with a gas stream with the composition given in Table 2. This gas stream has a much higher concentration of $\mathrm{H}_{2} \mathrm{~S}$ and consequently (as discussed below) the catalyst must be operated at a higher temperature. We found that at higher temperatures, there is significant $\mathrm{H}_{2}$ oxidation at the expense of $\mathrm{H}_{2} \mathrm{~S}$ oxidation.

The feed gas for the laboratory was formulated by mixing cylinder gases and the composition was chosen to simulate the Wabash syngas as closely as possible. The concentration of $\mathrm{H}_{2} \mathrm{~S}$ in the Wabash gas is much higher than the 300 ppm of $\mathrm{H}_{2} \mathrm{~S}$ Table 2. Simulated Wabash Syngas tested initially.

\section{Description of the Apparatus}

The experiments were performed in our small scale existing highpressures automated catalyst test apparatus shown in Figure 3 . This apparatus is similar to the field test apparatus except that it is designed for flowrates in the range of 1 standard liter/min and uses 4-5 grams of catalyst. Figure 3 is a photograph of the apparatus and Figure 4 is its' process and instrumentation diagram. The catalyst is held in a small fixed bed reactor that is made from a $1 / 2$

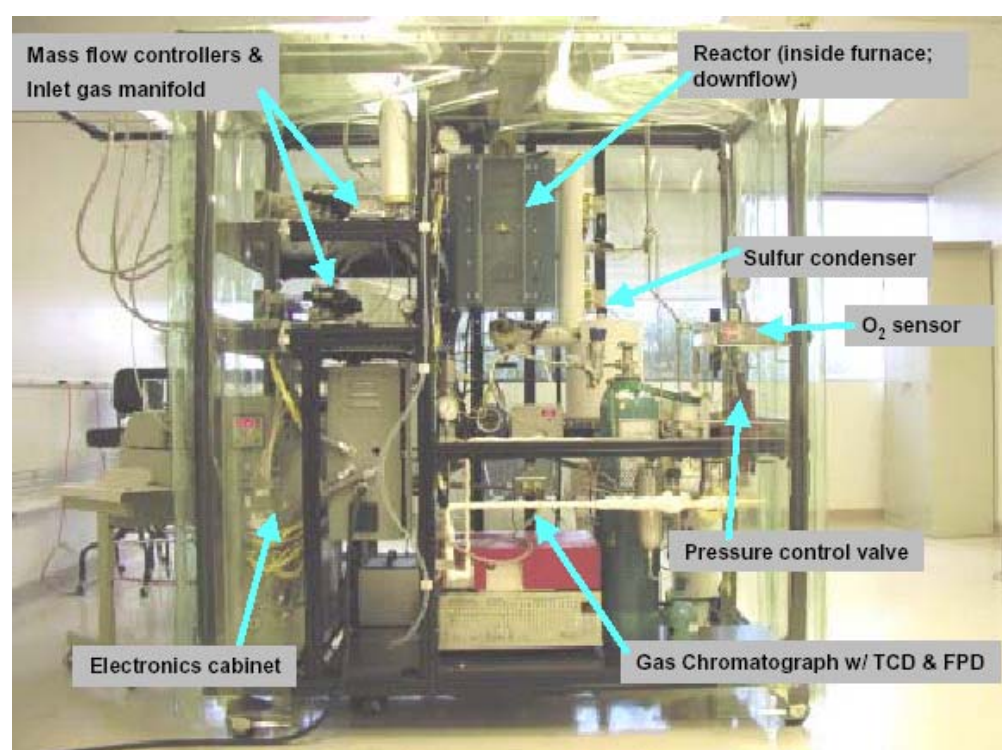

Figure 3. Photograph of the apparatus used for the small scale (4 grams of catalyst) tests with synthetic syngas in the laboratory. inch 316 stainless steel

\begin{tabular}{|l|l|}
\hline Gas & Vol. \% \\
\hline $\mathrm{H}_{2} \mathrm{~S}$ & 1.5 \\
$\mathrm{O}_{2}$ & 0.75 \\
$\mathrm{CO}$ & 22 \\
$\mathrm{CO}_{2}$ & 7 \\
$\mathrm{COS}$ & 0.07 \\
$\mathrm{H}_{2}$ & 13 \\
$\mathrm{H}_{2} \mathrm{O}$ & 20.8 \\
$\mathrm{~N}_{2}$ & 34.88 \\
\hline
\end{tabular}

VCR (face seal) fitting. The reactor holds about 5 grams of catalyst and is heated by a 3-zone Mellen tube furnace. Thermocouples at the inlet and outlet of the catalyst bed are used for recording and controlling the catalyst bed temperature. Gases $\left(\mathrm{N}_{2}, \mathrm{H}_{2} \mathrm{~S}\right.$, $\mathrm{CO}_{2}$, and $\mathrm{CH}_{4}$ ) are metered into the system using Porter electronic mass flow controllers. Water is injected into a heated tubing section with a chemical metering pump and toluene or other contaminants can be added with a high pressure (ISCO) syringe pump.

Downstream of the reactor, the sulfur vapor is condensed in a heat transfer coil. The coil has a $1 / 2$ inch O.D. 316 stainless steel tube inside of a 1 inch O.D. copper tube. To condense the sulfur we pump $120^{\circ} \mathrm{C}\left(248^{\circ} \mathrm{F}\right)$ oil through the copper jacket. Sulfur melts at about $115^{\circ} \mathrm{C}\left(\mathrm{ca} 240^{\circ} \mathrm{F}\right.$ ) and becomes very viscous at about $180^{\circ} \mathrm{C}$ (ca $360^{\circ} \mathrm{F}$ ). Using a $120^{\circ} \mathrm{C}$ thermostated bath allows us to condense the sulfur and maintain it in a low 
viscosity liquid state. Liquid sulfur drains out of the condenser into a single 2 liter stainless steel pressure rated cylinder. This collection container has 3 band heaters on it and is maintained at a temperature of $125^{\circ} \mathrm{C}$ to prevent the sulfur from solidifying and plugging the system. Water will be condensed when the dewpoint of the gas is above $125^{\circ} \mathrm{C}\left(257^{\circ} \mathrm{F}\right)$.

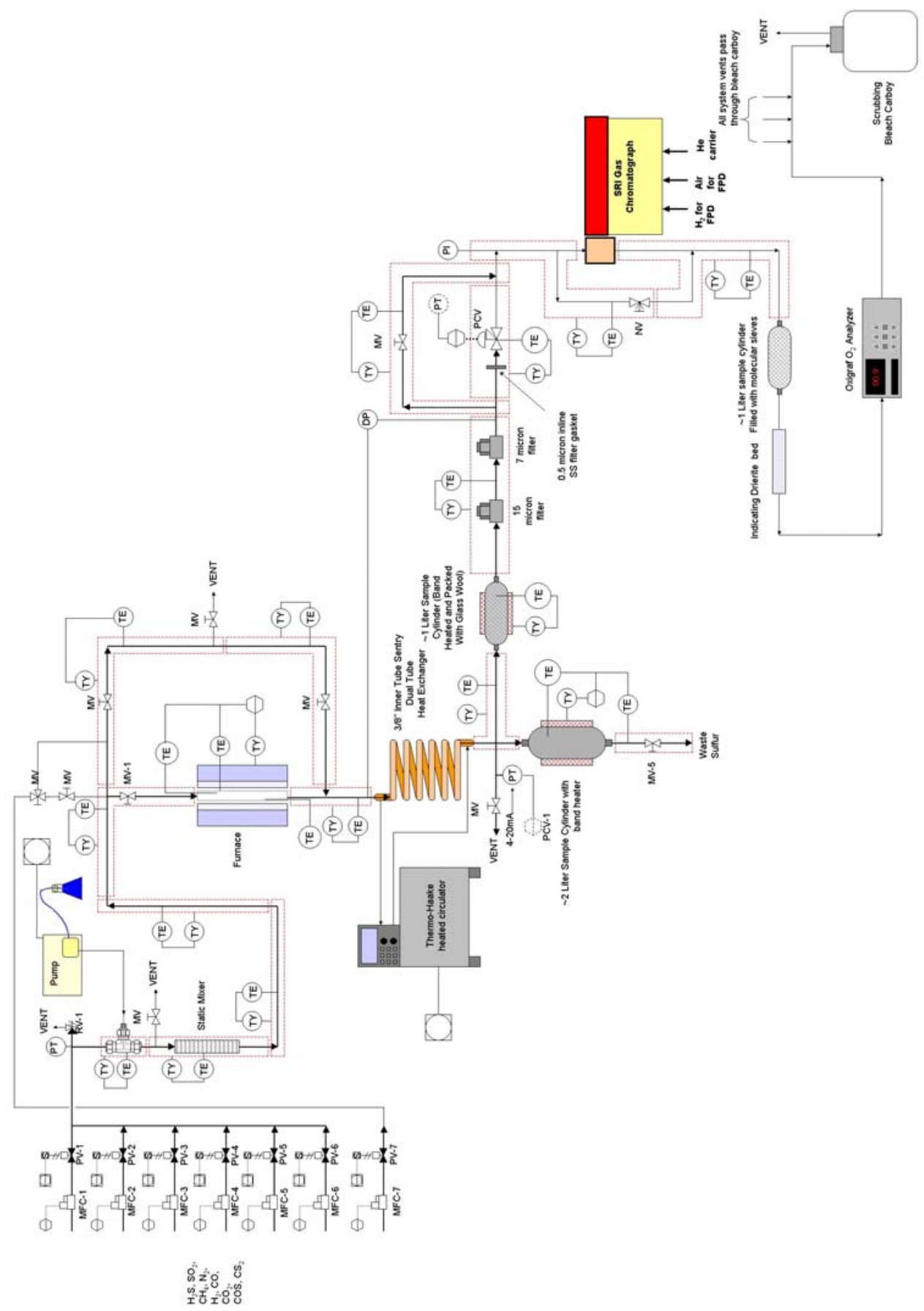

Figure 4. Process and instrumentation diagram for the laboratory scale catalyst testing apparatus. 
The gas exiting the sulfur collector has some sulfur vapor in it. To remove this vapor and prevent plugging of the pressure control valve, we placed a small (ca $300 \mathrm{~cm}^{3}$ ) horizontal stainless steel cylinder downstream of the liquid sulfur collector. This vapor knockout is maintained at a temperature of $90^{\circ} \mathrm{C}$ (below the freezing point of sulfur) and is filled with glass wool to collect the sulfur. Downstream of the knockout are two sintered stainless steel filter elements. Finally, the gas passes through the Badger Meter - pressure control valve (PCV).

The system pressure is computer controlled by using the pressure signal from the pressure transducer located upstream of the reactor to control the PCV. Downstream of the PCV the pressure is about 5 psig. This pressure is maintained by a needle valve on the slipstream of gas that passes into the gas chromatograph (GC). The GC is used to measure the concentrations of $\mathrm{H}_{2} \mathrm{~S}, \mathrm{COS}$ and $\mathrm{SO}_{2}$ in the product gas.

The GC has two detectors, a thermal conductivity detector (TCD) and a flame photometric detector (FPD). The TCD can detect all gases but has limited sensitivity. The FPD is selectively only for sulfur containing compounds. It works by burning the gas sample in a hydrogen flame. During combustion, electronically excited $\mathrm{S}_{2}$ species are formed that fluoresce at a specific wavelength. Special filters are used by the FPD to screen out all wavelengths expect the sulfur fluorescence and therefore the FPD only detects sulfur containing compounds. The FPD can detect sulfur compounds to subppm levels.

Downstream of the GC, the gas is dried with molecular sieve and Drierite and then passed through a paramagnetic oxygen analyzer. The $\mathrm{O}_{2}$ analyzer indicates if any $\mathrm{O}_{2}$ has broken through the catalyst bed without reacting. No oxygen breakthrough was observed. Finally, the gas is scrubbed through bleach $(5 \% \mathrm{NaOCl})$ to destroy unreacted $\mathrm{H}_{2} \mathrm{~S}$ and vented to the laboratory fume hood system.

The entire apparatus is computer controlled using a PC running OPTO22. The electronics cabinet on the apparatus contains the OPTO modules that are programmed by the PC. They can operate independently if the PC crashes and independently control the temperatures and system pressure using proportionalintegral-derivative (PID) control logic. All of the process parameters and the GC analyses are recorded to the computer hard disk. The apparatus can be operated overnight unattended which permits $24 / 7$ operation and data collection.

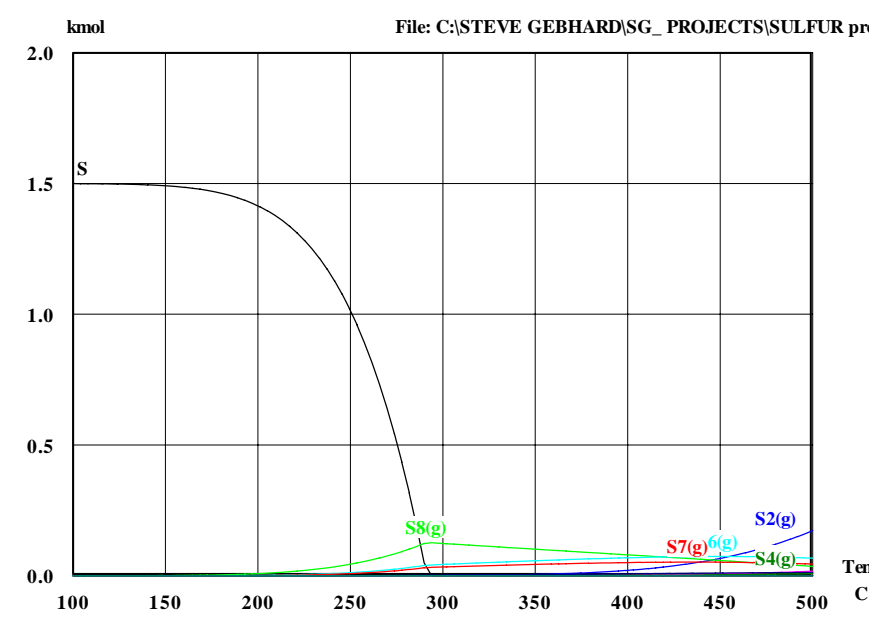

Figure 5. Sulfur Dewpoint Calculation for $1.5 \%$ Sulfur

\section{Sulfur Dewpoint for the Oxidation of $1.5 \% \mathrm{H}_{2} \mathrm{~S}$}

The HSC Chemistry plot for $1.5 \%$ sulfur vapor (100\% conversion of the $1.5 \% \mathrm{H}_{2} \mathrm{~S}$ in the Wabash syngas) at a pressure of 400 psig is shown Figure 5. At this pressure and 
sulfur vapor concentration, the dew point of sulfur is $280^{\circ} \mathrm{C}\left(536^{\circ} \mathrm{F}\right)$. Below this temperature liquid sulfur will condense in the catalyst pores, plugging them and deactivating the catalyst. Consequently, the minimum usable operating temperature is $280^{\circ} \mathrm{C}$.

\section{Experimental Results}

In the Wabash simulation experiments, we used a feed with the composition shown Table 2. The temperature was $280^{\circ} \mathrm{C}\left(536^{\circ} \mathrm{F}\right)$ and the pressure was $200 \mathrm{psig}$. From the outset, the $\mathrm{H}_{2} \mathrm{~S}$ conversion was essentially zero (Figure 6). After examining the apparatus, checking for instrument malfunctions, and ruling out other possible causes of this problem, we performed three additional experiments that definitively demonstrated that hydrogen oxidation was consuming all of the $\mathrm{O}_{2}$ at $280^{\circ} \mathrm{C}\left(536^{\circ} \mathrm{F}\right)$ resulting in no $\mathrm{H}_{2} \mathrm{~S}$ oxidation. The results are summarized in Table 3 .

Table 3. Summary of test results for hydrogen oxidation competing with $\mathrm{H}_{2} \mathrm{~S}$ oxidation.

\begin{tabular}{|l|l|l|}
\hline $\begin{array}{l}\text { Composition of Gas/Operating } \\
\text { Conditions }\end{array}$ & Result & Comments \\
\hline $\begin{array}{l}\text { Table } 2 \text { conditions at } 280^{\circ} \mathrm{C} \\
\text { and } 255 \text { psig. }\end{array}$ & No $\mathrm{H}_{2} \mathrm{~S}$ oxidation & Wabash simulated gas \\
\hline $\begin{array}{l}1.5 \% \mathrm{H}_{2} \mathrm{~S}, 0.75 \% \mathrm{O}_{2},, \text { bal } \mathrm{N}_{2}, \\
\mathrm{~T}=280^{\circ} \mathrm{C}, \mathrm{P}=255 \text { psig. }\end{array}$ & $\begin{array}{l}90 \% \text { conversion of } \mathrm{H}_{2} \mathrm{~S} \text { into } \\
\text { sulfur and water }\end{array}$ & $\begin{array}{l}\text { Use only } \mathrm{H}_{2} \mathrm{~S}, \mathrm{O}_{2}, \quad, \\
\text { nitrogen }\left(\mathrm{no} \mathrm{H}_{2}\right)\end{array}$ \\
\hline $\begin{array}{l}1.5 \% \mathrm{H}_{2} \mathrm{~S}, 0.75 \% \mathrm{O}_{2}, 10 \% \mathrm{H}_{2}, \\
\text { bal } \mathrm{N}_{2}, \mathrm{~T}=280^{\circ} \mathrm{C}, \mathrm{P}=255 \\
\text { psig. }\end{array}$ & No $\mathrm{H}_{2} \mathrm{~S}$ oxidation & Add back $10 \% \mathrm{H}_{2}$ \\
\hline
\end{tabular}

Apparently, at a catalyst temperature of $280^{\circ} \mathrm{C}\left(536^{\circ} \mathrm{F}\right)$ the catalyst was active for hydrogen oxidation. The autoignition temperature of hydrogen in air is approximately $570^{\circ} \mathrm{C}$ (ca $1050^{\circ} \mathrm{F}$ ) and consequently, any hydrogen oxidation in our system would have to be catalytic. In this case, all of the $\mathrm{O}_{2}$ is consumed (because of the very large excess of $\mathrm{H}_{2}$ ) and no $\mathrm{H}_{2} \mathrm{~S}$ oxidation takes place.

We then repeated the experiment except that we removed $\mathrm{H}_{2}, \mathrm{CO}$ and water from the feed. Nitrogen flow was used to make up the difference for the missing gases to

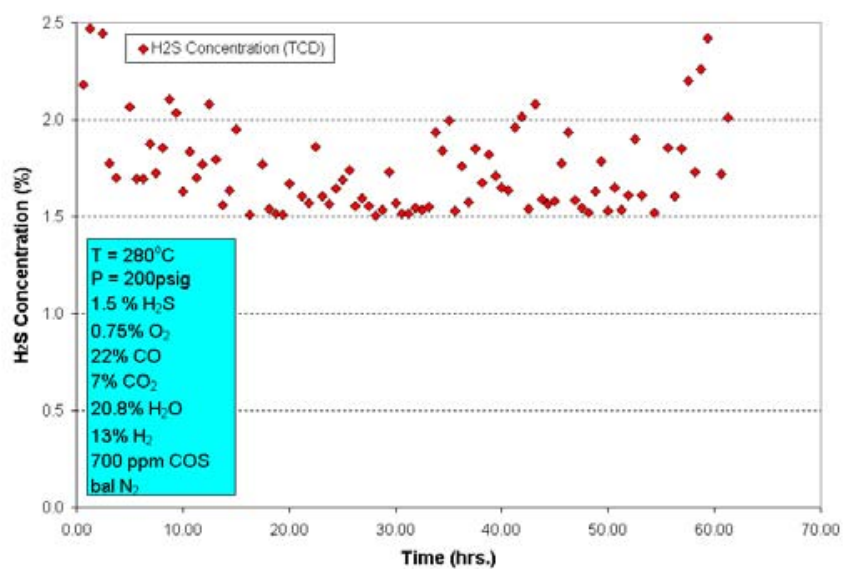

Figure 6. Attempted desulfurization in simulated syngas at $280^{\circ} \mathrm{C}$ showing no conversion of $\mathrm{H}_{2} \mathrm{~S}$ over the Direct Oxidation catalyst. keep the space velocity over the catalyst the same as in the full syngas test. As we have observed when we desulfurize natural gas, we obtained $90 \% \mathrm{H}_{2} \mathrm{~S}$ conversion with essentially $100 \%$ selectivity for elemental sulfur in a single pass. This convinced us that the apparatus was functioning correctly (i.e. mass flow controllers, process control, analytical methods etc. were fine.) 
While the system was still running, we then decreased the nitrogen flow slightly and introduced $13 \% \mathrm{H}_{2}$. Almost immediately, the $\mathrm{H}_{2} \mathrm{~S}$ conversion dropped to zero (Figure 7). The fact that the $\mathrm{H}_{2} \mathrm{~S}$ conversion abruptly drops to zero when the hydrogen is added (with the catalyst temperature at $280^{\circ} \mathrm{C}$ ) indicates that hydrogen is being oxidized at this temperature and that this consumes sufficient (or possibly all) oxygen that the rate of $\mathrm{H}_{2} \mathrm{~S}$ oxidation becomes negligible. With lower $\mathrm{H}_{2} \mathrm{~S}$ concentrations (e.g. 300 ppm) we can operate the catalyst at about $180^{\circ} \mathrm{C}\left(\mathrm{ca} 350^{\circ} \mathrm{F}\right)$ and at this temperature hydrogen does not react.

The conclusions we can draw from these experiments is that at some temperature between $180^{\circ} \mathrm{C}$ and $280^{\circ} \mathrm{C}$, the standard Direct Oxidation catalyst becomes active for hydrogen oxidation. Consequently there are two approaches to eliminating hydrogen oxidation. The first is to reduce the temperature until $\mathrm{H}_{2} \mathrm{~S}$ oxidation is observed and there is no hydrogen oxidation.

When the temperature is reduced, the $\mathrm{O}_{2} / \mathrm{H}_{2} \mathrm{~S}$ has to be reduced to reduce the $\mathrm{H}_{2} \mathrm{~S}$ conversion so that

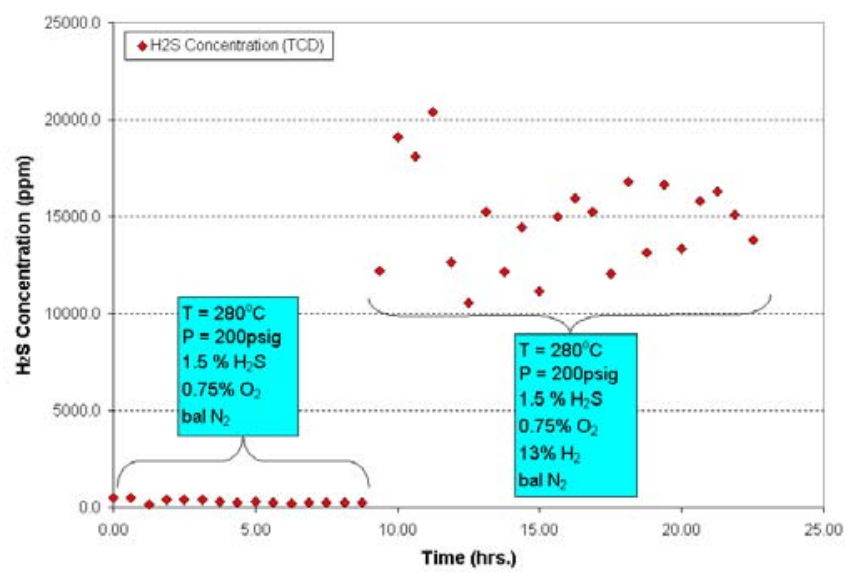

Figure 7. Oxidation Performance with $\mathrm{H}_{2}$ flow on and off with Direct Oxidation catalyst.

the sulfur formed does not condense in the catalyst bed. In principle we could oxidize $1.5 \% \mathrm{H}_{2} \mathrm{~S}$ at $180^{\circ} \mathrm{C}$ with stoichiometric $\mathrm{O}_{2} / \mathrm{H}_{2} \mathrm{~S}=0.5$, but this temperature is over $100^{\circ} \mathrm{C}$ below the dewpoint of the sulfur and the catalyst would become rapidly plugged with liquid sulfur and cease functioning. Consequently, to operated at a lower temperature (where $\mathrm{H}_{2}$ will not be oxidized) requires running at a lower $\mathrm{H}_{2} \mathrm{~S}$ conversion to keep the concentration of sulfur low enough that it won't condense in the catalyst bed.

Tests done at catalyst temperatures of $250^{\circ} \mathrm{C}\left(482^{\circ} \mathrm{F}\right)$ and $225^{\circ} \mathrm{C}\left(437^{\circ} \mathrm{F}\right)$ indicated that substantial hydrogen oxidation is still occurring at these temperatures over the standard Direct Oxidation catalyst. Worse, the concentration of sulfur vapor that gives a dewpoint of $225^{\circ} \mathrm{C}\left(437^{\circ} \mathrm{F}\right)$ is $2000 \mathrm{ppm}$. Starting with $1.5 \%(15,000 \mathrm{ppm}) \mathrm{H}_{2} \mathrm{~S}$ this would correspond to an unacceptably low conversion of $13 \%$. Clearly this approach would not be economically viable. The other (better) solution is to modify the catalyst so that it has activity for $\mathrm{H}_{2} \mathrm{~S}$ oxidation but not $\mathrm{H}_{2}$ oxidation at the higher temperature $\left(280^{\circ} \mathrm{C}\right)$.

\section{Catalyst Modifications to Eliminate Hydrogen Oxidation}

In the experiments to date, we used our standard Direct Oxidation catalyst. The standard Direct Oxidation catalyst contains mixed metal oxides, some of which are well known in the literature for having good low temperature oxidation activity. In fact, it is their low temperature activity that makes the Direct Oxidation catalyst successful with natural gas streams at temperatures near $180^{\circ} \mathrm{C}$ (or higher as long as there is no $\mathrm{H}_{2}$ in the gas). Unfortunately, at the higher temperature of $280^{\circ} \mathrm{C}$, the catalyst is too active for use in syngas streams and hydrogen is oxidized. Therefore, we need to reexamine the catalyst composition and tailor it specifically for syngas desulfurization. 
The Direct Oxidation catalyst used in the tests so far represents the best combination of $\mathrm{H}_{2} \mathrm{~S}$ oxidation activity with the highest possible selectivity for sulfur with the ultimate application for use with natural gas. For this purpose the performance of the catalyst is excellent.

During the development of the best Direct Oxidation catalyst, we examined approximately 100 other catalyst formulations and some were better than others. In addition, in a previous GRI (now GTI) contract, we examined modifying the Direct Oxidation catalyst to enhance/maintain the Direct Oxidation activity while minimizing the reverse Claus activity. As a result of these efforts, we have quite a bit of understanding of what catalyst compositions give what levels of activity for $\mathrm{H}_{2} \mathrm{~S}$ oxidation, and how catalyst composition affects both activity and selectivity for sulfur production. Therefore, we have a solid foundation for starting the development of the more challenging application of oxidizing $\mathrm{H}_{2} \mathrm{~S}$ at relatively high temperature in the presence of syngas.

The fact that we can oxidize $300 \mathrm{ppm}$ of $\mathrm{H}_{2} \mathrm{~S}$ at $179^{\circ} \mathrm{C}$ in the presence of $10 \% \mathrm{H}_{2}$ and 20\% CO indicates that (at least on the standard Direct Oxidation catalyst) that the activation energy for $\mathrm{H}_{2} \mathrm{~S}$ oxidation is lower than the activation energy for hydrogen oxidation. The reason that $\mathrm{H}_{2} \mathrm{~S}$ oxidation stops when the temperature is increased to $280^{\circ} \mathrm{C}$ is that the great excess of $\mathrm{H}_{2}$ consumes all of the $\mathrm{O}_{2}$. If the activation energy for $\mathrm{H}_{2} \mathrm{~S}$ oxidation is lower than that of $\mathrm{H}_{2}$ oxidation, then $\mathrm{H}_{2} \mathrm{~S}$ oxidation will proceed at a faster rate than hydrogen all other factors being equal. Unfortunately, there is so much $\mathrm{H}_{2}$ in the system relative to $\mathrm{H}_{2} \mathrm{~S}$ and the temperature is such that the rate of $\mathrm{H}_{2} \mathrm{~S}$ oxidation cannot compete with the rate of $\mathrm{H}_{2}$ oxidation.

The encouraging part, however, is that because the activation energy is lower for $\mathrm{H}_{2} \mathrm{~S}$ oxidation than $\mathrm{H}_{2}$ oxidation, it may be possible to find a catalyst where the $\mathrm{E}_{\mathrm{a}}$ is high enough for $\mathrm{H}_{2}$ oxidation that little or no oxidation takes place at $280^{\circ} \mathrm{C}$. This can be accomplished by examining catalysts that chemisorb $\mathrm{H}_{2}$ poorly.

In most catalytic reactions involving $\mathrm{H}_{2}$, when an $\mathrm{H}_{2}$ molecule approaches the surface of the catalyst, the orbitals on the surface atoms overlap with the antibonding orbitals of the $\mathrm{H}_{2}$ molecule, which causes the $\mathrm{H}-\mathrm{H}$ bond to rupture and the hydrogen to adsorb atomically (Kiselev and Krylov 1989). As a result, $\mathrm{H}$ atoms are typically the adsorbed directly onto the active sites on most catalysts. Catalysts that cannot dissociate $\mathrm{H}_{2}$ prevent the formation of adsorbed hydrogen atoms (which are very reactive) and therefore are good candidates for having low activity for $\mathrm{H}_{2}$ oxidation (in other words finding a catalyst that activates $\mathrm{H}_{2} \mathrm{~S}$ and $\mathrm{O}_{2}$ but not $\mathrm{H}_{2}$ ). In the case of $\mathrm{H}_{2} \mathrm{~S}$, dissociation of the $\mathrm{H}_{2} \mathrm{~S}$ molecule into $\mathrm{H}_{\text {(adsorbed) }}$ and $\mathrm{SH}_{\text {(adsorbed) }}$ is energetically easier $\left(\mathrm{D}_{0}=90\right.$ $\mathrm{kcal} / \mathrm{mole})$ than breaking the $\mathrm{H}-\mathrm{H}$ bond in $\mathrm{H}_{2}\left(\mathrm{D}_{0}=101 \mathrm{kcal} / \mathrm{mole}\right)$. Consequently, it may be possible to design a catalyst that has good $\mathrm{H}_{2} \mathrm{~S}$ oxidation activity but poor $\mathrm{H}_{2}$ oxidation activity. We recently received a Phase I DOE SBIR contract to develop a catalyst specifically for $\mathrm{H}_{2} \mathrm{~S}$ oxidation in the presence of syngas. This is discussed in more detail below., 


\section{Field Test Unit - Design and Construction}

We have completed the design and construction of the field test apparatus. A detailed description is given in this section. Figure 8 is a diagram of the reactor for the field test unit. The thermocouples pass up into the bed of ceramic balls and catalyst from the bottom to make the reactor easier to fill. Below is a discussion of the stress analysis used in the design of the reactor. After design and assembly, we performed a 1000 psig hydrostatic test of the reactor to ensure weld integrity.

The reactor was designed to process 5 actual liters/min $(10.6 \mathrm{ACFH})$ at $400 \mathrm{psig}$ and $390^{\circ} \mathrm{F}$. This flowrate of gas with a space velocity of 1000 $\mathrm{cm}^{3}{ }_{\text {gas }} / \mathrm{cm}_{\text {catalyst }}^{3} /$ hour requires 240 grams of $1 / 8$ inch catalyst pellets. The catalyst will be placed in a single 2.5 inch O.D. SCH 80, 304 stainless steel pipe that uses $300 \mathrm{lb}$ stainless steel flanges. The wall thickness of 2.5 inch $\mathrm{SCH} 80$ pipe is 0.276 inches. The overall length of the reactor tube is 30 inches.

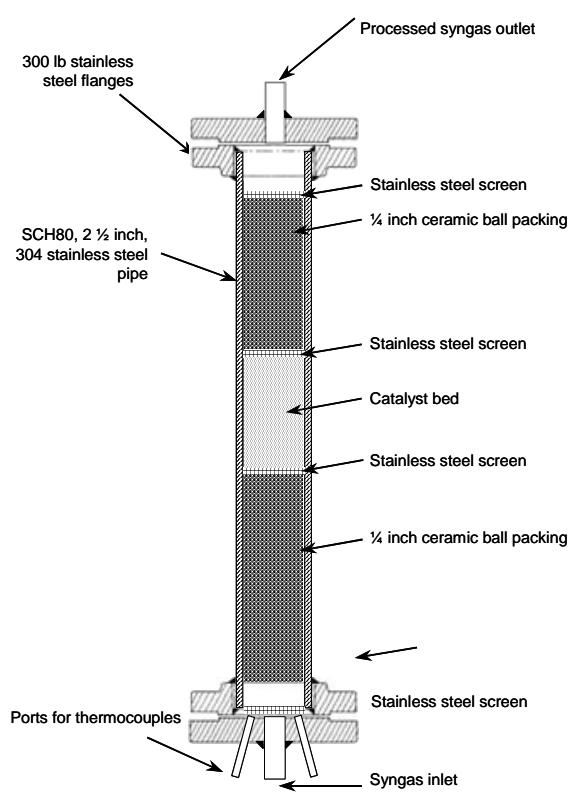

Figure 8. Drawing of reactor.

\section{Stress Analysis}

The design pressure for continuous operation of the reactor was 500 psig and the design temperature was $1000^{\circ} \mathrm{F}\left(537^{\circ} \mathrm{C}\right)$. To determine the strength of the reactor under these conditions, we performed a Von Mises stress analysis on the reactor (Shigley 1977). This analysis takes into account both the stress in the material due to radial expansion of the pipe under pressure but also includes the stress due to stretching of the pipe (the ends are effectively closed by the flanges so there is a substantial axial force stretching the pipe in it's long dimension). The maximum allowable stress used for the strength calculations was chosen to be $\sigma=$ $25 \mathrm{ksi}$ which is the stress that causes creep rupture in 304 SS after 10,000 hours (Figure 9).

The tabulated data of tensile strengths of metals are usually obtained under conditions of pure axial loading. This can be a very different situation than the situation where the same material is in a triaxial stress state (i.e. forces are acting in 3 directions: $x, y$ and $z$ ). The best method for comparing the triaxial stress case of a stress element in an actual physical

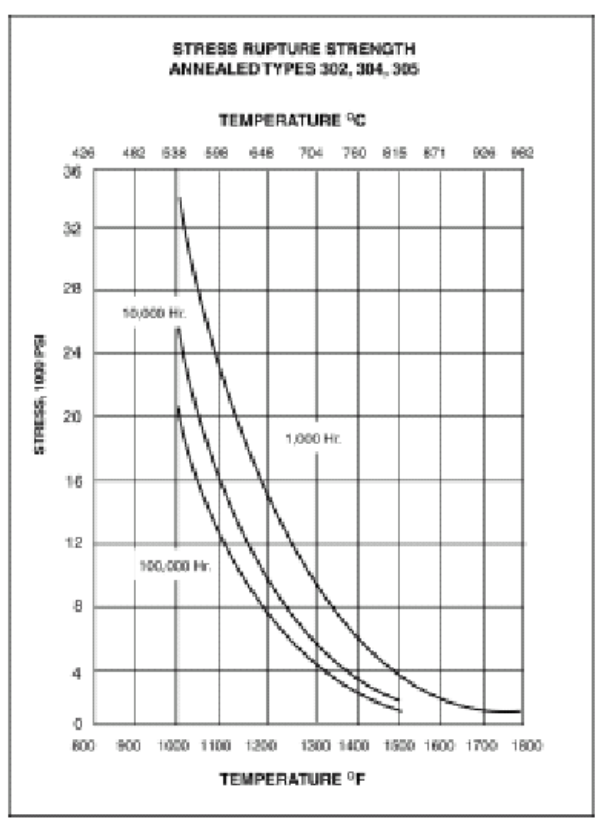

Figure 9. Rupture stress vs. temperature for 300 series stainless steels 
item (such as our reactor tube) with tensile test data for the material of which it is made is the so-called distortion energy theory (Shigley 1977) also known as Von Mises theory. Using this approach gives a more conservative estimate of the strength of the material (i.e. lower) compared to simply comparing the maximum principal tangential (hoop) stress with tensile test data. In the distortion energy approach, an equivalent stress is calculated from the three principal stresses of the triaxial stress state and then the equivalent stress is compared with the tensile strength data for the material.

Figure 10 shows the equations used to calculate the principle stresses labeled $\sigma_{\mathrm{a}}$ (axial stress), $\sigma_{\mathrm{t}}$ (tangential or hoop stress) and $\sigma_{\mathrm{r}}$ (radial stress) and the resulting equivalent stress, $S_{y}$ for the case of the reactor tube. The $300 \mathrm{lb}$ flanges are located outside of the furnace and will not get as hot as the reactor tube. They are ASME rated for continuous operation at $600 \mathrm{psi}$ at $500^{\circ} \mathrm{F}$ (Baumeister et al. 1978) and can be used directly without having to performing a stress analysis.

Because the reactor body is cylindrical, the principal stresses are in the same direction of the three major axes (axial, radial and tangential) (Figure 11). For other geometries, a Mohr's circle analysis is required to calculate the magnitudes and directions of the principal stresses that are needed to calculate the equivalent stress. The stress calculations were done by coding the equations in Figure 10 into MathCad.

The axial stress $\left(\sigma_{a}\right)$ includes the stretching force due to the pressure on the ends (because of the

$$
\begin{aligned}
& \sigma_{a}:=\frac{F_{\text {axial }}}{A_{\text {metal }}}+2\left(P_{i}-P_{o}\right) \\
& \sigma_{t}:=\frac{a^{2} \cdot P_{i}-b^{2} \cdot P_{o}}{b^{2}-a^{2}}+\frac{a^{2} \cdot b^{2} \cdot\left(P_{i}-P_{o}\right)}{\left(b^{2}-a^{2}\right) \cdot \rho^{2}} \\
& \sigma_{r}:=\frac{a^{2} \cdot P_{i}-b^{2} \cdot P_{0}}{b^{2}-a^{2}}-\frac{a^{2} \cdot b^{2} \cdot\left(P_{i}-P_{o}\right)}{\left(b^{2}-a^{2}\right) \cdot \rho^{2}} \\
& S_{y}:=\left[\frac{\left(\sigma_{t}-\sigma_{a}\right)^{2}+\left(\sigma_{a}-\sigma_{r}\right)^{2}+\left(\sigma_{r}-\sigma_{t}\right)^{2}}{2}\right]^{0.5} \\
& \text { SafetyFactor }:=\frac{\sigma_{\text {allowable }}}{S_{y}}
\end{aligned}
$$

Figure 10. Equations used to calculate principal stresses $\left(\sigma_{i}\right)$ and the equivalent stress $\left(S_{y}\right)$ in the reactor body

flanges) as well as the static weight of the reactor. The reactor hangs from the top flanges and its weight was estimated to be about $45 \mathrm{lb}_{\mathrm{f}}$. The $\mathrm{P}_{\mathrm{i}}-\mathrm{P}_{\mathrm{o}}$ (internal - external) pressure term in the equation of $\sigma_{a}$ accounts for the force on each end of the cylinder due to the internal gas pressure. 
The formulas in Figure 10 are used to calculate the stresses in a thick walled cylinder (Higdon et al. 1976). These formulas reduce to the more familiar thin walled cylinder formulas when the wall thickness ( $b-a$ in Figure 11$)$ is less than more than about $10 \%$ of the outer cylinder radius (b). For a cylinder under internal pressure, the maximum principle stress is the hoop (tangential) stress and it is highest at the inner wall of the tube ( $\rho=a$ in Figure 11). This is the value of $\sigma_{t}$ that is used in the calculation of the equivalent stress $S_{y}$.

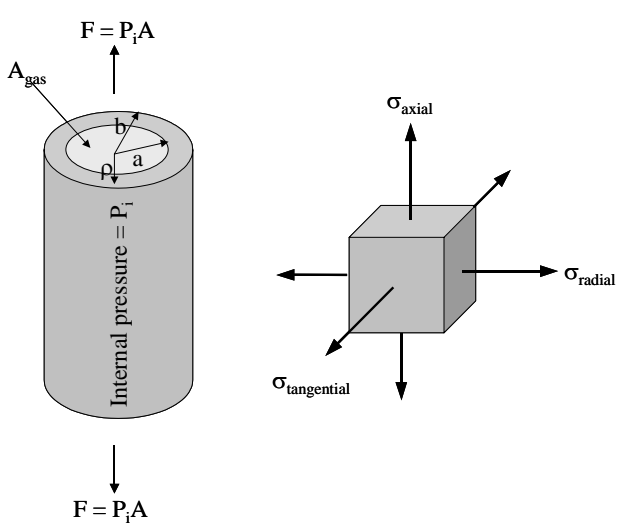

The safety factors for the reactor body are determined by dividing the maximum allowable design stress $(25 \mathrm{ksi})$ by the equivalent stress $\mathrm{S}_{\mathrm{y}}$ calculated using the equations in Figure 10. The

Figure 11. Thick walled cylinder under internal pressure (left) and its' triaxial stress element showing principal stress directions.

equivalent stress for the reactor tube was 2423 psi which when divided into 25,000 psi gives a safety factor of SF $=10$. Thus, the reactor is very overdesigned.

Figure 12 shows the overall safety analysis for the reactor. The blue curve shows the maximum safe operating pressure that corresponds to an equivalent stress of $2400 \mathrm{psi}$ as a function of temperature. Below this line, the reactor will not rupture in 10,000 hours at a given temperature and pressure.

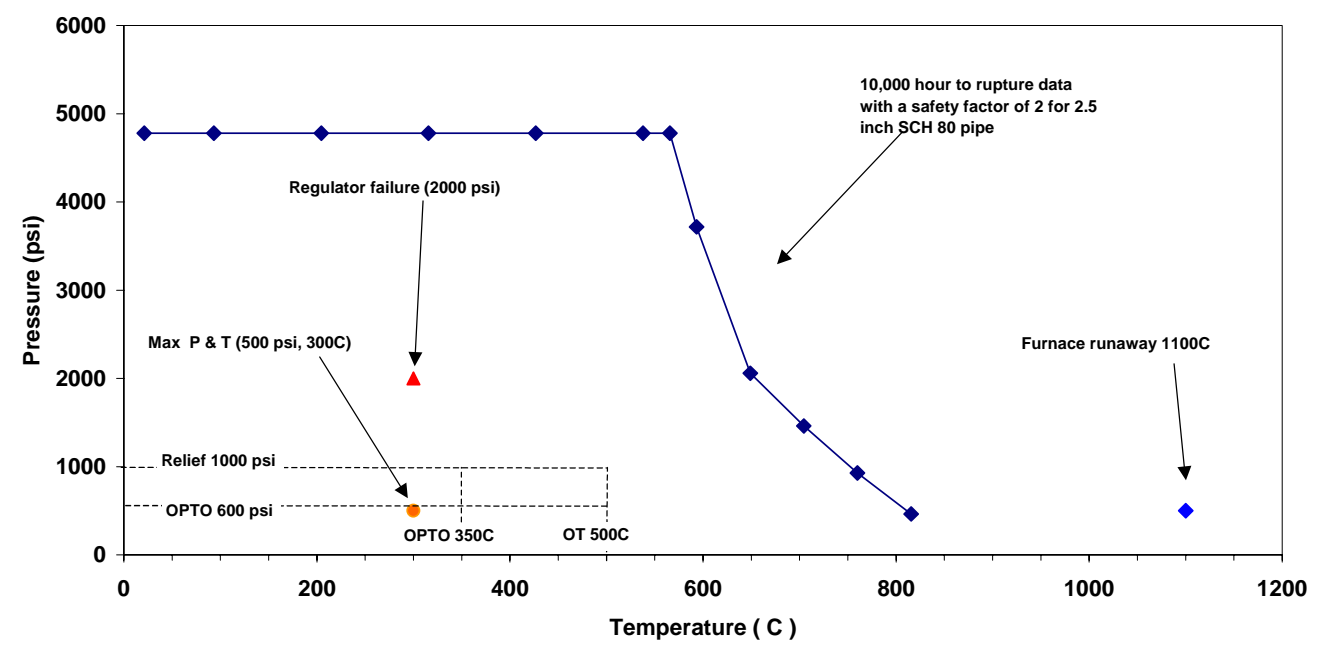

Figure 12. Safety analysis for catalytic reactor in field test apparatus.

Also shown in Figure 12 are the possible accident situations of over-pressure or over-temperature. The highest possible pressure possible would be from a regulator failure on a gas cylinder (in the lab shakedown tests) in which case components of the system could be exposed to pressures as high as 2000 psi. Figure 12 shows that this would not cause the reactor to fail. While such a high pressure would not cause a safety problem, it might damage the pressure transducers or other components of the system so we incorporated pressure relief valves and software shutdowns to reduce the damage such an event might cause. The setting levels are shown in Figure 12. All are well 
below the blue maximum pressure vs. temperature curve. Finally, we performed a 1000 psig hydrostatic test of the reactor to ensure weld integrity.

Over temperature represents a possible hazardous situation. Figure 12 shows that if the electric furnace heating the reactor were to heat uncontrolled, then the temperature could become high enough to be a hazard. The theoretical furnace max is $1100^{\circ} \mathrm{C}$ $\left(2012^{\circ} \mathrm{F}\right)$. Heat losses would likely prevent the temperature from getting this high, but we need to safeguard against a temperature runaway. This was done by using both the control software to cut off all power to the heaters and furnace if an over-temperature is detected. To back up the computer, we have a separate over-temperature module that uses independent thermocouples (in case the control thermocouple were to fail, the over-temperature modules need to be totally independent). The settings are shown in Figure 12. .

While a similar analysis could be done for the tubing and fittings it was not necessary because there are published data for 304 SS tubing and 316 SS fittings (the apparatus uses Swagelok and Cajon stainless steel fittings and tubing). The strength of the tubing (1/2 inch O.D. x 0.049 inch thick wall) was determined using standard published data (Figure 13) de-rated for continuous operation at elevated temperature (Figure 14).

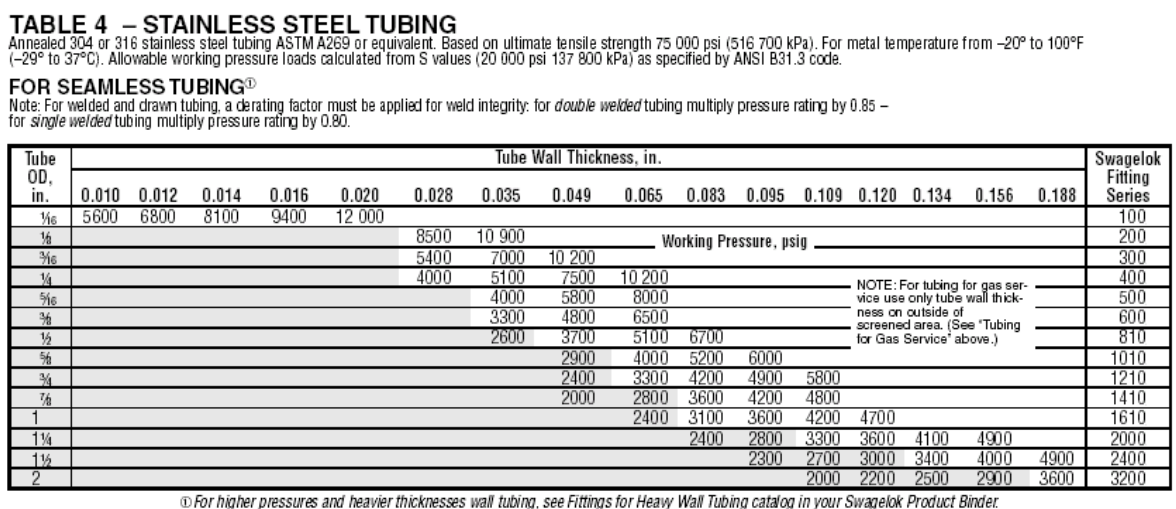

Figure 13. Swagelok tubing data

\begin{tabular}{|cccccccc|}
\hline \multicolumn{10}{|c|}{ Factors } \\
\hline${ }^{\circ} \mathrm{F}$ & ${ }^{\circ} \mathrm{C}$ & Aluminum & Copper & Steel/2 & 304SS & $316 \mathrm{SS}$ & Alloy 400 \\
\hline 200 & 93 & 1.00 & 0.80 & 0.95 & 1.00 & 1.00 & 0.87 \\
\hline 400 & 204 & 0.40 & 0.50 & 0.87 & 0.93 & 0.96 & 0.79 \\
\hline 600 & 315 & - & - & - & 0.82 & 0.85 & 0.79 \\
\hline 800 & 426 & - & - & - & 0.76 & 0.79 & 0.75 \\
\hline 1000 & 537 & - & - & - & 0.69 & 0.76 & - \\
\hline 1200 & 648 & - & - & - & 0.30 & 0.37 & - \\
\hline
\end{tabular}

Figure 14. Swagelok strength de-rating factors 
Figure 15 shows the safety analysis for the $1 / 2$ inch tubing in the system. All the points that correspond to normal operating conditions as well as various temperature and pressure failure modes are well below the strength curve and therefore there is no danger of tubing failure. Heating tapes are used to maintain the tubing above the sulfur dew point. A heating tape temperature runaway $\left(T=760^{\circ} \mathrm{C}=1400^{\circ} \mathrm{F}\right)$ will not cause a rupture. As before both software and an independent over-temperature module protect the system from thermal runaway. This analysis also applies for the fittings, which are

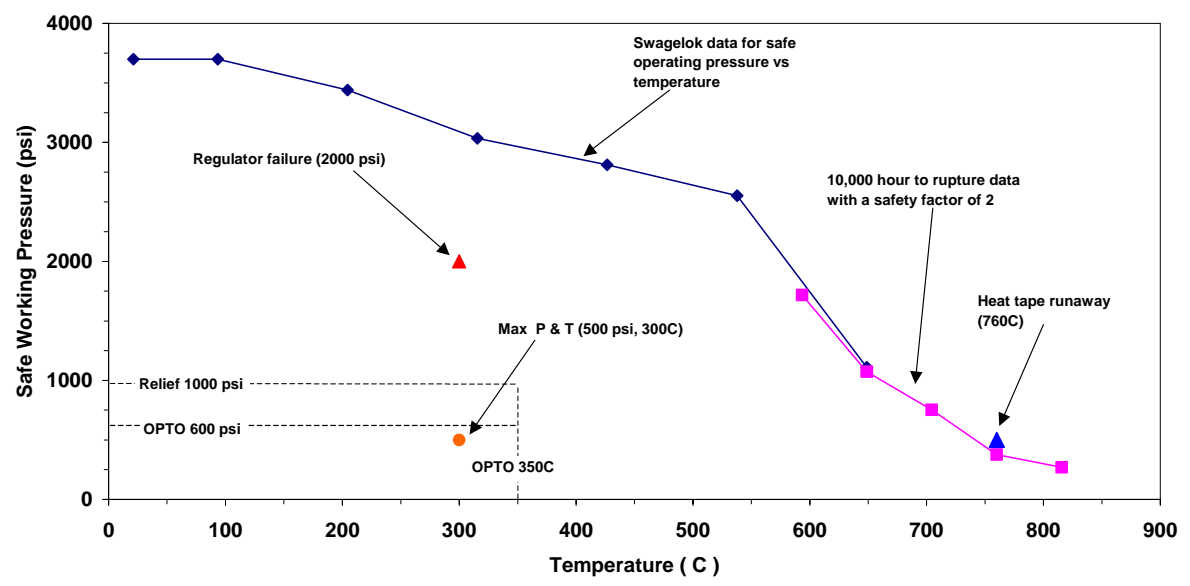

Figure 15. Safety analysis for tubing components in field test apparatus.

designed to ASME standards and are at least as strong as the tubing under the same pressure and temperature conditions.

\section{Photographs of the apparatus}

Figure 16 through Figure 18 are recent photographs of the field test apparatus. All of the major components and subsystems are labeled. The reactor is heated by the tube furnace at the left in the photo. Raw syngas passes through a tar knockout vessel and through a control valve before entering the reactor. As per our meeting at the Wabash plant, we will add an orifice flowmeter between the tar knockout and the control valve to directly measure the inlet gas flowrate (before we planned to use low temperature measurements at the gas exit using a turbine flowmeter for flow control). $\mathrm{H}_{2} \mathrm{~S}$ oxidation occurs in the reactor (Figure 17) and the sulfur remains in the vapor phase because all of the components between the reactor and condenser are kept above the sulfur dewpoint (i.e. $280^{\circ} \mathrm{C}$ or slightly hotter). The syngas plus sulfur vapor then passed up through the top of the reactor and over into two condensers placed in series. The condensers operate at about $250^{\circ} \mathrm{F}$ and use a hot-oil heat transfer fluid that is circulated with a thermostatically controlled oil bath to maintain the correct temperature. The temperature is kept at $120^{\circ} \mathrm{C}\left(248^{\circ} \mathrm{F}\right)$ so that sulfur remains liquid but will not polymerize (which could happen if the liquid sulfur were overheated). 


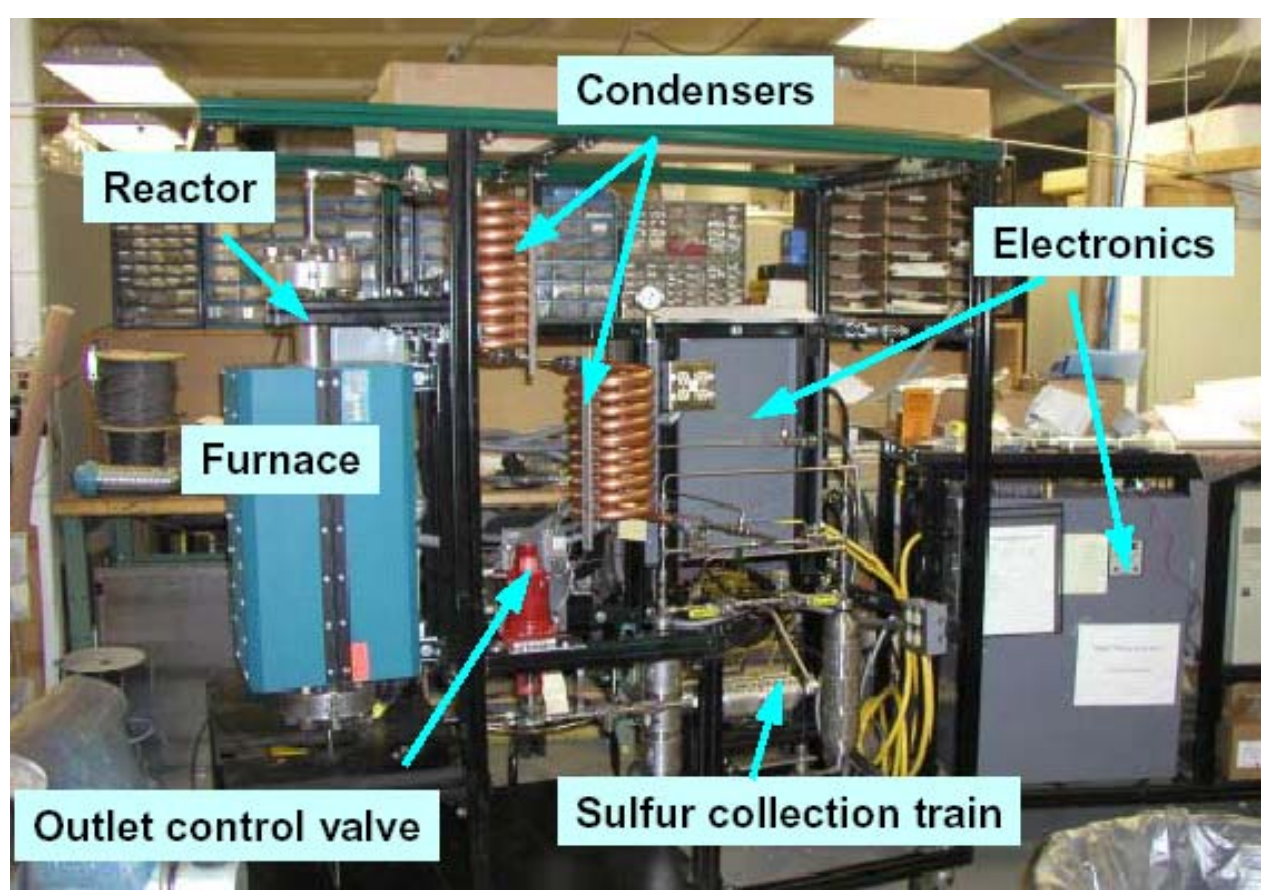

Figure 16. Photograph overview of apparatus as of April 30, 2004.

Liquid sulfur from the condenser coils then passed into the sulfur collection vessels. The condensers will also remove most of the water because the water dewpoint of the gas is $320^{\circ} \mathrm{F}$ and the vessels are kept at $250^{\circ} \mathrm{F}$. Two vessels are used so that one can be filling while the other is being drained. Because there is so much water in the syngas (ca. $20 \%$ ) each trap will have to be drained every $2-2.5$ hours.

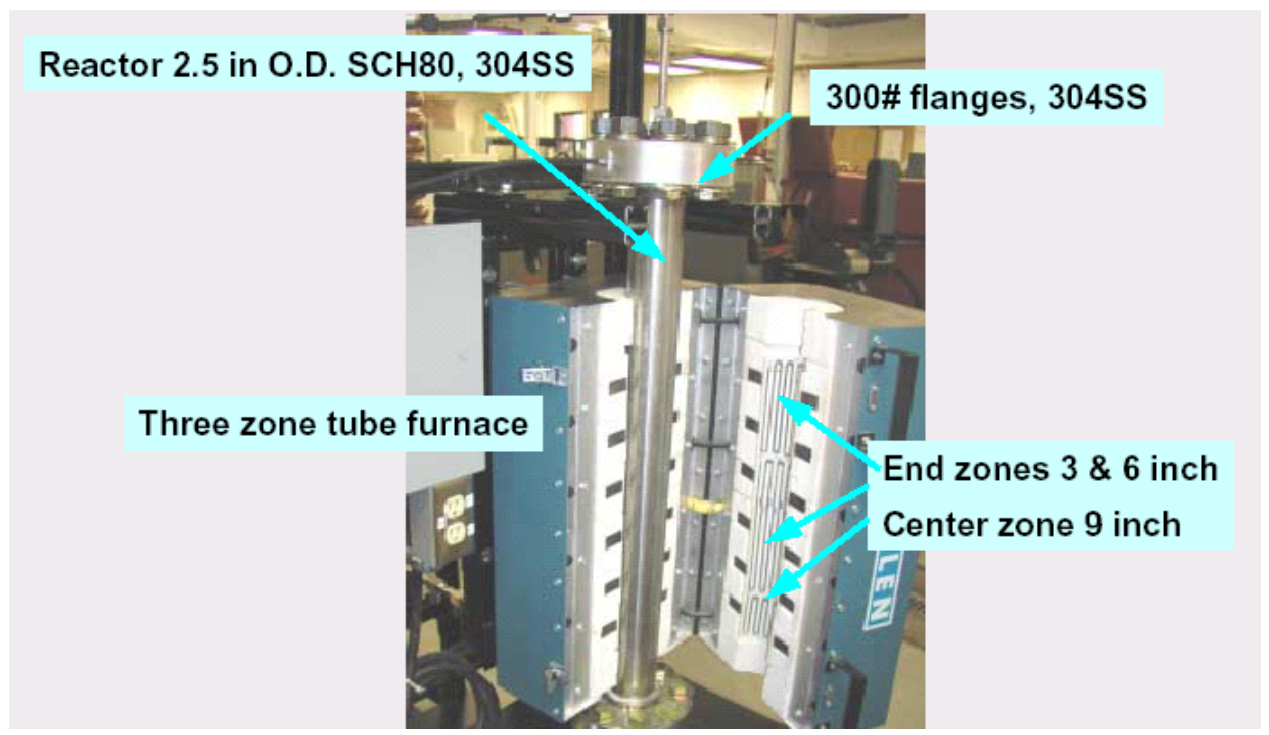

Figure 17. Photograph of reactor located in 3-zone furnace.

Because the sulfur is condensed into the liquid state, there will be some sulfur vapor in the gas phase due to equilibrium with the liquid. To remove this vapor, the gas exiting the sulfur collectors (which are maintained at $250^{\circ} \mathrm{F}$ ) passes through a small horizontal stainless steel high pressure cylinder that is maintained at $90^{\circ} \mathrm{C}\left(194^{\circ} \mathrm{F}\right)$. This 
temperature is below the melting point of sulfur $\left(115^{\circ} \mathrm{C}=239^{\circ} \mathrm{F}\right)$ and the cylinder is packed with Pyrex glass wool. Most of the sulfur vapor will condense be trapped by the glass wool. Figure 18 is a photograph of this section of the apparatus. Downstream of the sulfur vapor knockout but upstream of the exit control valve, there are two sintered stainless steel filters to catch any solid sulfur particles that make it past the glass wool in order to prevent plugging the control valve.

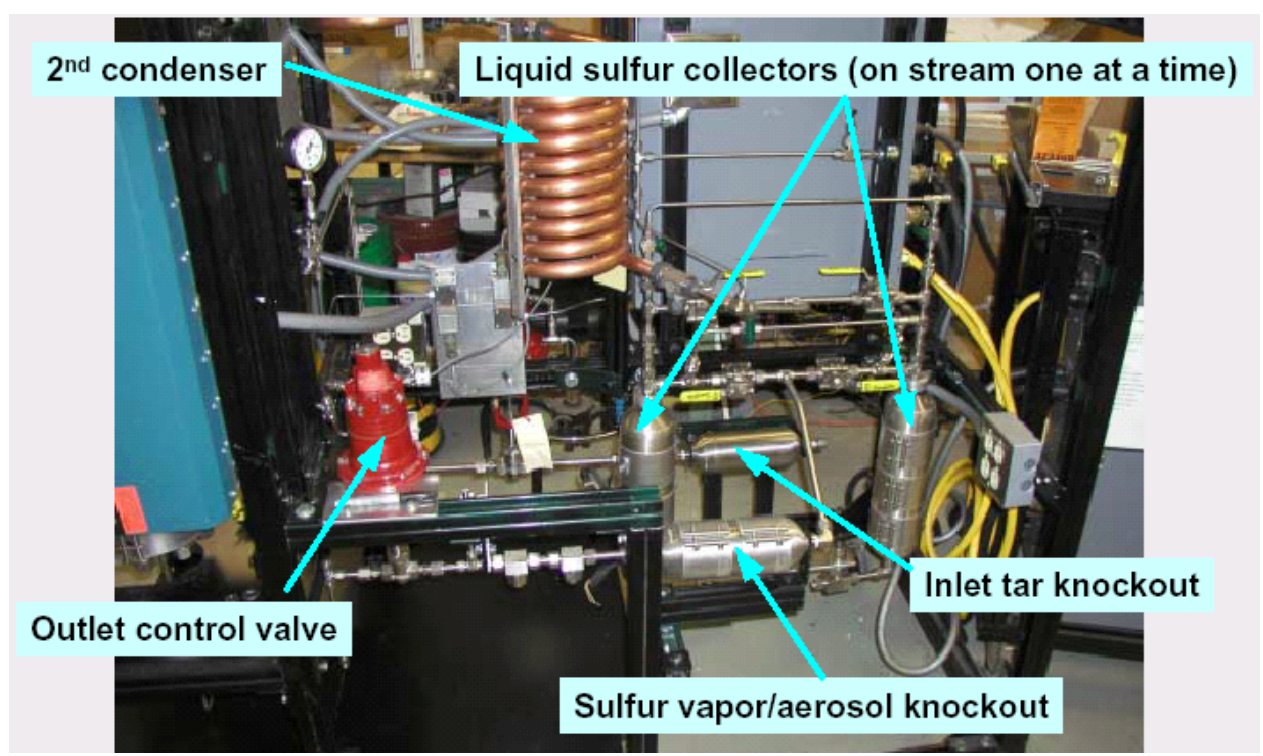

Figure 18. Photograph of sulfur condensation train and outlet control valve.

\subsection{DOE Phase I Award - Testing New Catalyst Formulations}

We have just recently received a Department of Energy Phase I grant for Multicomponent Warm Gas Cleanup, which will focus on the development of a catalyst suitable for $\mathrm{H}_{2} \mathrm{~S}$ removal in syngas. We plan to use this opportunity to develop a catalyst, which will be more appropriate for the conditions present at the Wabash plant followed by a field test with the new catalyst.

The overall objective of the project is to develop a catalyst that can be used for desulfurizing syngas and the demonstrate that the process is capable of simultaneously removing $\mathrm{H}_{2} \mathrm{~S}$, COS and mercury from syngas at high pressure (200 - 500 psig) and warm gas temperatures of $300-500^{\circ} \mathrm{F}$. To meet these objectives, in Phase I, we will:

- Determine the catalyst composition, reactor and catalyst configuration, and operating conditions that give us maximize $\mathrm{H}_{2} \mathrm{~S}$ and $\mathrm{COS}$ conversion and that result in the highest selectivities for elemental sulfur.

- Measure the kinetics of the reactions between $\mathrm{CO}$ and sulfur and $\mathrm{H}_{2}$ and sulfur to determine how to minimize COS formation and maximize $\mathrm{H}_{2} \mathrm{~S}$ oxidation in the process.

- Measure the kinetics of mercuric sulfide (HgS) formation and condensation in the sulfur condenser (HgS should be removed simultaneous by reacting with the elemental sulfur produced by $\mathrm{H}_{2} \mathrm{~S}$ oxidation). 
- Perform a detailed economic analysis of the process and compare it to conventional amine+Claus+SCOT syngas cleanup.

In order to develop the direct oxidation process that it can simultaneously remove $\mathrm{H}_{2} \mathrm{~S}$, $\mathrm{COS}$ and $\mathrm{Hg}$ vapor from syngas (without $\mathrm{H}_{2}$ oxidation), we have divided the project into four technical tasks and a fifth reporting task. In Task 1, we will examine the simultaneous hydrolysis of $\mathrm{COS}$ and oxidation of $\mathrm{H}_{2} \mathrm{~S}$ at the laboratory scale. Batches of various catalysts will be made and tested using a synthetic syngas stream. The affects of catalyst composition, temperature, pressure, COS concentration, $\mathrm{H}_{2} \mathrm{~S}$ concentration and humidity will be examined. In Task 2, we will measure the rate and extent of COS formation due to the reaction between $\mathrm{CO}$ and sulfur vapor (in the reactor) and $\mathrm{CO}$ and liquid sulfur in the condenser; we will also examine the reaction between $\mathrm{H}_{2}$ and elemental sulfur. The reactions between $\mathrm{CO}$ and sulfur (and $\mathrm{H}_{2}$ and sulfur) are thermodynamically irreversible $(\Delta G<0)$ at warm gas cleanup temperatures and therefore, we will examine these reactions to determine the operating conditions that minimize/eliminate this undesirable reactions from occurring. Task 3 will address $\mathrm{Hg}$ vapor removal from the syngas. In coal derived syngas, $\mathrm{Hg}$ is a significant source of contamination. We will use a two-pronged approach 1 ) we will measure the rate of reaction between $\mathrm{Hg}$ and sulfur vapor under various process conditions and 2) we will conduct $\mathrm{Hg}$ removal experiments where we are operating the simultaneous catalytic $\mathrm{H}_{2} \mathrm{~S}$ oxidation/COS hydrolysis reactions. In Task 4, we will address process economics. Specifically, we will examine the capital and operating costs of the process that uses different tail gas treatment/gas-polishing options. The results for various scenarios will be presented in terms of dollars per ton of sulfur removed and dollars per pound of $\mathrm{Hg}$ removed. Finally, Task $\mathbf{5}$ is reporting the progress of the project to DOE and the technical monitor.

\section{References}

Baumeister, T, Avallone, E.A., and Baumeister T. (III), (1978) Mark's Standard Handbook for Mechanical Engineers, $8^{\text {th }}$ ed., McGraw Hill.

Henrich, V.E. and Cox, P.A. (1994) The Surface Science of Metal Oxides, Cambridge University Press.

Higdon, A.; Olson, E.H.; Stiles, W.B; Wesse, J.A. and Riley, W.F.; (1976) Mechanics of Materials, $3^{\text {rd }}$ ed. , John Wiley and Sons, page 161

Kiselev, V.F., and Krylov, O.V. (1989) Adsorption and Catalysis on Transition Metals and Their Oxides, Springer Verlag, NY.

Shigley, J.E. (1977) Mechanical Engineering Design, $3^{\text {rd }}$ ed., McGraw Hill. 


\section{APPENDIX II}

Final Report from Nucon International, Inc.

On

“SLIPSTREAM TESTING OF REGENERABLE ACTIVATED CARBON FOR

REMOVING TRACE LEVELS OF SULFUR CONTAMINANTS FROM SYNGAS” 


\section{SLIPSTREAM TESTING OF REGENERABLE ACTIVATED CARBON FOR}

REMOVING TRACE LEVELS OF SULFUR CONTAMINANTS FROM SYNGAS

Final Report

Joseph C. Enneking

Clinton B. Summers

Issued April 2007

DE-FC26-99FT40659

Task number 2.3.1

NUCON International Inc.

7000 Huntley Rd.

Columbus, OH 43229

09CONPH1107/10 


\section{SLIPSTREAM TESTING OF REGENERABLE ACTIVATED CARBON FOR REMOVING TRACE LEVELS OF SULFUR CONTAMINANTS FROM SYNGAS}

\section{EXECUTIVE SUMMARY}

The purpose of this project was to investigate a regenerable activated carbon adsorption technology in removing sulfur species in Syngas to a level suitable for methanol synthesis. The work included laboratory investigations to determine technical feasibility and to develop design parameters for a slipstream unit to perform plant testing. The pilot plant was to be designed, built, and operated to obtain test data at an operating plant.

Several different metal oxide impregnants were studied to determine which was the most efficient for chemisorbing sulfur gases and being regenerated in place for subsequent adsorption cycle. Multiple adsorption/regeneration cycles were run on the best material to investigate the operating performance and to develop design parameters for the slipstream unit. These tests showed effective removal of the sulfur gases being investigated.

A pilot plant was designed and built. It incorporated automatic operating and safety devices to provide continuous and safe operation. It was shipped to the Wabash Coal Gasification Plant in Terre Haute, Indiana, installed and operated. Several installation and operating difficulties were overcome and valid operating data was generated.

The Operating results for removing hydrogen sulfide from the Syngas stream showed that the slipstream unit met the desired levels. However, the carbonyl sulfide removal for the slipstream unit was inadequate. With new carbon, the outlet concentrations were acceptable for a period of time but the regenerated carbon showed immediate breakthrough.

\section{TASK 2.2.1.2. CONDUCT LABORATORY TESTING WITH SIMULATES SYNGAS}

Objective: The purpose of this study was to determine the feasibility and best means for the removal of sulfur-containing compounds from a syngas flow. The removal of the sulfur containing compounds (hydrogen sulfide, $\mathrm{H}_{2} \mathrm{~S}$, and carbonyl sulfide, COS, in this study) is critical in preventing the poisoning of the catalyst used to drive the formation of methanol.

\section{Laboratory Test Summary:}

There were three major objectives for this task:

1. To determine the best metal oxide impregnant for removing sulfur gases from syngas. 
2. To establish that the adsorbent could be regenerated effectively

3. To run tests under field conditions to develop sizing parameters for the slipstream unit.

\section{Impregnant:}

Activated carbon is impregnated with a metal oxide and is used to remove low molecular weight sulfur compounds such as $\mathrm{COS}$ and $\mathrm{H}_{2} \mathrm{~S}$ from a gas stream. Three characteristics are important in choosing the impregnant:

1. High capacity for the sulfur gases

2. Easily regenerable

3. Inexpensive and simple to manufacture.

A series of tests were run to determine the capacity and ease of regeneration of four different metal oxide impregnated adsorbents. Since the impregnant identities are proprietary, they were simply numbered MO1 thru MO4.

Dynamic adsorption data for the four types of adsorbent are shown below:

Table 1: Test Parameters for initial experiments evaluating metal oxide impregnated granular activated carbon ( $20 \mathrm{x} 40$ mesh) for the removal of hydrogen sulfide and carbonyl sulfide from a syngas mixture.

\begin{tabular}{|l|l|}
\hline Bed Depth & 2.0 inches $\quad(0.167 \mathrm{ft})$ \\
\hline Internal Diameter & 0.296 inches $\left({ }^{1} \mathrm{CA}=4.78 \times 10^{-4} \mathrm{ft}^{2}\right)$ \\
\hline Flow Rate & $0.5^{2} \mathrm{LPM}(0.0177 \mathrm{CFM})$ \\
\hline Velocity & $45.09 \mathrm{FPM}$ \\
\hline Residence Time & $0.33 \mathrm{sec}$ \\
\hline
\end{tabular}

${ }^{1}$ CA, cross-sectional area define LPM, etc.

${ }^{2}$ LPM, Liters Per Minute, CFM, Cubic Feet per Minute

These tests were accelerated to minimize the time required to obtain comparative data. They do not reflect the results that would be obtained in actual field operation where the bed sizing and flow rates would be chosen to give a desired adsorption cycle length. The syngas mixture used for these experiments was composed of 38.5\% hydrogen with the balance being carbon monoxide (carbon dioxide was present at $15 \mathrm{ppm}$ or less). Experiments for hydrogen sulfide and carbonyl sulfide were carried out separately with the hydrogen sulfide present in the syngas mixture at approximately $300 \mathrm{ppm}$ and carbonyl sulfide present at $25 \mathrm{ppm}$. Results of the tests are shown below: 
Table $2 \mathbf{H}_{2} \mathrm{~S}$ : Data for metal oxide impregnated carbons ( 20 x 40 mesh)

\begin{tabular}{|c|c|c|c|c|}
\hline Impregnant & MO1 & MO2 & MO3 & $\mathrm{MO} 4$ \\
\hline (in) & 2.0 & 2.0 & 2.0 & 2.0 \\
\hline $\mathrm{T}_{\mathrm{b}} \quad(\min )$ & 135 & 192 & 102 & 221 \\
\hline $\mathrm{T}_{\mathrm{s}} \quad(\mathrm{min})$ & 210 & 267 & 315 & 296 \\
\hline $\mathrm{T}_{50} \quad(\min )$ & 170.8 & 231.7 & 200.3 & 253.0 \\
\hline$\Delta \mathrm{T} \quad(\min )$ & 75 & 75 & 213 & 75 \\
\hline U $\quad$ (in/min) & 0.012 & 0.009 & 0.01 & 0.008 \\
\hline MTZ (in) & 0.9 & 0.68 & 2.13 & 0.6 \\
\hline Capacity $(\mathrm{mg} / \mathrm{g})$ & 23 & 33 & 18 & 38 \\
\hline
\end{tabular}

Table 3 COS: Data for metal oxide impregnated carbons ( 20 x 40 mesh)

\begin{tabular}{|c|c|c|c|c|}
\hline Impregnant & MO1 & $\mathrm{MO} 2$ & $\mathrm{MO} 3$ & MO4 \\
\hline (in) & 2.0 & 2.0 & 2.0 & 2.0 \\
\hline $\mathrm{T}_{\mathrm{b}} \quad(\min )$ & 135 & 192 & 165 & 221 \\
\hline $\mathrm{T}_{\mathrm{S}} \quad(\min )$ & 210 & 252 & 255 & 281 \\
\hline $\mathrm{T}_{50} \quad(\mathrm{~min})$ & 150.8 & 209.9 & 181.9 & 208.4 \\
\hline$\Delta \mathrm{T} \quad(\min )$ & 75 & 60 & 90 & 60 \\
\hline (in/min) & 0.015 & 0.01 & 0.011 & 0.01 \\
\hline MTZ (in) & 0.3 & 0.6 & 0.99 & 0.6 \\
\hline Capacity (mg/g) & 41 & 59 & 50.6 & 58 \\
\hline
\end{tabular}

Note that the breakthrough times for COS are "apparent" values, as the conversion of $\mathrm{COS}$ to $\mathrm{H} 2 \mathrm{~S}$ will occur as long as reactive metal ions are present)

$\mathrm{L}=$ bed depth

$\mathrm{Tb}=$ time to breakthrough

Ts $=$ time to saturation

T50 = time to $50 \%$ breakthrough

$\Delta \mathrm{T}=$ time to saturation - time to breakthrough

$\mathrm{U}=$ rate of travel

MTZ = mass transfer zone

Adsorbents identified as MO1 and MO3 show significantly poorer performance than the other two. Adsorbent MO4 is difficult and expensive to manufacture. Therefore, adsorbent MO2 was chosen for the rest of the test program. 


\section{Regeneration:}

A number of tests were run to check the regenerability of the adsorbent. The first tests were run using 20/40 particle size to reduce the time required to complete the tests.

Regeneration was performed in an oven to maintain the proper temperature. Nitrogen was heated in a coil inside the furnace and then passed through the spent adsorbent. A small amount of air (1\% oxygen in the regeneration stream) was then added to convert the metal impregnant back to the oxide. In the early stages of regeneration, sulfur oxides are formed which depletes the oxygen. When the oxygen content in the outlet was the same as the inlet (1\%), the regeneration was considered complete

Table 4. Regeneration tests, 20/40 particle size

$\begin{array}{lcccccc}\text { Test No. } & 1 & 2 & 3 & 4 & 5 & 6 \\ \text { Date } & 1 / 4 / 04 & 1 / 4 / 04 & 1 / 4 / 04 & 1 / 12 / 04 & 1 / 12 / 04 & 1 / 12 / 04 \\ \text { Particle Size } & 20 / 40 & 20 / 40 & 20 / 40 & 20 / 40 & 20 / 40 & 20 / 40 \\ \text { Type } & \text { New } & \text { Regened Regened } & \text { New } & \text { Regened Regened } \\ \text { Impregnant } & \text { MO } & \text { MO2 } & \text { MO2 } & \text { MO2 } & \text { MO2 } & \text { MO2 } \\ \text { Impregnant Content, \% } & 8.0 & 8.0 & 8.0 & 8.0 & 8.0 & 8.0 \\ \text { Bed Dia, in } & 0.296 & 0.296 & 0.296 & 0.296 & 0.296 & 0.296 \\ \text { Bed Depth, in. } & 1 & 1 & 1 & 1 & 1 & 1 \\ \text { Bed Weight, g } & 1.13 & 1.13 & 1.13 & 1.13 & 1.13 & 1.13 \\ \text { Flow, slpm } & 0.2 & 0.2 & 0.2 & 0.2 & 0.2 & 0.2 \\ \text { Temp, }{ }^{\circ} \mathrm{C} & 100 & 100 & 100 & 100 & 100 & 100 \\ \text { Pressure, psia } & 14.4 & 14.4 & 14.4 & 14.4 & 14.4 & 14.4 \\ \text { Residence time, sec } & 0.11 & 0.11 & 0.11 & 0.11 & 0.11 & 0.11 \\ \mathrm{H}_{2} \text { S Conc, ppmv } & 300 & 300 & 300 & 0 & 0 & 0 \\ \text { COS Conc, ppmv } & 0 & 0 & 0 & 25 & 25 & 25 \\ \mathrm{H}_{2} S \text { Breakthrough, min. } & 30 & 30 & 30 & & & \\ \text { COS Breakthrough, min. } & & & & 30 & 30 & 30 \\ \mathrm{H}_{2} \text { S Saturation, min } & 585 & & & & & \\ \text { COS Saturation, min } & & & & 180 & & \\ & & & & & & \end{array}$

A relatively high adsorption temperature was chosen to test the capability of the adsorbent to operate at higher than intended temperatures. It also shortened the test times, but might not give a realistic measure of the equilibrium adsorption capacity.

The breakthrough times were the same after regeneration as for new carbon. The regeneration technique was judged effective.

Adsorption and regeneration tests were also performed on $1.5 \mathrm{~mm}$ pellets, the particle size that would be used in the slip stream tests. 
Table 5 Regeneration tests, $1.5 \mathrm{~mm}$ diameter particle size

$\begin{array}{lcccccc}\text { Test No. } & 1 & 2 & 3 & 4 & 5 & 6 \\ \text { Date } & 3 / 8 / 04 & 3 / 8 / 04 & 3 / 8 / 04 & 4 / 4 / 04 & 4 / 4 / 04 & 4 / 4 / 04 \\ \text { Particle Size } & 1.5 \mathrm{~mm} & 1.5 \mathrm{~mm} & 1.5 \mathrm{~mm} & 1.5 \mathrm{~mm} & 1.5 \mathrm{~mm} & 1.5 \mathrm{~mm} \\ \text { Type } & \mathrm{New} & \text { Regened Regened } & \mathrm{New} & \text { Regened Regened } \\ \text { Impregnant } & \mathrm{MO} 2 & \mathrm{MO} 2 & \mathrm{MO} 2 & \mathrm{MO} 2 & \mathrm{MO} 2 & \mathrm{MO} 2 \\ \text { Impregnant Content, \% } & 8.0 & 8.0 & 8.0 & 8.0 & 8.0 & 8.0 \\ \text { Bed Dia, in } & 0.85 & 0.85 & 0.85 & 0.85 & 0.85 & 0.85 \\ \text { Bed Depth, in. } & 3 & 3 & 3 & 3 & 3 & 3 \\ \text { Bed Weight, g } & 16.74 & 16.74 & 16.74 & 16.74 & 16.74 & 16.74 \\ \text { Flow, slpm } & 0.6 & 0.6 & 0.6 & 0.6 & 0.6 & 0.6 \\ \text { Temp, }{ }^{\circ} \mathrm{C} & 100 & 100 & 100 & 100 & 100 & 100 \\ \text { Pressure, psia } & 14.4 & 14.4 & 14.4 & 14.4 & 14.4 & 14.4 \\ \text { Residence time, sec } & 2.8 & 2.8 & 2.8 & 2.8 & 2.8 & 2.8 \\ \mathrm{H}_{2} \mathrm{~S} \text { Conc, ppmv } & 301 & 301 & 301 & 276 & 276 & 276 \\ \text { COS Conc, ppmv } & 25 & 25 & 25 & 0 & 0 & 0 \\ \mathrm{H}_{2} \text { S Breakthrough, min. } & 300 & 360 & 360 & 780 & 859 & 836 \\ \text { COS Breakthrough, min. } & 427 & 600 & 600 & & & \\ \mathrm{H}_{2} \mathrm{~S} \text { Saturation, min } & 1800 & & & 2446 & & \\ \text { COS Saturation, min } & 960 & & & & & \end{array}$

The regenerated carbon actually showed an improvement in performance. That could be because the regeneration technique resulted in a better conversion of the metal oxide than the original manufacturing process.

\section{Tests under actual operating conditions:}

In order to determine appropriate slipstream design parameters, a series of tests were performed under actual operating conditions. 
Table 6 Adsorption and regeneration tests, operating conditions

\begin{tabular}{|c|c|c|c|c|c|c|}
\hline Test No. & 1 & 2 & 3 & 4 & 5 & 6 \\
\hline Date & $5 / 24 / 04$ & $5 / 24 / 04$ & $5 / 24 / 04$ & $6 / 10 / 04$ & $6 / 10 / 04$ & $6 / 10 / 04$ \\
\hline Particle Size & $1.5 \mathrm{~mm}$ & $1.5 \mathrm{~mm}$ & $1.5 \mathrm{~mm}$ & $1.5 \mathrm{~mm}$ & $1.5 \mathrm{~mm}$ & $1.5 \mathrm{~mm}$ \\
\hline Type & New & Regened & Regened & New & Regened & Regened \\
\hline Impregnant & MO2 & MO2 & MO2 & MO2 & MO2 & MO2 \\
\hline Impregnant Content, \% & 8.0 & 8.0 & 8.0 & 8.0 & 8.0 & 8.0 \\
\hline Bed Dia, in & 0.86 & 0.86 & 0.86 & 0.86 & 0.86 & 0.86 \\
\hline Bed Depth, in. & 3 & 3 & 3 & 3 & 3 & 3 \\
\hline Bed Weight, g & 16.74 & 16.74 & 16.74 & 16.74 & 16.74 & 16.74 \\
\hline Flow, slpm & 8.3 & 8.3 & 8.3 & 8.3 & 8.3 & 8.3 \\
\hline Temp, ${ }^{\circ} \mathrm{C}$ & 37.8 & 37.8 & 37.8 & 37.8 & 37.8 & 37.8 \\
\hline Pressure, psia & 364 & 364 & 364 & 364 & 364 & 364 \\
\hline Residence time, sec & 1.3 & 1.3 & 1.3 & 1.3 & 1.3 & 1.3 \\
\hline $\mathrm{H}_{2} \mathrm{~S}$ Conc, ppmv & 301 & 301 & 301 & & & \\
\hline COS Conc, ppmv & & & & 25 & 25 & 25 \\
\hline $\mathrm{H}_{2} \mathrm{~S}$ Breakthrough, min. & 15 & 30 & 30 & & & \\
\hline COS Breakthrough, min. & & & & 15 & 15 & \\
\hline $\mathrm{H}_{2} \mathrm{~S}$ Saturation, min & 150 & & & & & \\
\hline COS Saturation, min & & & & 50 & & \\
\hline
\end{tabular}

Since the mass flow rate was approximately 14 times that in the low pressure tests, the amount of sulfur gases introduced to the carbon was much higher and breakthrough occurred much sooner. However, regeneration was shown to be effective and the adsorption capacity for H2S (the controlling factor for breakthrough) was calculated to be $1.7 \%$. Because this value was approximately $50 \%$ of that originally used to size the slipstream bed, we decided to lengthen the bed to $4 \mathrm{ft}$ instead of the original $2 \mathrm{ft}$. We also provided capability to accurately measure flow rates as low as $0.2 \mathrm{acfm}$ to insure that adsorption cycle lengths will be longer than 16 hours. 


\section{Task 2.2.1.3 Design, Procure and Fabricate Slipstream Unit}

The design for the slipstream unit was based on results of the laboratory tests.

$\begin{array}{ll}\begin{array}{ll}\text { Process Flow: } \\ \text { Temperature: }\end{array} & \begin{array}{l}2 \mathrm{acfm} \\ \text { Pressure: }\end{array} \\ \begin{array}{ll}10{ }^{\circ} \mathrm{F} \text { to } 120^{\circ} \mathrm{F} \\ 350 \mathrm{psig}\end{array} \\ \begin{array}{l}\text { Stream Composition: } \\ \text { Carbon Monoxide: }\end{array} & 45 \% \\ \begin{array}{l}\text { Carbon Dioxide } \\ \text { Hydrogen }\end{array} & 16 \% \\ \text { H2S Concentration: } & 35 \% \\ \text { COS Concentration: } & \text { up to } 300 \mathrm{ppmv} \\ & \text { up to } 30 \mathrm{ppmv}\end{array}$

A detailed process design description is attached in Appendix A

As part of the engineering task, a process safety analysis was conducted. The Failure analysis is included in Appendix A

The Piping and Instrument Diagram is also included in Appendix A

A picture of the completed Slipstream unit is shown below. 


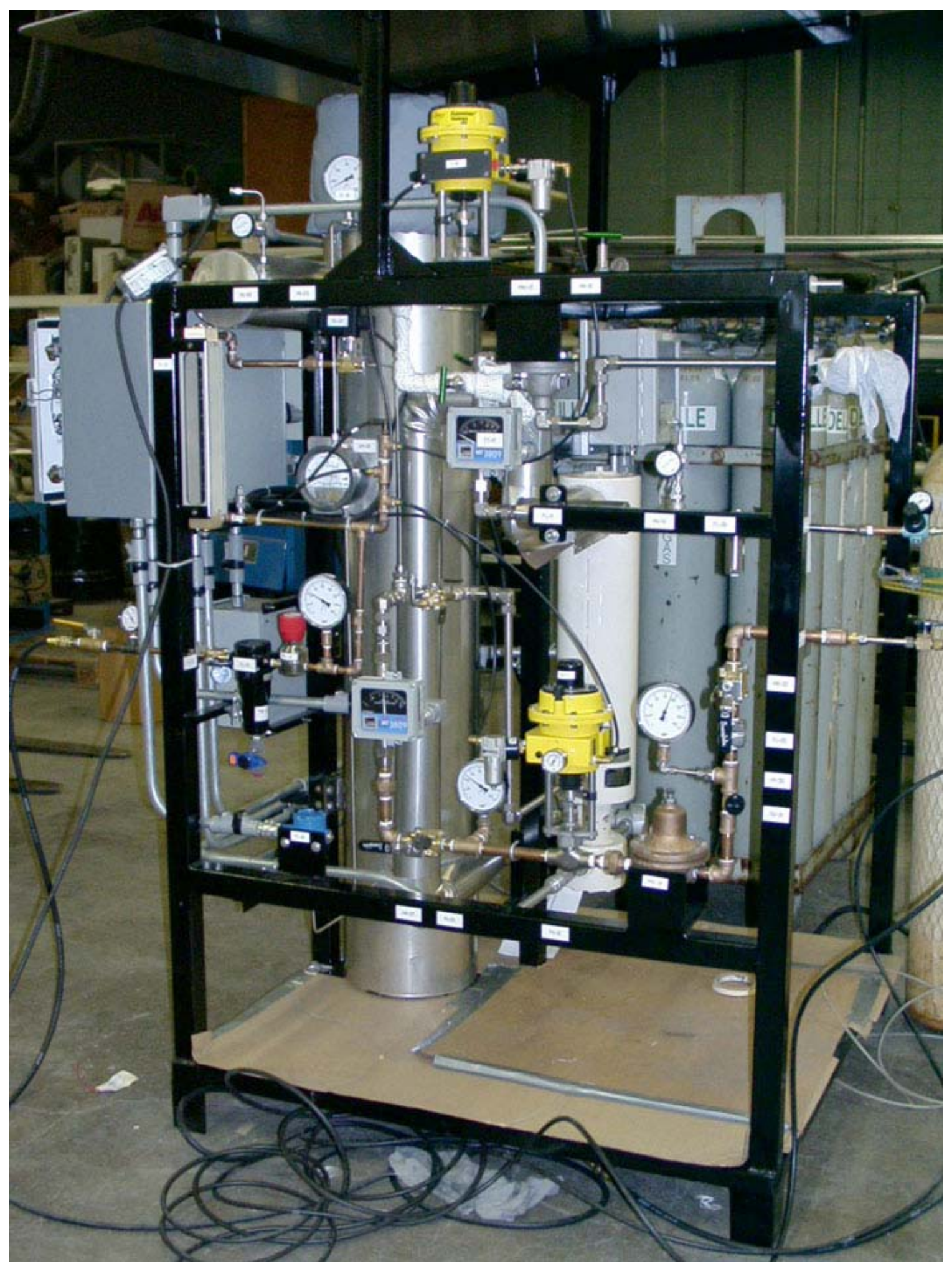




\section{Task 2.2.2.1. Install slipstream unit at WREL}

After initial installation of the slipstream pilot plant, initial startup activities were conducted during November 2005. A process safety review was conducted and as a result, some modifications to the equipment were made. An initial adsorption run was conducted in early January 2006

\section{Task 2.2.2.2. Startup, operate and test slipstream unit.}

\section{Installation Test Runs}

The first adsorption run showed an initial breakthrough of H2S (to approximately 5\% of inlet concentration) in the 6 to 7 hours with saturation not occurring after 24 hours. COS breakthrough in the initial run was before the H2S, approximately 5 hours. Subsequent runs indicated that COS began breaking through even earlier, with a final run where COS was initially present in the adsorber outlet at the same concentration as the inlet. Even though COS is not strongly adsorbed after a number of initial runs, the H2S capacity is not affected. Regeneration of the carbon is effective.

\section{Adsorption Column Description}

The adsorption column was jacketed for heat control. The overall dimensions were a nominal ID of 4 inches and a carbon bed depth of approximately 42 inches. The adsorbent used for these trials was NUSORB ${ }^{\circledR}$ CR-3.

\section{Carbon Bed Parameters}

For purposes of capacity estimation, the apparent density of the adsorbent material is 0.56 $\mathrm{g} / \mathrm{ml}$. For a column with 4 inch ID and 42-inch bed depth this corresponds approximately $0.3 \mathrm{ft}^{3}$ or 10.5 lbs. of carbon.

\section{Observations}

It was observed that COS is initially adsorbed well by the carbon, but over the course of just a few adsorption/regeneration cycles, breaks through immediately. There may be a chemical reaction between the COS and the surface oxide groups on the carbon which were effective in removing COS during the initial adsorption runs. The surface of activated carbon has a number of oxygen containing functional groups (hydroxyl, 
carboxylic, lactone) that may react with COS in an irreversible process. The beginning density of these groups on the carbon surface would mean there would be abundant "sites" for the COS to interact with, resulting in it's removal from the gas stream. Over the course of a few adsorption cycles, these reactive sites are consumed, and when the number of sites is insignificant in relation to the amount of COS present, the COS moves through the adsorber bed with only minimal hold up. This phenomena was not observed in the lab trials. The number of surface oxides present may be have been sufficient to effectively remove the COS over a few short adsorption cycles, never being completely consumed.

\section{Repairs and Modifications}

1. During January, there was a failure of the regeneration cycle. Upon investigation, it was discovered that a control module had malfunctioned. A replacement was obtained and installed in late January. During the next adsorption cycle, COS breakthrough occurred immediately.

2. During startup, the inlet line filled with water and froze. Upon thawing, liquid water was introduced to the carbon bed. That was thought to be one of the causes of poor COS adsorption and the carbon was replaced in late February with new material. Upon reassembling the unit, it failed the pressure test and the cause was determined to be a faulty valve. A new one was obtained and installed in late April

3. Prior to operation, due to the water vapor content of the syngas stream and the extremely low temperatures, the source line filled with water and froze. The source line for the syngas was steam traced.

4. Installation of a pressure safety valve.

5. Installation of a pressure regulator to adjust nitrogen pressure for regeneration cycle.

6. Installation of additional sampling points to allow manual sampling as well as the tubing that runs directly to the site GC.

7. Replacement of a temperature control module that regulated the regeneration cycle.

8. Carbon was changed out. One concern here is that we were seeing reduced efficiency due to the adsorption column being filled with water and then freezing during the initial start-up.

9. Replacement of a valve that isolates the regeneration cycle. This valve was leaking at a substantial rate and not allowing the adsorption column to hold pressure. 
10. Removal of the differential pressure gauge to monitor pressured drop across the adsorption bed.

\section{Final Test Runs}

Date

Activity

21-Aug-06 On site began modifications to unit (sample loops, regulator, additional ports)

22-Aug-06 On site, completed modifications to unit, began regen cycle to prep for adsorption run

23-Aug-06 adaptation and installation of instrumentation for H2S measurement, 1st adsorb cycle

24-Aug-06 Regen cycle with SO2 monitoring and O2 monitoring to check on completion of regeneration

25-Aug-06 H2S adsorb cycle, regen cycle. PAD arrived on site for COS measurement

26-Aug-06 First COS measurements in adsorb cycle and regen

27-Aug-06 Second COS measurement cycle, H2S monitoring till saturation

28-Aug-06 Full regen cycle

29-Aug-06 Final measurement of COS breakthrough, depart site

\section{Modifications to Slipstream Unit}

Prior to beginning this series of experiments, modifications to the sample train were made to allow the pressure and temperature to be reduced to ambient conditions to facilitate concentration determinations for the gases of interest. This involved installing a secondary sample loop with a CGA regulator to reduce the pressure. Decreasing the pressure to just above 15 PSI and allowing for a short run of tubing upstream of the instrument resulted in a temperature only slightly above ambient.

\section{New Instrumentation}

Previous operation of the slipstream unit was monitored by on-site gas chromatographs. Since they were not available for this test series, measurements of $\mathrm{H}_{2} \mathrm{~S}$ and COS were carried out using different instrumentation. $\mathrm{H}_{2} \mathrm{~S}$ concentrations were monitored continuously using an AIM multigas monitor based on electrochemical specific cells. The instrument continuously monitored a small stream of gas that had been reduced to ambient pressure and temperature passively, with data recorded at 3 minute intervals. The range of the cell for H2S detection was 0 to 100 ppmv with a resolution of 1 ppmv with an uncertainty of $+/-1 \%$ of full scale $(1 \mathrm{ppmv})$. The AIM multigas monitor was also used to check for SO2 being released during regeneration and to monitor the oxygen content of the regeneration gas stream to allow optimization of the regeneration process. 
COS was measured using a photo acoustic infrared gas monitor (INNOVA model 1412) with an IR filter specific for COS installed. In order to prevent interferences from CO, $\mathrm{CO}_{2}$, and water vapor the instrument was calibrated with COS in the presence of these gases at the concentrations typical to synthesis gas (60\% CO, 30\% hydrogen, $10 \% \mathrm{CO}_{2}$ ) saturated with water vapor. The INNOVA 1412 gas monitor also continuously monitors water vapor concentration and corrects for this interference.

\section{Operating Conditions}

Adsorption Cycle: During the adsorption cycle, synthesis gas was supplied to the column at a nominal temperature of $120^{\circ} \mathrm{F}$ at $340 \mathrm{PSI}$ at a flow rate of approximately 2 ACFM (45.3 SCFM). During the course of the adsorption cycles the $\mathrm{H}_{2} \mathrm{~S}$ concentration ranged from 20 to 30 ppmv as measured by the on-site gas chromatographs, corresponding well with the concentrations detected by the AIM gas monitor. COS concentrations, as measured by the on-site gas chromatographs was typically in excess of 90 ppmv with occasional excursions over 100 ppmv. The COS concentrations as measured by the photoacoustic infrared gas monitor agreed closely with these measurements.

Regeneration Cycle: Regeneration was carried out using hot nitrogen $\left(350^{\circ} \mathrm{F}\right)$ at a nominal pressure of 80 PSI. Once $350^{\circ} \mathrm{F}$ was reached, air was introduced to bring the nitrogen stream to $1 \%$ oxygen content to convert the metal sulfides back to the active metal oxide form.

\section{Performance Analysis}

$\mathrm{H}_{2} \mathrm{~S}$ concentrations were monitored at 3-minute intervals by allowing the synthesis gas to pass over the detector cell with the AIM monitor operating in "passive" mode (sample pump not operating). In two of the three cases where $\mathrm{H}_{2} \mathrm{~S}$ concentrations were measured, the adsorption cycle ran until saturation (outlet concentration of $\mathrm{H}_{2} \mathrm{~S}$ and inlet concentration of $\mathrm{H}_{2} \mathrm{~S}$ equal). In the third case, the $\mathrm{H} 2 \mathrm{~S}$ concentration was monitored for approximately 9 hours and then a regeneration cycle was started.

COS determinations were carried out by collecting 1 liter samples of the gas in Tedlar bags, at 30 minute intervals until saturation was achieved, typically two to three hours. Due to the fact that the photoacoustic infrared monitor was not available until 25 August, data was collected for COS only on 26 August, followed by a full regeneration. Data for 27 August includes measurement of COS till saturation and the adsorption cycle was allowed to continue with H2S concentrations being recorded by the AIM gas monitor. A final test of the COS adsorption was completed 29 August.

\section{Observations}

\section{Operating Conditions}

Data collected during this test series was consistent with previous data collected using the on-site gas chromatographs for determining $\mathrm{H}_{2} \mathrm{~S}$ and COS concentrations. 


\section{H2S adsorption}

One observation that has been consistent through the different trials is that on start-up of the adsorber with no previous exposure to synthesis gas, H2S removal remains consistent from the "first" run, through subsequent regenerations. Initial breakthrough is typically seen after approximately 8 hours and saturation of the adsorber occurs after about 16 hours.

The definition of breakthrough is generally arbitrary. Sometimes it is defined as the first detectable level in the outlet. However, instrument errors and sensitivity can result in low concentrations that will not substantially reduce the overall efficiency of the adsorption process. Therefore, a value of $10 \%$ of the inlet concentration is normally used as an indicator of breakthrough. For these experiments, that would be 3 ppmv (Please see Figure 1). While the outlet concentration reached 3 ppmv in about 500 minutes, it did not begin to rise substantially above that until about 800 minutes. This should be considered the time of breakthrough used to calculate length and travel of the mass transfer zone. The following are the calculated values for this test series.

$$
\begin{aligned}
& \mathrm{U}=\mathrm{L} / \mathrm{t}_{50} \\
& \mathrm{M}=\mathrm{Ut}
\end{aligned}
$$

Where:

$$
\begin{array}{lll}
\mathrm{U} & = & \text { rate of travel, in./min } \\
\mathrm{L} & = & \text { length of bed, inches } \\
\mathrm{t}_{50} & = & \text { time to } 50 \% \text { breakthrough, minutes } \\
\mathrm{M} & = & \text { mass transfer zone length, inches } \\
\mathrm{t} & = & \text { time to saturation - time to breakthrough, minutes }
\end{array}
$$

Rate of travel of mass transfer zone $=42 / 950=.044 \mathrm{in} / \mathrm{min}$

The mass transfer zone length $=.044 * 200=8.8 \mathrm{in}$.

The $\mathrm{H}_{2} \mathrm{~S}$ capacity of the adsorber bed was approximately $1 \%$ (wt./wt.) over the course of the experiments.

\section{COS Adsorption}

Previous lab scale tests were performed to provide a preliminary evaluation of the COS adsorption characteristics. These tests were performed with COS only (no $\mathrm{H}_{2} \mathrm{~S}$ in the gas stream) at $25 \mathrm{ppmv}$ in a synthesis gas mixture, with no water vapor present. In laboratory tests, while the COS capacity was lower than that measured for $\mathrm{H}_{2} \mathrm{~S}$, the adsorbent still 
demonstrated some adsorption capacity and that capacity was restored using hot nitrogen regeneration.

In the pilot tests the inlet COS concentration was much higher than anticipated. The laboratory tests were conducted at $25 \mathrm{ppmv}$ concentration while the concentration at the plant was almost 100 ppmv. Breakthrough time of COS in the pilot plant on new carbon was about 4 hours with saturation in about 6 hrs. However after regeneration, breakthrough occurred immediately and the carbon was saturated after two hours (See Figure 2, COS Breakthrough Concentration).

\section{Regeneration}

The regeneration of the adsorber bed was carried out by running nitrogen through the adsorber bed, while heating to 350 degrees F. Once this temperature had been reached, air was introduced into the nitrogen stream in a quantity sufficient to supply $1 \%$ oxygen to the nitrogen stream. In this way, the metal sulfides formed by the $\mathrm{H}_{2} \mathrm{~S}$ removal process are converted back to the metal oxide forms.

\section{Gas Analysis during regeneration}

Using the AIM gas monitor with an electrochemical sensor for oxygen, the regeneration process was monitored until the outlet oxygen concentration was equal to the nominal $1 \%$ inlet oxygen concentration. An outlet oxygen concentration of approximately $1 \%$ serves to indicate that the regeneration process is complete, with the reactive metal oxides again present on the activated carbon. Oxygen concentration measurements on a regeneration cycle peformed after the $\mathrm{H}_{2} \mathrm{~S}$ adsorption cycle had gone to saturation (implying that all of the reactive metal oxide sites had reacted), indicated that approximately 4 hours was required to recover the metal centers in the oxide form.

Additionally, the outlet stream of the adsorber bed was monitored for sulfur dioxide during regeneration. While it appeared that Sulfur dioxide was detected, the concentration never exceeded $2 \mathrm{ppm}$ and was below the detection threshold of the the AIM gas monitor (1 ppm, nominal) for the majority of the regeneration cycle.

\section{Effectiveness of regeneration.}

Regeneration of the adsorber bed had no adverse effect on the $\mathrm{H}_{2} \mathrm{~S}$ adsorption or capacity, as can be seen by the consistent breakthrough curves for $\mathrm{H}_{2} \mathrm{~S}$. (See Appendix B) Regeneration was not effective for COS adsorption

\section{CONCLUSIONS}

The metal oxide impregnated carbon is effective in removing H2S and COS from a syngas stream 
The pilot plant that was constructed was effective in obtaining data on the actual syngas stream.

While the process gas chromatographs were somewhat effective in measuring gas concentrations, specific portable instruments were much more effective.

Regeneration with hot nitrogen is effective in restoring the original capacity of the adsorbent to remove hydrogen sulfide from the syngas stream. It is not very effective for carbonyl sulfide adsorption. 


\section{Appendix A \\ Slipstream Unit Documents}

Process Design Description, NUCON 06CONPH1170/02 R1

Process Safety Analysis

P\&ID, Drawing. no. CH-101-01 


\title{
System Design Description
}

For

\author{
Slip Stream Pilot Plant
}

For:

\section{Wabash River IMPPCCT, Integrated Methanol and Power Production from Clean Coal Technologies}

\author{
15 April 2004
}

Distribution: $\quad$ CONOCOPHILLIPS Co.: Albert Tsang

NUCON: Master File

Marketing

Engineering

NUCON 06CONPH1170/02 R1 


\section{Original Issue 9 Feb 04}

\section{Prepared By \\ O. P. Q Eneking}

J. C. Enneking

\section{Rev 1, 15 Apr 04}

\&. P. Enneking

J. C. Enneking
Reviewed By

(D. \& ofreman

W. P. Freeman

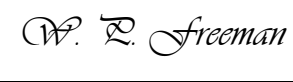

W. P. Freeman
Eng Approval

\&. \&. Dale

J. L. Dale

๙. \& Dale

J. L. Dale 


\subsection{Summary}

Laboratory testing has proven the ability of a metal oxide impregnated carbon to remove low concentrations of sulfur gases from a syn-gas stream. Based on laboratory information, a small-scale unit will be designed and constructed to provide performance data on a slipstream of gas at the Wabash River plant.

\subsection{Basis for design}

The unit will operate on two different gas streams, the WREL dry product syngas and on a gas downstream of the Direct Sulfur Oxidation slipstream unit.

$\begin{array}{ll}\text { Process Flow: } & 2 \text { acfm } \\ \text { Temperature: } & 100{ }^{\circ} \mathrm{F} \text { to } 120^{\circ} \mathrm{F} \\ \text { Pressure: } & 350 \mathrm{psig} \\ & \\ \text { Stream Composition: } & \\ & \\ \text { Carbon Monoxide: } & 45 \% \\ \text { Carbon Dioxide } & 16 \% \\ \text { Hydrogen } & 35 \% \\ \text { H2S Concentration: } & \text { up to } 300 \mathrm{ppmv} \\ \text { COS Concentration: } & \text { up to } 30 \mathrm{ppmv}\end{array}$

\subsection{Process Description}

The process is shown in the attached Drawing no. CH-101-01

The adsorber will be 4 " diameter pipe with a $2 \mathrm{ft}$ deep bed. It will be heated externally to allow regeneration temperatures to be maintained. The process piping will be $5 / 8$ ” metal tubing.

\section{Adsorption cycle}

The adsorption cycle is intended to proceed overnight. The level of saturation of the bed will depend on the concentration. The regeneration system will be isolated from the adsorber by closing manual valves HV-14 and HV-15. The adsorption system will be connected with the feed gas by opening valve HV-13. The adsorber will be allowed to pressurize and valve HV-13 will then be closed to perform a leak test. The length of time and allowable pressure loss will be determined at startup. Valve HV13 will then be reopened and HV-16 will be opened to allow flow through the vessel to the pipeline. The process control system will detect the flow rate from FT-01 and regulate $\mathrm{FV}-01$ at the preset value. 
Gas samples will be taken at the inlet and outlet of the bed and transmitted to the analyzer system supplied by the plant. Provision will be made to periodically sample the gas with Draeger tubes to confirm the analyzer data. The pressure and temperature of the inlet and outlet gas will be monitored by PT-02, TT-03 and TT-07. The adsorption process will run automatically overnight. It is recommended that an operator periodically observe the unit and record the pressure at gauge PI-08, and the differential pressure at DPI-05.

Safety shutdown will occur if readings from TT-04, TT-07, PT-02, or FT-01 exceed set points.

\section{Regeneration Cycle}

The regeneration cycle will be performed during the day. The adsorption system will be isolated by closing valves HV-13 and HV-16. Valve HV-15 will be opened to depressurize the adsorber and allow the gas to flow to the waste gas header. Valve HV-14 will then be opened to allow regeneration gas to flow through the adsorber.

To begin the regeneration cycle, valve HV-15 must be opened. The automated system will then be started and the nitrogen flow will be regulated by FV-12, which is controlled through FIT-12. Pressure regulator PRV-17 will maintain 50 psig on gauge PI-08. Heater HX002 will then be turned on and the gas will be heated to 500 ${ }^{\circ} \mathrm{F}$ as indicated by TT-03. Heater HX001 will be turned on to maintain temperature within the adsorber. If the temperature as measured by TT-03 exceeds set point value, HX002 will be shut off. If the flow as measured by FT-12 is lower than the FAL set point value, HX002 will be shut off.

When the temperature as measured at TT- 07 reaches $350^{\circ} \mathrm{F}$, the compressed air will be introduced by opening XV-24. The amount of Oxygen will be controlled to a level of $0.5 \%$ by setting the correct flow reading on FI-22 by adjusting flow using HV-23. If the temperature measured at TT-07 exceeds the set point value, closing XV-24 will stop the compressed air flow.

The time required to complete regeneration based on the outlet oxygen content in the outlet gas will be determined at startup. This time will become the set point for ending the heating step. At that time, Heater HX002 and Heater HX001 will be shut off. Closing XV-24 will shut off compressed air flow. Nitrogen will continue to flow until the temperature measured by TT-07 reaches $100^{\circ} \mathrm{F}$.

\subsection{Control system}

The process will be automatically controlled by a PLC. The start of the adsorption and regeneration cycles will be done manually. Data will be recorded 
NUCON International, Inc.

P.O. Box 29151 Columbus, Ohio 43229

FAILURE ANALYSIS

PROJECT $\quad$ 06CONPH1170

ITEM ADSORB STREAM

\begin{tabular}{|c|c|c|c|c|}
\hline Designation & Failure Model/Type & Consequence & Design Precaution & Remedial Action \\
\hline & Temp too high & $\begin{array}{l}\text { Reduced performance and } \\
\text { possible equipment damage }\end{array}$ & $\begin{array}{l}\text { Alarm from TT03@150F, } \\
\text { shutdown@ } 300^{\circ} \mathrm{F} .\end{array}$ & \\
\hline & Temp too low & Reduced performance & No safety/performance issues & \\
\hline & Pressure too high & $\begin{array}{l}\text { Possible equipment } \\
\text { damage/rupture }\end{array}$ & Relief valve on inlet to adsorber & \\
\hline & Pressure too low & Reverse flow from pipeline & None & Consider adding low flow alarm \\
\hline & Flow too high & Fluidize bed & Screen on outlet nozzle \& filter & \\
\hline & Flow too low & None & & Consider adding low flow alarm \\
\hline & Wrong flow/valve lineup & $\begin{array}{l}\text { Syngas to waste header } \\
\text { Syngas to utility supplies } \\
\text { Pipeline to wastegas } \\
\text { Pipeline to utlilties }\end{array}$ & $\begin{array}{l}\text { Utility lines contain check valves } \\
\text { but these may not be completely } \\
\text { leak tight. }\end{array}$ & Client to advise consequences \\
\hline & & & & \\
\hline & & & & \\
\hline & & & & \\
\hline & & & & \\
\hline & & & & \\
\hline
\end{tabular}


NUCON International, Inc.

P.O. Box 29151 Columbus, Ohio 43229

FAILURE ANALYSIS

PROJECT $\quad$ 06CONPH1170

ITEM REGEN STREAM

\begin{tabular}{|c|c|c|c|c|}
\hline Designation & Failure Model/Type & Consequence & Design Precaution & Remedial Action \\
\hline & $\begin{array}{l}\text { Temp too high/control } \\
\text { failure }\end{array}$ & $\begin{array}{l}\text { Possible equipment damage } \\
\text { Note: ignition of carbon not } \\
\text { likely w/o additional failure } \\
\text { of compressed air system }\end{array}$ & Hi temp alarms & \\
\hline & Temp too low & $\begin{array}{l}\text { Inability to regen / } \\
\text { incomplete regen }\end{array}$ & Temp alarms & \\
\hline & Pressure too high & $\begin{array}{l}\text { Reduced/no ability to add } \\
\text { air }\end{array}$ & PI25 gives local indication & \\
\hline & Pressure too low & $\begin{array}{l}\text { Extended regen } \\
\text { Heater damage } \\
\text { Incorrect composition (too } \\
\text { high } \mathrm{O}_{2} \text { concentration) }\end{array}$ & $\begin{array}{l}\text { Sheath overtemp protection shuts } \\
\text { off heater; manual reset required }\end{array}$ & \\
\hline & Flow too high & $\begin{array}{l}\text { Fluidize bed } \\
\text { Reduced capacity of heater } \\
\text { Increased regen time and/or } \\
\text { incomplete regen }\end{array}$ & $\begin{array}{l}\text { Screen on outlet nozzle \& filter } \\
\text { High flow alarm }\end{array}$ & \\
\hline
\end{tabular}


NUCON International, Inc.

P.O. Box 29151 Columbus, Ohio 43229

\section{FAILURE ANALYSIS}

PROJECT

06CONPH1170

ITEM REGEN STREAM

\begin{tabular}{||l|l|l|l|l||}
\hline \hline $\begin{array}{c}\text { Designation } \\
\text { Tag. No. }\end{array}$ & \multicolumn{1}{|c|}{ Failure Model/Type } & \multicolumn{1}{|c|}{ Consequence } & \multicolumn{1}{|c|}{ Design Precaution } & Remedial Action \\
\hline & Flow too low & Reduced/no ability to regen & $\begin{array}{l}\text { Possible overheating of } \\
\text { HX002 }\end{array}$ & $\begin{array}{l}\text { FAL12 and sheath overtemp } \\
\text { monitor shuts off heater. }\end{array}$ \\
& Oxygen content too high - \\
& possible fire & $\begin{array}{l}\text { Carbon ignition temperature } \\
\text { higher than regen temperature } \\
\text { Low nitrogen flow or TAH07 } \\
\text { shuts off compressed air. }\end{array}$ & \\
\hline
\end{tabular}




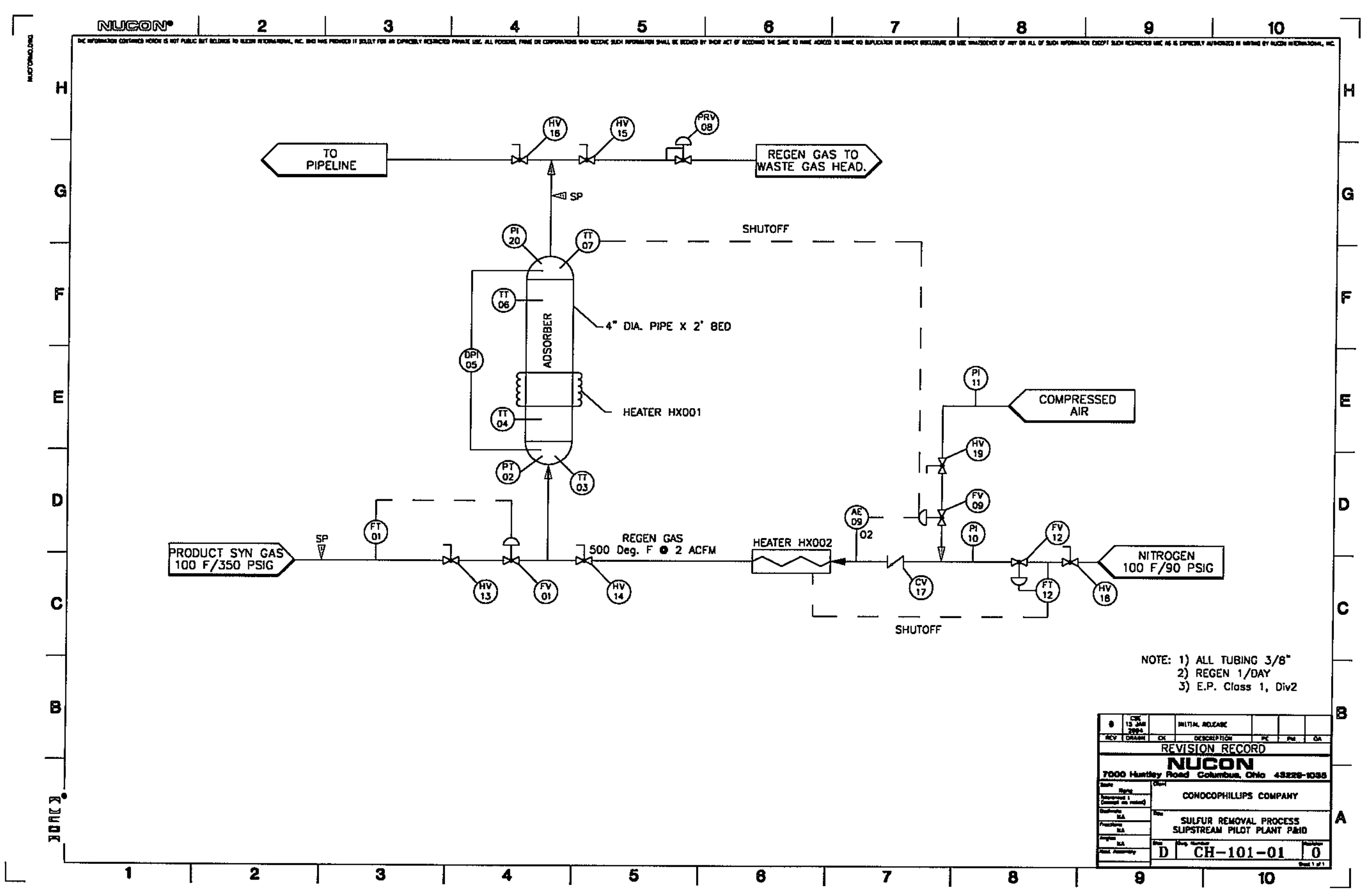




\title{
Appendix B
}

\author{
H2S Adsorption Chart \\ COS Adsorption Chart
}


Figure 1, H2S Outlet Concentration

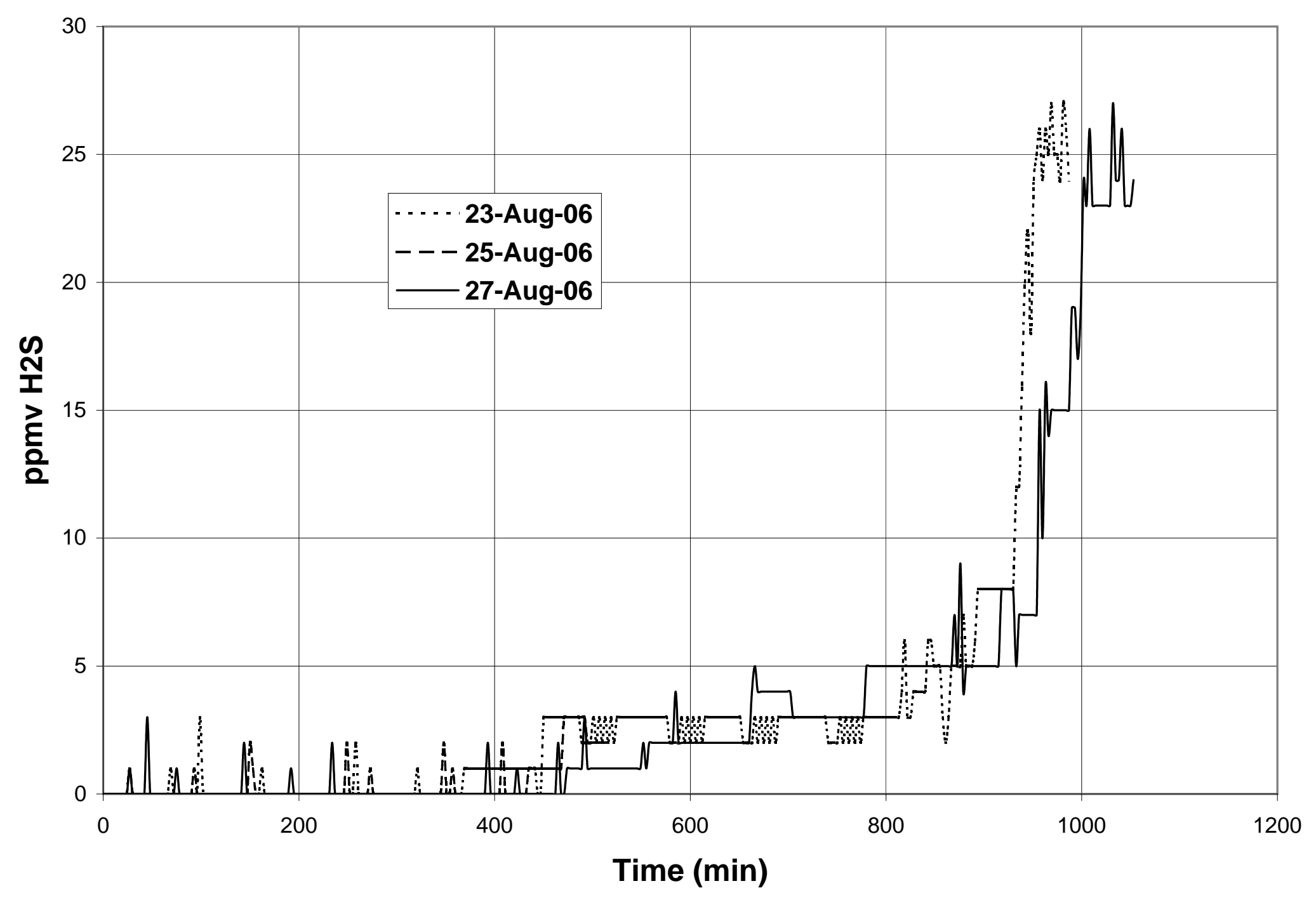




\section{COS breakthrough Concentration, ppmv}

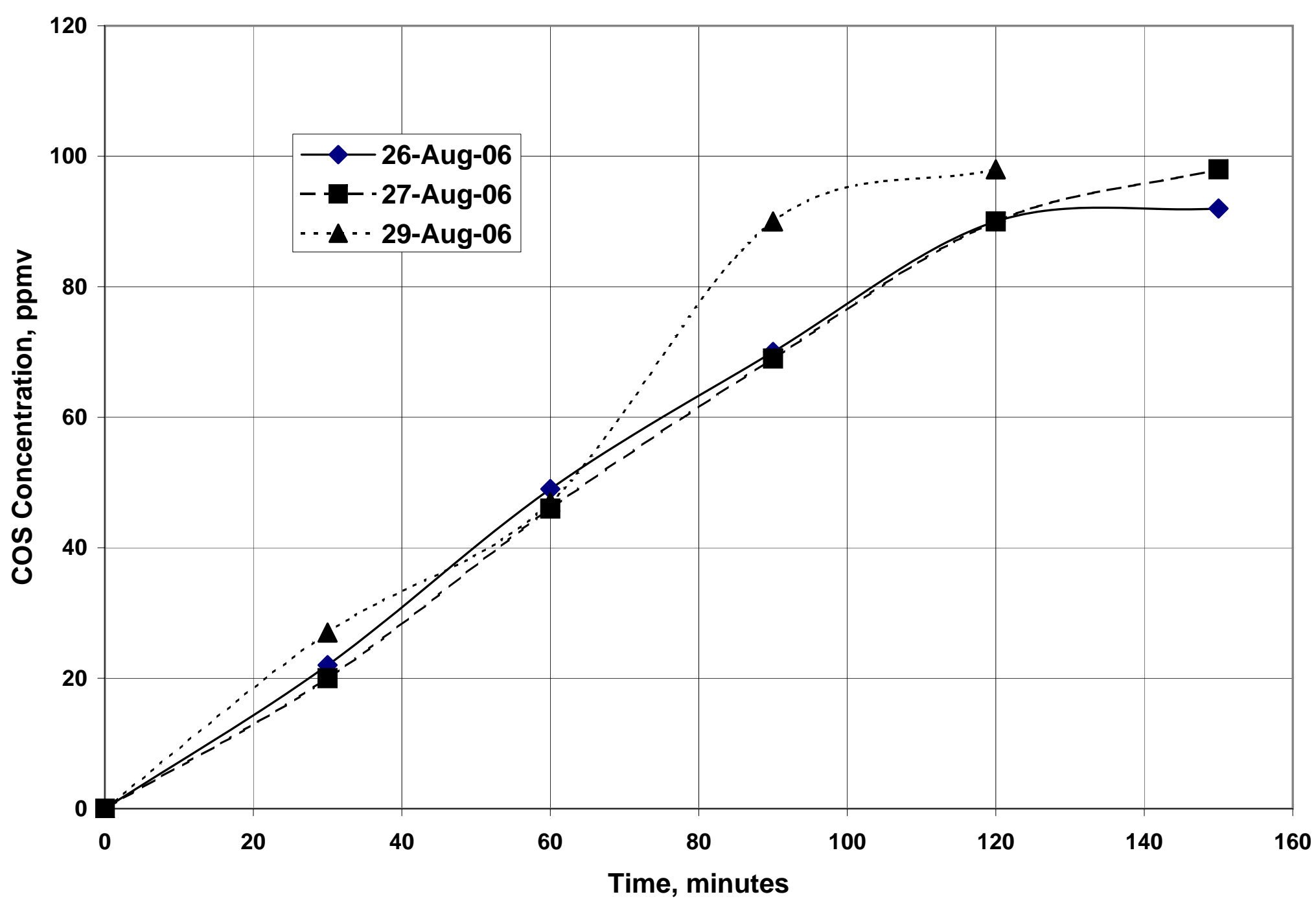




\section{APPENDIX III}

Topical Report from ConocoPhillips

On

\section{“TESTING OF CONOCOPHILLIPS' SORBENT FOR REMOVAL OF SULFUR FROM SYNGAS \\ AT HIGH TEMPERATURE"}




\section{Testing of ConocoPhillips' Sorbent for Removal of Sulfur from Syngas at High Temperature}

\section{Topical Report}

Phase II, Task 2.5

July 10, 2007

Prepared for

U.S. Department of Energy

Cooperative Agreement No. DE-FC26-99FT40659

by

ConocoPhillips Company

600 N. Dairy Ashford

Houston, Texas 77079-1175 


\section{DISCLAIMER}

This report was prepared by ConocoPhillips Company as an account of work pursuant to a cooperative agreement partially sponsored by an agency of the United Sates Department of Energy. Neither the ConocoPhillips Company, nor any of its subcontractors, nor the United States Department of Energy, nor any person or agency acting on behalf of either:

(A) Makes any warranty, express or implied, or assumes any legal liability or responsibility for the accuracy. Completeness, or usefulness of any information, apparatus, product or process disclosed, or represents that its use would not infringe privately owned rights.

(B) Assumes any liabilities with respect to the use of, or for damages resulting from the use of any information, apparatus, method or process disclosed in this report.

Reference herein to any specific commercial product, process, or service by trade name, trademark, manufacturer, or otherwise does not necessarily constitute or imply its endorsement, recommendation, or favoring by the United States Department of Energy nor any agency thereof. The views and opinions of authors expressed therein do not necessarily state or reflect those of the United States Department of Energy or any agency thereof. 


\section{EXECUTIVE SUMMARY}

Synthesis gas (Syngas) is commonly produced from the gasification of coal and other carbonaceous materials. Once cleaned, the syngas can be used to produce electricity, fuels, and chemicals. Phase II of the Wabash River Integrated Methanol and Power Production from Clean Coal Technologies (IMPPCCT) Project is focused on identifying, testing, and evaluating novel processes for removing sulfur and trace contaminants present in coal-derived syngas. The target level for removal is set to minimize poisoning of a methanol synthesis catalyst. In addition these processes should be capable of reducing the overall cost of the gasification process. ConocoPhillips Company's S Zorb ${ }^{\mathrm{TM}}$ SRT technology appears to be suited for meeting these objectives.

In this study, ConocoPhillips tested the ability of its new generation of regenerable $\mathrm{S}$ Zorb $^{\mathrm{TM}}$ sulfur sorbents to remove sulfur from the hot raw syngas produced by the E-Gas gasifier located at SG Solutions LLC's Wabash River Coal Gasification Facility in West Terre Haute, Indiana. The sorbent is a commercial product for removing sulfur from gasoline. Sorbent activity and capacity were first measured in a laboratory test unit at pressure and temperature using a feed that simulates the syngas stream from the E-Gas gasifier. Sorbent tolerance for contaminants was determined by a slipstream test conducted at the Wabash Facility.

The sorbent, as tested in a fixed-bed reactor, removed the sulfur contaminants, reaching near theoretical sulfur loading capacity of the sorbent, with very low sulfur levels $(<5 \mathrm{ppm})$ measured at the reactor outlet through all of the absorption cycles. The sorbent is easily regenerated with no degradation of the sorbent observed from the multi-cycle test. Economic analysis showed significant capital cost savings when employing the $S$ Zorb $^{\mathrm{TM}}$ SRT warm gas desulfurization process with the E-Gas technology.

The study was conducted under the Phase II of the IMPPCCT Project, Task 2.5 Implement Updated Research, Development, and Testing Plan. 


\section{TABLE OF CONTENTS}

\section{EXECUTIVE SUMMARY}

\section{INTRODUCTION}

Project Background

ConocoPhillips' S Zorb ${ }^{\mathrm{TM}}$ SRT Process

Testing Plan and Approach

\section{PROJECT TASKS AND RESULTS}

Task 1.0 - Conduct Laboratory Tests to Determine Best Sorbent and Operating Conditions for Slipstream Unit

Task 2.0 - Design and Fabricate Slipstream Unit

Task 3.0 - Install Slipstream Unit

Task 4.0 - Start Up and Perform Testing on Slipstream

Start Up

Performance Testing

Results and Discussions

Task 5.0 - Process Economics

\section{CONCLUSIONS AND RECOMMENDATIONS}

\section{ACKNOWLEDGEMENTS}

\section{REFERENCES}




\section{TESTING OF CONOCOPHILLIPS' SORBENTS FOR REMOVAL OF SULFUR FROM SYNGAS AT HIGH TEMPERATURE}

\section{INTRODUCTION}

\section{Project Background}

Synthesis gas (Syngas) is commonly produced from the gasification of coal and other carbonaceous materials. Once cleaned, the syngas can be used to produce electricity, fuels, and chemicals. Phase II of the Wabash River Integrated Methanol and Power Production from Clean Coal Technologies (IMPPCCT) Project is focused on identifying, testing, and evaluating novel processes for removing sulfur and trace contaminants present in coal-derived syngas. The target level for removal is set to minimize poisoning of a methanol synthesis catalyst. In addition these processes should be capable of reducing the overall cost of the gasification process. ConocoPhillips Company's S Zorb ${ }^{\mathrm{TM}}$ SRT technology appears to be suited for meeting these objectives.

\section{ConocoPhillips' S Zorb ${ }^{\mathrm{TM}}$ SRT Process}

Over the last ten years, ConocoPhillips Company (COP) has devoted significant resources in the development and implementation of the S Zorb ${ }^{\mathrm{TM}}$ SRT process to remove sulfur from gasoline and diesel fuels to meet the U.S. Environmental Protection Agency's ultra low sulfur fuel requirement, which went into effect in 2006. This process is unique in that it uses a fluidized-bed absorbent to remove the sulfur. The proprietary S Zorb ${ }^{\mathrm{TM}}$ sorbent is a descendent of the earlier material, Z Sorb ${ }^{\mathrm{TM}}$, developed to remove mercaptans and hydrogen sulfide $\left(\mathrm{H}_{2} \mathrm{~S}\right)$ in natural gas and syngas applications. The newer $\mathrm{S} \mathrm{Zorb}^{\mathrm{TM}}$ material has significantly improved sorbent properties that include more active metals and better attrition resistance. COP has numerous patents on sulfur removal processes, catalysts, and sorbents. A short list of some of the more significant patents is given in the Reference section [Ref. 1-7].

There are currently four commercial-scale S Zorb ${ }^{\mathrm{TM}}$ SRT units operating in COP refineries and several units licensed to other domestic and international refining companies. Two of these licensed units are already operating with several more under construction. In these gasoline desulfurization units, the gasoline is completely vaporized and mixed with hydrogen. The gas flow rate to the absorber in the COP's Borger, Texas, refinery, the first demonstration unit of the technology, ranges from 10-20 million cubic feet per day. It has been operating since April 2001. The latest unit in COP's Wood River, Missouri refinery has been operating since February 2007 and has gas flow rates through the absorber of approximately 100 million cubic feet per day. The S Zorb ${ }^{\mathrm{TM}}$ SRT absorber is operated at process conditions similar in temperature and pressure to the hot raw unscrubbed syngas produced in the E-Gas gasification process.

A flow sheet for the S Zorb ${ }^{\mathrm{TM}}$ SRT process is shown is Figure 1. Gasoline is mixed with hydrogen, heated and vaporized by heat exchangers and a furnace to approximately $800^{\circ} \mathrm{F}$. 
The feed is then passed through the fluidized-bed absorber with the S Zorb ${ }^{\mathrm{TM}}$ sorbent which is very selective for sulfur compounds. The absorber product gas is cooled, condensed, and passed to a product separator to remove the hydrogen, which is recompressed and recycled. The final gasoline product is again fractionated in a stabilizer to ensure constant product vapor pressures. The sorbent is circulated from the absorber into the regeneration system where in a smaller fluidized-bed, the sulfur on the sorbent is converted to sulfur dioxide $\left(\mathrm{SO}_{2}\right)$ with air.

Figure 1 - S Zorb ${ }^{T M}$ SRT Gasoline Desulfurization Process

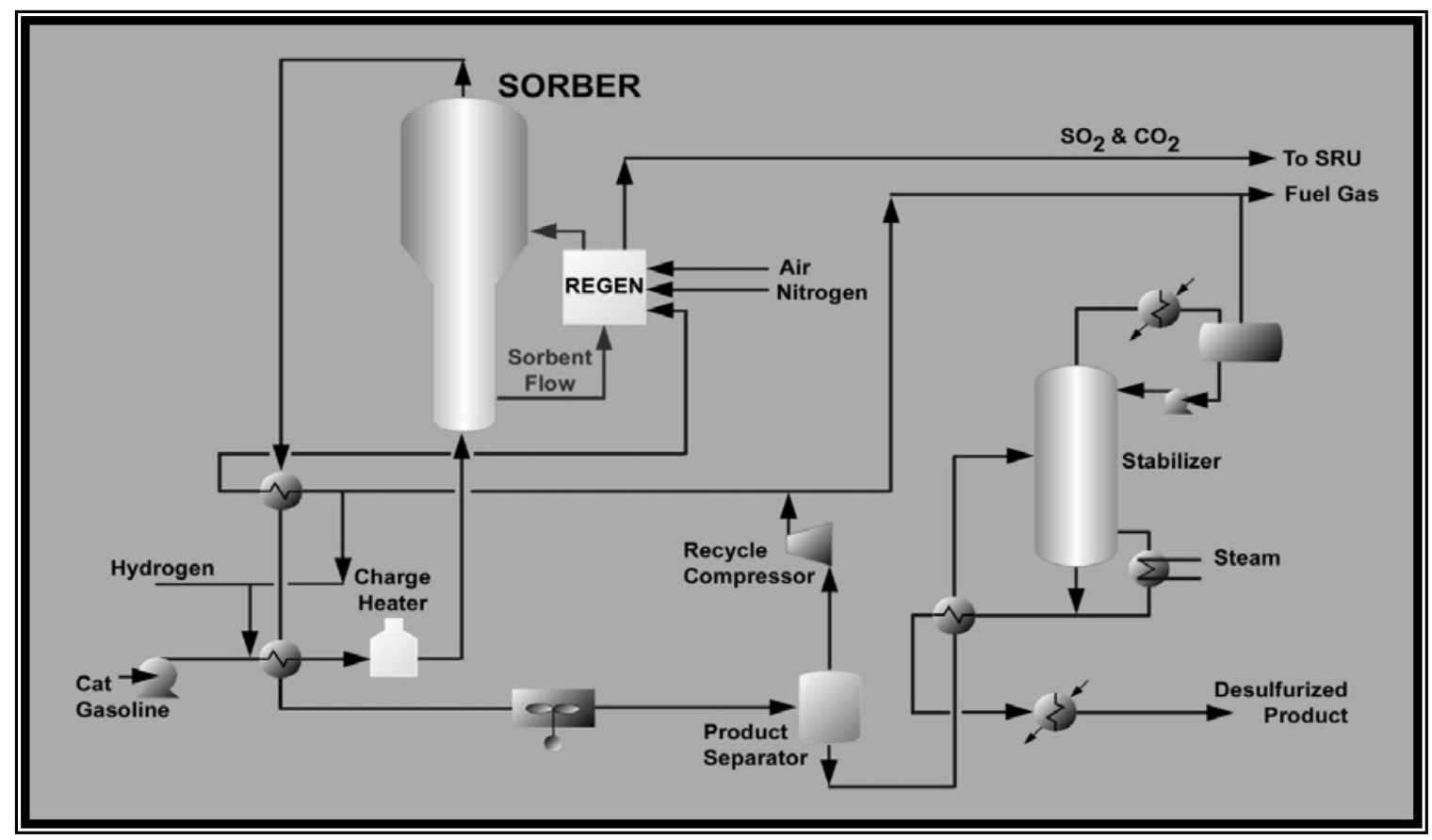

The key differences between syngas and gasoline desulfurization are the amount and type of sulfur compounds in the two feeds. In syngas, the major sulfur compounds are $\mathrm{H}_{2} \mathrm{~S}$ and carbonyl sulfide (COS), while in gasoline, the major sulfur compounds are methylthiophenes and methyl-benzothiophenes. The removal rate for $\mathrm{H}_{2} \mathrm{~S}$ is several orders of magnitude faster than for thiophenic sulfur. Thus it is anticipated that the S Zorb ${ }^{\mathrm{TM}}$ SRT absorber should easily remove $\mathrm{H}_{2} \mathrm{~S}$, leaving less than $1 \mathrm{ppm}$ concentration in the hot product syngas.

COP has accumulated vast experience in developing the S Zorb ${ }^{\mathrm{TM}}$ SRT technology, through testing in bench-scale and pilot plant facilities, scaling up to commercial units, and start ups and operation of these units. On sorbent development, COP has developed the ability to produce commercial-like sorbent on a small scale and has worked with commercial catalyst vendors to translate laboratory formulations into commercial production. Three commercial vendors are currently licensed to produce the material. The current material is made in a much simpler and more economical manner than the previous Z Sorb ${ }^{\mathrm{TM}}$ sorbent and has superior attrition-resistant properties. A test procedure 
has also been developed which provides a more accurate and predictive measurement of sorbent attrition than the standard laboratory tests such as the Davidson Index for fluid catalytic cracking catalysts.

\section{Testing Plan and Approach}

COP's plan was to test the current commercially available S Zorb ${ }^{\mathrm{TM}}$ sorbent for its activity and sulfur removal capacity with a simulated syngas feedstock. If the laboratory tests with the $\mathrm{S}$ Zorb $^{\mathrm{TM}}$ sorbents showed positive results, then further testing with a slipstream unit using actual syngas produced at a coal gasification facility would be conducted to determine the impact of the actual feed composition and contaminants. This slipstream test would be conducted at the SG Solutions LLC (SGS) Wabash River Coal Gasification Facility in West Terre Haute, Indiana.

\section{PROJECT TASKS AND RESULTS}

\section{Task 1.0 - Conduct Laboratory Tests to Determine Best Sorbent and Operating Conditions for the Slipstream Unit}

Activities commenced in January 2005. A bench-scale set up capable of simulating the temperature and pressure in the E-Gas process was constructed in a laboratory in COP's Bartlesville Technology Center in Bartlesville, Oklahoma. A schematic diagram and a photo of the laboratory set up are shown in Figures 2 and 3, respectively. Current commercially available S Zorb ${ }^{\mathrm{TM}}$ sorbent was tested in a fixed-bed, down-flow reactor. A syngas feed with composition similar to the raw syngas produced at the SGS Facility was prepared by a gas blending system. However, the gas had to be diluted with nitrogen at up to $30 \%$ by volume to meet laboratory safety requirements. Absorption reaction conditions of $600-800^{\circ} \mathrm{F}$ at up to 350 psig were investigated. The $\mathrm{S} \mathrm{Zorb}^{\mathrm{TM}}$ sorbent removed $\mathrm{H}_{2} \mathrm{~S}$ to $<1 \mathrm{ppm}$ in all cases until a catalyst loading of approximately $15-18 \%$ by weight of sulfur was reached. The $\mathrm{H}_{2} \mathrm{~S}$ and COS absorption breakthrough curve for the tests is shown in Figure 4.

The ability to regenerate the $\mathrm{S}$ Zorb $^{\mathrm{TM}}$ sorbent was also confirmed in tests after fully loading it with sulfur. The regeneration conditions used were at a temperature between $800-1000^{\circ} \mathrm{F}$, and at atmospheric pressure with air. Regeneration procedures used initially were similar to those used for the commercial $\mathrm{S} \mathrm{Zorb}^{\mathrm{TM}}$ sorbent for gasoline desulfurization applications. Because of the high sulfur content in the syngas compared to in the gasoline, the sulfur loading in the spent sorbent was very high. The regular regeneration procedure would result in uncontrolled burn-off of the sulfur and temperature excursion that would cause permanent deactivation of the sorbent. The procedure was therefore modified to allow a gradual burn-off of the sulfur. The modified regeneration procedure also reduced the regeneration time by approximately $50 \%$ without causing detrimental effects to the sorbent.

Once the absorption and regeneration procedures were optimized, a fifteen-cycle test of loading the sorbent with sulfur and regeneration was conducted and successfully completed. The $\mathrm{S}$ Zorb ${ }^{\mathrm{TM}}$ sorbent removed $\mathrm{H}_{2} \mathrm{~S}$ quantitatively within detection limits of 
$<1 \mathrm{ppm}$ in all fifteen cycles until capacity was reached. No sorbent deterioration was observed over the fifteen cycles. The positive result from the test confirms the stability of the sorbent under conditions typical to the E-Gas gasification process being operated at the SGS Facility.

Completion of the fifteen-cycle test satisfactorily completed all the laboratory testing planned for Task 1.0.

Figure 2 - Schematic of COP S Zorb ${ }^{T M}$ SRT Warm Gas Desulfurization Laboratory Unit

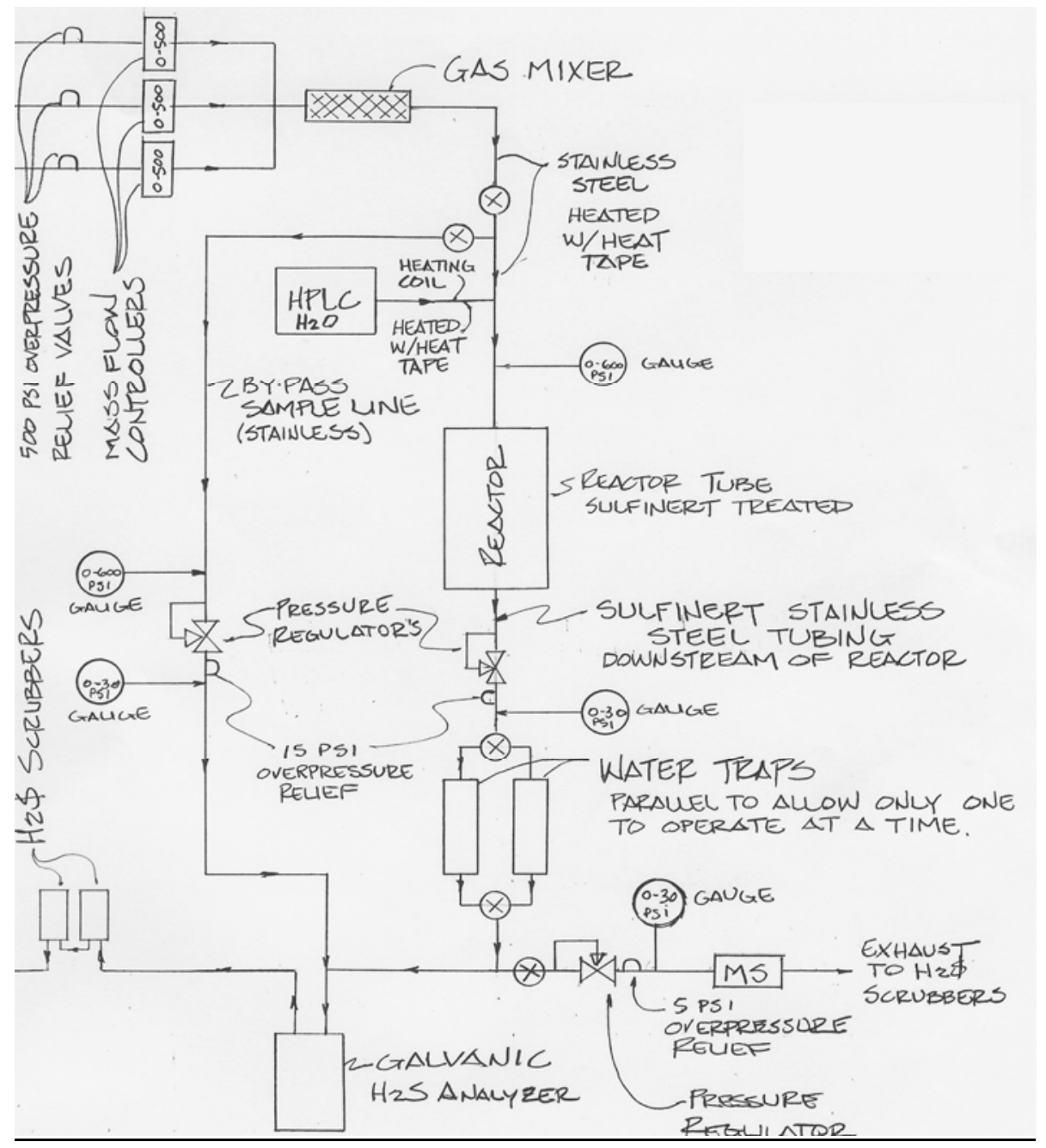


Figure 3 - Photograph of COP S Zorb ${ }^{T M}$ SRT Warm Gas Desulfurization Laboratory Unit

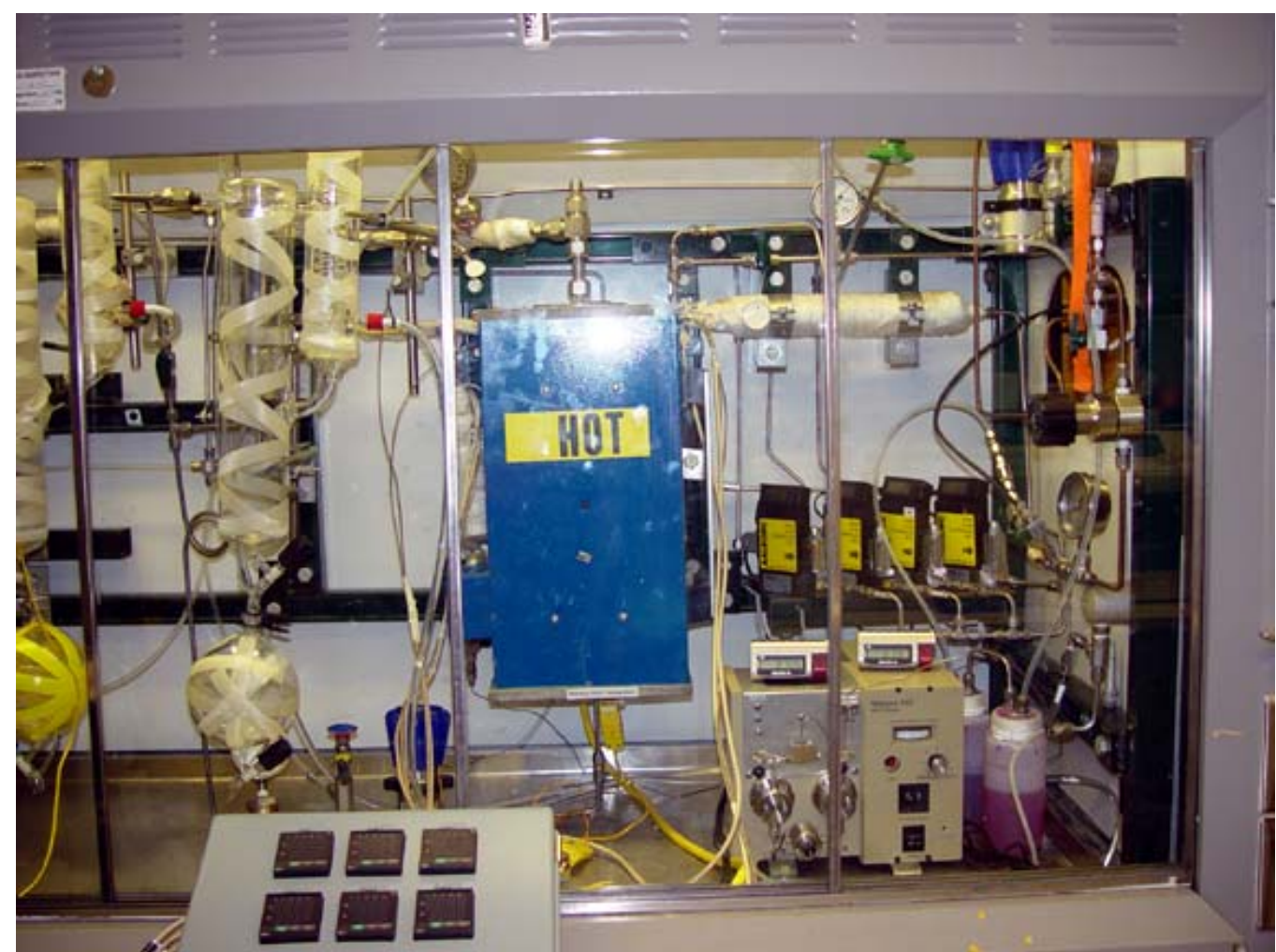

Figure $4-\mathrm{H}_{2} \mathrm{~S} / \mathrm{COS}$ Absorption Breakthrough Curve - S Zorb ${ }^{T M}$ Sorbent

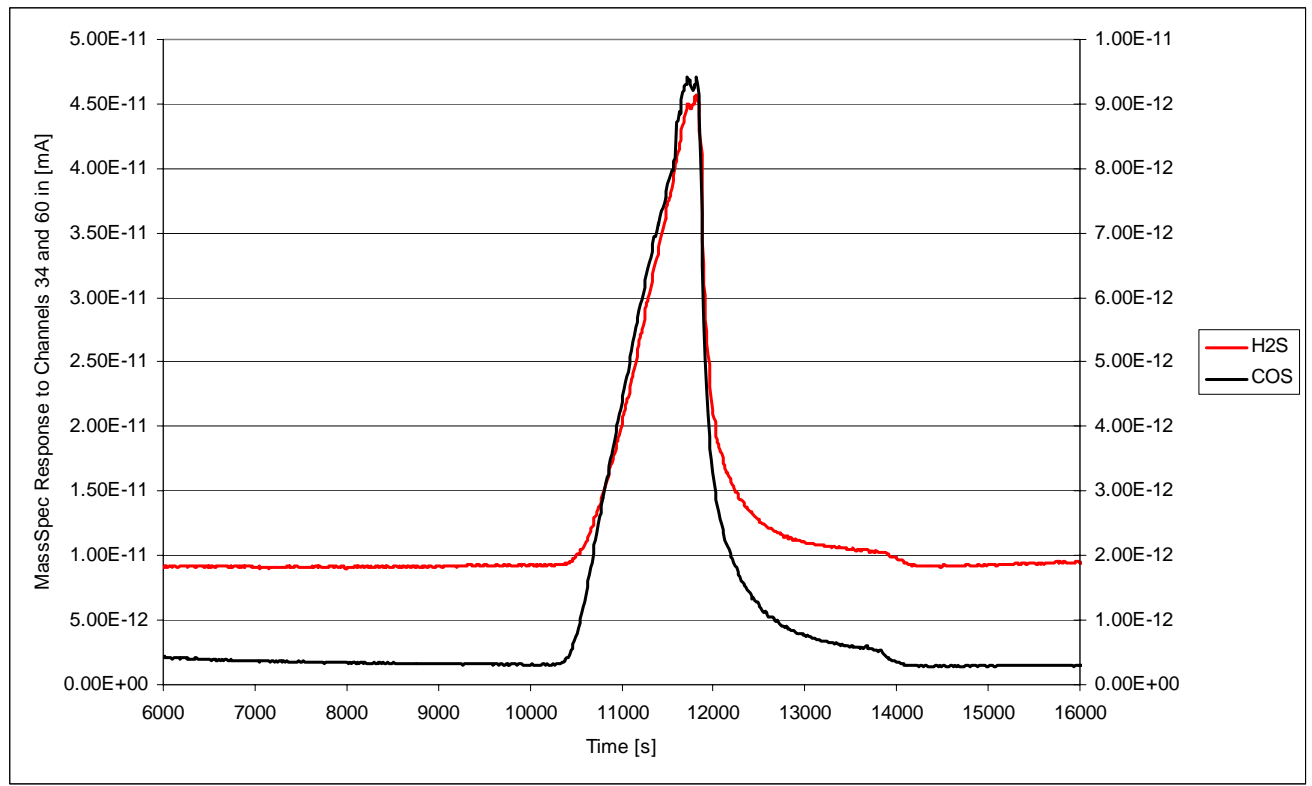




\section{Task 2.0 - Design and Fabricate Slipstream Unit}

After confirming the feasibility of the $\mathrm{S}$ Zorb ${ }^{\mathrm{TM}}$ technology for syngas application in the laboratory tests, work was initiated in May 2005 to prepare a slipstream unit for transport and testing at the SGS Facility. The unit was housed in a mobile trailer used previously for environmental sampling at refineries.

An absorber unit was designed, constructed, and delivered to the SGS Facility. This slipstream unit includes an absorber vessel, electric heater, flow measurement devices, pressure control, and online process analysis for $\mathrm{H}_{2} \mathrm{~S}$ similar to the laboratory unit constructed and tested in Task 1.0. Some minor modifications were made to the mobile trailer in order to meet plant electrical and safety requirements. Construction and system check out of the slipstream unit was completed in August 2005, and the unit was delivered to the SGS Facility on September 1, 2005. Photographs in Figures 5-7 show the bench-scale slipstream unit as it was installed in the mobile trailer.

Figure 5 - S Zorb ${ }^{T M}$ SRT Slipstream Test Unit Installed in Mobile Trailer

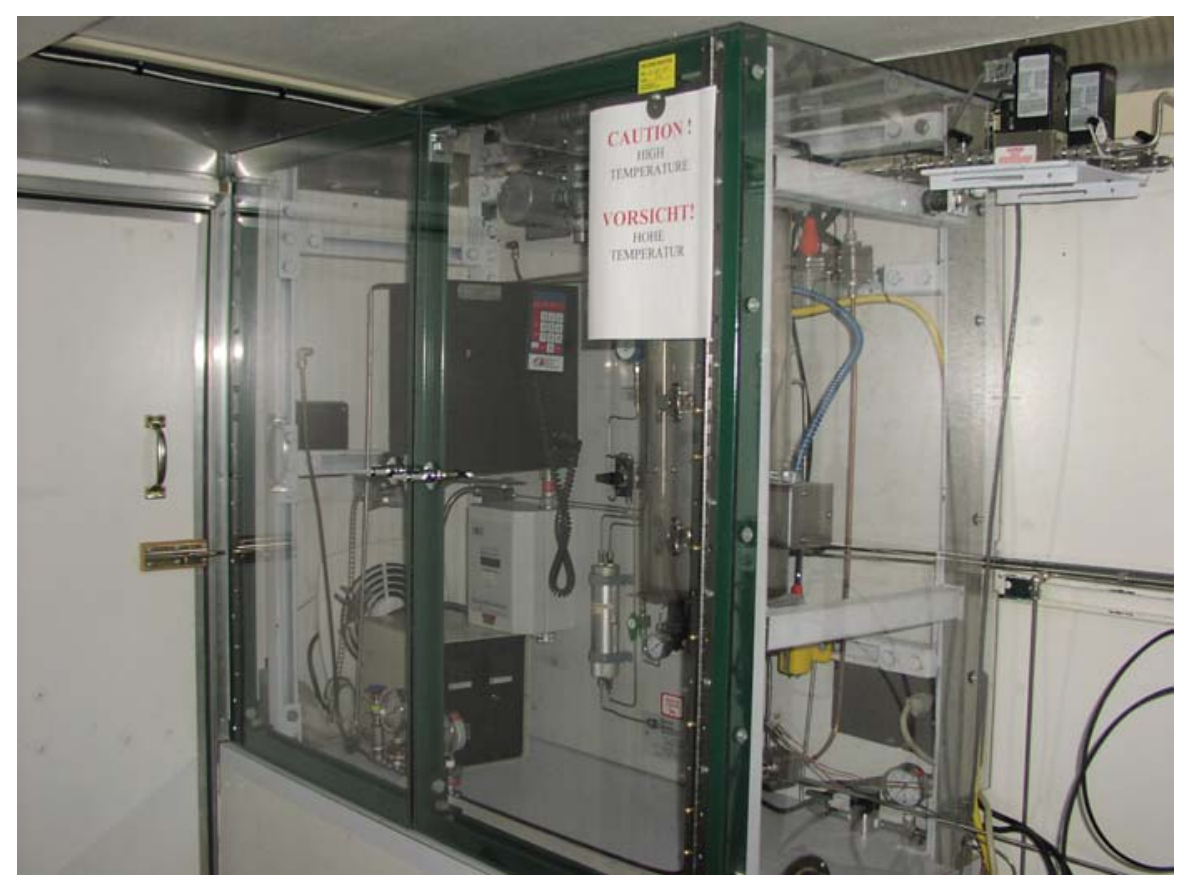


Figure 6-S Zorb ${ }^{T M}$ SRT Slipstream Test Unit Installed in Mobile Trailer

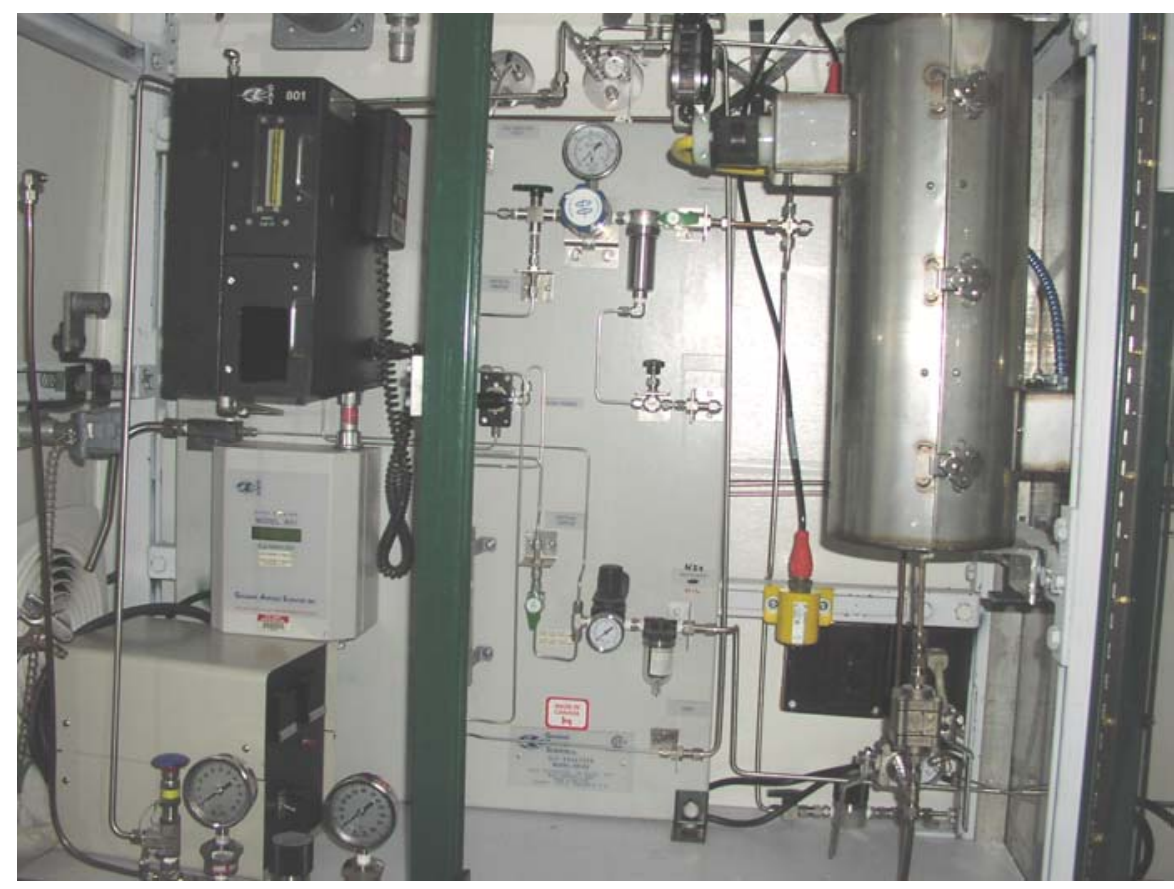

Figure 7 - S Zorb ${ }^{T M}$ SRT Slipstream Test Unit Installed in Mobile Trailer

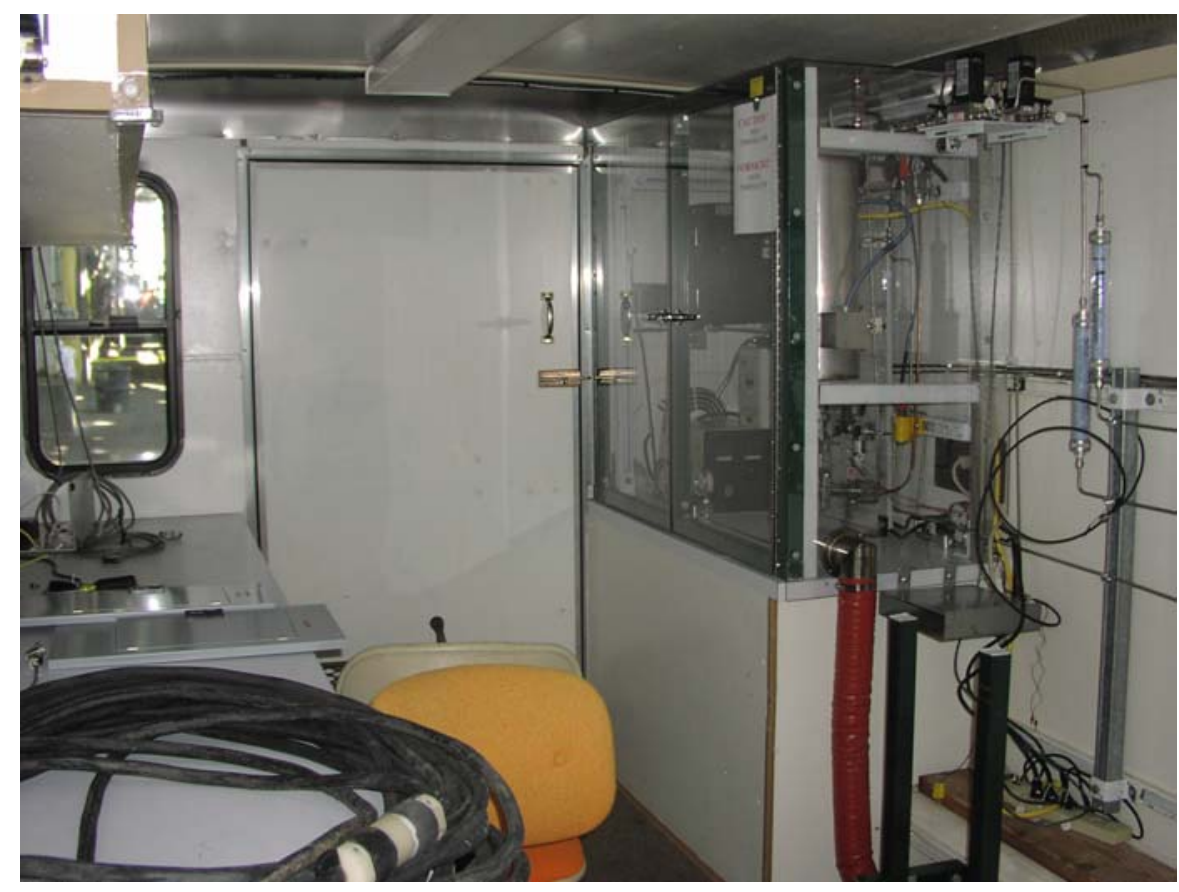




\section{Task 3.0 - Install Slipstream Unit}

The installation of the slipstream unit was done primarily with on-site subcontractors under the supervision of COP personnel at the SGS Facility. Heat-traced syngas sample tubing from the gasification piping system was installed and connected to the slipstream unit, and product gases from the slipstream unit were routed into the tank vent system in the SGS Facility. Utilities were provided by the SGS Facility distribution system and were connected to the slipstream unit. System checkout was performed under the direction of the SGS operating personnel with the assistance of COP personnel. Installation of the slipstream unit was completed in early October 2005, prior to SGS Facility's fall maintenance outage. Figure 8 shows the mobile trailer unit installed at the SGS Facility.

Figure 8-S Zorb ${ }^{T M}$ Slipstream Test Mobile Trailer Unit Installed in SGS Facility

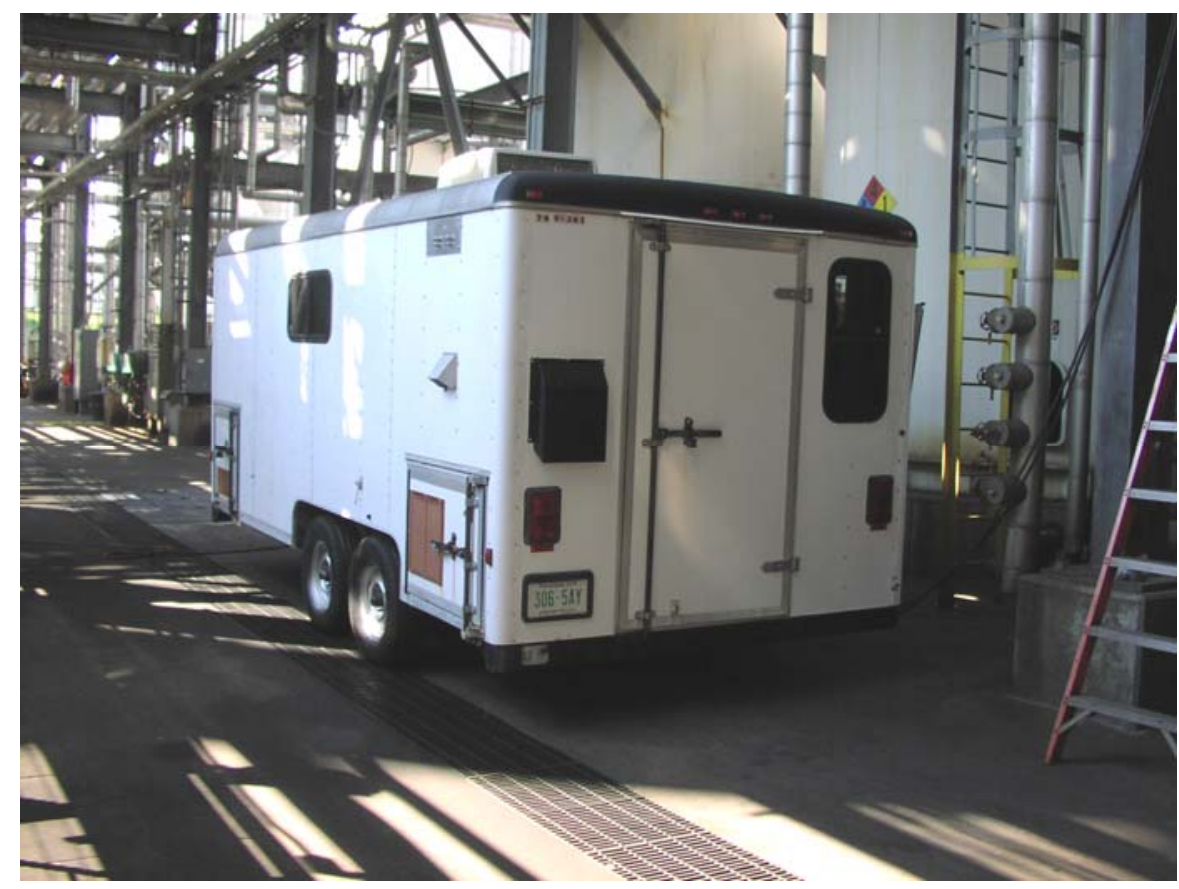

\section{Task 4.0 - Start Up and Perform Testing on Slipstream}

\section{Startup}

Startup activities commenced in November 2005 when the SGS Facility returned to normal operation. A thorough pre-startup safety audit was conducted by COP and SGS operations personnel, and the safety protocols and standard operating procedures (SOP) were reviewed. No major issues were identified that would prevent the start up and operation of the unit. Recommendations from the review were implemented.

The initial attempt to operate the bench-scale slipstream unit in record cold, single digit temperatures for the Terre Haute area proved to be challenging. Since the dew point of the feed gas is $>300^{\circ} \mathrm{F}$ and the flow to the slipstream unit was very low, extensive additional heat tracing and insulation were required both outside and inside the trailer on 
all sample and analyzer feed lines. Other problems encountered during the startup included syngas flow measurement and control, several valves not sealing properly, analyzer malfunctioning, exhaust gas line freezing, etc. These problems were resolved and an initial test with S Zorb ${ }^{\mathrm{TM}}$ sorbent was conducted on December 1, 2005.

\section{Performance Testing}

In this test, raw, filtered but unscrubbed syngas produced by the SGS Facility was continuously fed to the slipstream unit at process temperatures and pressures. The sorbent was placed in a down-flow fixed-bed reactor and heated to $420^{\circ} \mathrm{C}\left(788^{\circ} \mathrm{F}\right)$. The unit operated at 408 psig, which was the operating pressure of the SGS system. The electrically heat traced sample tubing prevented the moisture in the feed syngas from condensing.

After each absorption cycle, the $\mathrm{S} \mathrm{Zorb}^{\mathrm{TM}}$ sorbent was regenerated in air at elevated temperatures. Hot nitrogen dried the sorbent prior to air introduction. The regeneration starting conditions were $400^{\circ} \mathrm{C}\left(752^{\circ} \mathrm{F}\right)$ and $100 \mathrm{ml} / \mathrm{min}$ air flow. Both parameters were increased stepwise to a final setting of $550^{\circ} \mathrm{C}\left(1022^{\circ} \mathrm{F}\right)$ at $30-50^{\circ} \mathrm{C}$ increments and an air flow of $1 \mathrm{~L} / \mathrm{min}$ at $250 \mathrm{ml} / \mathrm{min}$ increments. Oxygen and $\mathrm{SO}_{2}$ levels were monitored in the combustion off-gases to determine that the regeneration was complete.

Initial results from the absorption and regeneration cycles showed that the sorbent bed was removing $\mathrm{H}_{2} \mathrm{~S}$ and COS effectively, and that the sorbent can be easily regenerated. After all operational problems were resolved and the operational procedures refined, the sorbent was subjected to an one absorption-regeneration cycle a day operation.

Six sulfur loading and sorbent regeneration cycles, under plant conditions, were performed. Sulfur breakthrough was measured by a Galvanic Sulfur Analyzer (Galvanics Applied Science, Model 902D2) that has the capability to measure sulfur species to a detection limit of less than $1 \mathrm{ppm}$. Other components in the stream were analyzed by online mass spectrometry (ESS EcoSys Instrument). When loaded with sulfur, the spent sorbent was regenerated with air and reused in the next cycle. Oxygen uptake and $\mathrm{SO}_{2}$ generation, as measured by mass spectrometry, determined the regeneration time.

In order to investigate changes to the sorbent during loading and regeneration, samples were taken after each sulfur loading and regeneration experiment from the top of the sorbent bed. These samples were analyzed by x-ray fluorescence (XRF) to determine the sulfur loading and the amount of sulfur that remained after regeneration, and by $\mathrm{x}$-ray diffraction (XRD) to determine if any changes occurred to the sorbent structure. In addition carbon, hydrogen, nitrogen, and sulfur analysis and attrition tests were performed on selected samples of the sorbent to further assess changes to the sorbent during the loading and regeneration cycles.

An attempt was made to determine the ability of the sorbent to capture mercury. However, since the facility was operating on a petroleum coke feedstock at the time instead of coal, the mercury level in the syngas was too low to be measured accurately.

The slipstream testing was completed in mid-December, 2005. 


\section{$\underline{\text { Results \& Discussion }}$}

The $\mathrm{S}$ Zorb $^{\mathrm{TM}}$ sorbent removed sulfur in the syngas from $>1.2 \mathrm{~mol} \%$ down to the analyzer's detection limit of $1-4 \mathrm{ppm}$. Removal efficiencies of $>99.97 \%$ were achieved for a period of about 1.5 hours as shown in Figure 9. As shown in the plot, the S Zorb ${ }^{\mathrm{TM}}$ sorbent continued to remove sulfur even after its detection for several hours. The removal efficiency remained between 98-92 \% for several hours before reaching the termination point of 1000 ppm set for the experiment.

Figure 9 - Total Sulfur Removal Measured by a Galvanic Sulfur Analyzer

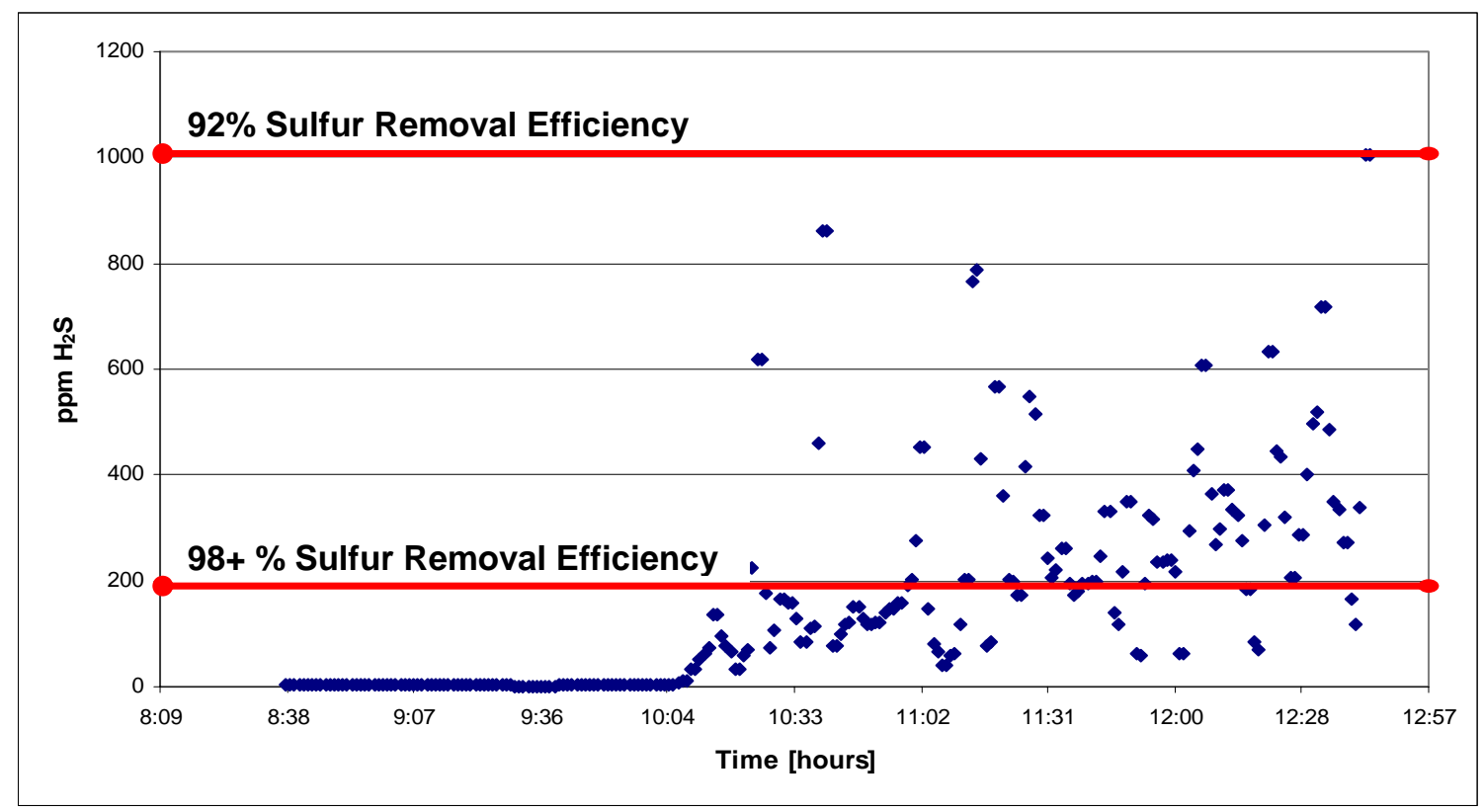

The S Zorb ${ }^{\mathrm{TM}}$ sorbent also removed COS and hydrogen chloride (HCl) to their detection limit. These feed contaminants broke through simultaneously with the $\mathrm{H}_{2} \mathrm{~S}$ as shown in Figure 10. Ammonia and hydrogen cyanide were not removed and passed through the sorbent bed undisturbed.

During sulfur loading a small amount of carbon deposited as coke on the sorbent. The carbon deposits varied between 0.2-0.5 wt\%. During regeneration this coke burned-off as $\mathrm{CO}_{2}$ before $\mathrm{SO}_{2}$ was detected from combustion of sulfur deposits as shown in Figure 11. An attrition test conducted on the spent sorbent showed that it did not soften after multiple loading and regeneration cycles. 
Figure 10 - Corresponding Mass Spectrometer Data at Sulfur Breakthrough

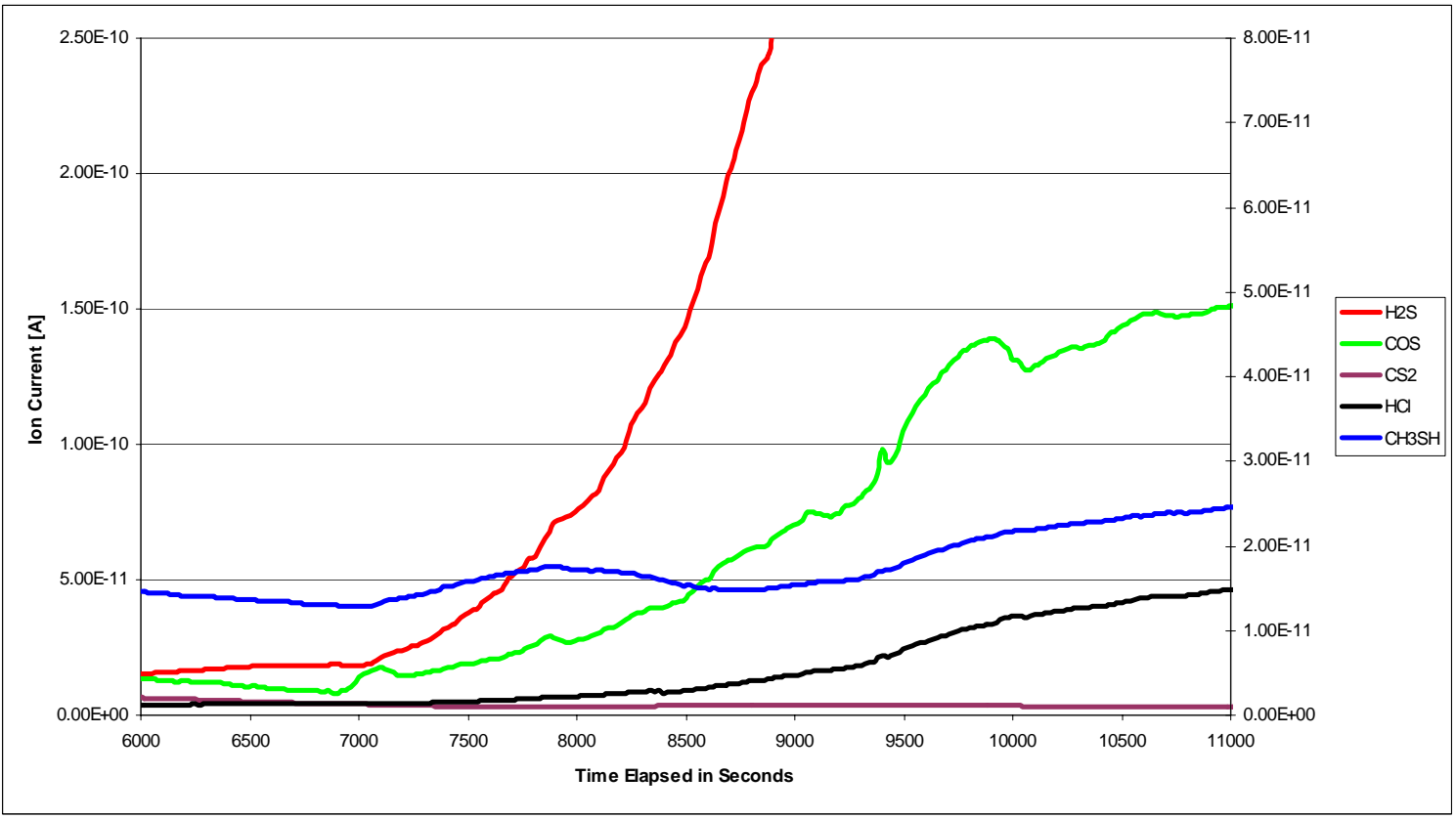

Figure 11 - Mass Spectrometer Data of Sorbent Regeneration

(Note: $\mathrm{CO}_{2}$ scale is approximately $40 x$ smaller than the $\mathrm{SO}_{2} / \mathrm{O}_{2}$ scale.)

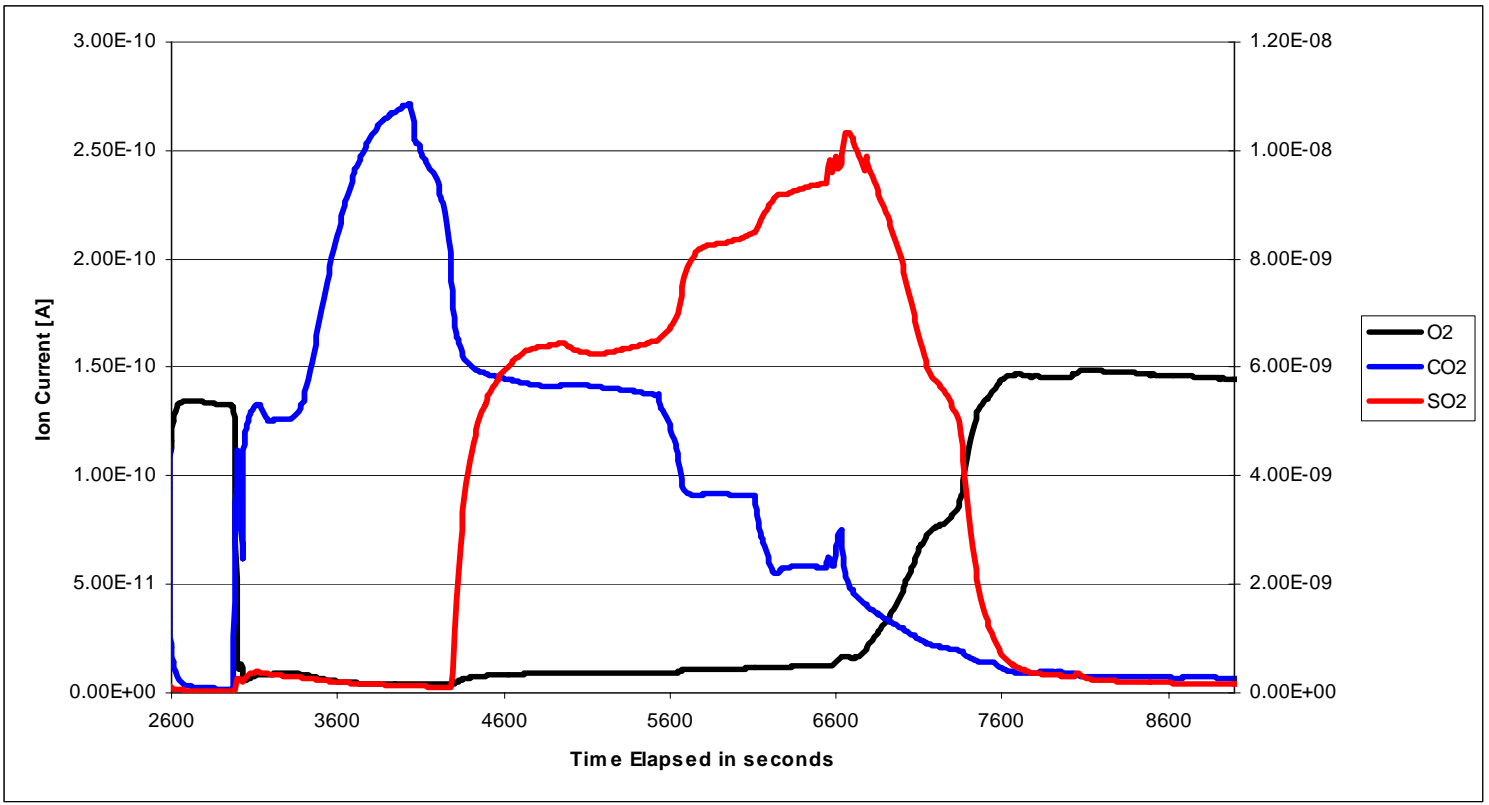


Sulfur Loading Capacity: XRF examination showed an average of $25.9 \mathrm{wt} \%$ sulfur loading on the sorbent samples taken from the top of the sorbent bed as shown in Figure 13.

In a separate experiment from the six-cycle test, after loading the sorbent to sulfur breakthrough, the absorber bed was unloaded in four different sections and each section analyzed separately. These samples showed sulfur loadings ranging from $20.2 \mathrm{wt} \%$ at the top to $16.9 \mathrm{wt} \%$ at the bottom of the sorbent bed as shown in Figure 12.

Figure 12 - Sulfur Loading at Various Sorbent Zones.

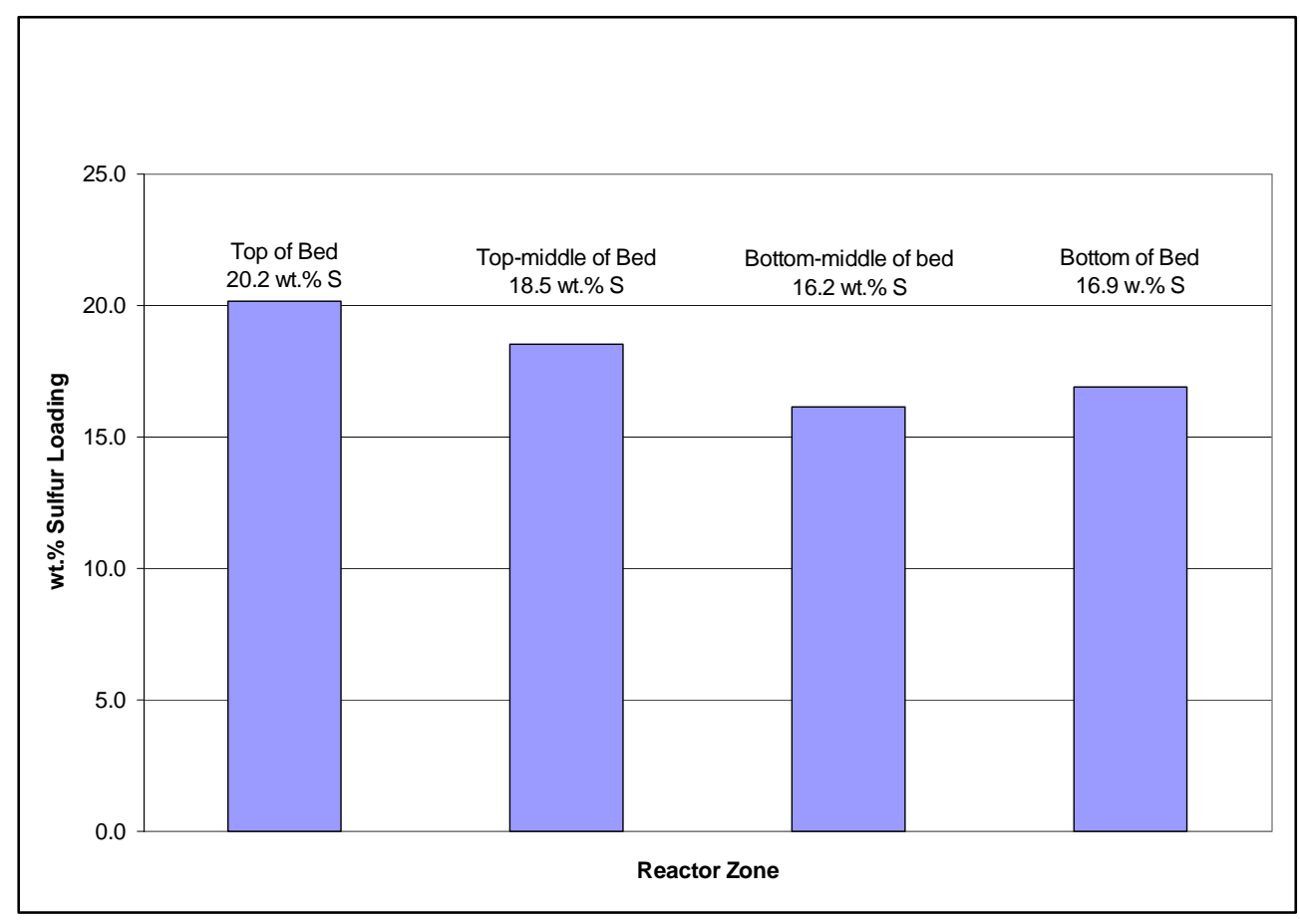

Sulfur Remaining after Regeneration: In the six-cycle experiment an average of $3.5 \mathrm{wt} . \%$ sulfur remained on the sorbent as shown in Figure 13, with an average regeneration efficiency of $87.5 \%$ (sulfur content after regeneration vs. sulfur content after sulfur absorption). This residual sulfur level is deemed adequate for a continuously operated system with closed loop aborption-regenration cycle, and complete regeneration is not necessary. 
Figure 13 - Sulfur Loading Before and After Regeneration

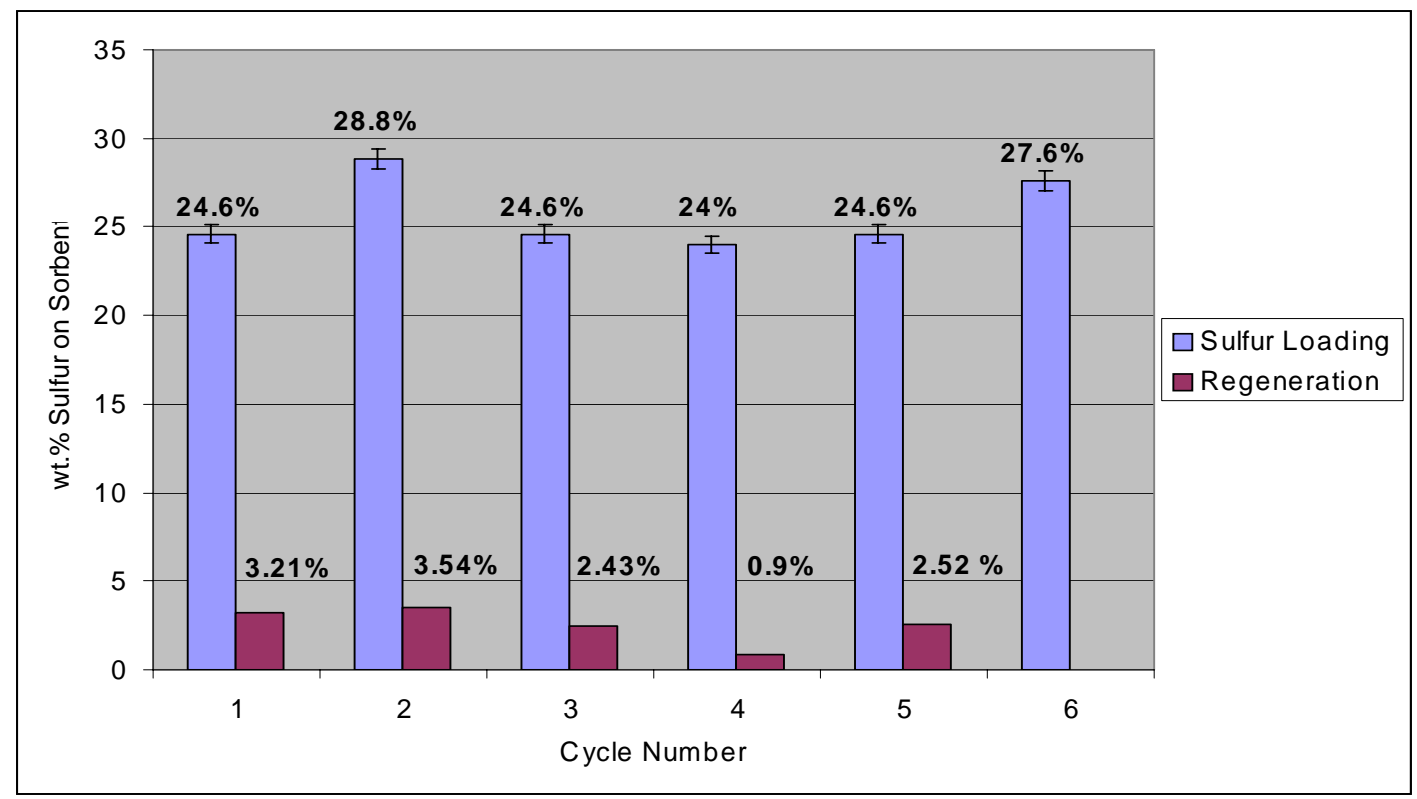

\section{Task 5.0 - Process Economics}

In view of the encouraging slipstream test results, a process and economic evaluation of the S Zorb ${ }^{\mathrm{TM}}$ warm gas desulfurization technology integrated into the E-Gas process was undertaken by the COP Gasification Process Engineering Group. This evaluation was not planned in the original work scope. A conventional amine-based syngas cleanup scheme shown in Figure 14 was compared to the S Zorb ${ }^{\mathrm{TM}}$ SRT warm gas cleanup scheme, shown in Figure 15. The conventional S Zorb ${ }^{\mathrm{TM}}$ system design being used for the refinery application was assumed. This includes a fluidized-bed reactor and a continuous sorbent regeneration system as shown in Figure 1. Regeneration gas is oncethrough, heated dry air. Offgas from the regenerator, containing nitrogen, oxygen, carbon monoxide, carbon dioxide, and sulfur oxides, is used for sulfuric acid production in a conventional sulfuric acid plant.

Figure 14 - Convention Amine-Based Syngas Cleanup Scheme

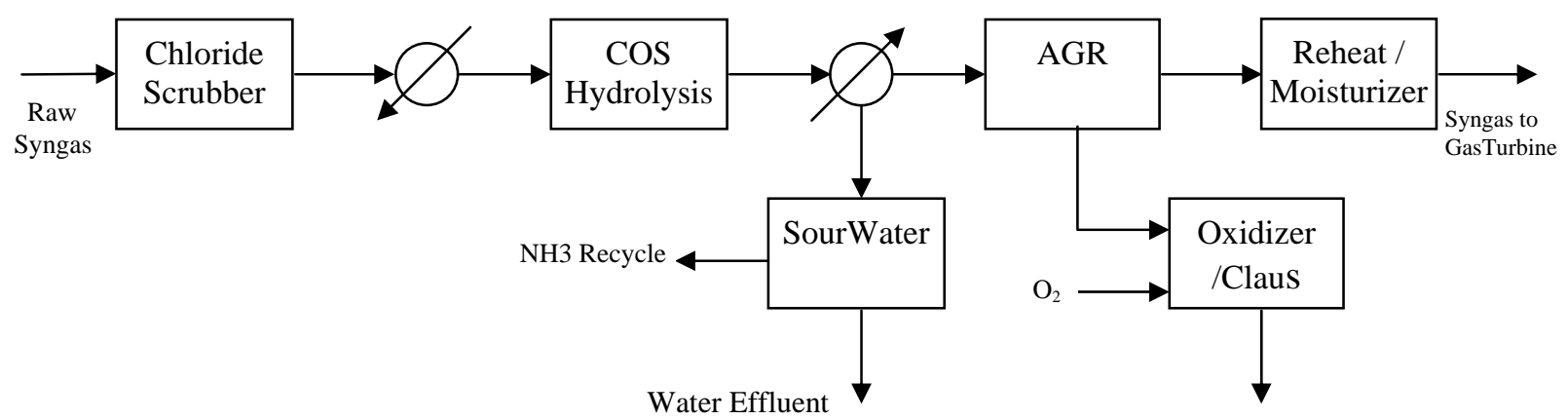


Figure 15 - S Zorb ${ }^{T M}$ SRT Warm Gas Cleanup Scheme

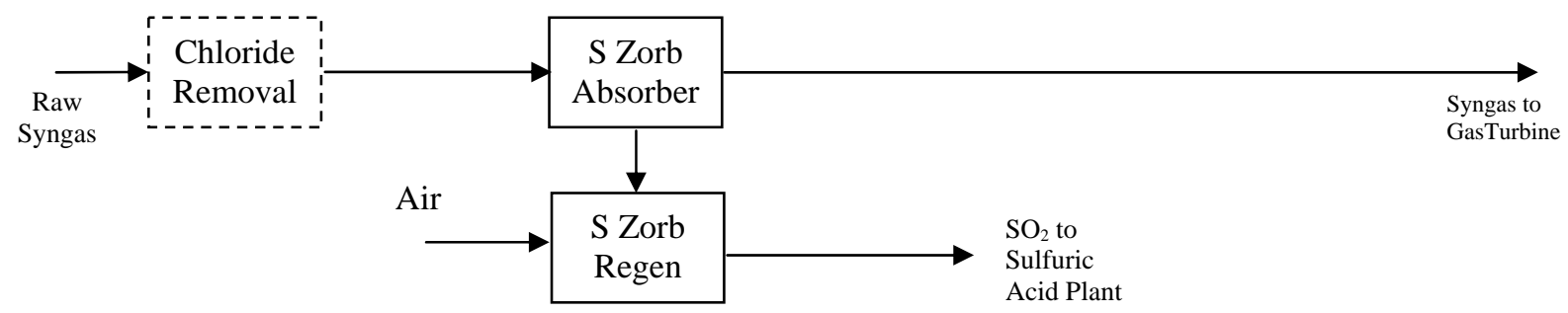

The evaluation showed that compared to the conventional gas cleanup process using amines, the $S$ Zorb $^{\mathrm{TM}}$ retrofit would result in a reduction in capital cost by as much as $40 \%$ in the gas cleanup section of the E-Gas process. The savings would be even greater if a Selexol or Rectisol system is used to deliver a lower sulfur-content syngas such as that obtainable from the S Zorb ${ }^{\mathrm{TM}}$ system.

The evaluation and cost estimates compared favorably with the information presented by Eastman Chemical Company and Research Triangle Institute (RTI) at the 2006 Gasification Technology Conference [Ref. 8]. The RTI/Eastman work is very similar to the E-Gas/S Zorb ${ }^{\mathrm{TM}}$ warm gas cleanup process that was evaluated under the IMPPCCT Project.

\section{CONCLUSIONS AND RECOMMENDATIONS}

This study has demonstrated the technical feasibility of using the S Zorb ${ }^{\mathrm{TM}}$ SRT sulfur removal technology for the E-Gas process. The sorbent, as tested in a fixed-bed reactor, successfully removed the sulfur contaminants, reaching near theoretical sulfur loading capacity of the sorbent, with very low sulfur levels $(<5 \mathrm{ppm})$ measured at the absorber outlet through all of the absorption cycles. The sorbent is easily regenerated with no degradation of the sorbent observed from the multi-cycle test. Economic analysis showed significant capital savings employing the S Zorb ${ }^{\mathrm{TM}}$ SRT warm gas desulfurization process. Further investigation of the process such as in pilot plant testing with actual syngas is recommended.

\section{ACKNOWLEDGEMENTS}

Financial support for this work from DOE/NETL under Cooperative Agreement No. DEFC26-99FT40659 is gratefully acknowledged. Cooperation from the ConocoPhillips, SG Solutions, and contract personnel on site the SGS Facility is greatly appreciated. 


\section{REFERENCES}

1. "Desulfurization and Sorbents for Same"; Sughrue, Edward, L.; Johnson, Marvin M.; et al; United States Patent 6,656,877, Dec. 2, 2003.

2. "Sorbents for Desulfurizing Gasolines and Diesel Fuel”; Dodwell, Glenn W.; United States Patent 6,429,170, Aug 6, 2002.

3. "Desulfurization and Novel Sorbent for Same”; Sughrue, Edward, L.; Khare, Gyanesh P.; Bertus, Brent J.; Johnson, Marvin M.; United States Patent 6,254,766, July 3, 2001.

4. "Fluidizable Sulfur Sorbent and Fluidized Sorption Process"; Khare, Gyanesh P.; Cass, Bryan W.; United States Patent 5,439,867, August 5, 1995.

5. "Absorption Composition Comprising Zinc Titanate for Removal of Hydrogen Sulfide from Fluid Streams”; Kidd, Dennis R.; United States Patent 5,045,522, September 3, 1991.

6. "Selective Removal of Hydrogen Sulfide Over Zinc Titanate and Alumina"; Kidd, Dennis R.; United States Patent 4,725,415, February 16, 1988.

7. "Hydrodesulfurization of Organic Sulfur Compounds and Hydrogen Sulfide Removal with Incompletely Sulfided Zinc Titanate Materials”; Fahra, Floyd H.; United States Patent 4,313,820, February 2, 1982.

8. "Field Testing of a Warm-Gas Desulfurization Process in a Pilot-Scale Transport Reactor System", Gasification Technology Conference, Washington D.C., October 2006.

9. "Slipstream Testing of Novel Sulfur Removal Processes for Gasification Application", Tsang, el al; $22^{\text {nd }}$ International Pittsburgh Coal Conference, Pittsburgh, PA, September 2005.

10. "Sulfur Removal from E-Gas Gas Streams with S Zorb ${ }^{\mathrm{TM}}$ Sulfur Removal Technology", Schmidt, et al, $23^{\text {rd }}$ International Pittsburgh Coal Conference, Pittsburgh, PA, September 2006. 


\section{APPENDIX IV}

“Slipstream Testing of Novel Sulfur Removal Processes for Gasification Application”

Presented in the

$22^{\text {nd }}$ International Pittsburgh Coal Conference

September 14, 2005 


\title{
Slipstream Testing of Novel Sulfur Removal Processes for Gasification Application
}

\author{
Albert Tsang, Joe Cross, Roland Schmidt, ConocoPhillips Company \\ Clinton Summers, Nucon International, Inc. \\ Robert Kornosky, U. S. Department of Energy, National Energy Technology Laboratory
}

\begin{abstract}
The Wabash River Integrated Methanol and Power Production from Clean Coal Technologies (IMPPCCT) project is investigating an Early Entrance Coproduction Plant (EECP) concept to evaluate integrated electrical power generation and methanol production from coal and other carbonaceous feedstocks. Research, development, and testing (RD\&T) that is currently being conducted under the project is evaluating cost effective process systems to remove contaminants, particularly sulfur species, from the synthesis gas to a level acceptable for the methanol synthesis catalyst. The RD\&T will include laboratory testing followed by benchscale, field testing at the SG Solutions LLC Gasification Plant which is located in West Terre Haute, Indiana. Actual synthesis gas produced by the plant will be utilized at system pressure and temperature during the benchscale, field testing.
\end{abstract}

The presentation will briefly discuss the RD\&T Plan to evaluate a regenerable activated carbon system developed by Nucon International, Inc. in removing sulfur species from an industrial gas stream to parts-perbillion (ppb) levels, and a regenerable sorbent developed by ConocoPhillips Company to remove sulfur contaminants from gasoline at high temperatures. Laboratory data, if available, will be presented.

The project is being managed by the National Energy Technology Laboratory under U.S. Department of Energy Cooperative Agreement No. DE-FC26-99FT40659.

\section{INTRODUCTION}

The Wabash River Integrated Methanol and Power Production from Clean Coal Technologies (IMPPCCT) Project was awarded by the U. S. Department of Energy (DOE) under the Early Entrance Coproduction Plant (EECP) solicitation to the former Gasification Engineering Corporation (GEC). The project is now under the leadership of ConocoPhillips Company (COP) after it acquired GEC and the E-Gas gasification technology from Global Energy Inc. in July 2003. The project evaluates the integration of gasification-based electrical generation and methanol production processes to determine the economic and technical feasibility of power and chemicals coproduction. A multi-industry team led by the previous GEC and consisting of Air Products and Chemicals, Inc., Dow Chemical Company, Dow Corning Corporation, Methanex Corporation, and Siemens Westinghouse Power Corporation has completed the Phase I feasibility study. The Phase II research, development, and testing (RD\&T) work, which is currently in progress, is led by COP and is supported by Nucon International, Inc. (Nucon).

The IMPPCCT Project investigation is based on the E-Gas gasification technology utilizing coal, petcoke, and other feedstocks. The E-Gas process features a slurry-based, oxygen-blown, continuous-slagging, two-stage entrained-flow gasifier. Heat is recovered by a fire-tube boiler and particulates are removed by a hot/dry filter system. At the SG Solutions LLC (SGS) Plant, hydrogen sulfide $\left(\mathrm{H}_{2} \mathrm{~S}\right)$ in the synthesis gas (syngas) is removed by an amine-based acid gas removal unit and converted to elemental sulfur in an oxygen-enriched Claus system. The syngas fired in a gas turbine, combined with output from the steam turbine in an IGCC (Integrated Gasification Combined Cycle) setting, produces a net 262MW of electricity input to the power grid at Cinergy's Wabash River Power Station located in West Terre Haute, Indiana. The methanol synthesis systems investigated include both conventional gas phase and Air Products and Chemicals, Inc. Liquid Phase Methanol $\left(\mathrm{LPMEOH}^{\mathrm{TM}}\right)$ processes.

The feasibility study conducted in Phase I of the Project confirmed that the integration of the E-Gas gasification technology and methanol production was feasible for the coproduction of power and chemicals. While there 
were minimal integration issues that may impact the deployment of the coproduction concept, the major concern was the removal of sulfur and other trace contaminants, which are known methanol catalyst poisons, from the syngas.

The objective of Phase II is to conduct RD\&T to address the technical concerns identified in Phase I to make the IMPPCCT concept competitive in the commercial marketplace. Studies will investigate the cleanup of the syngas by removing contaminants, particularly sulfur species, to a level acceptable for the methanol synthesis catalyst. Processes that will reduce the cost of the current sulfur removal system, such as via warm gas cleanup technologies, will also be investigated. Laboratory testing followed by on-site field testing at the SGS Gasification Plant with bench-scale slipstream units will be pursued. Evaluation will utilize actual syngas produced by the facility at system pressure and temperature.

Two novel processes identified to be capable of removing sulfur contaminants to parts-per-billion (ppb) levels and low in capital and operating costs are being investigated for syngas applications:

1. A regenerable activated carbon system developed by Nucon for removing sulfur species in a product syngas stream at low temperatures, and

2. A regenerable sorbent (S Zorb) developed by COP to remove sulfur contaminants from gasoline at "warm" temperatures.

\section{SYNGAS POLISHING TO REMOVE LOW LEVEL SULFUR CONTAMINANTS}

Catalytic systems are usually necessary to convert syngas to the desired chemicals. For methanol synthesis, the catalysts currently available are extremely sensitive to sulfur poisoning. A sulfur level of less than $0.06 \mathrm{ppm}$ in the syngas is generally required. IGCC facilities typically employ amine-based solvent systems to remove $\mathrm{H}_{2} \mathrm{~S}$ due to its low cost and ease of operation. However, amine-based systems can only remove $\mathrm{H}_{2} \mathrm{~S}$ in the syngas to the ppm range, typically $>25 \mathrm{ppm}$. Also, amine solvents cannot remove carbonyl sulfide (COS). Sacrificial guard beds using zinc oxide, coupled with a hydrogenation unit to convert the COS to $\mathrm{H}_{2} \mathrm{~S}$, are economical only for low ppm level residual sulfur. Ultimately, the amine-based sulfur removal system has to be replaced or supplemented with a costly system such as Rectisol ${ }^{\circledR}$. A regenerable system for syngas polishing downstream of the currently used amine solvent system, if proven to work, would greatly enhance the economics of the coproduction concept.

\section{METAL OXIDE IMPREGNATED CARBON}

Use of activated carbon, either impregnated with metal oxides like copper or non-impregnated (Ref. 1), has been investigated by others to remove sulfur compounds from gas and liquid streams. The mechanism for removal of sulfur compounds is physical adsorption on the surface of the activated carbon and chemical reaction with the impregnant. The metal, such as iron or copper, forms a very stable sulfide compound and retains the sulfur compound inside the activated carbon particle. However, the capacity of the carbon is either very low or the carbon can not be regenerated, especially when COS and carbon dioxide are present in the gas stream. NUCON, a subcontractor selected for this project, has successfully developed activated carbon products and in-situ regeneration techniques for such applications. NUSORB ${ }^{\circledR}$ FC, an activated carbon impregnated with metal oxides, and similar NUCON products have been successfully employed in removing sulfur compounds from liquid hydrocarbon and non oxygen-containing gas streams. A commercial-scale system installed in a refinery has been operating satisfactorily in removing COS from a propane stream. The regenerability of the carbon is well demonstrated in that application. This carbon is being evaluated for syngas applications in this project.

\section{LABORATORY TESTING - METAL OXIDE IMPREGNATED CARBON}

Preliminary laboratory testing was conducted at NUCON. A blended syngas stream with a composition similar to that produced at SGS was used. Four impregnated carbons were tested, initially at atmospheric pressure and then at 350 psig. Because of analytical limitations in the NUCON laboratory, $\mathrm{H}_{2} \mathrm{~S}$ and COS were tested 
separately. Both sulfur species were removed to non-detectable levels. The spent carbons were successfully regenerated by a mixture of air and nitrogen. Consecutive cycles of adsorption and regeneration tests were also conducted with no loss in activity of the sorbent observed. Results are summarized in Table 1 and Figure 1. The adsorption capacity for $\mathrm{H}_{2} \mathrm{~S}$, the controlling factor for breakthrough, was determined to be $1.7 \% \mathrm{H}_{2} \mathrm{~S}$ by weight of the impregnated carbon. The adsorption capacity is expected to be higher in the slipstream and commercial units because of the difference in the bed geometry that results in improved mass transfer characteristics, compared to the laboratory unit.

Table 1 - Laboratory Adsorption and Regeneration Tests - Metal Oxide Impregnated Carbon

Test No.

Particle Size

Type of Sorbent

Impregnant

Impregnant Content, wt\%

Bed Weight, g

Flow Rate, std. liter/min

Temp, ${ }^{\circ} \mathrm{C}$

Pressure, psia

Residence time, sec

$\mathrm{H}_{2} \mathrm{~S}$ Inlet Conc, ppmv

COS Inlet Conc, ppmv

$\mathrm{H}_{2} \mathrm{~S}$ Breakthrough, min.

COS Breakthrough, min.

$\mathrm{H}_{2} \mathrm{~S}$ Saturation, min

COS Saturation, min

$\begin{array}{cccccc}1 & 2 & 3 & 4 & 5 & 6 \\ 1.5 \mathrm{~mm} & 1.5 \mathrm{~mm} & 1.5 \mathrm{~mm} & 1.5 \mathrm{~mm} & 1.5 \mathrm{~mm} & 1.5 \mathrm{~mm} \\ \text { New } & \text { Regen'ed } & \text { Regen'ed } & \text { New } & \text { Regen'ed } & \text { Regen'ed } \\ \text { MO2 } & \text { MO2 } & \text { MO2 } & \text { MO2 } & \text { MO2 } & \text { MO2 } \\ 8.0 & 8.0 & 8.0 & 8.0 & 8.0 & 8.0 \\ 16.74 & 16.74 & 16.74 & 16.74 & 16.74 & 16.74 \\ 8.3 & 8.3 & 8.3 & 8.3 & 8.3 & 8.3 \\ 37.8 & 37.8 & 37.8 & 37.8 & 37.8 & 37.8 \\ 364 & 364 & 364 & 364 & 364 & 364 \\ 1.3 & 1.3 & 1.3 & 1.3 & 1.3 & 1.3 \\ 301 & 301 & 301 & 0 & 0 & 0 \\ 0 & 0 & 0 & 25 & 25 & 25 \\ 15 & 30 & 30 & - & - & - \\ - & - & - & 15 & 15 & 15 \\ 150 & - & - & - & - & - \\ - & - & - & 50 & - & -\end{array}$

Figure 1 - Absorption Characteristics of Metal Oxide Impregnated Carbons
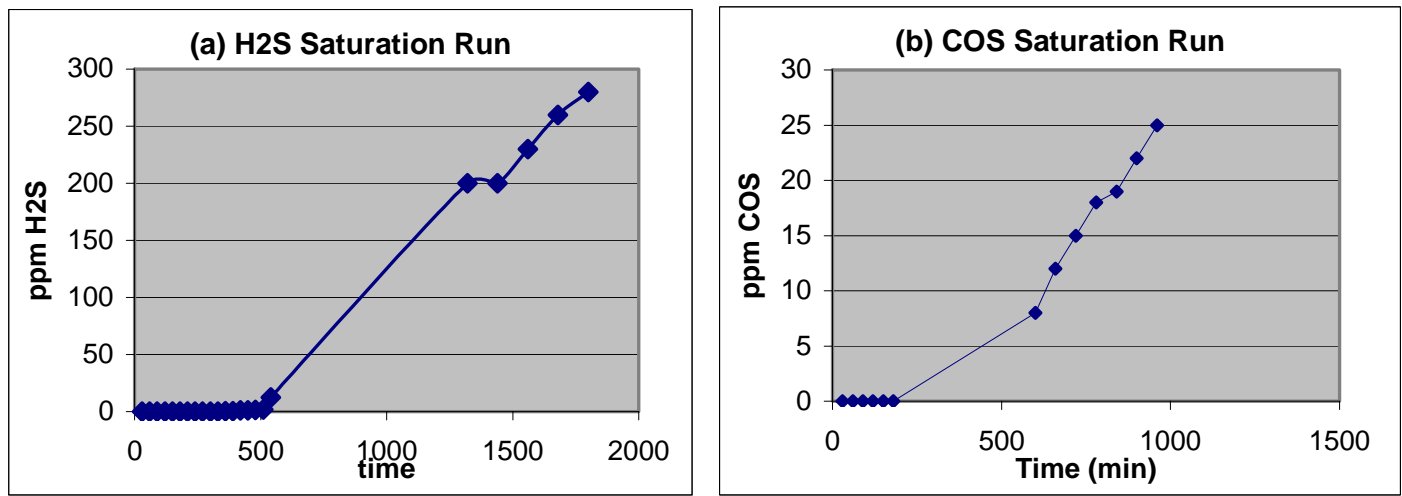

\section{BENCH-SCALE SLIPSTREAM UNIT - METAL OXIDE IMPREGNATED CARBON}

After the successful completion of the laboratory tests, a bench-scale slipstream unit was constructed for testing at SGS. A schematic diagram of the unit is shown in Figure 2, and a photo of the completed unit is shown in Figure 3. The unit has a capacity of 2 ACFM and is designed for one adsorption-regeneration cycle a day. The unit has been delivered and installed at SGS. Startup is scheduled to be in the summer of 2005. A test of twoweeks duration is planned. 
Figure 2 - Schematic of Bench-Scale Slipstream Unit - Metal Oxide Impregnated Carbon

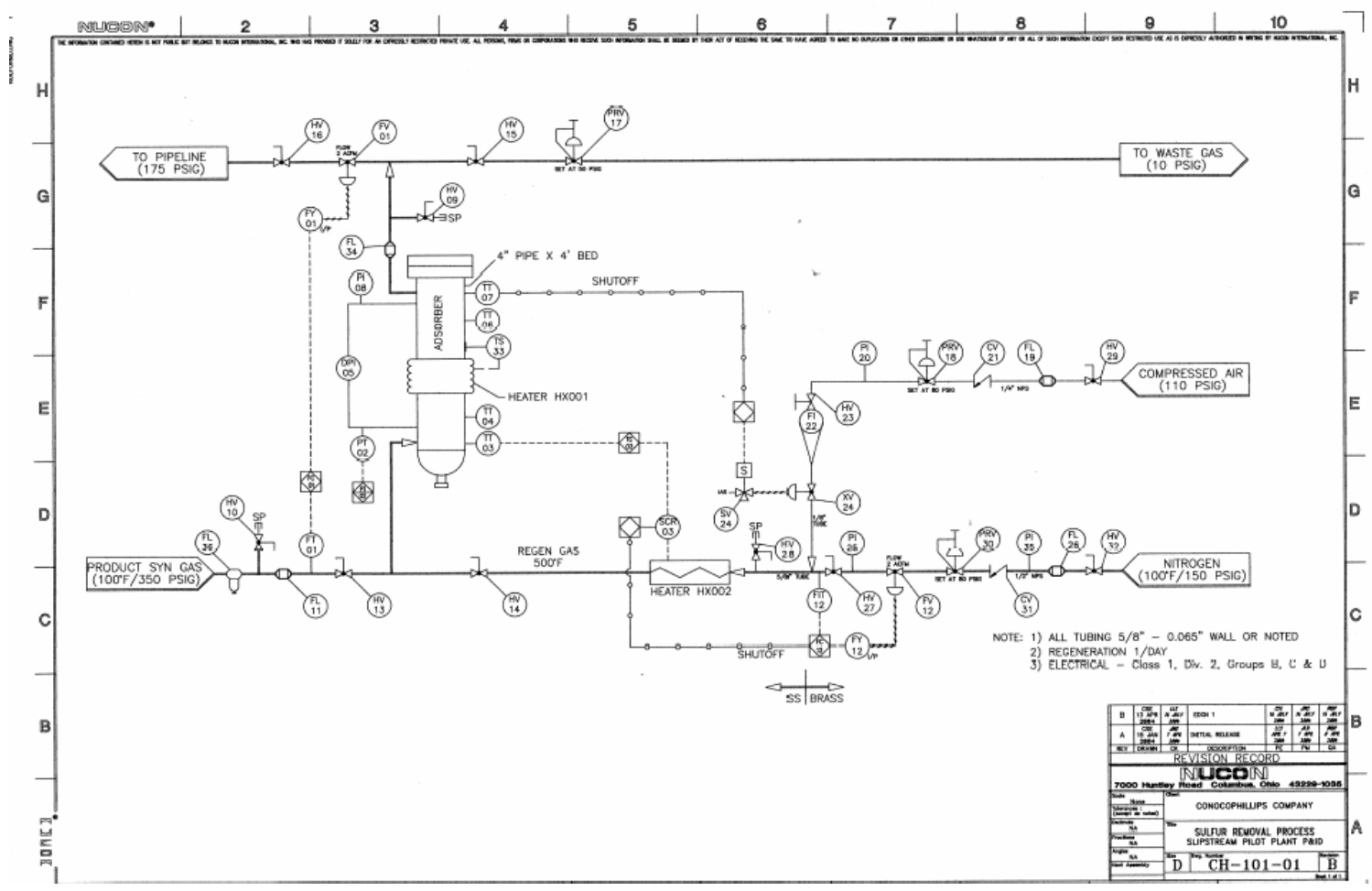

Figure 3 -Photograph of Bench-Scale Slipstream Unit - Metal Oxide Impregnated Carbon

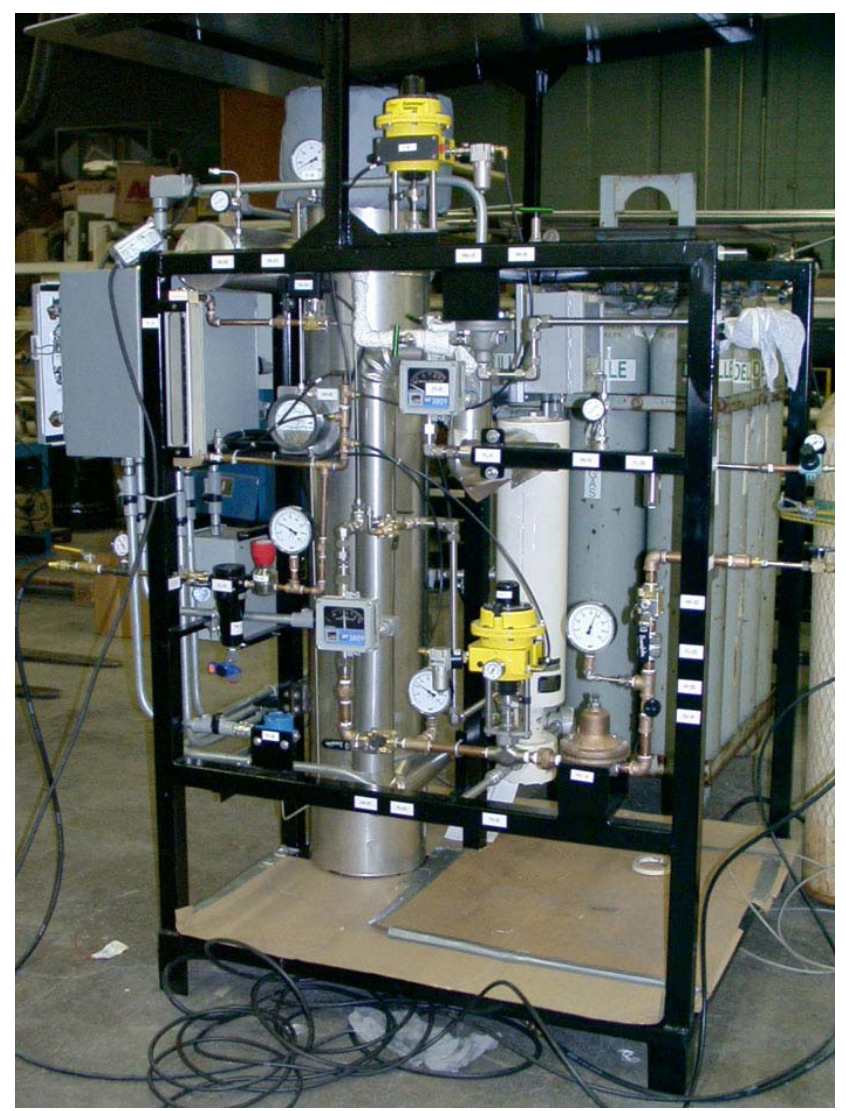




\section{WARM GAS DESULFURIZATION}

The SGS Plant, like other gasification facilities, uses a low temperature acid gas removal system (AGR) such as MDEA to remove $\mathrm{H}_{2} \mathrm{~S}$. This requires cooling the syngas to a temperature of about 100F. After the AGR, the syngas is reheated and moisturized before it is sent to the gas turbine to improve the efficiency of the process. Since MDEA does not remove COS, a catalytic COS hydrolysis reactor system has to be used. A water scrubber is used to remove the chlorides in the raw syngas to avoid degrading the COS catalyst and the AGR. During the cooling of the syngas, the sour condensate collected is stripped of ammonia $\left(\mathrm{NH}_{3}\right)$ and the water is recycled or disposed. A simplified block flow diagram of the current process scheme is shown as follows. In such a system the numerous recycle streams containing various contaminants often create unexpected processing problems when the fuel mix or fuel quality is changed.

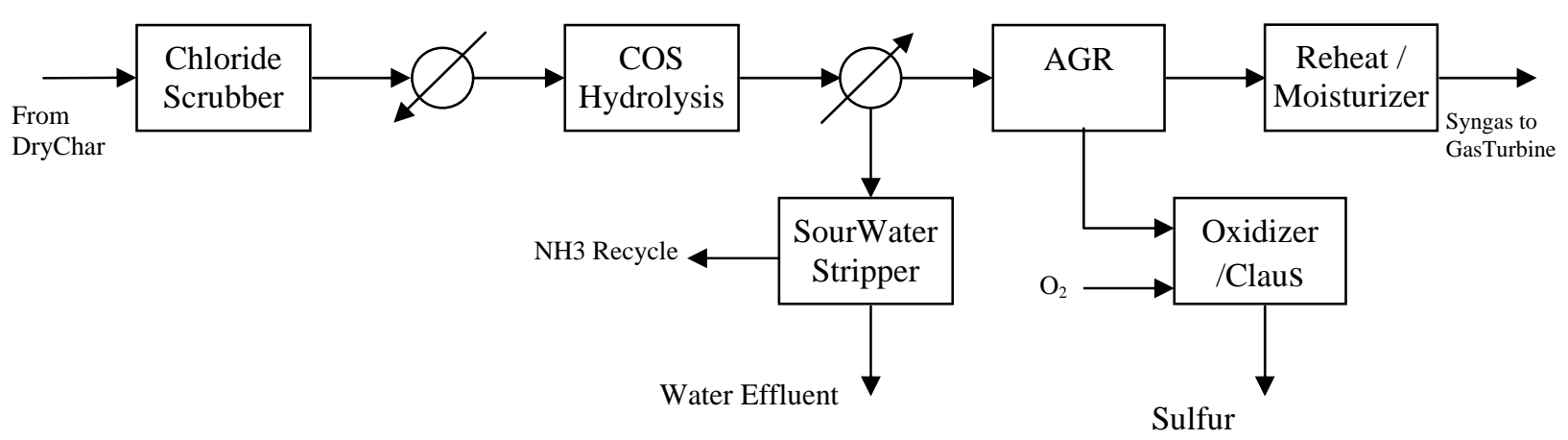

The hot or warm gas cleanup concept promoted by DOE would greatly simplify the process. The concept is to remove the sulfur species in the raw syngas at high temperatures so that the gas does not need to be reheated to feed it to the gas turbine. By not having to cool the syngas, no sour water would be produced and therefore, no sour water stripping would be necessary. The scheme will be greatly simplified as shown in the following block flow diagram. A recent DOE-funded study by Siemens Westinghouse Power Corporation (Ref. 2) shows that the capital cost and efficiency of the overall IGCC process could be greatly improved.

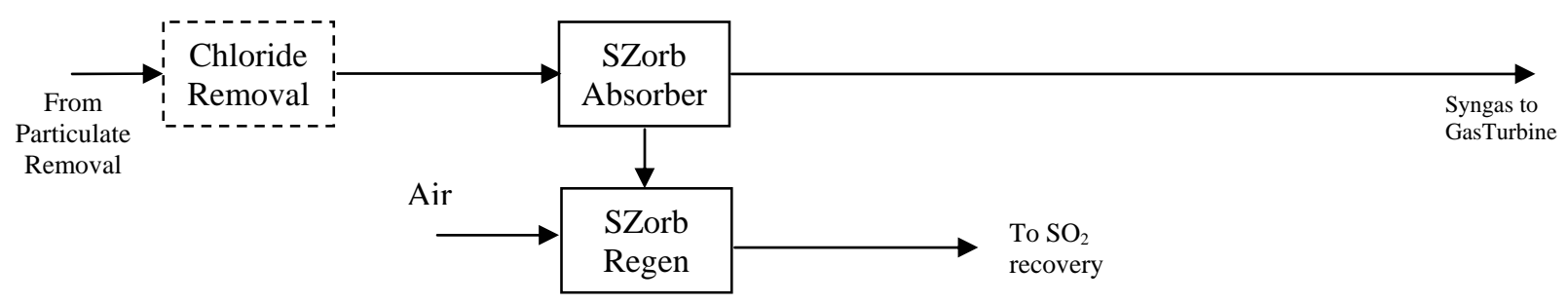

However, for such a scheme to work, the sulfur removal technology would need to be able to remove COS as well as $\mathrm{H}_{2} \mathrm{~S}$ at high temperatures (600-900F), and the sorbent could not be degraded by chlorides or other contaminants. COP's S Zorb SRT technology has the potential to meet these criteria.

\section{CONOCOPHILLIPS S ZORB SRT TECHNOLOGY}

COP's patented S Zorb SRT technology (Ref. 3, 4), developed to remove sulfur from gasoline, uses a fluidizedbed absorbent. The proprietary S Zorb sorbent is a descendent of the earlier material, Z Sorb, developed in the early 1990's for syngas desulfurization. The newer material is significantly more active and attrition resistant. The sorbent also removes COS and is resistant to chlorides. Three commercial vendors are currently licensed to produce the material. 
There are currently two commercial S Zorb SRT units operating with a third unit under construction in COP. In these gasoline desulfurization units, the gasoline is vaporized and mixed with hydrogen. The unit in the COP's Borger, Texas refinery has been operating since April 2001. COP's Ferndale, Washington unit has been operating since December 2003. The unit just installed at Lake Charles, Louisiana, is being started up. The S Zorb SRT absorber is operated at process conditions similar in temperature and pressure to the hot unscrubbed syngas produced in the E-Gas gasification process.

A flow sheet for the S Zorb SRT process is shown is Figure 4. Gasoline is mixed with hydrogen, heated and vaporized by heat exchangers and a furnace to approximately 800F. The feed is then passed through the fluidized-bed absorber, which is very selective for sulfur compounds. The absorber product gas is cooled, condensed, and passed to a product separator to remove the hydrogen, which is recompressed and recycled. The final gasoline product is again fractionated in a stabilizer to ensure constant product vapor pressure. The sorbent is circulated from the absorber into the regeneration system where in a smaller fluidized bed, the sulfur on the sorbent is converted to $\mathrm{SO}_{2}$ with air.

The key differences between syngas and gasoline desulfurization are the amount and type of sulfur compounds in the two feeds. In syngas the major sulfur compounds are $\mathrm{H}_{2} \mathrm{~S}$ and $\mathrm{COS}$, while in gasoline the major sulfur compounds are methyl-thiophenes and methyl-benzothiophenes. $\mathrm{H}_{2} \mathrm{~S}$ reacts at several orders of magnitude faster than thiophenic sulfur, and thus it is anticipated that the S Zorb SRT absorber should easily remove $\mathrm{H}_{2} \mathrm{~S}$, leaving less than $1 \mathrm{ppm}$ sulfur in the hot gas.

\section{Figure 4 - S Zorb SRT Gasoline Desulfurization Process}

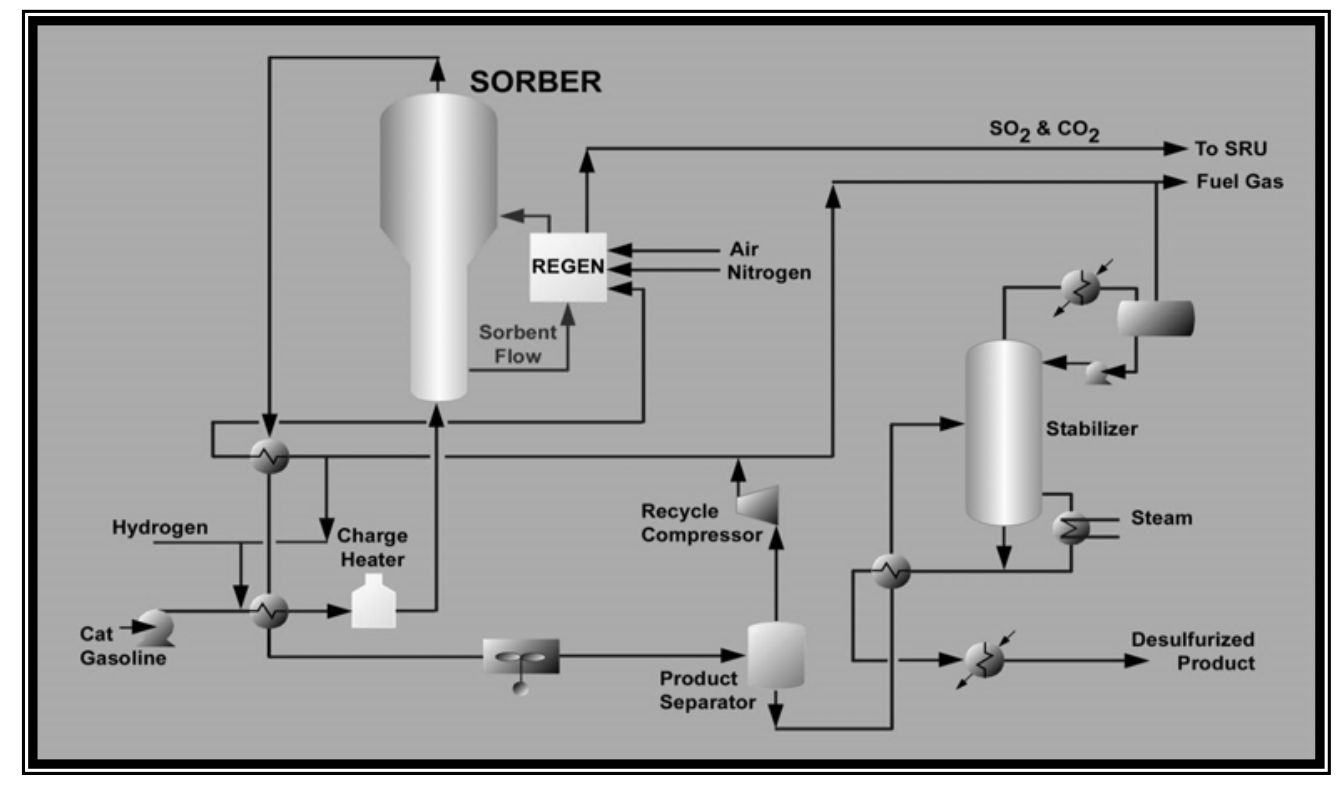

\section{LABORATORY TESTING - S ZORB SRT WARM GAS DESULFURIZATION}

The objective of this study is to demonstrate, in a bench-scale slipstream test conducted at SGS, the S Zorb technology for "warm" gas desulfurization and to investigate the tolerance of the sorbent for contaminants. Initial laboratory testing was conducted at COP's Technology Center in Bartlesville, Oklahoma. A schematic diagram and a photo of the laboratory set up is shown in Figures 5 and 6, respectively. The sorbent was tested in a fixed-bed, down-flow reactor with a syngas blend similar to that produced at SGS, but diluted with nitrogen at up to $50 \%$ by volume for safety reasons. Absorption reaction conditions of $600-800^{\circ} \mathrm{F}$ at up to 350 psig were investigated. The S Zorb sorbent removed $\mathrm{H}_{2} \mathrm{~S}$ to $<1 \mathrm{ppm}$ in all cases until capacity was reached. $\mathrm{A}_{2} \mathrm{~S}$ and COS absorption breakthrough curve is shown in Figure 7. 
Figure 5 - Schematic of COP S Zorb SRT Warm Gas Desulfurization Laboratory Unit

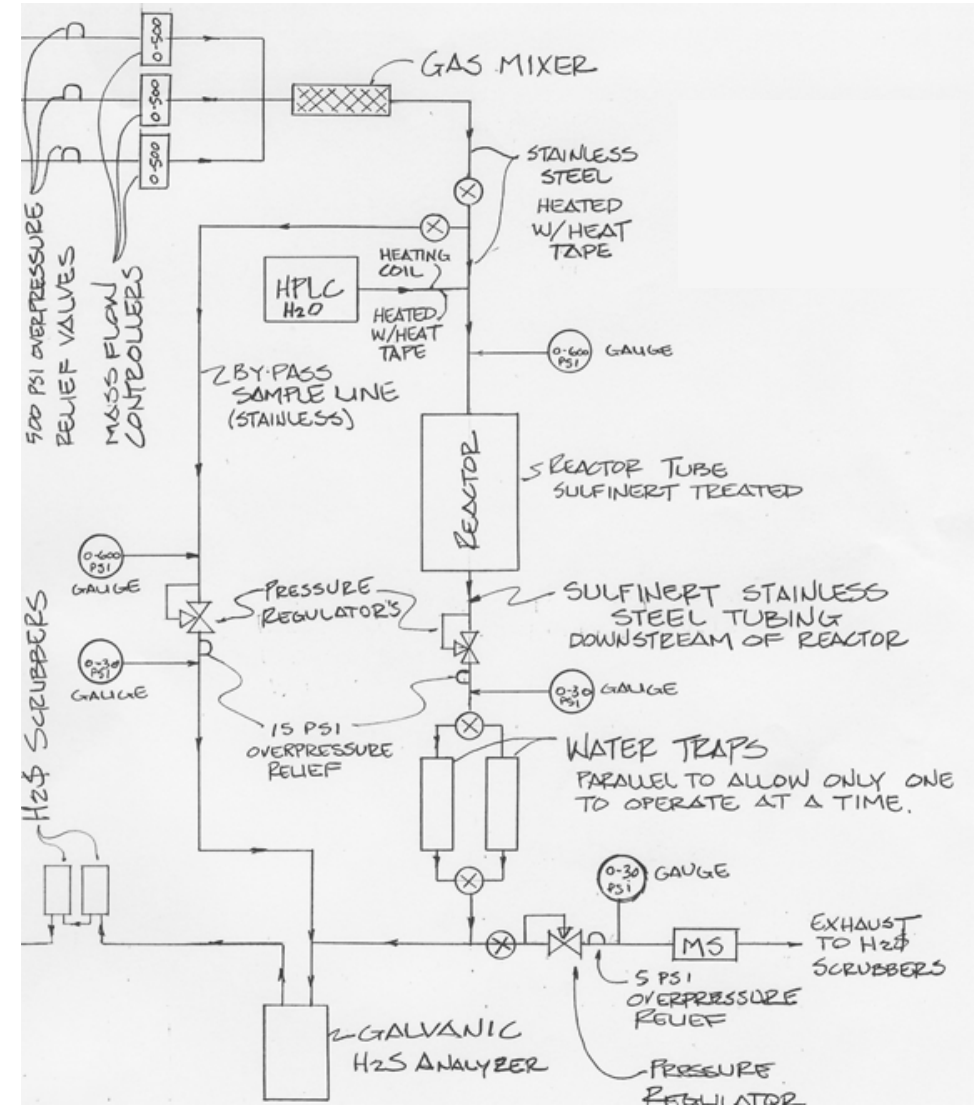

Figure 6 - Photograph of COP S Zorb SRT Warm Gas Desulfurization Laboratory Unit

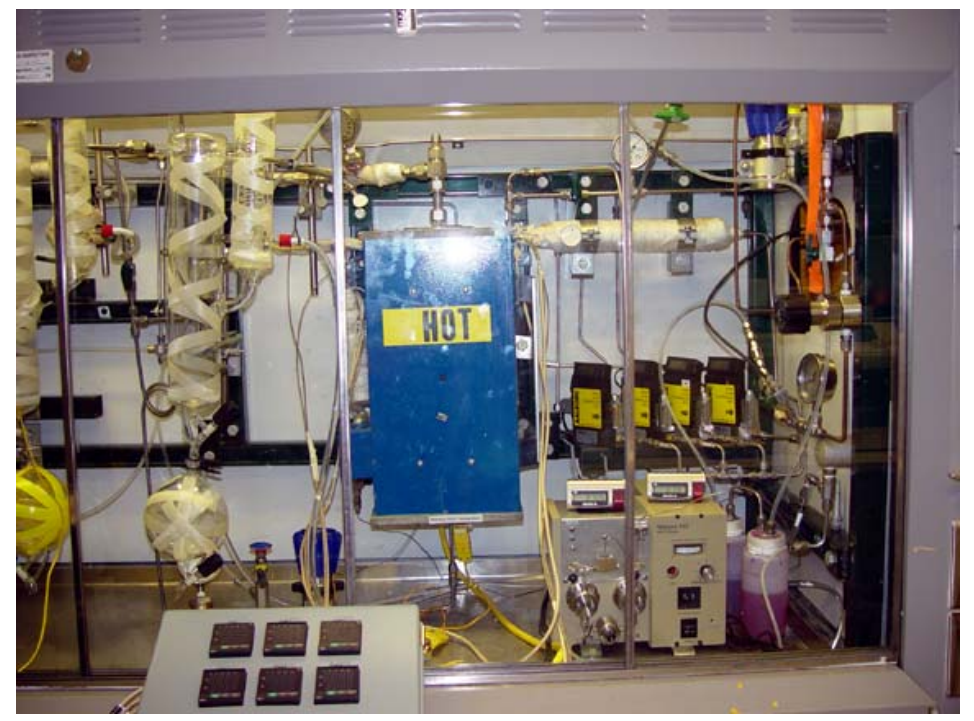


Figure 7 - $\mathbf{H}_{2} \mathrm{~S} / \mathrm{COS}$ Absorption Breakthrough Curve - S Zorb SRT

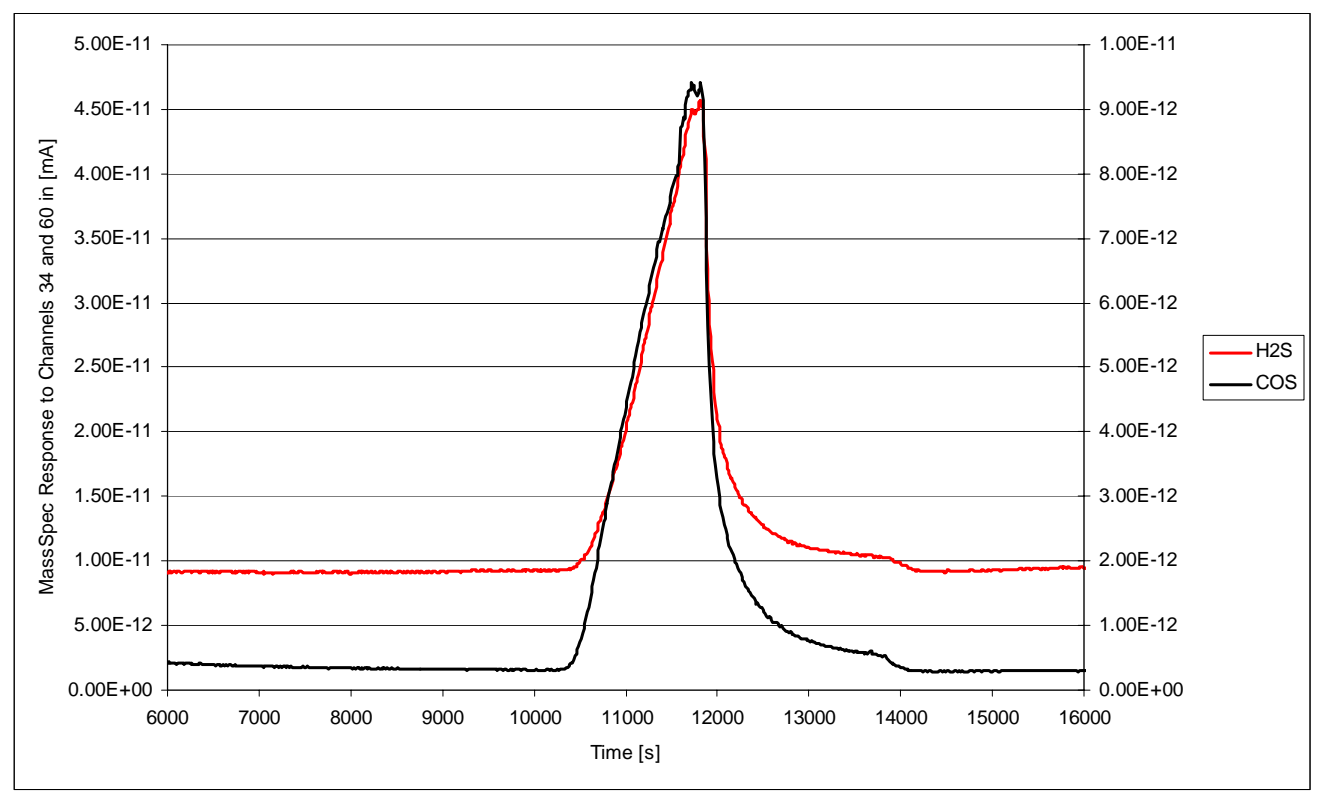

The ability to regenerate the S Zorb sorbent was also confirmed in tests after fully loading it with sulfur. The regeneration conditions used were at a temperature between $800-1000^{\circ} \mathrm{F}$, and at atmospheric pressure with air. Regeneration conditions used initially were similar to those developed for the commercial S Zorb sorbent for gasoline desulfurization applications. The regeneration condition was later optimized for $\mathrm{H}_{2} \mathrm{~S}$ and syngas application.

A fifteen-cycle run of loading the sorbent with sulfur and regeneration was successfully completed. No sorbent deterioration was observed over the fifteen cycles. The $\mathrm{S}$ Zorb sorbent removed $\mathrm{H}_{2} \mathrm{~S}$ quantitatively within detection limits of $<1 \mathrm{ppm}$ in all fifteen cycles until capacity was reached. The positive results from the test confirms the stability of the sorbent under conditions typical of operation at SGS. Completion of the fifteencycle test satisfactorily completed all the laboratory testing planned for the warm gas desulfurization concept.

After confirming the feasibility of the S Zorb application in the laboratory tests, work was initiated in May 2005 to prepare the slipstream unit, which will be housed in a mobile trailer, for testing at SGS. Construction and assembly of the unit is nearly complete. The field test is currently scheduled for early fall.

\section{MERCURY AND TRACE METALS REMOVAL}

Sulfur impregnated activated carbon has been successfully used for many years in refineries and natural gas applications to remove mercury and trace metal contaminants from both liquid and gaseous streams. The carbon to be tested in this work will contain sulfur and metal sulfides from the impregnant reacting with the $\mathrm{H}_{2} \mathrm{~S}$ and COS that are removed from the syngas stream. It is highly likely that the trace metals and mercury would be removed with the sulfur contaminants as well, especially at the low temperatures (approximately $100^{\circ} \mathrm{F}$ ) that the carbon would be used. Similarly with the S Zorb SRT process, there were indications in refinery applications that some trace metals could be removed by the sorbent. The removal of mercury and trace metals would be an added benefit for the sulfur removal systems being proposed. Sampling and analysis during the slipstream testing will determine what metals will be removed and the stability of these metals during the regeneration sequence. 


\section{SUMMARY}

Under Phase II of the IMPPCCT Project, RD\&T is being conducted to evaluate cost effective process systems to remove sulfur contaminants from syngas to a level acceptable for the methanol synthesis catalyst. A regenerable metal oxide impregnated carbon developed by NUCON in removing sulfur species from an industrial gas stream, and a regenerable sorbent system developed by COP to remove sulfur contaminants from gasoline at warm gas temperatures are being investigated. Laboratory testing on both processes has been completed with satisfactory results. Bench-scale slipstream units will be installed at SGS. Actual syngas produced by the plant will be utilized at system pressure and temperature for the testing scheduled in the summer/fall of 2005.

\section{ACKNOWLEDGEMENT}

Financial support for this work from DOE/NETL under Cooperative Agreement No. DE-FC26-99FT40659 is gratefully acknowledged. Mr. Joe Enneking and the engineering staff at Nucon International, Inc. were instrumental in bringing the metal oxide impregnated carbon from project initiation to the slipstream testing stage. Dr. Ed Sughrue of ConocoPhillips has provided invaluable technical guidance for the S Zorb SRT evaluation.

\section{REFERENCES}

1. “How to Produce Methanol from Coal” by Emil Supp, Springer-Verlag Berlin, Heidelberg Publishing, 1990, p. 46-48

2. “Development Progress on the SWPC Novel Gas Cleaning Process”, Pittsburgh Coal Conference, September 2003

3. Sughrue, Edward, L.; Johnson, Marvin M.; et.al.; “Desulfurization and Sorbents for Same”; United States Patent 6,656,877, Dec. 2, 2003.

4. Dodwell, Glenn W., "Sorbents for Desulfurizing Gasolines and Diesel Fuel”; United States Patent 6,429,170, Aug 6, 2002. 


\title{
Slipstream Testing of Novel Sulfur Removal Processes for Gasification Application
}

\author{
Pittsburgh Coal Conference 2005
}

Albert Tsang, Joe Cross, Roland Schmidt - ConocoPhillips Company

Clinton Summer - Nucon International, Inc.

Robert Kornosky - DOE NETL

Cooperative Agreement No. DE-FC26-99FT40659 
Investigation conducted under:

\section{Wabash River Integrated Methanol and Power Production from Clean Coal Technologies (IMPPCCT)}

Cooperative Agreement No. DE-FC26-99FT40659

An Early Entrant Co-Production (EECP) Project 


\section{IMPPCCT Objective:}

Development of an engineering design and economics for a single plant that produces methanol and electric power from the gasification of coal and other carbonaceous feedstocks 


\section{Once-through Methanol Coproduction with IGCC Electric Power}

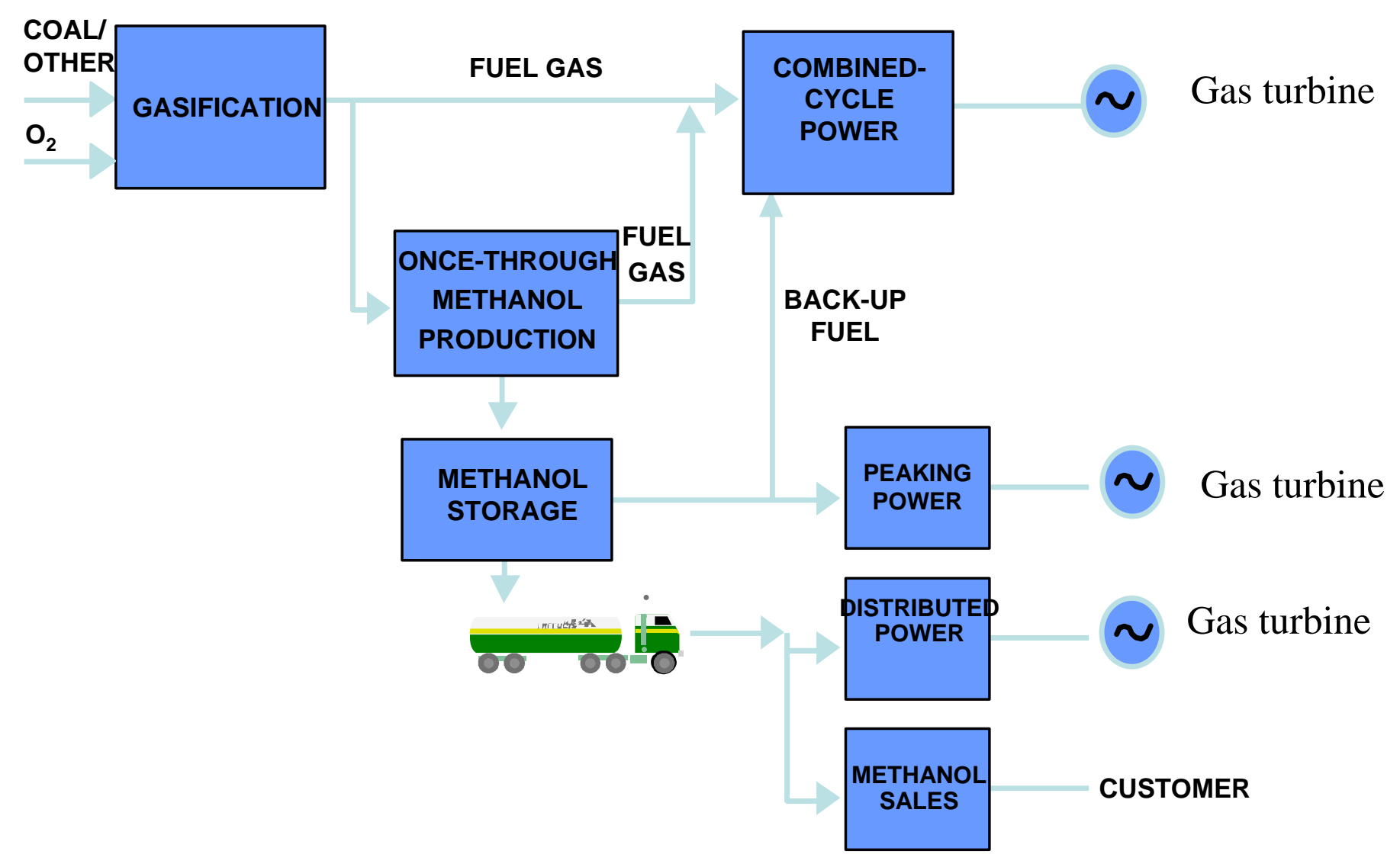




\section{IMPPCCT Phase I}

Participants:

Dynegy (Lead)

Methanex
Air Products

Siemens Westinghouse
Dow Corning

Dow Chemical

\section{Conclusions:}

- Concept for Methanol and Power CoProduction is feasible with minimal integration issues for E-Gas

- Economics sensitive to methanol and energy prices

> Ultra-clean syngas is essential

> Opportunity in reducing the cost of sulfur removal and syngas cleanup 


\section{Objectives for IMPPCCT Phases II:}

To conduct RD\&T on viable and cost effective syngas desulfurization and cleanup systems:

- $\quad$ Regenerable Metal Oxide Impregnated Carbon for Syngas Polishing

- $\quad$ ConocoPhillips'S Zorb SRT Warm Gas Desulfurization System

Approach

- $\quad$ Laboratory confirmation with blended syngas

- $\quad$ Slipstream testing at SG Solutions’ Wabash River IGCC Facility to evaluate impact of contaminants 


\section{SG Solutions Wabash River IGCC Facility}

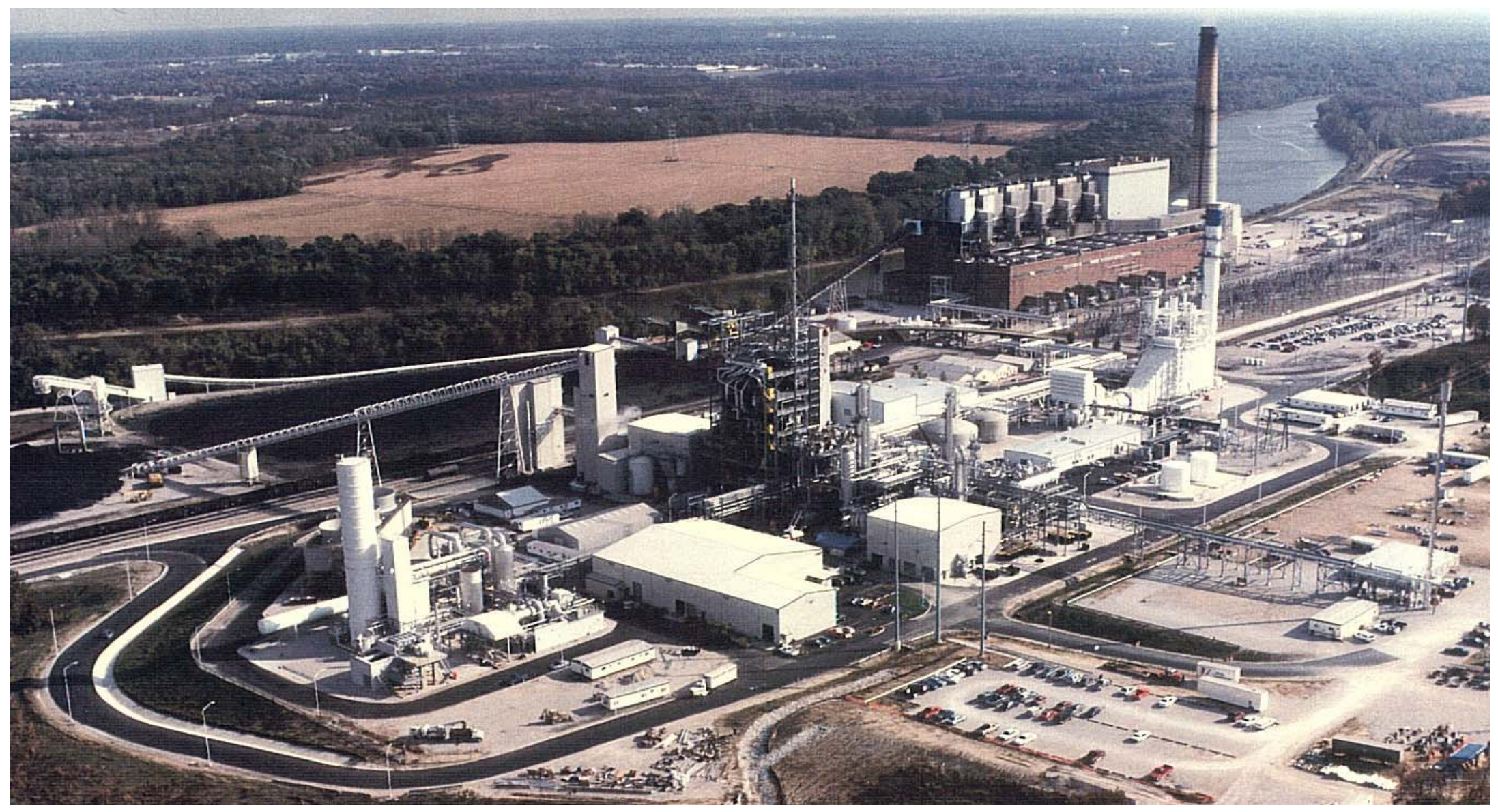




\section{Wabash River Project Overview}

- Coal Gasification Combined Cycle Repowering

- Licensed E-Gas gasification facility

- 262 MWe Net Output by repowering 100 MW 1953 PC Unit

- Operational since 1995

- Bituminous Coal and Petcoke, up to $7 \%$ S

- Heat Rate Improved by 20\% ( $8900 \mathrm{Btu} / \mathrm{kWh} \mathrm{HHV}$ )

- Cleanest Coal/Coke Fired Power Plant in the World

- Highest demonstrated petcoke throughput of any gasifier

- $\quad$ Named Power Plant of the Year in 1996 


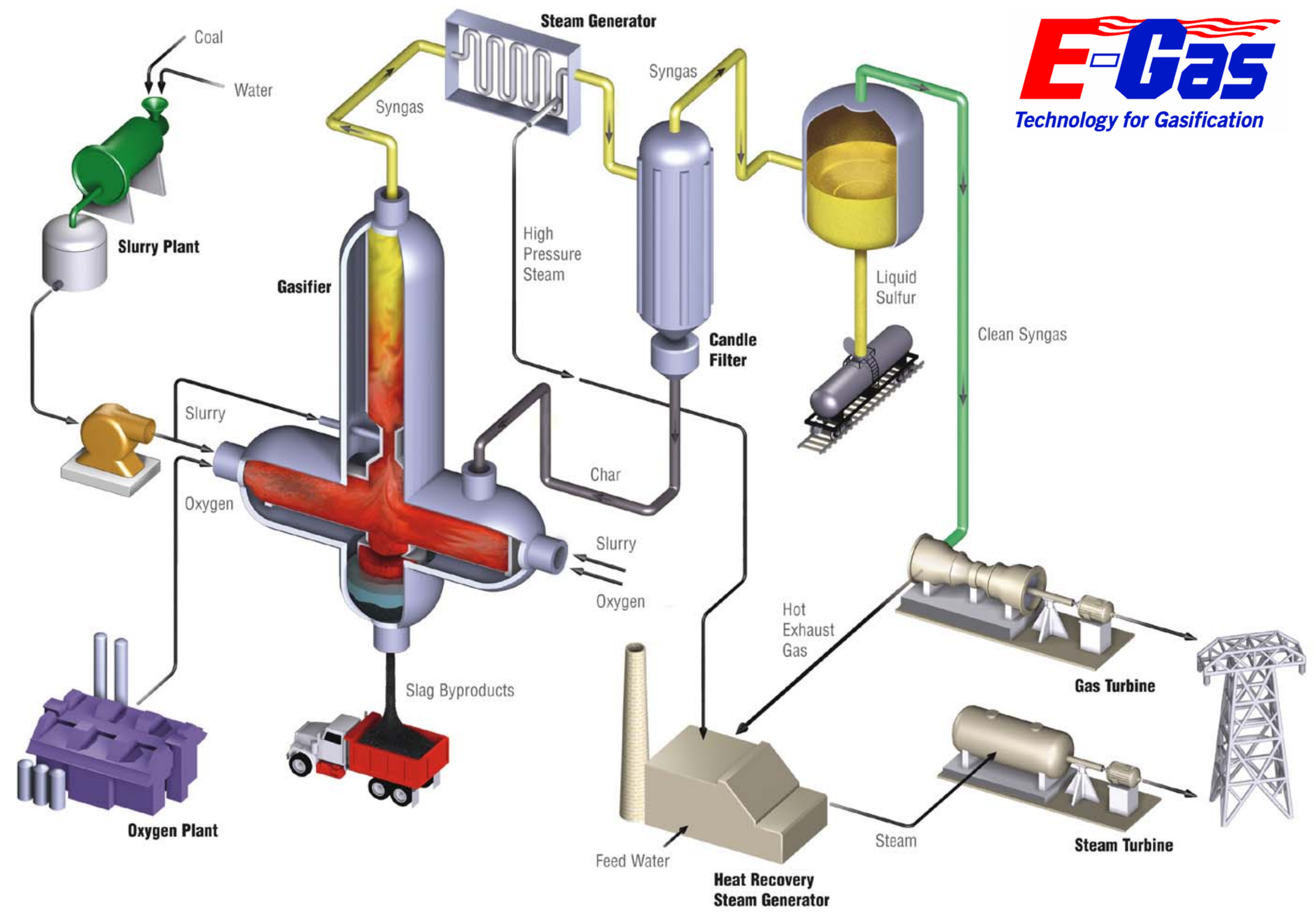




\section{Metal Oxide Impregnated Carbon}

- Sorbent and process system supplied by Nucon International, Inc.

- Activated carbon impregnated with metal oxides

- Removes sulfur compounds to sub-ppm levels

- Sorbent regenerable

- Commercial installation has demonstrated COS removal from a propane stream 


\section{Metal Oxide Impregnated Carbon \\ Laboratory Performance}

- Blended syngas simulates Wabash conditions

- Sulfur removed to sub-ppm levels

- Sorbent successfully regenerated to original capacity

- Absorption capacity for $\mathrm{H}_{2} \mathrm{~S}$ approximately $1.7 \%$ by weight of sorbent
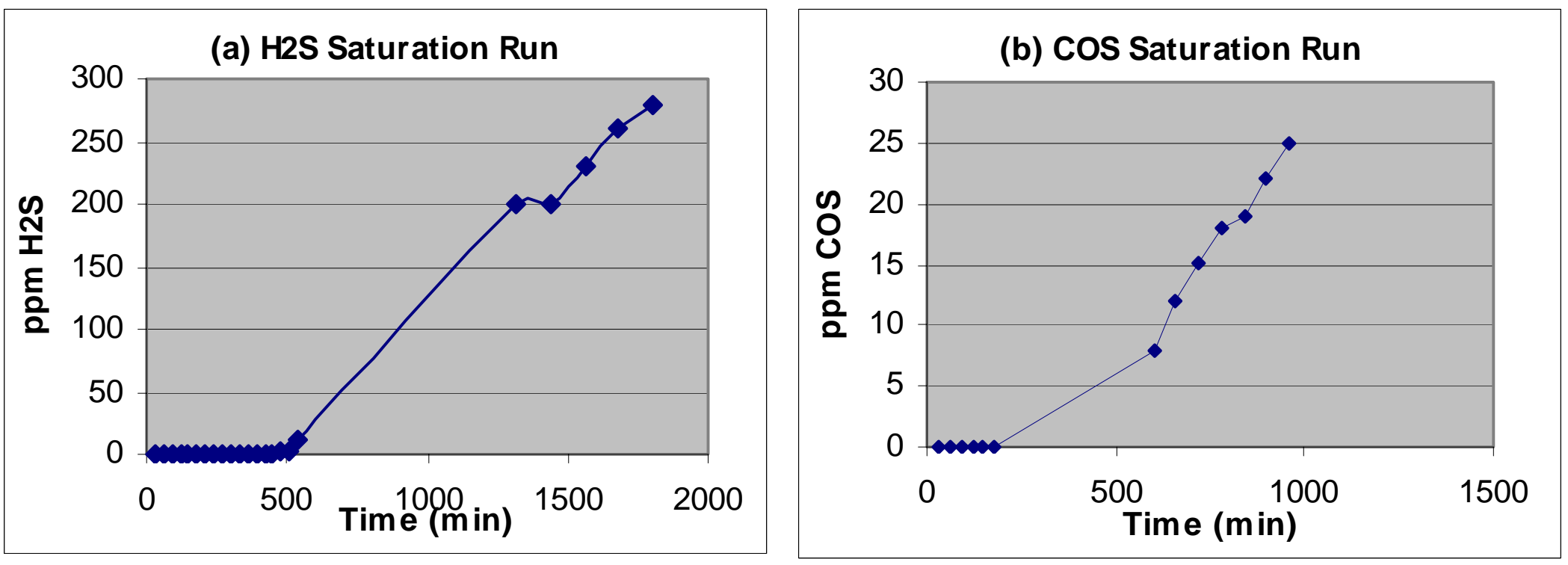


\section{Metal Oxide Impregnated Carbon}

\section{Laboratory Testing Results}

\begin{tabular}{|l|c|c|c|c|c|c|}
\hline Test No. & 1 & 2 & 3 & 4 & 5 & 6 \\
\hline Type of Sorbent & New & Regen'ed & Regen'ed & New & Regen'ed & Regen'ed \\
\hline Impreg. Content, wt\% & 8.0 & 8.0 & 8.0 & 8.0 & 8.0 & 8.0 \\
\hline Bed Weight, g & 16.74 & 16.74 & 16.74 & 16.74 & 16.74 & 16.74 \\
\hline Flow Rate, std. liter/min & 8.3 & 8.3 & 8.3 & 8.3 & 8.3 & 8.3 \\
\hline Temp, ${ }^{\circ}$ C & 37.8 & 37.8 & 37.8 & 37.8 & 37.8 & 37.8 \\
\hline Pressure, psia & 364 & 364 & 364 & 364 & 364 & 364 \\
\hline Residence time, sec & 1.3 & 1.3 & 1.3 & 1.3 & 1.3 & 1.3 \\
\hline H. $_{2}$ Inlet Conc, ppmv & 301 & 301 & 301 & 0 & 0 & 0 \\
\hline COS Inlet Conc, ppmv & 0 & 0 & 0 & 25 & 25 & 25 \\
\hline H$_{2}$ S Breakthrough, min. & 15 & 30 & 30 & - & - & - \\
\hline COS Breakthrough, min. & - & - & - & 15 & 15 & 15 \\
\hline Saturation, min & 150 & - & - & 50 & - & - \\
\hline
\end{tabular}




\section{Metal Oxide Impregnated Carbon}

\section{Slipstream Schematics}

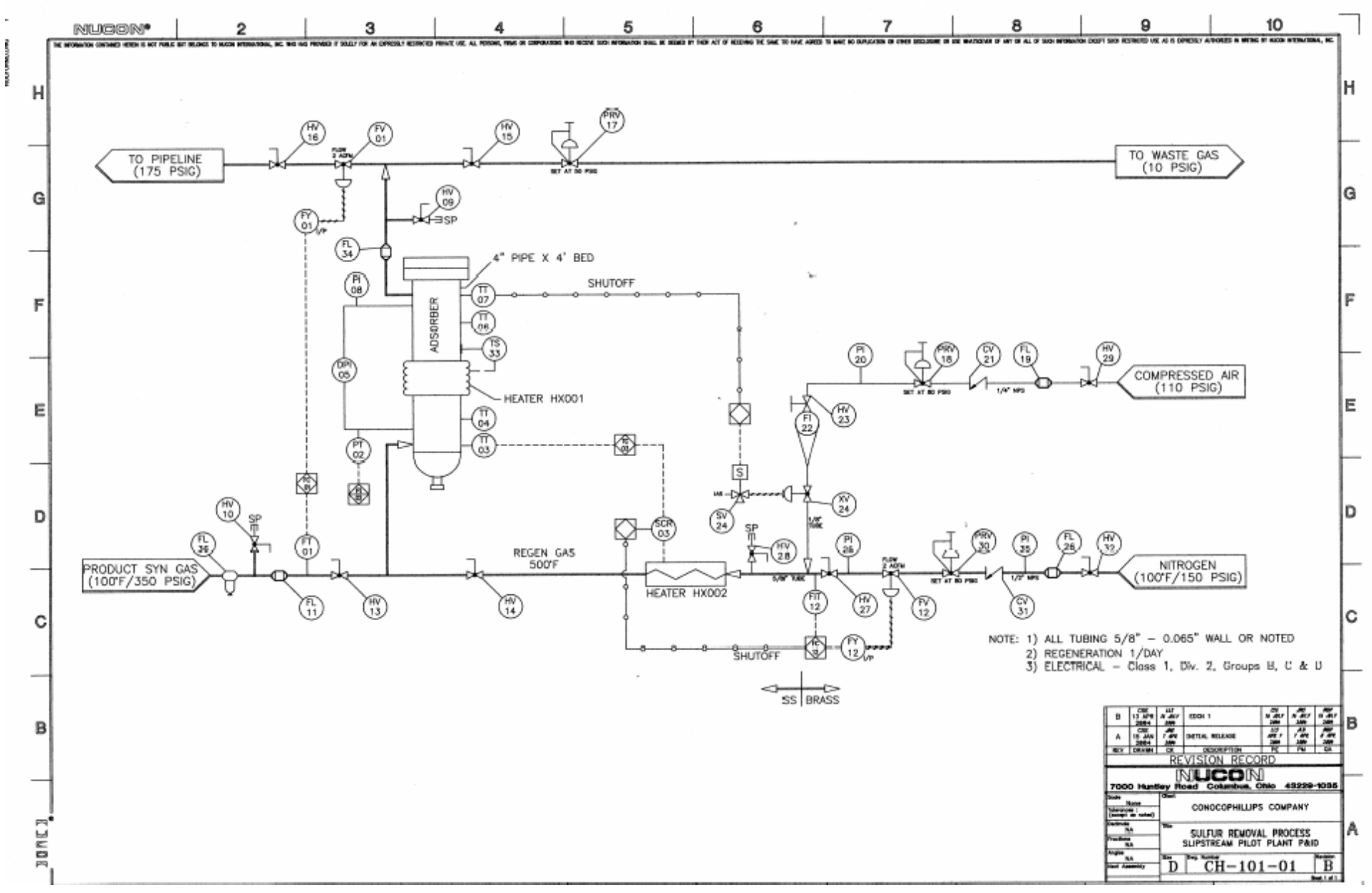




\section{Metal Oxide Impregnated Carbon Slipstream Unit}

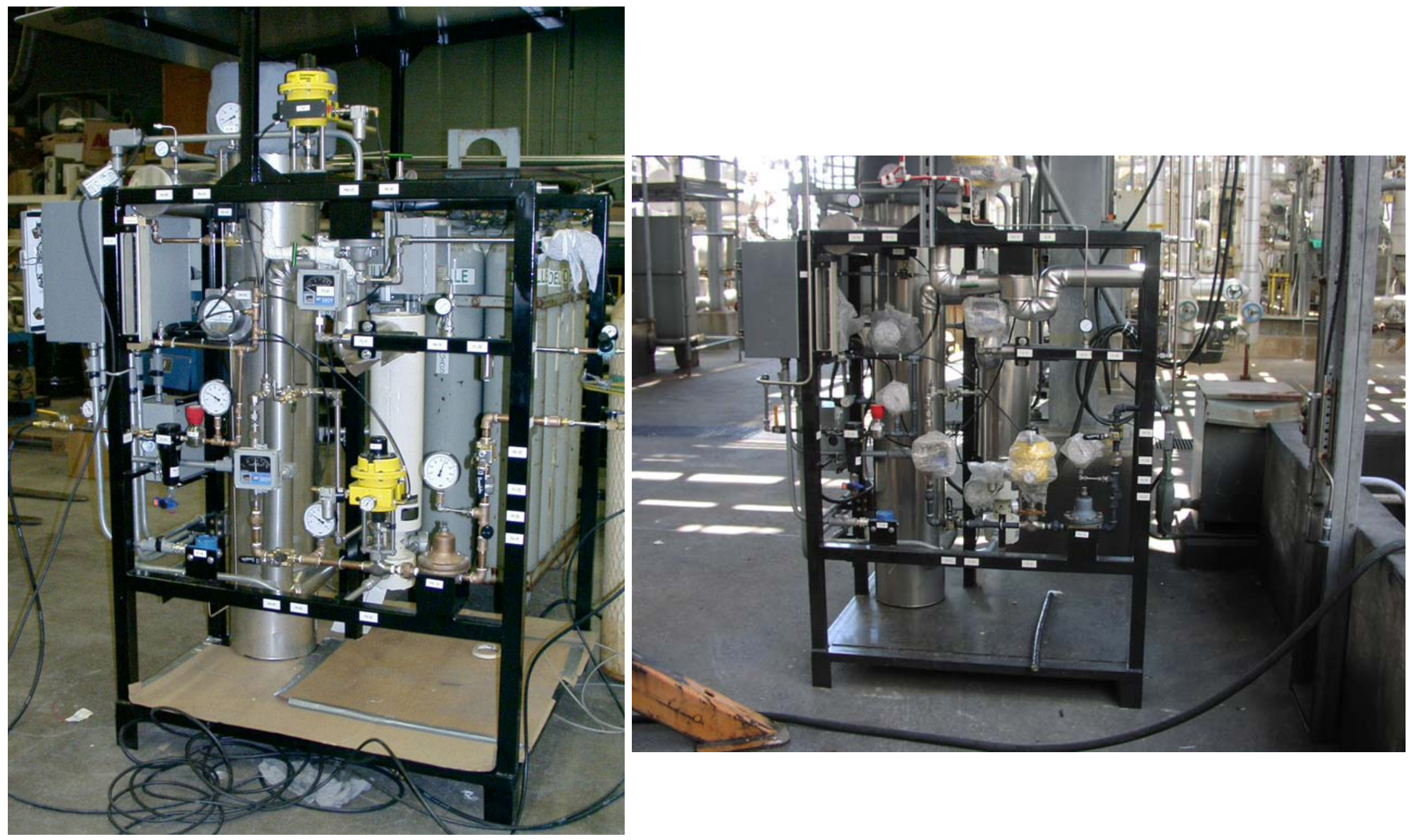




\section{Sulfur Removal Processes for Gasification}
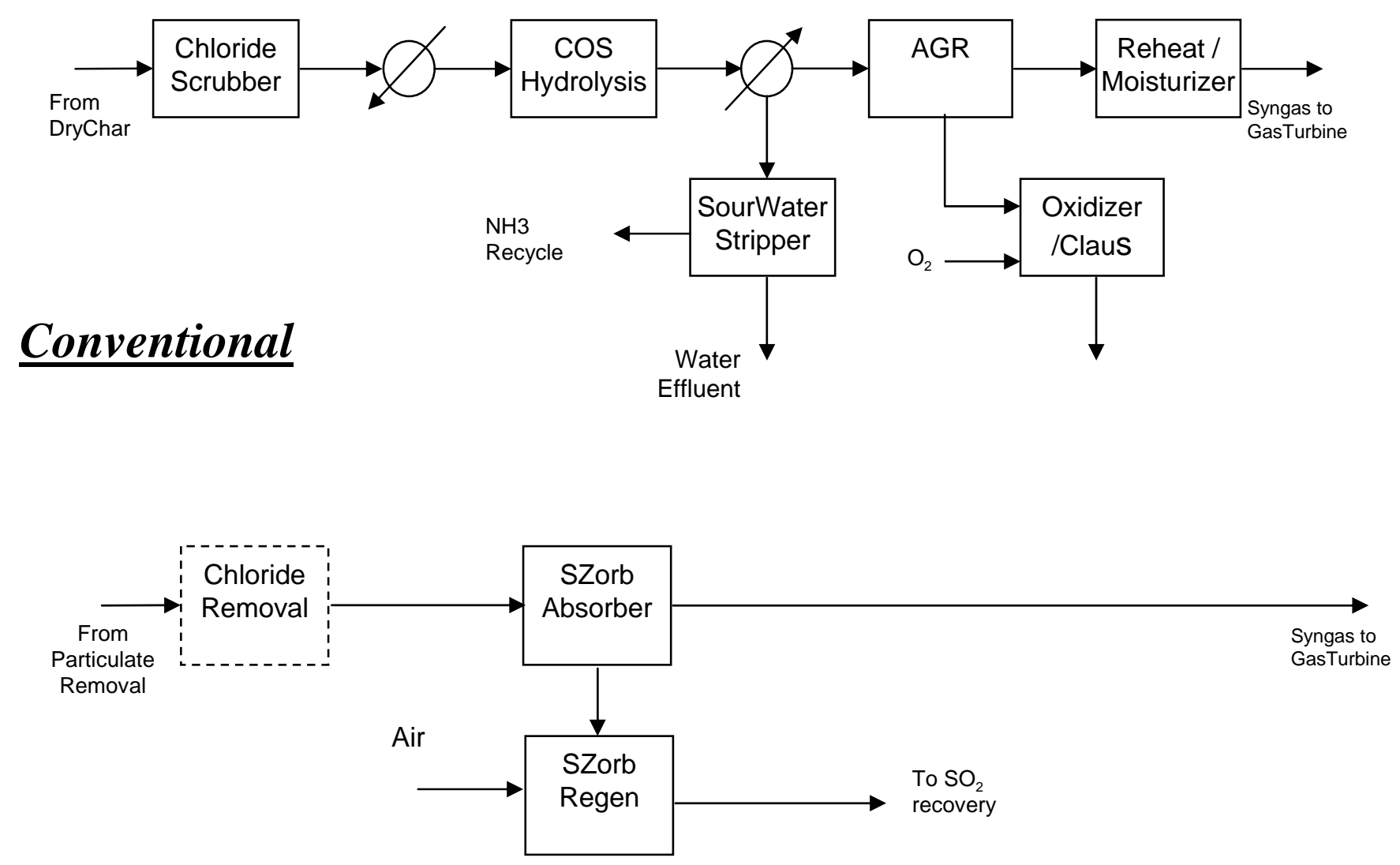

Warm Gas Cleanup 


\section{ConocoPhillips' S Zorb SRT Technology}

- New generation Z Sorb from early 90's

- Developed for removing thiophenic sulfur from gasoline

- Improved activity and attrition resistance

- Fixed and fluidize-bed sorbents

- Three commercial vendors licensed to produce the sorbent

- Commercial-scale units in three COP refineries:

- Borger, TX, since April 2001

- Ferndale, WA, since Dec. 2003

- Lake Charles, La, starting up in Sept. 2005 


\section{ConocoPhillips}

- NYSE: COP

- Eighth largest publicly owned energy company - based on oil \& gas reserves

- Third largest integrated energy company in the United States

- Largest refiner in US, $4^{\text {th }}$ in world

- World's leading producer of petroleum coke

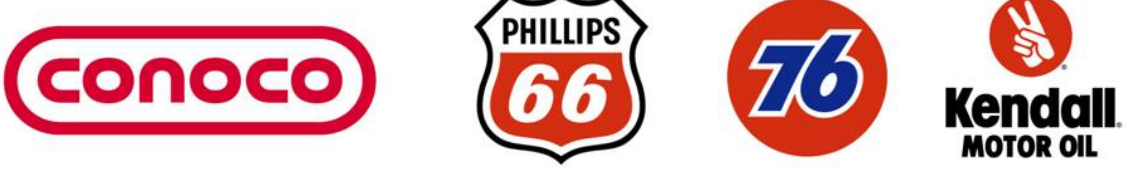

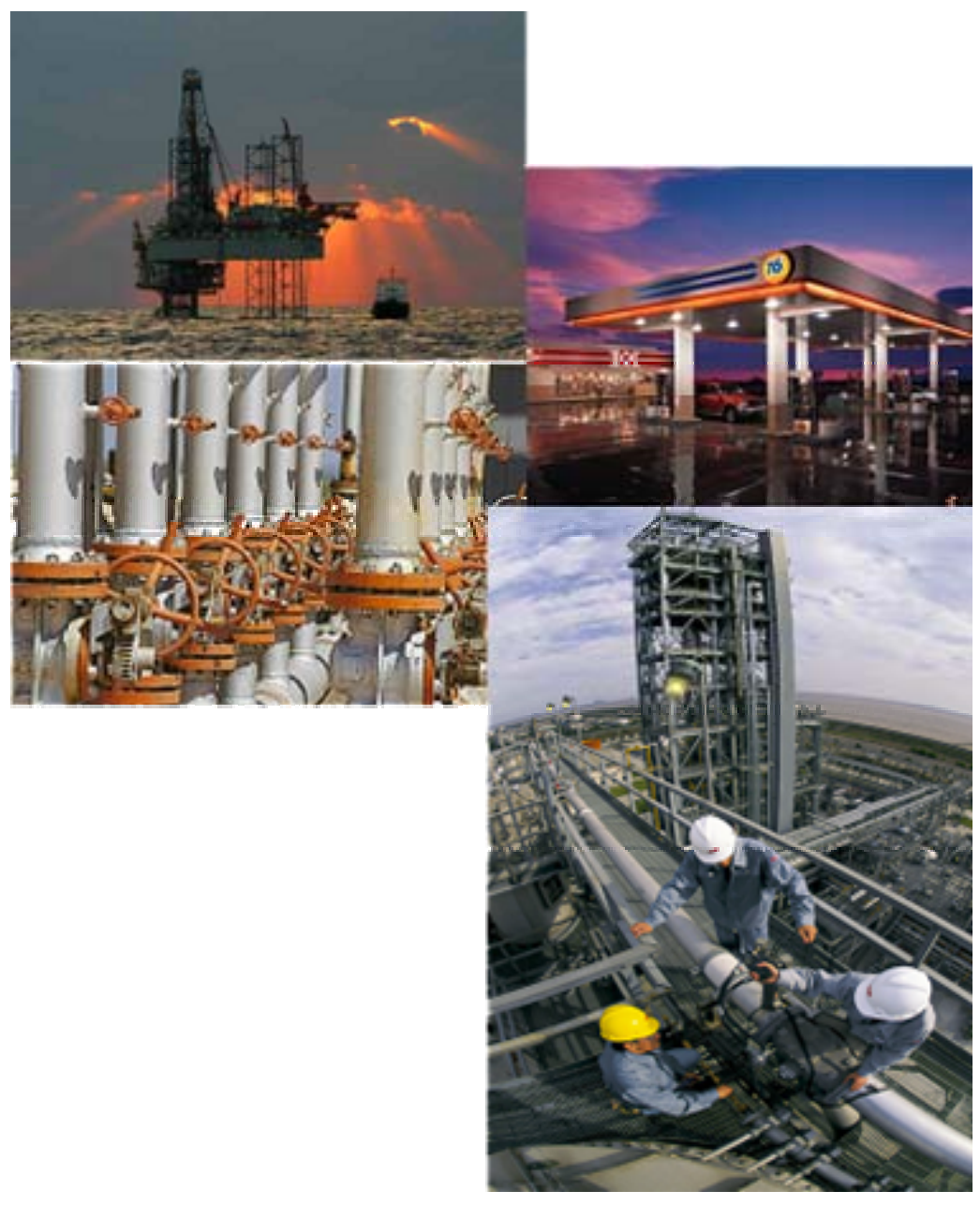




\section{LICENSED TECHNOLOGIES}

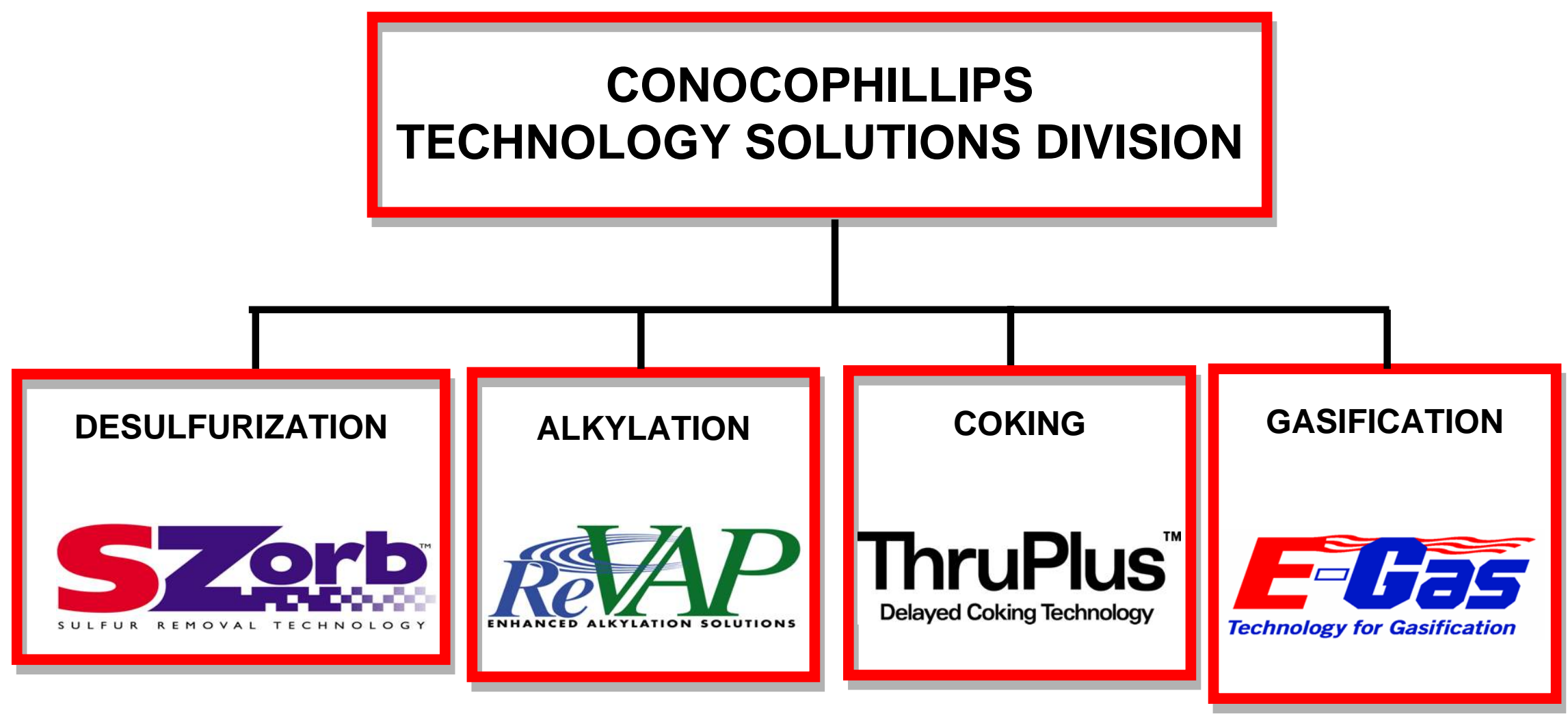




\section{S Zorb SRT Process}

\section{[for gasoline desulfurization]}

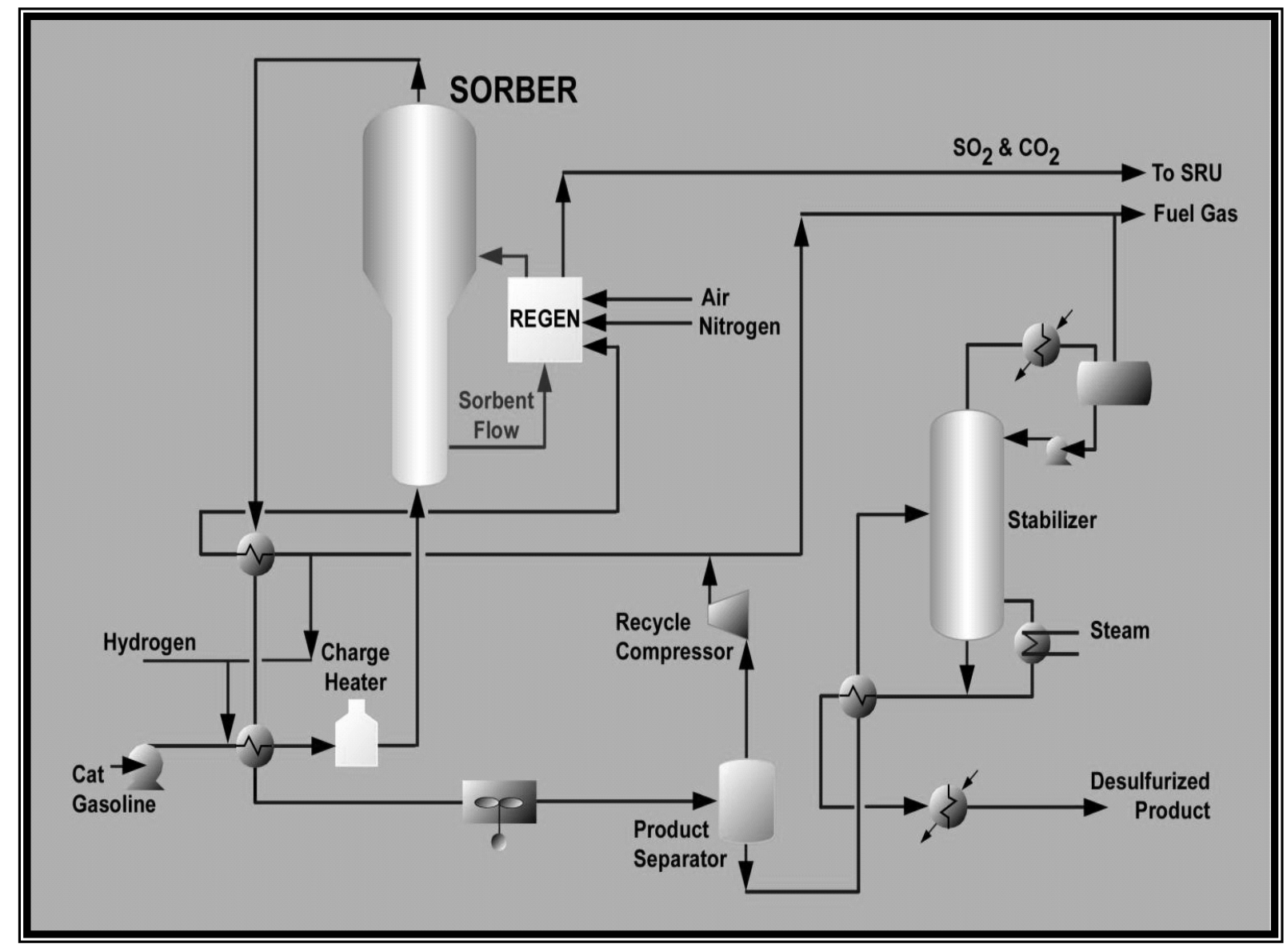

ConocoPhillips 


\section{S Zorb Laboratory Testing Unit}
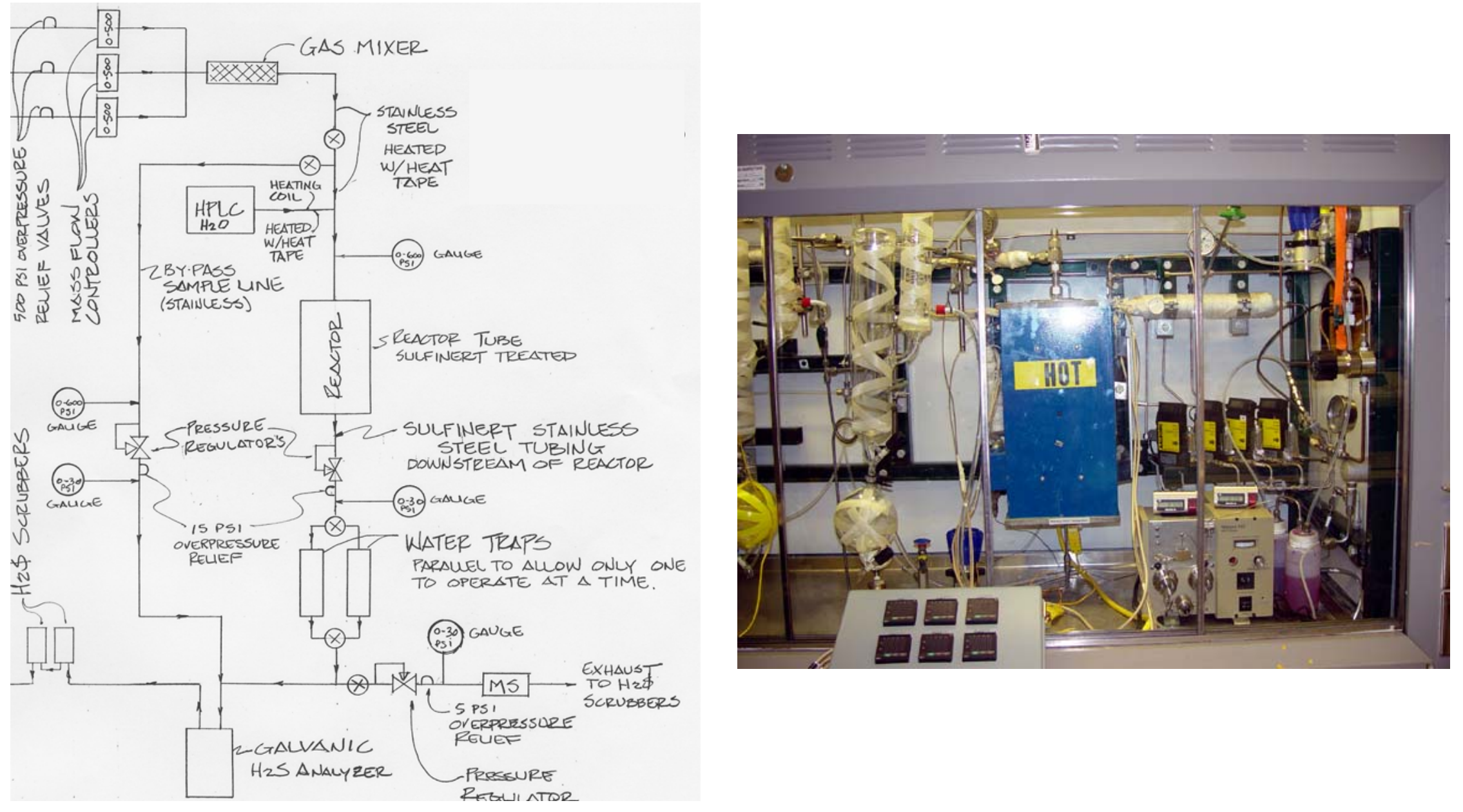


\section{S Zorb Warm Gas Desulfurization Laboratory Testing Results}

- Fixed-bed pressurized system

- Blended syngas similar to Wabash, diluted with $\mathrm{N}_{2}$

- Test conditions:

- Absorption at 600-800F and 350 psig, <1 ppm $\mathrm{H}_{2} \mathrm{~S}$

- Regen at 800-1000F with air $/ N_{2}$

- Sorbent capacity $>10 \%$ wt. of sulfur

- Regen conditions for gasoline desulfurization slightly modified for $\mathrm{H}_{2} \mathrm{~S}$ /syngas application

- Fifteen-cycle test completed with no sorbent deterioration 


\section{S Zorb Slipstream Unit}

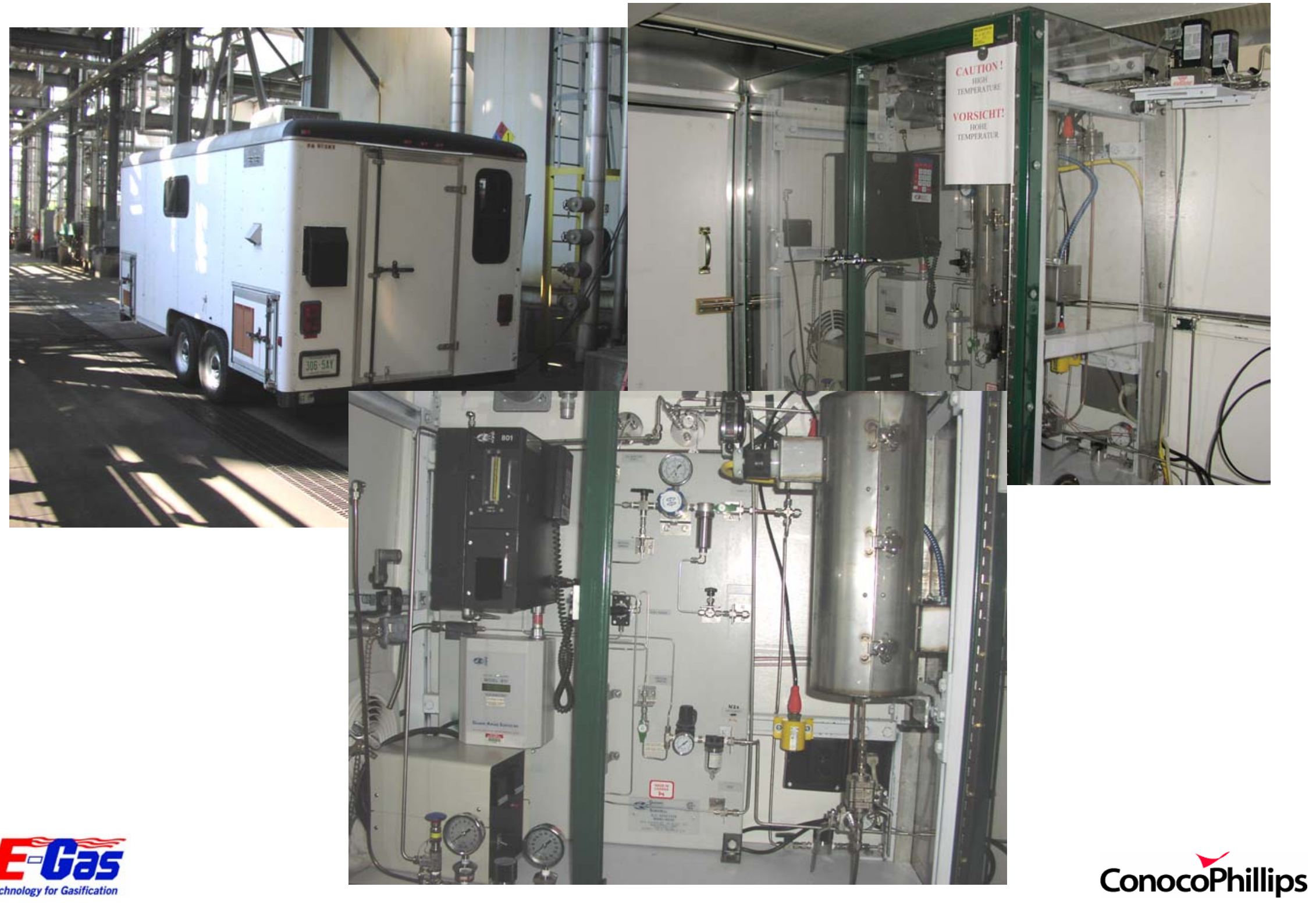




\section{Project Plans}

- Startup slipstream unit to evaluate Nucon's metal oxide impregnated carbon

- 4-5 weeks' startup/testing

- Sampling for trace metals including mercury

- Install and startup the slipstream unit to evaluate ConocoPhillips'S Zorb SRT sorbent

- 4-5 weeks' startup/testing

- Sampling for trace metals including mercury 


\section{Acknowledgements}

- Financial support from DOE/NETL under Cooperative Agreement No. DE-FC26-40659

- Mr. Joe Enneking and the Nucon engineering staff for their support

- Dr. Ed Sughrue of ConocoPhillips for his technical guidance 


\section{APPENDIX V}

“Sulfur Removal from E-Gas ${ }^{\mathrm{TM}}$ Technology Gas Streams using SZorb ${ }^{\mathrm{TM}}$ Sorbent”

Presented in the

$23^{\text {rd }}$ International Pittsburgh Coal Conference

September 27, 2006 


\title{
Sulfur Removal from E-Gas Gas Streams with S Zorb ${ }^{\mathrm{TM}}$ Sulfur Removal Technology (SRT)
}

\author{
by \\ Roland Schmidt, Joe Cross, Albert Tsang and Ed Sughrue, \\ ConocoPhillips Company \\ Robert Kornosky, U. S. Department of Energy, National Energy Technology \\ Laboratory
}

\begin{abstract}
The SG Solutions (SGS) facility in Terre Haute, IN produces syngas (hydrogen/carbon monoxide stream) for power generation using ConocoPhillips' E-Gas ${ }^{\mathrm{TM}}$ Technology to gasify coal or petroleum coke. The syngas can contain high levels of sulfur contaminants (>1 weight \%). These contaminants must be removed from the gas stream prior to power generation. ConocoPhillips' proprietary $\mathrm{S}$ Zorb $^{\mathrm{TM}}$ sulfur removal technology (SRT) utilizes proprietary sorbents that can remove these sulfur contaminants under warm-gas conditions. A slipstream study at the SGS facility demonstrated sulfur reduction to ppm levels under plant operating conditions.

The work used ConocoPhillips' proprietary S Zorb ${ }^{\mathrm{TM}}$ sorbents as part of a test program under the "Wabash River Integrated Methanol and Power Production from Clean Coal Technologies (IMPPCCT)" Project funded by the U.S. Department of Energy Cooperative Agreement No. DE-FC26-99FT40659, and managed by the National Energy Technology Laboratory.
\end{abstract}

\section{Introduction}

The SG Solutions (SGS) facility in Terre Haute, IN utilizes ConocoPhillips' (COP) E-Gas technology to gasify coal or petroleum coke, to produce syngas (hydrogen/carbon monoxide) for power generation [1,2]. The syngas contains high levels of sulfur contaminants (>1 wt.\%). These contaminants must be extracted from the gas stream prior to power generation. An adsorption process using S Zorb ${ }^{\mathrm{TM}}$ SRT sorbents was investigated as a cost reducing technology to remove these sulfur contaminants under warm-gas conditions $\left(350-430{ }^{\circ} \mathrm{C}\right.$, 350-450 psi). 
Conventionally, the produced gas undergoes multiple cleaning steps including amine scrubbers for sulfur removal (AGR) (see Figure 1). These scrubbers require a gas cool down, from $400{ }^{\circ} \mathrm{C}$ to near ambient temperatures. After the amine scrubbers, the desulfurized syngas is reheated to $\sim 250^{\circ} \mathrm{C}$ before it is sent to power generating turbines [3]. The energy penalties associated with these temperature changes can result in efficiency losses and expenses. In addition, the scrubbing agent's regeneration is costly and cumbersome.

Figure 1: Conventional gas clean-up system.

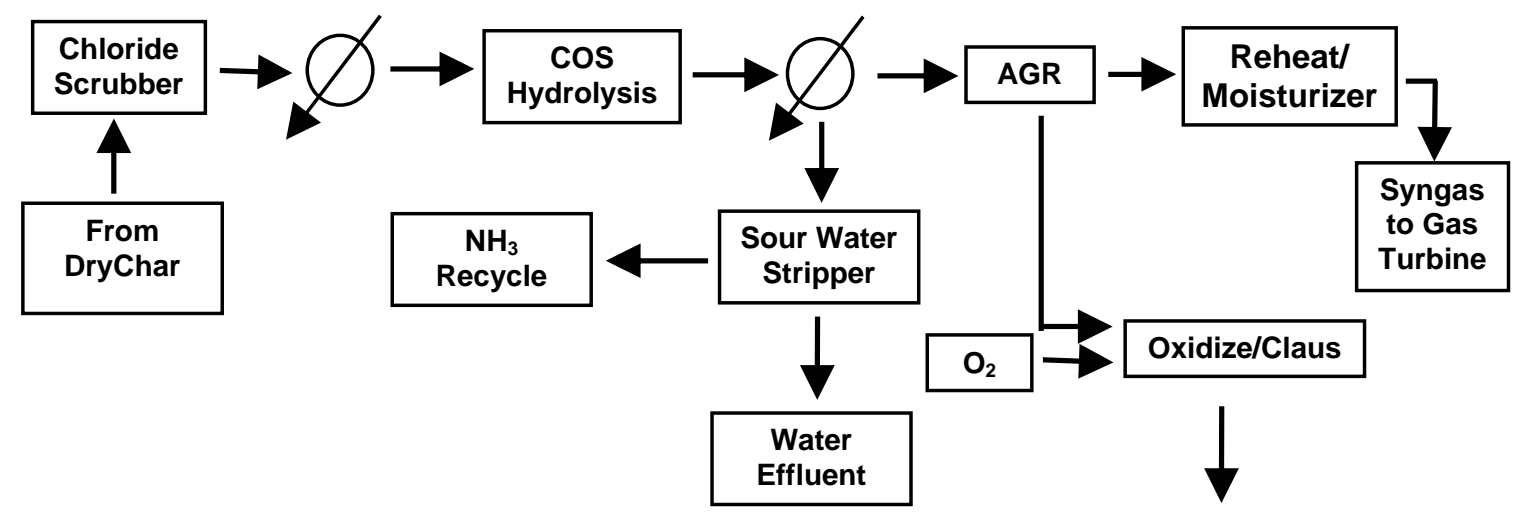

Replacing amine scrubbers with a technology that operates under warm-gas conditions can lead to significant cost reductions. Such a technology can improve the E-Gas technology efficiency and its competitiveness. S Zorb ${ }^{\mathrm{TM}}$ SRT sorbent allows simplified and cost effective process design (see Figure 2).

Figure 2: Simplified gas clean-up employing S Zorb ${ }^{\mathrm{TM}}$ SRT sorbent.

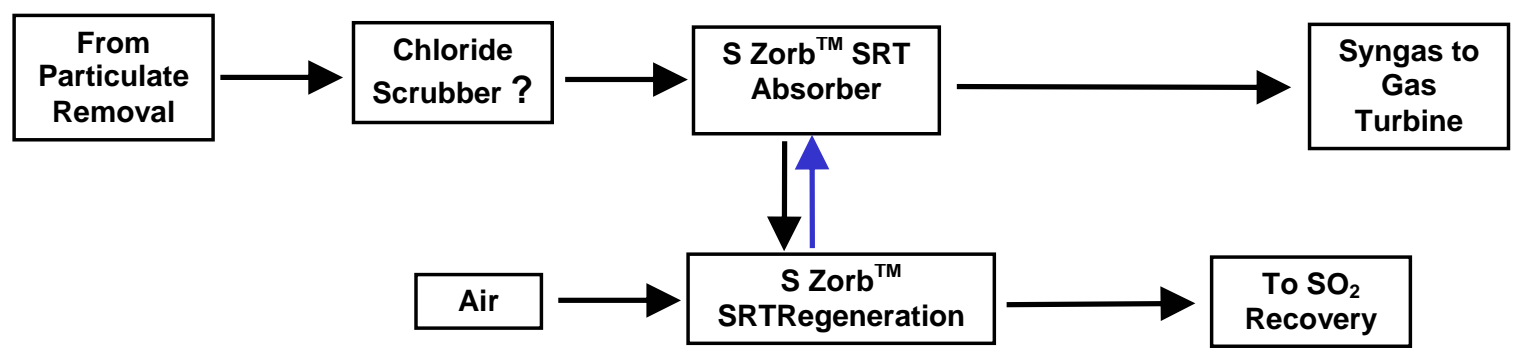

\section{Experimental}

In order to prove the concept that S Zorb ${ }^{\mathrm{TM}}$ SRT sorbent is able to remove sulfur contaminants under warm-gas conditions, the sorbent was exposed to a slipstream from the E-Gas process at SGS. The main components of the slipstream were $\mathrm{CO}, \mathrm{H}_{2}$, steam, $\mathrm{CO}_{2}$ and hydrogen sulfide $\left(\mathrm{H}_{2} \mathrm{~S}\right)$. 
Six sulfur loading and sorbent regeneration cycles, under plant conditions, were performed. Sulfur breakthrough, was measured by a Galvanic Sulfur Analyzer (Galvanics Applied Science, Model 902D2) that has the capability to measure sulfur to a detection limit of less than $1 \mathrm{ppm}$. Other components in the stream were analyzed by on-line mass spectrometry (ESS EcoSys ${ }^{\circledR}$ Instrument). When loaded with sulfur, the spent sorbent was regenerated with air and reused. Oxygen uptake and $\mathrm{SO}_{2}$ generation, measured by mass spectrometry, determined the time spent for regeneration.

In order to investigate the sorbent's changes during loading and regeneration; sorbent samples were collected after each sulfur loading and regeneration experiment from the top of the sorbent bed. These samples were analyzed by $\mathrm{x}$ ray fluorescence (XRF) to determine the sulfur loading and the amount of sulfur that remained after regeneration and by $\mathrm{x}$-ray diffraction (XRD) to determine if any changes occurred to the sorbent structure. In addition $\mathrm{C}, \mathrm{H}, \mathrm{N}, \mathrm{S}$-analysis and attrition tests were performed on selected samples of the sorbent to further assess changes to the sorbent during the loading and regeneration cycles.

The sorbent was placed in a downflow fixed-bed reactor and heated to $420{ }^{\circ} \mathrm{C}$. The operational E-Gas slipstream pressure was $\sim 410$ psi. The feed contained high levels of steam (dew point $\sim 150^{\circ} \mathrm{C}$ ) that had to be kept in the gas phase during the sulfur absorption cycle.

After each absorption cycle, S Zorb ${ }^{\mathrm{TM}}$ sorbent was regenerated in air. Hot nitrogen dried the sorbent prior to air introduction. The regeneration starting conditions were $400{ }^{\circ} \mathrm{C}$ and $100 \mathrm{ml} / \mathrm{min}$ air flow. Both parameters were increased stepwise to a final setting of $550{ }^{\circ} \mathrm{C}\left(30-50{ }^{\circ} \mathrm{C}\right.$ increments) and an air flow of $1 \mathrm{~L} / \mathrm{min}\left(100 \mathrm{ml} / \mathrm{min}\right.$ to $250 \mathrm{ml} / \mathrm{min}$ steps). Oxygen and $\mathrm{SO}_{2}$ levels were monitored in the combustion off-gases to determine that the regeneration was complete.

\section{Results \& Discussion}

Sulfur concentration was reduced by use of $\mathrm{S}$ Zorb ${ }^{\mathrm{TM}}$ sorbent from $>1.2 \mathrm{wt} . \%$ down to the analyzer's detection limit of 1-4 ppm. Removal efficiencies $>99.97 \%$ were achieved for typically 1.5 hours. As shown in Figures $3 \& 4$, sulfur removal continued for several hours. The removal efficiency remained between 92-98\% for several hours before reaching the termination point of $1000 \mathrm{ppm}$ (see Figure 3). 
Figure 3: Total sulfur removal measured by a Galvanics sulfur analyzer

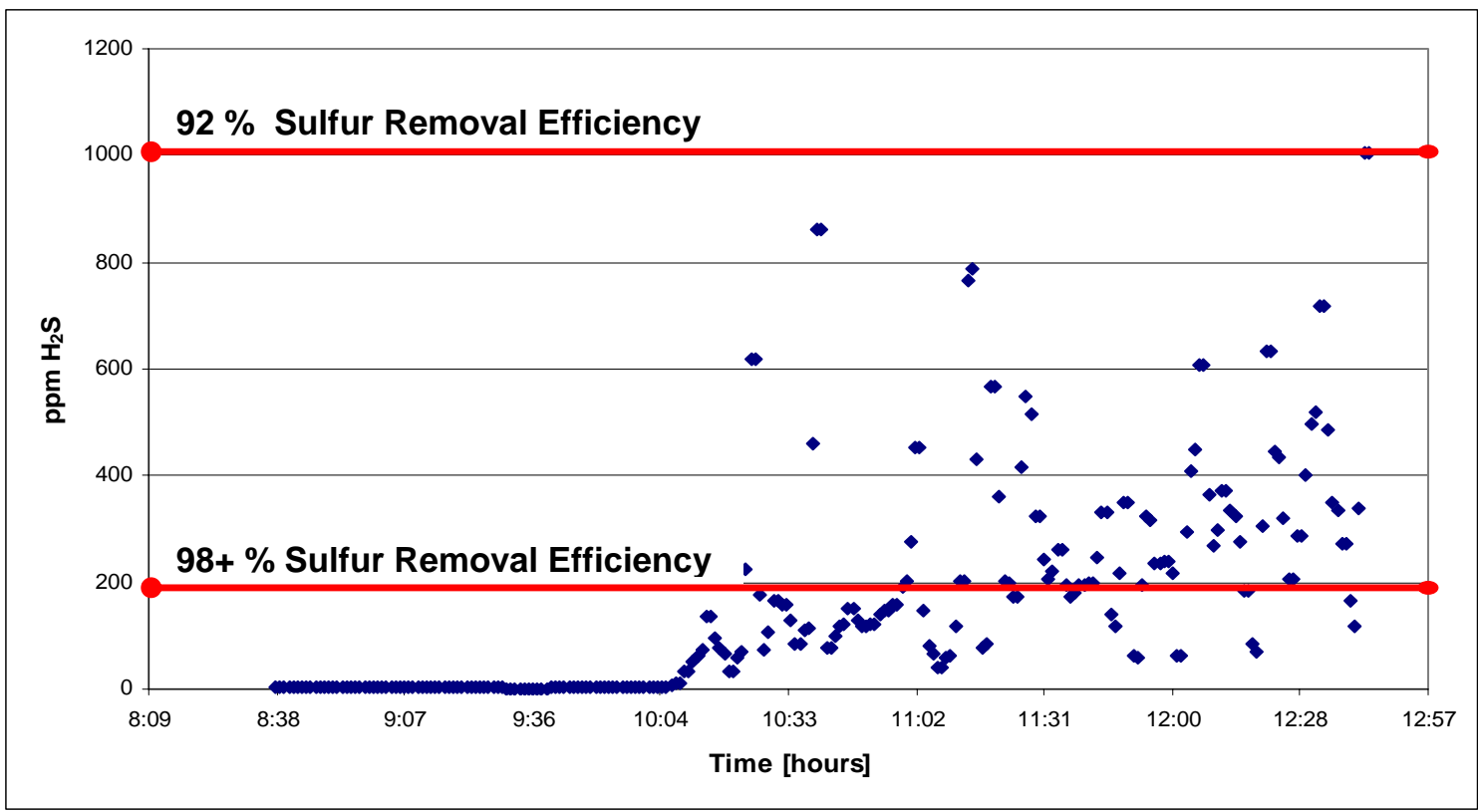

$\mathrm{S}$ Zorb ${ }^{\mathrm{TM}}$ sorbent also removed $\mathrm{COS}$ and $\mathrm{HCl}$ to their detection limit. These feed contaminants broke through simultaneously with the $\mathrm{H}_{2} \mathrm{~S}$ (see Figure 4).

Figure 4: Corresponding Mass Spectrometer data at sulfur breakthrough point

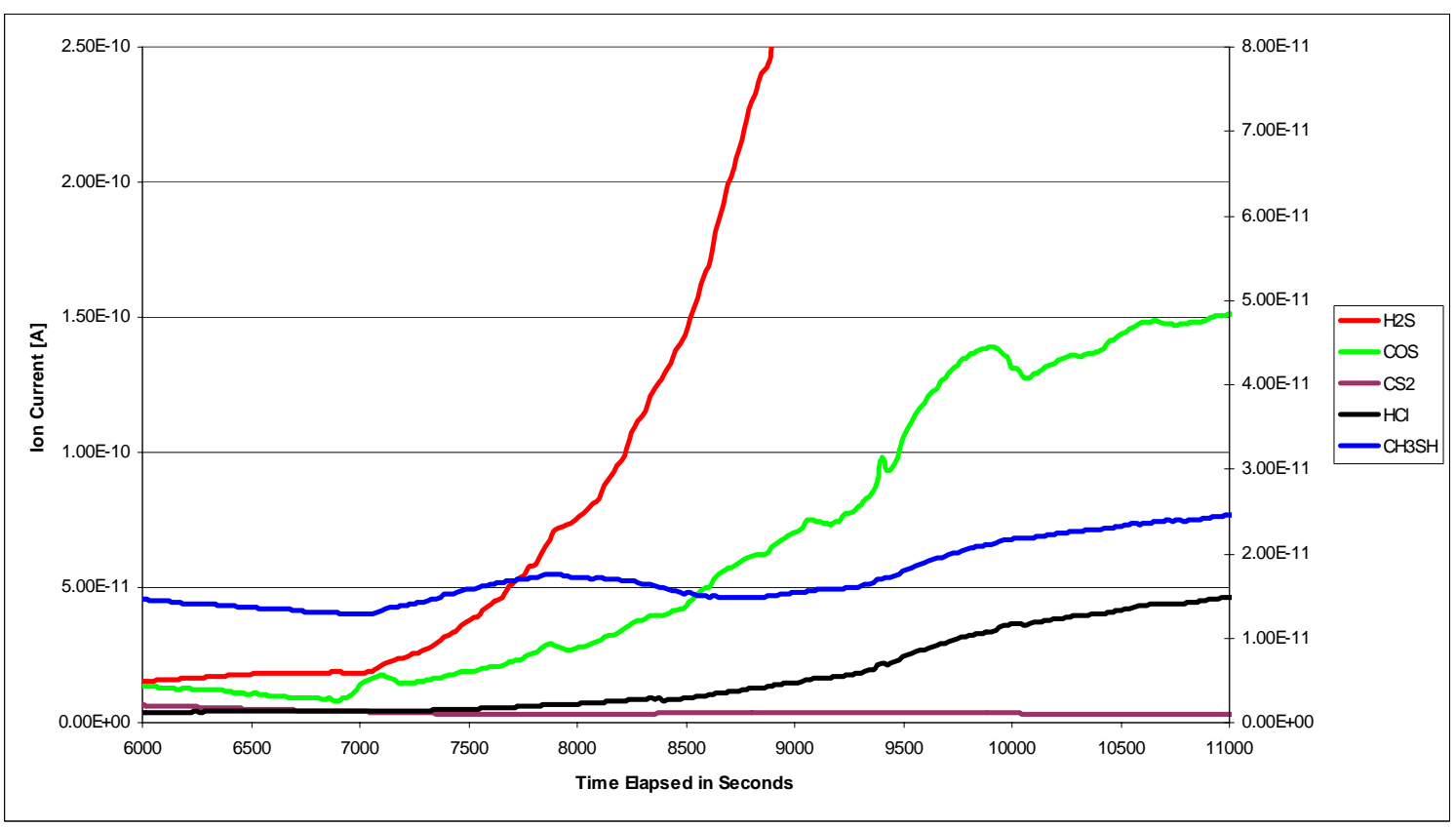


During sulfur loading a small amount of carbon deposited as coke on the sorbent. The carbon deposits varied between 0.2-0.5 wt.\%. During regeneration this coke burned-off as $\mathrm{CO}_{2}$ before $\mathrm{SO}_{2}$ was detected from combustion of sulfur deposits (see Figure 5). Note that the $\mathrm{CO}_{2}$ scale is approximately $40 \mathrm{x}$ smaller than the $\mathrm{SO}_{2} / \mathrm{O}_{2}$ scale.

Figure 5: Mass Spectrometer data of sorbent regeneration

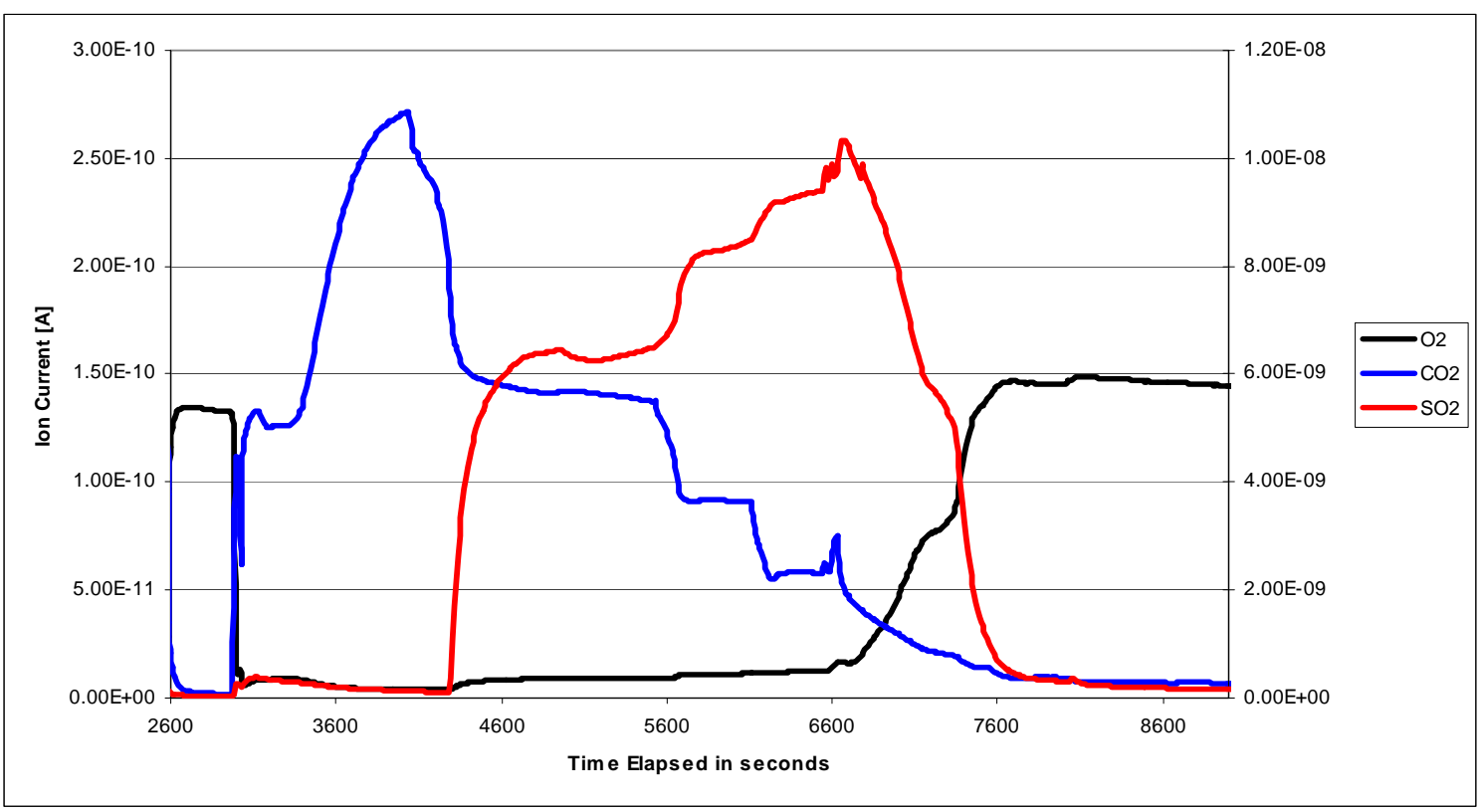

Sulfur Loading Capacity: XRF examination showed an average of about $25 \mathrm{wt} . \%$ sulfur loading on the sorbent samples taken from the top of the sorbent bed as described in the experimental section above.

In a separate experiment (i.e. different sorbent sample loaded in the reactor bed), after sulfur loading, the reactor bed was unloaded in four different sections and each section analyzed separately. After sulfur breakthrough, these samples showed sulfur loadings ranging from about $20 \mathrm{wt} . \%$ at the top of the sorbent bed to 17 wt.\% at the bottom (See Figure 6). 
Figure 6: Sulfur loading at various sorbent zones.

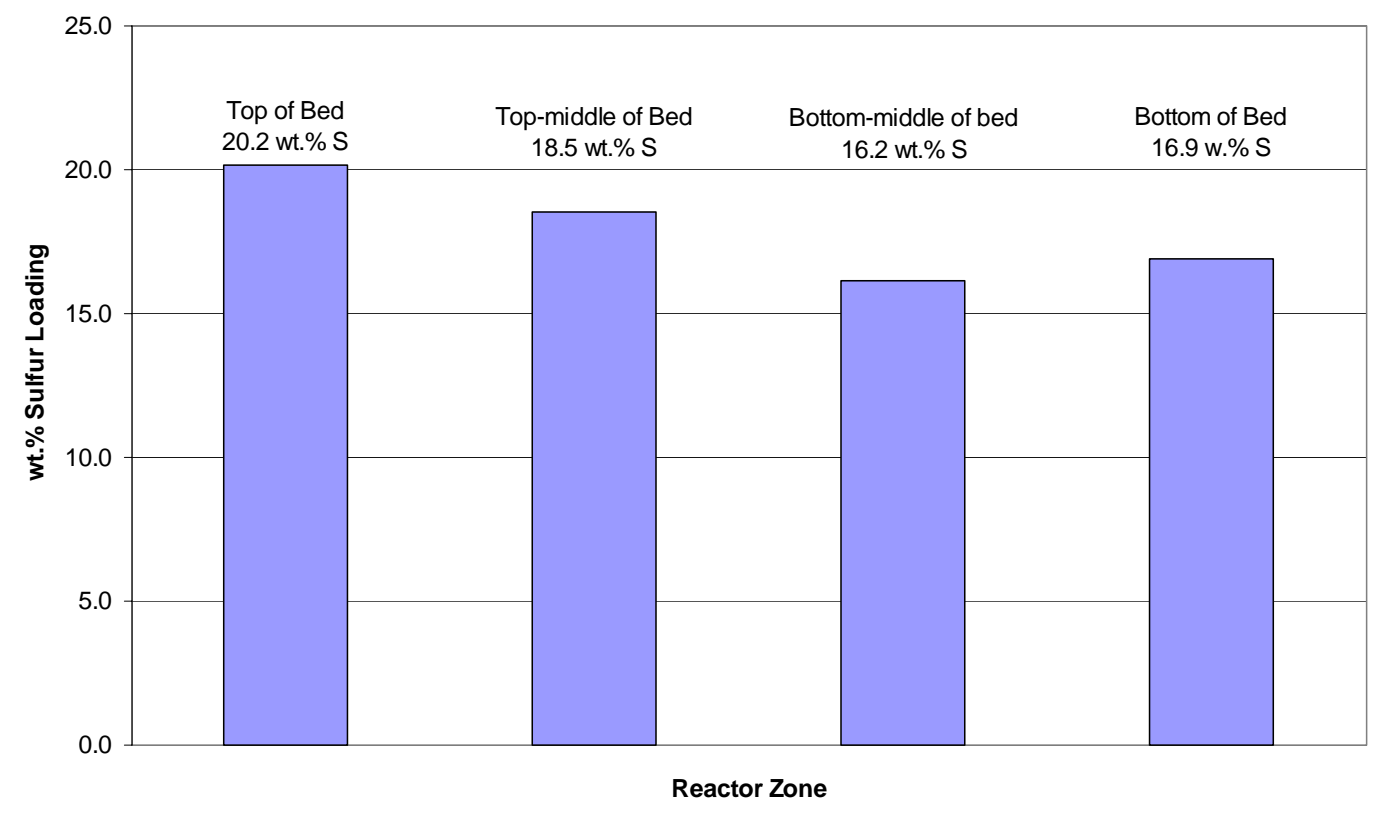

Sulfur Remaining after Regeneration: In the 6 cycle experiments, the average regeneration efficiency was $87.5 \%$ (sulfur content after regeneration vs. sulfur content after sulfur absorption). An average of $3.5 \mathrm{wt} . \%$ sulfur remained on the sorbent (See Figure 7).

Figure 7: Sorbent removal efficiency

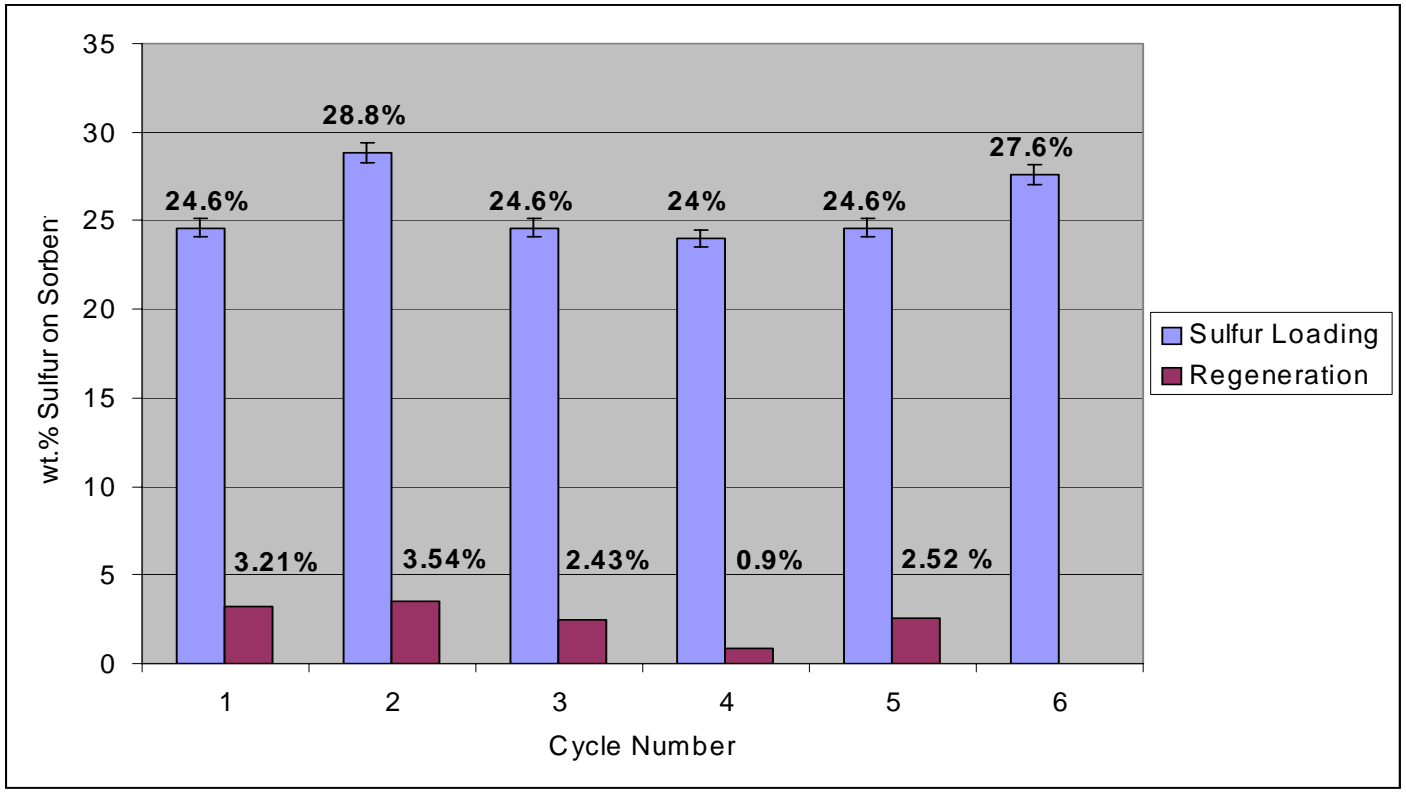




\section{Conclusions \& Recommendations}

This study has demonstrated the technical feasibility of using $S$ Zorb ${ }^{\mathrm{TM}}$ sorbent under warm gas conditions as a sulfur removal technology for the E-Gas process. The sorbent, as tested in a fixed bed reactor, successfully removed the sulfur contaminants, reaching near theoretical sulfur loading capacity of the sorbent, with very low sulfur levels $(<5 \mathrm{ppm})$ measured at the reactor outlet through most of the absorption cycle.

\section{Acknowledgements}

Financial support for this work from DOE/NETL under Cooperative Agreement No. DE-FC26-99FT40659 is gratefully acknowledged. Bob Levingston, Gary Young, Jon Nelson and Dennis Schultz significantly contributed to the success of this project.

\section{References}

[1] National Geographic, March 2006, pp. 98-103.

[2] A. Tsang, J. Cross, R. Schmidt, C. Summers, R. Kornosky, Proceedings - Annual International Pittsburgh Coal Conference $22^{\text {nd }}, 2005$.

[3] A. Tsang, private communication, April 2006. 


\title{
ConocoPhillips
}

Sulfur Removal from E-Gas ${ }^{\mathrm{TM}}$ Gas Streams with S Zorb ${ }^{\text {TM }}$ Sulfur Removal Technology (SRT)

\author{
By \\ Roland Schmidt \\ Joe Cross \\ Albert Tsang \\ Ed Sughrue, and \\ Robert Kornosky (NETL)
}




\section{Overview}

-Who is ConocoPhillips ?

- Technology Overview

- EGas ${ }^{\mathrm{TM}}$ gasification technology

- Field Data Review (Fixed Bed Results)

- Effect on Total Sulfur

- Change in Specific Gases

- Sorbent Loading

- Sorbent Regeneration

- Conclusions

- Acknowledgements 


\section{ConocoPhillips}

- NYSE: COP

- Third largest international, integrated energy company in the US based on market capitalization and oil \& gas reserves \& production

- $2^{\text {nd }}$ largest refiner in US, $4^{\text {th }}$ in world

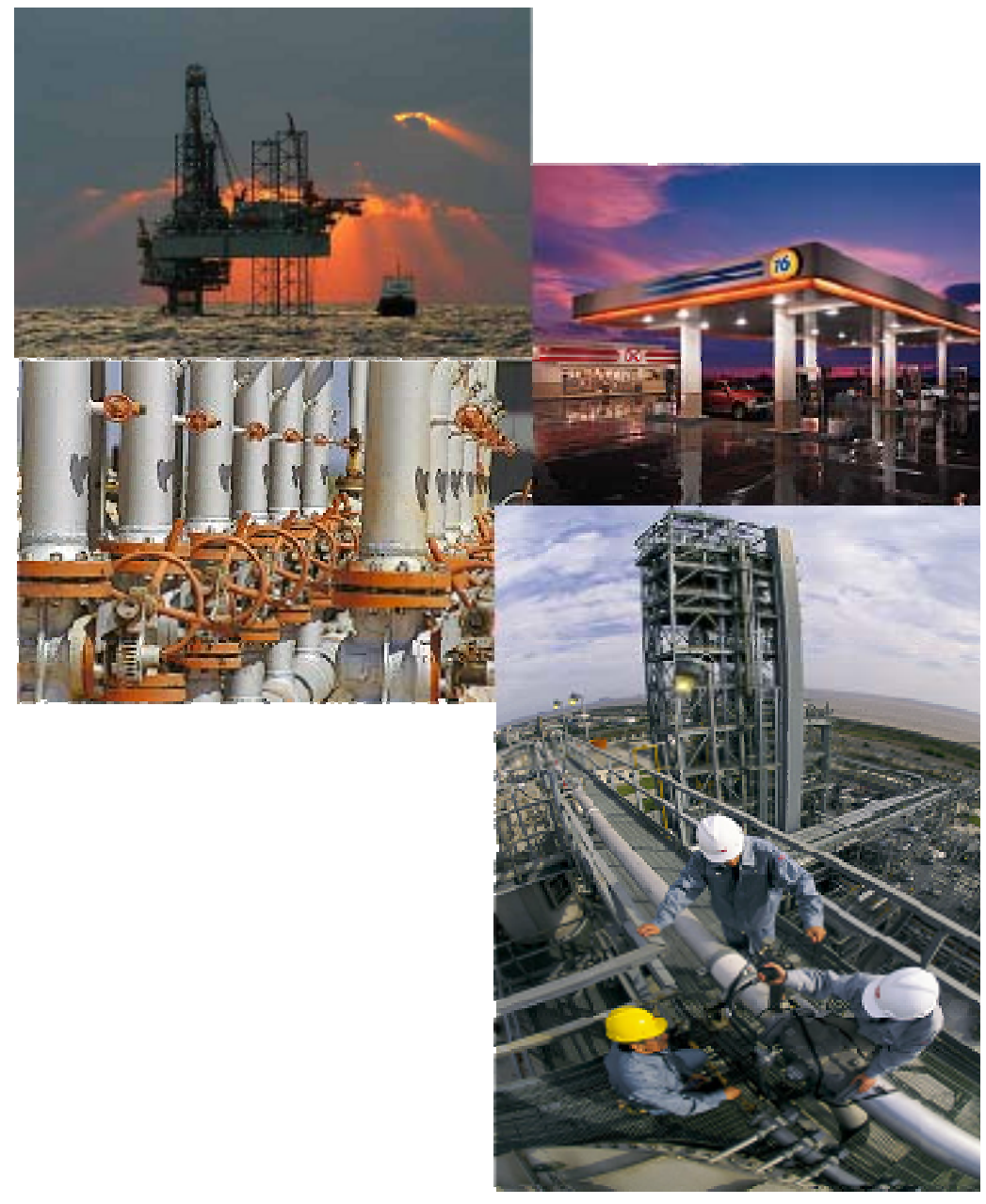

- $5^{\text {th }}$ largest company worldwide based on proved reserves

- World's leading producer of petroleum coke

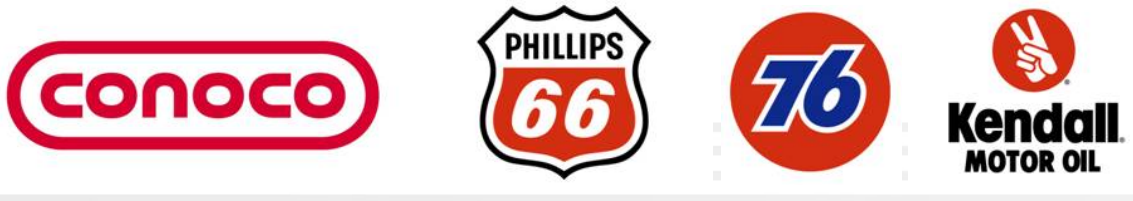




\section{What is E-Gas ${ }^{\mathrm{TM}}$ ?}

- $\mathrm{C}$ (Petcoke, Coal) $+\mathrm{O}_{2}+\mathrm{H}_{2} \mathrm{O} \longrightarrow \mathrm{H}_{2}+\mathrm{CO}+\mathrm{CO}_{2}+$ Steam

- $400^{+}$psi \& $400^{+\circ} \mathrm{C}$

- Acid Gas Byproducts: $\mathrm{H}_{2} \mathrm{~S}, \mathrm{NH}_{3}, \mathrm{HCl}, \mathrm{COS}, \mathrm{CH}_{3} \mathrm{SH}$ 


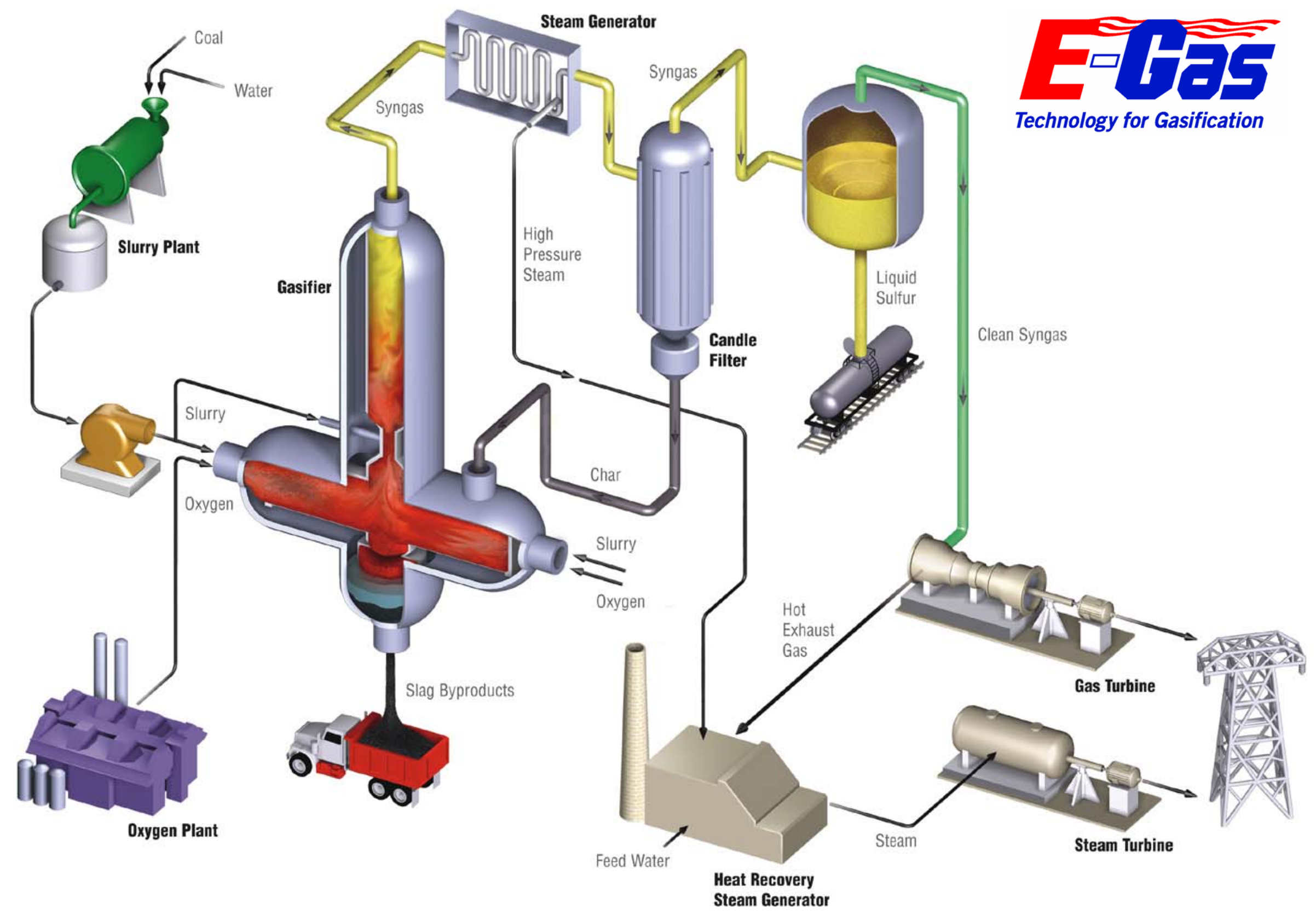




\section{What is S Zorb ${ }^{T M}$ SRT?}

S Zorb Sulfur Removal Technology (SRT) is designed to remove sulfur to ultra-low levels without sacrificing product quality.

It uses a proprietary sorbent to remove sulfur from fuels and minimizes its environmental impact. 


\section{ConocoPhillips' S Zorb'M SRT Technology}

- Developed for removing sulfur from gasoline

- Fixed and fluidized bed sorbents

- Three commercial vendors licensed to produce sorbent

- Commercial-scale units in three COP refineries:

Borger, TX, 6,000 bbl/d (750 mtpd 8 WHSV); since April 2001

Ferndale, WA, 20,000 bbl/d (2500 mtpd); since Dec. 2003

Lake Charles, LA, 38,500 bbl/d, (4730 mtpd); since Nov. 2005 *

4th ConocoPhillips Unit 30,000 bbl/d (3600 mtpd);

Projected Startup Early 2007

Initiated design work on three additional licensed units in late 2004:

- U.S. Refiner, 40,000 BPD (5000 mtpd)*

- Asian Refiner, 29,000 BPD (3430 mtpd)* 


\section{Sulfur Removal Processes for Gasification}
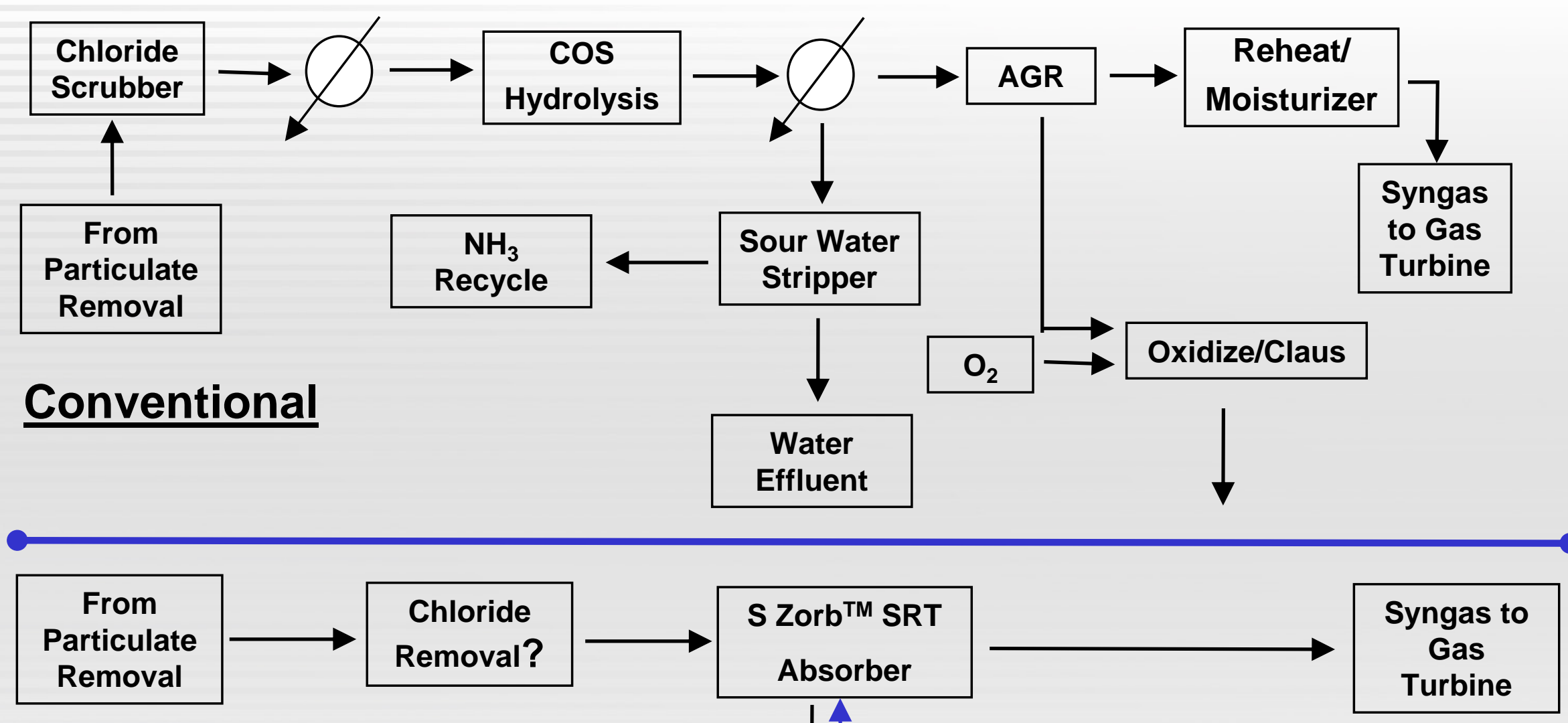

Warm Gas Cleanup

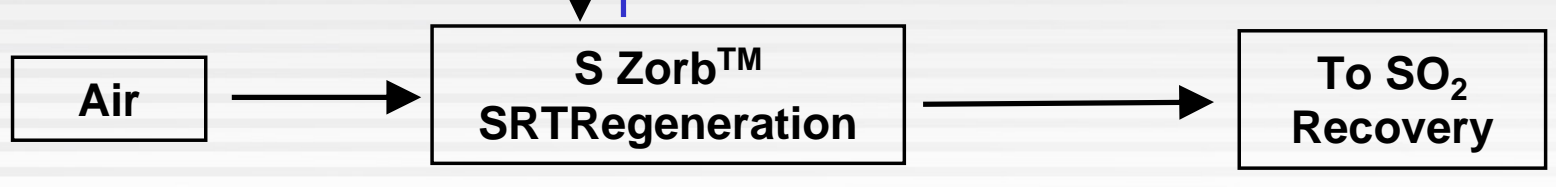

SZorb ${ }^{\text {TM }}$ SRT allows simplified and cost effective process design 


\section{Field Data Review}




\section{Experimental Conditions}

- Downflow Fixed Bed Reactor

- $420^{\circ} \mathrm{C}$

- 400 psi Pressure

- Regeneration at Atmospheric Pressure in Air and 400-550 ${ }^{\circ} \mathrm{C}$

- Feed Components:

$\mathrm{CO}, \mathrm{H}_{2}, \mathrm{CO}_{2}, \mathrm{H}_{2} \mathrm{O}, \mathrm{CH}_{4}, \mathrm{~N}_{2}$

- Feed Contaminants:

$\mathrm{H}_{2} \mathrm{~S}$ (>1 vol.\%), COS, $\mathrm{HCl}, \mathrm{NH}_{3}$ 
S Zorbтм SRT Slipstream Unit \& Analytical Instruments Employed

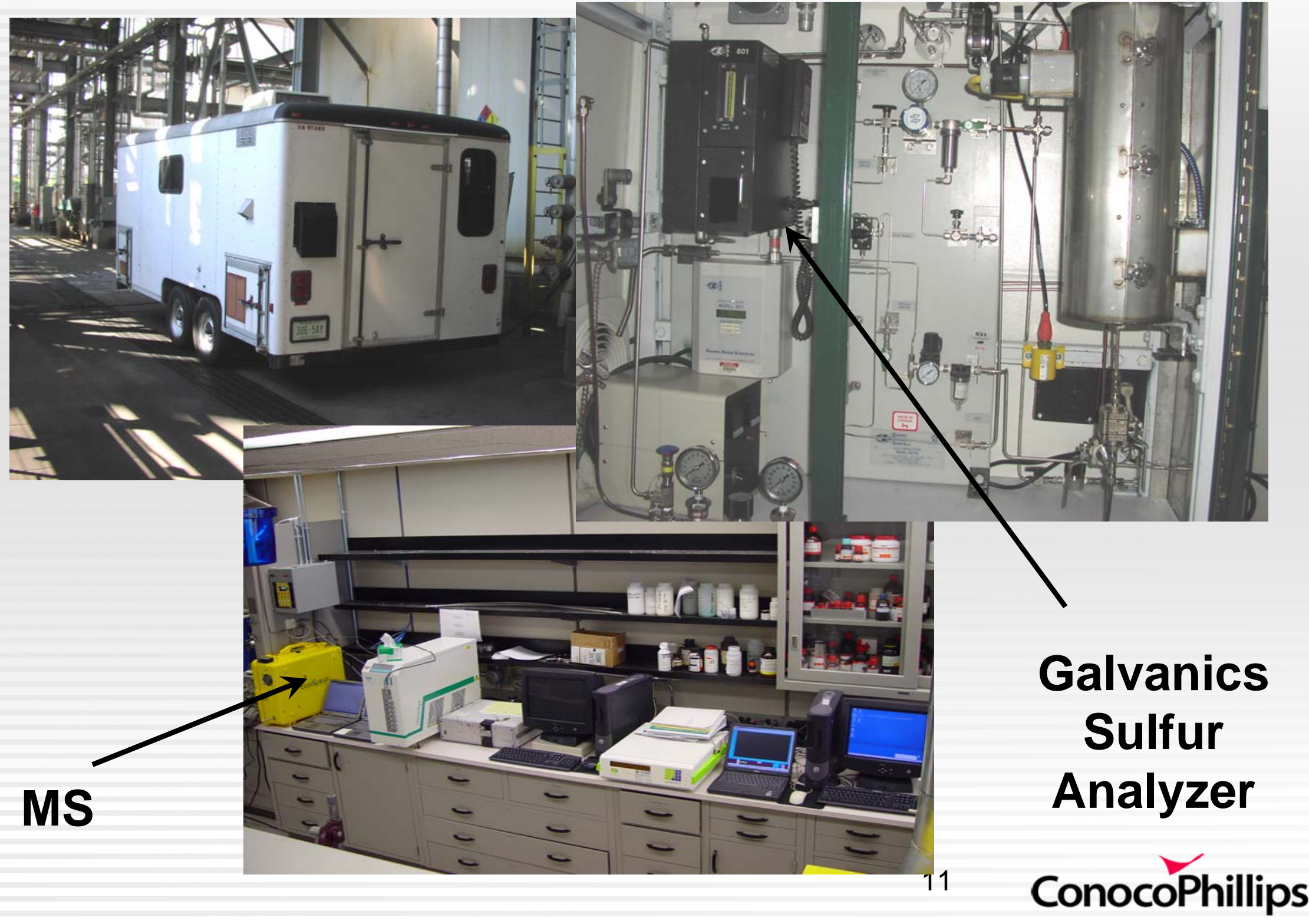




\section{Sulfur Removal in a Typical Experiment}

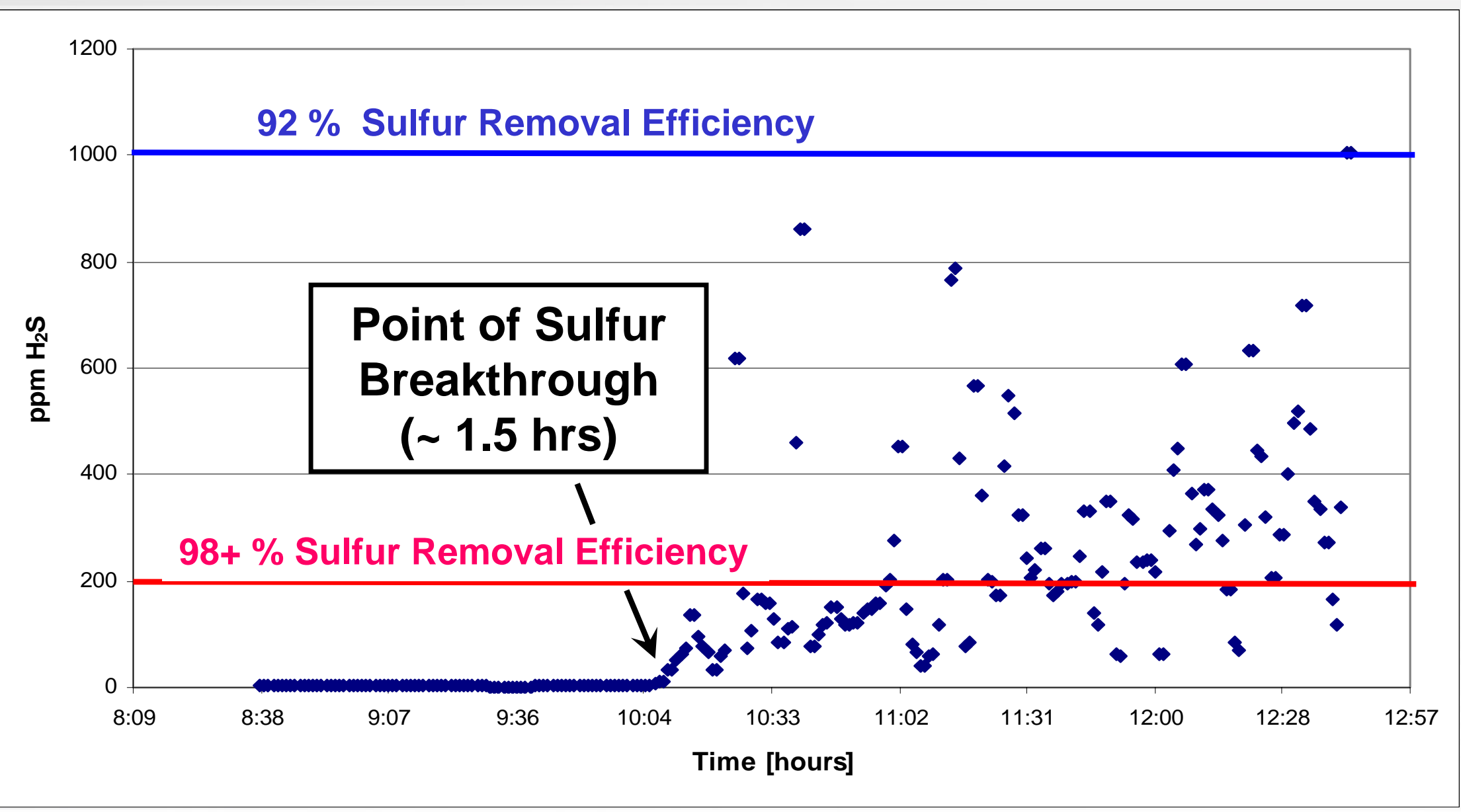

Data from Galvanics Sulfur Analyzer 


\section{Change in Specific Gases}

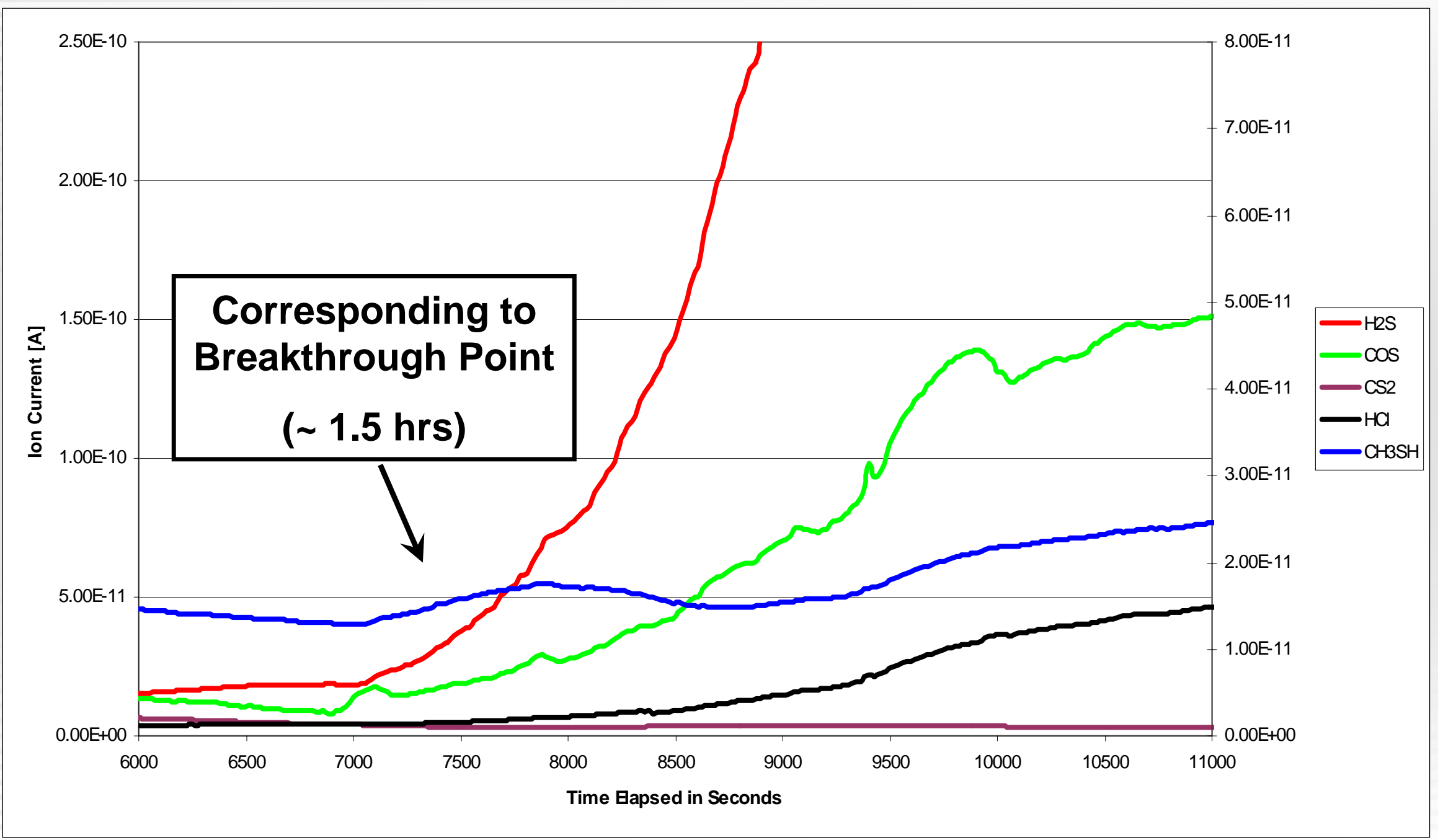

Data from Mass Spectrometer

Note: Y-Scales adjusted to fit into one plot 


\section{Sorbent Sulfur Loading at Various Sorbent Bed Zones}

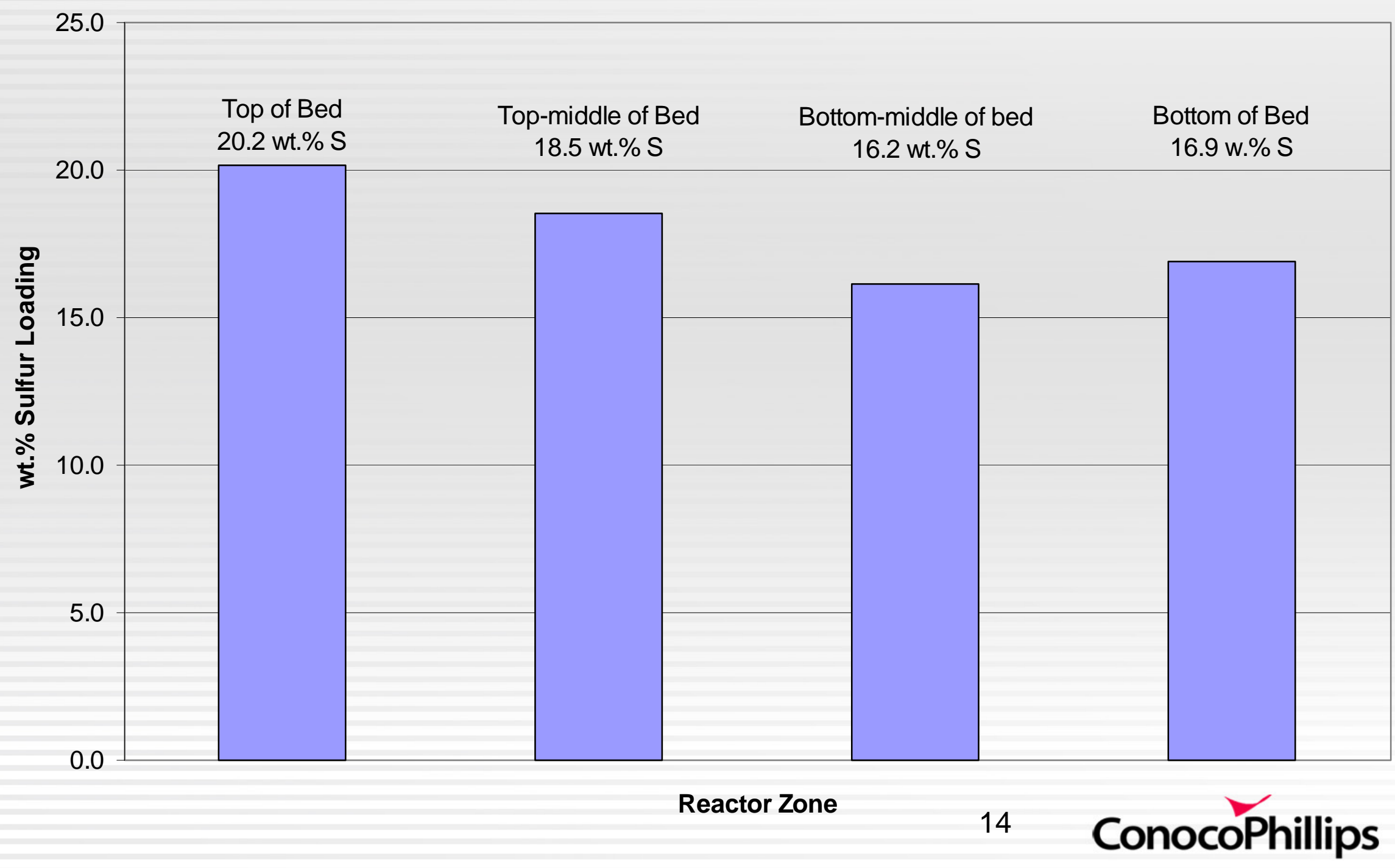




\section{Sorbent Regeneration}

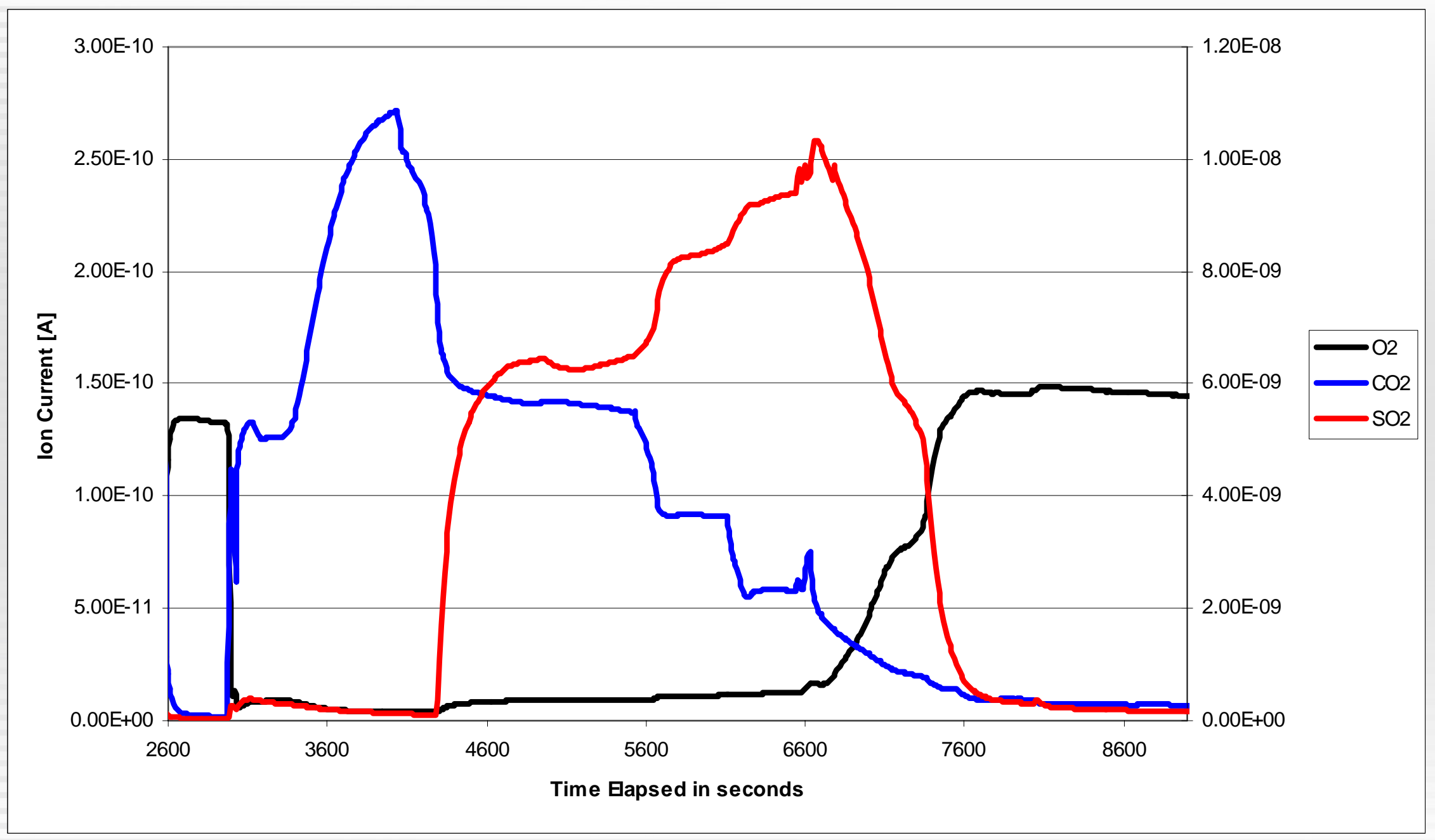

Initial: $400^{\circ} \mathrm{C} / 100 \mathrm{ml} / \mathrm{min}$ Air - End: $550^{\circ} \mathrm{C} / 1 \mathrm{~L} / \mathrm{min}$ Air; alternating, stepwise increase

Note: $\mathrm{CO}_{2}$ scale $\sim 40 x$ smaller than $\mathrm{SO}_{2} / \mathrm{O}_{2}$ scale 


\section{Regeneration Efficiency}

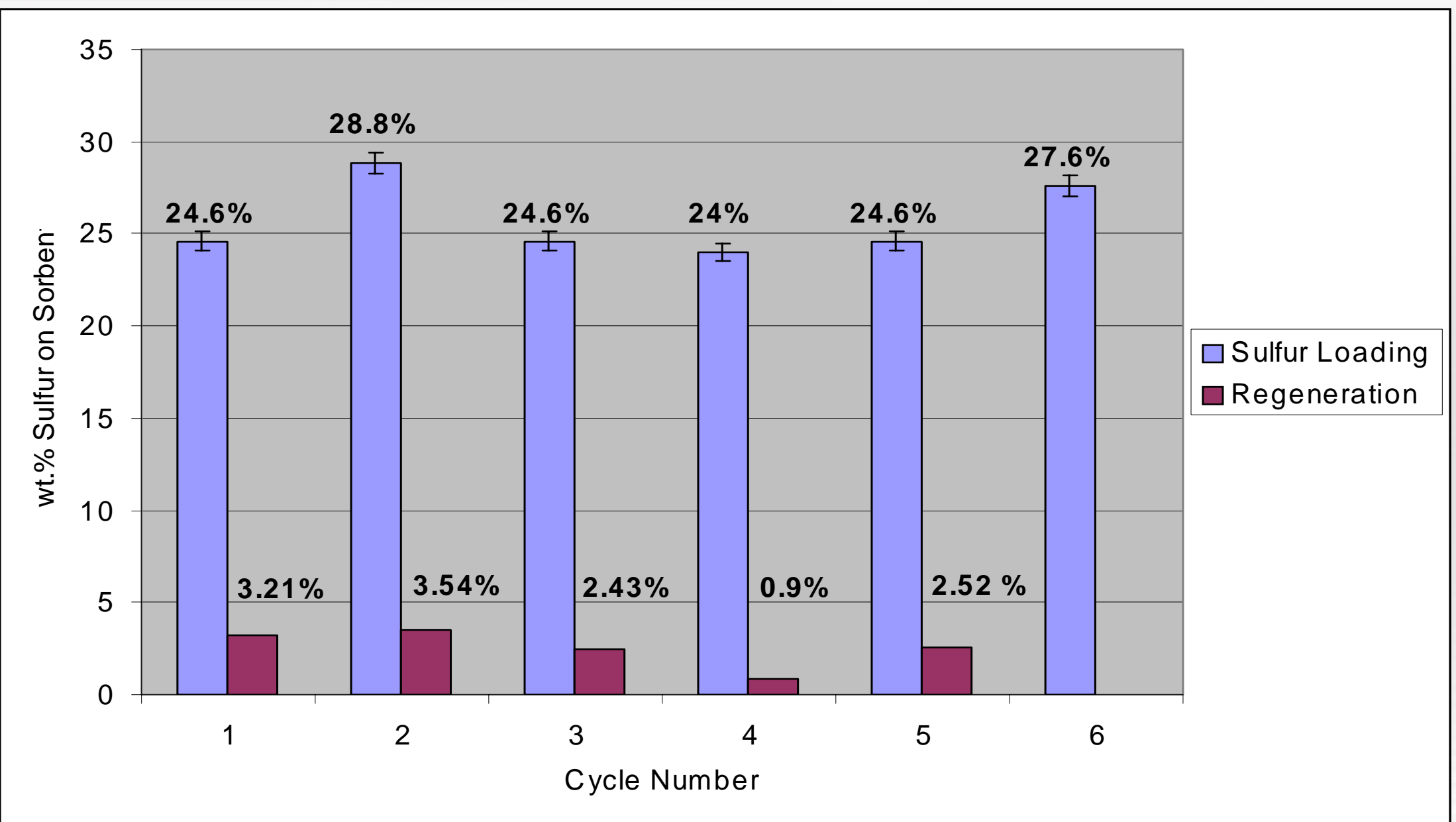

Avg. Regeneration Efficiency $90 \%$; 


\section{Conclusions}

\section{Proof of Principle:}

Sulfur Removal:

- > 99.9 \% Sulfur removal possible

- Sulfur removal to detection limit of 1 ppm

- $\mathrm{H}_{2} \mathrm{~S}, \mathrm{COS} \& \mathrm{HCl}$ removed

- Sulfur loading on sorbent $\sim 20^{+}$wt. $\%$

Sorbent Regeneration:

- S Zorb ${ }^{\text {TM }}$ SRT repeatedly regenerable $>90^{+} \%$ 


\section{Acknowledgements}

Project was partially funded by the U.S. Department of Energy Cooperative Agreement No. DE-FC26-99FT40659, and managed by the National Energy Technology Laboratory 